\title{
Supporting Information: Selective Inhibition of DNA Polymerase $\beta$ by a Covalent Inhibitor
}

Shelby C. Yuhas ${ }^{\mathrm{a}}$, Daniel J. Laverty ${ }^{\mathrm{a}}$, Huijin Lee ${ }^{\mathrm{a}}$, Ananya Majumdar ${ }^{\mathrm{b}}$ and Marc M. Greenberg*a

aJohns Hopkins University, Department of Chemistry, 3400 N. Charles St., Baltimore, MD 21218, United States

bJohns Hopkins University, Biomolecular NMR Center, 3400 N. Charles St., Baltimore, MD 21218, United States

mgreenberg@jhu.edu

Contents:

1. General Methods (S3-S4)

2. Scheme S1. Synthesis of bis-pentenoyl DOB phosphoramidite (4). (S5)

3. Experimental Procedures (S6-S42)

4. Scheme S2. Synthesis of pro-14. (S27)

5. Table S1. DNA Substrates for Assays (S33)

6. Table S2. 10X preincubation mixture for primer extension assays (S36)

7. Table S3. Reaction mixture for primer extension assays. (S37)

8. Chart S1. Carboxylic acids used to prepare inhibitor candidates. (S43-S51)

9. Figure S1. (a) Fluorescence-based strand displacement assay. (b) First-generation hit compounds from initial screen. (S52)

10. Figure S2. The inhibitory activity of first-generation inhibitor $\mathbf{7}$. (S53)

11. Figure S3. IC 50 value of 14 under exact conditions used to evaluate 2.(S54)

12. Figure S4. The effect of pro-14 on MMS cytotoxicity in MEFs containing or lacking Pol $\lambda$. (S55)

13. Figure S5 . The effect of greater concentrations of pro-14 on MMS cytotoxicity in MEFs lacking Pol $\beta$ and/or Pol $\lambda$. (S56)

14. Figure S6. ${ }^{1} \mathrm{H}$ NMR spectra of $\mathbf{S 1}$ (S57)

15. Figure S7. ${ }^{1} \mathrm{H}$ NMR spectra of $\mathbf{S 2}$ (S57)

16. Figure S8. ${ }^{1} \mathrm{H}$ and ${ }^{13} \mathrm{C}$ NMR spectra of S3 (S58)

17. Figure S9. ${ }^{1} \mathrm{H}$ and ${ }^{13} \mathrm{C}$ NMR spectra of S4 (S59)

18. Figure S10. ${ }^{1} \mathrm{H}$ NMR spectra of S5a and S5b (S60)

19. Figure $\mathbf{S 1 1 .}{ }^{13} \mathrm{C}$ NMR spectra of S5 (S61)

20. Figure $\mathbf{S 1 2} .{ }^{1} \mathrm{H}$ NMR spectra of $\mathbf{S 6}$ (S61)

21. Figure $\mathrm{S} 13 .{ }^{1} \mathrm{H}$ and ${ }^{13} \mathrm{C}$ NMR spectra of 4 (S62)

22. Figure S14. ${ }^{31} \mathrm{P}$ NMR spectra of 4 (S63)

23. Figure S15. ${ }^{1} \mathrm{H}$ NMR spectra of precursor to 3 (S63)

24. Figure S16. ${ }^{1} \mathrm{H}$ and ${ }^{13} \mathrm{C}$ NMR spectra of 3 (S64)

25. Figure $\mathrm{S} 17 .{ }^{1} \mathrm{H}$ and ${ }^{13} \mathrm{C}$ NMR spectra of 5 (S65)

26. Figure S18. ${ }^{31} \mathrm{P}$ NMR spectra of 5 (S66)

27. Figure S19. ${ }^{1} \mathrm{H}$ and ${ }^{13} \mathrm{C}$ NMR spectra of 6 (S67)

28. Figure S20. ${ }^{31} \mathrm{P}$ NMR spectra of 6 (S68)

29. Figure S21. ${ }^{1} \mathrm{H}$ and ${ }^{13} \mathrm{C}$ NMR spectra of precursor to 7 (S69)

30. Figure S22. ${ }^{31} \mathrm{P}$ NMR spectra of precursor to 7 (S70) 
31. Figure S23. ${ }^{1} \mathrm{H}$ and ${ }^{13} \mathrm{C}$ NMR spectra of 8 (S71)

32. Figure S24. ${ }^{1} \mathrm{H}$ and ${ }^{13} \mathrm{C}$ NMR spectra of precursor to 9 (S72)

33. Figure $\mathrm{S25} .{ }^{1} \mathrm{H}$ and ${ }^{13} \mathrm{C}$ NMR spectra of 9 (S73)

34. Figure S26. ${ }^{1} \mathrm{H}$ NMR spectra of precursor to 10 (S74)

35. Figure S27. ${ }^{1} \mathrm{H}$ and ${ }^{13} \mathrm{C}$ NMR spectra of 10 (S75)

36. Figure S28. ${ }^{1} \mathrm{H}$ and ${ }^{13} \mathrm{C}$ NMR spectra of precursor to $\mathbf{S 7}$ (S76)

37. Figure S29. ${ }^{1} \mathrm{H}$ and ${ }^{13} \mathrm{C}$ NMR spectra of 12 (S77)

38. Figure $\mathrm{S} 30 .{ }^{31} \mathrm{P}$ and ${ }^{19} \mathrm{~F}$ NMR spectra of $12(\mathrm{~S} 78)$

39. Figure S31. ${ }^{1} \mathrm{H}$ and ${ }^{13} \mathrm{C}$ NMR spectra of 13 (S79)

40. Figure S32. ${ }^{31} \mathrm{P}$ NMR spectra of 13 (S80)

41. Figure S33. ${ }^{31} \mathrm{P}$ NMR spectra of precursor to 14 (S80)

42. Figure S34. ${ }^{1} \mathrm{H}$ and ${ }^{13} \mathrm{C}$ NMR spectra of precursor to 14 (S81)

43. Figure $\mathrm{S} 35 .{ }^{1} \mathrm{H}$ NMR spectra of 14 (S82)

44. Figure S36. ${ }^{1} \mathrm{H}$ and ${ }^{13} \mathrm{C}$ NMR spectra of $\mathbf{S 8}$ (S83)

45. Figure S37. ${ }^{1} \mathrm{H}$ and ${ }^{13} \mathrm{C}$ NMR spectra of S9 (S84)

46. Figure S38. ${ }^{1} \mathrm{H}$ NMR spectra of $\mathrm{S} 10$ (S85)

47. Figure S39. ${ }^{1} \mathrm{H}$ and ${ }^{31} \mathrm{P}$ NMR spectra of $\mathrm{S} 11$ (S86)

48. Figure S40. ${ }^{1} \mathrm{H}$ and ${ }^{13} \mathrm{C}$ NMR spectra of precursor to pro-14 (S87)

49. Figure S41. ${ }^{31} \mathrm{P}$ NMR spectra of precursor to pro-14 (S88)

50. Figure S42. ${ }^{31} \mathrm{P}$ NMR spectra of pro-14 (S88)

51. Figure $543 .{ }^{1} \mathrm{H}$ and ${ }^{13} \mathrm{C}$ NMR spectra of pro-14 (S89)

52. Figure S44. UPLC-MS analysis of precursor to 7 (S90)

53. Figure S45. UPLC-MS analysis of 7 (S91)

54. Figure S46. UPLC-MS analysis of precursor to 14. (S92)

55. Figure S47. UPLC-MS analysis of 14. (S93)

56. Figure S48. UPLC-MS analysis of pro-14. (S94)

57. Figure S49. Primary fluorescence data of screened first-generation library. (S95)

58. Figure S50. Primary fluorescence data of screened second-generation library. (S97)

59. Figure S51. Annotated MS/MS Spectra of modified peptide 1 (S99)

60 . Figure S52. Annotated MS/MS Spectra of modified peptide 2 (S101)

61. References (S102-S103) 


\section{General Methods}

Modified oligonucleotides were synthesized on an Applied Biosystems Incorporated 394 oligonucleotide synthesizer. Oligonucleotide synthesis reagents including 5'-phosphorylation reagent (Solid CPR II), SIMA HEX (dichloro diphenyl fluorescein) phosphoramidite, THF abasic site analogue (dSpacer), TAMRA phosphoramidite, and BHQ phosphoramidite were purchased from Glen Research (Sterling, VA). Oligonucleotides containing only native nucleotides were purchased from Integrated DNA Technologies (Coralville, IA) and were purified by 20\% denaturing polyacrylamide gel electrophoresis (PAGE) (See below). Oligonucleotides were characterized using a Bruker AutoFlex III Maldi-TOF/TOF system.

All chemicals were purchased from Sigma Aldrich, Fisher, or Alfa and were used without further purification. Small quantities of all library compounds (Chart S1) were purchased from Sigma Aldrich but were from a variety of vendors. Pol $\eta$ was purchased from EnzyMax. Sybr Gold was purchased from ThermoFisher. Trypsin, dNTPs, terminal deoxynucleotide transferase, Klenow exo-, and T4 polynucleotide kinase were obtained from New England Biolabs. Radionuclides were from Perkin Elmer. Poly-Prep columns were from BioRad. C18-Sep-Pak cartridges were obtained from Waters. Zip-Tips were purchased from Millipore. Quantification of radiolabeled oligonucleotides was carried out using a Molecular Dynamics Phosphorimager 840 equipped with ImageQuant.

UPLC-MS/MS analyses were carried out on a Waters Acquity/Xevo-G2 UPLC-MS system equipped with an ACQUITY UPLC HSS T3 Column (100 A, $1.8 \mu \mathrm{m}, 2.1 \mathrm{~mm}$ x $100 \mathrm{~mm})$. Masses were obtained via deconvolution using MassLynx 4.2 software or BioPharmaLynx 1.3.2 software. 
Well plates used for organic solvents and photolyses were obtained from VWR. Well plates used for fluorescence assays were obtained from Corning (CLS3825, 384 well plates, for homogenous luminescent and HTRF assays). Fluorescence data were collected on a Varian Cary Eclipse fluorescence spectrophotometer equipped with a well plate attachment. Fluorescence anisotropy measurements were conducted using an AVIV Biomedical Model ATF 107 spectrofluorometer at the Center for Molecular Biophysics at Johns Hopkins University.

The following items were generous gifts from colleagues. Plasmids for the $8 \mathrm{kDa}$ and 31 $\mathrm{kDa}$ domains were from Dr. Sam Wilson, NIH. The Pol $\beta$ domains were prepared using previously reported conditions. ${ }^{1,2}$ Pol $\lambda$ plasmid was from Professor Zucai Suo, Florida State University. Pol $\lambda$ was expressed and purified using previously reported conditions. ${ }^{3,4}$

Dulbecco's Modified Eagle Medium (DMEM) with high glucose was obtained from ThermoFisher. Antibiotic antimycotic solution (penicillin, streptomycin, and amphotericin B), and fetal bovine serum (FBS) were obtained from MilliporeSigma. PBS buffer was obtained from Quality Biological. Cells were counted using a BioRad TC20 cell counter.

All small molecules synthesized were characterized using a Bruker Avance $400 \mathrm{MHz}$ Spectrometer or an Avance Neo $800 \mathrm{MHz}$ spectrometer at Johns Hopkins University. 
All $R_{f}$ values provided in TLC information correspond to the product unless otherwise explicitly stated.

Scheme S1. Synthesis of bis-pentene DOB phosphoramidite (4).
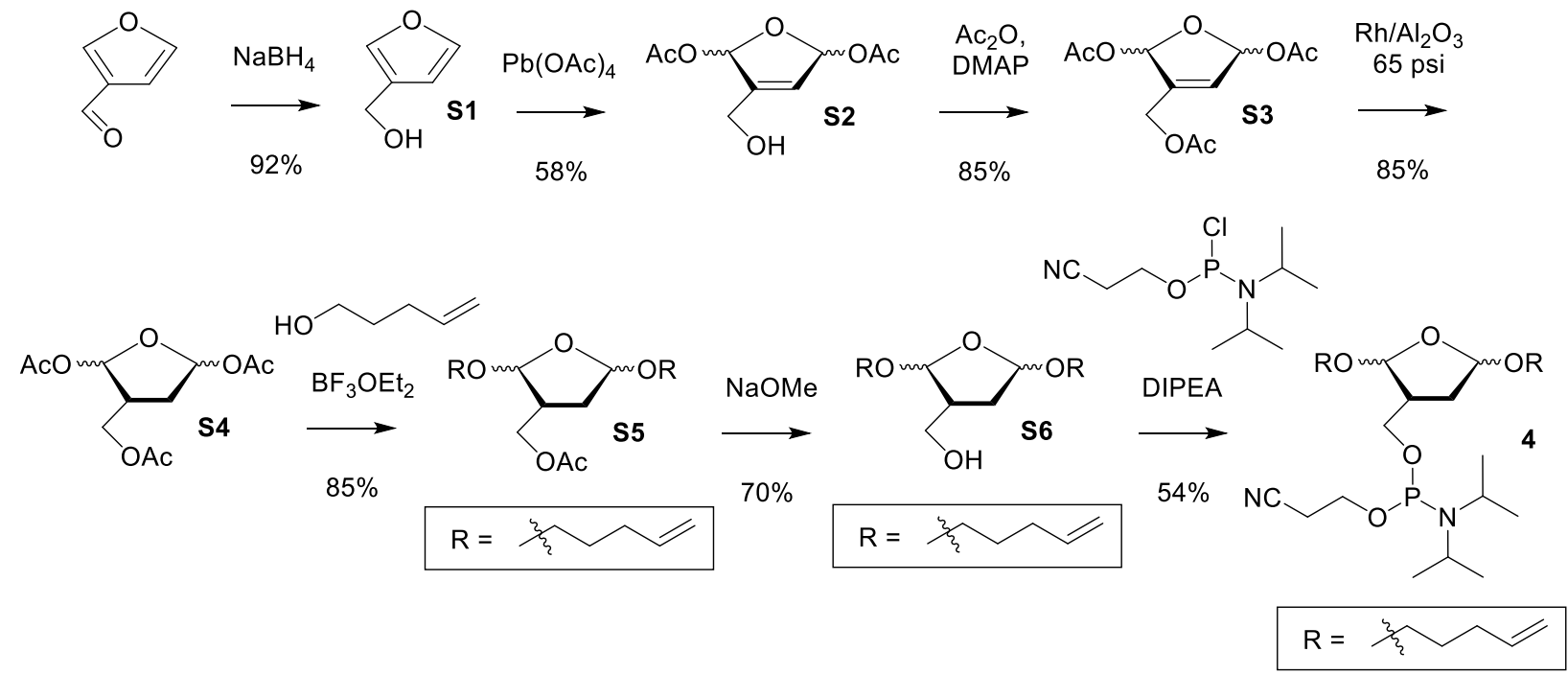


\section{Preparation of $\mathbf{S 1}^{5,6}$}

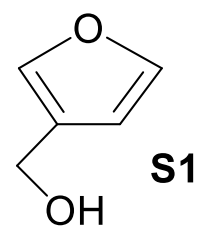

Commercially available 3-furaldehyde $(4.38 \mathrm{~mL}, 5 \mathrm{~g}, 52.4 \mathrm{mmol}, 1 \mathrm{eq})$ was added to a mixture of $10: 1 \mathrm{Et}_{2} \mathrm{O} / \mathrm{H}_{2} \mathrm{O}(59 \mathrm{~mL})$. The mixture was cooled to $0{ }^{\circ} \mathrm{C}$ and stirred. Small aliquots of NaBH4 (3.27 g, $86.4 \mathrm{mmol}, 6.65 \mathrm{eq})$ were added to the mixture carefully over a period of $15 \mathrm{~min}$. The reaction was stirred in air for $30 \mathrm{~min}$. After $30 \mathrm{~min}$, TLC $\left(4: 1 \mathrm{Hex} /\right.$ EtOAc, $\left.\mathrm{R}_{\mathrm{f}}=0.3\right)$ showed the complete conversion of the starting material $\left(\mathrm{R}_{\mathrm{f}}=0.5, \mathrm{UV}\right.$ active, did not stain with PAA) to a slightly more polar spot that was not UV active and stained dark purple with PAA. The reaction was quenched with water until there was no more bubbling. The ether layer was washed with water $(2 \times 50 \mathrm{~mL})$ and the combined aqueous layers were extracted with ether $(6 \times 40 \mathrm{~mL})$. The final organic layer was washed with brine $(1 \times 50 \mathrm{~mL})$, dried with $\mathrm{MgSO} 4$, and concentrated under vacuum at $0{ }^{\circ} \mathrm{C}$ to yield $4.714 \mathrm{~g}(91.7 \%)$ of a yellow liquid. The product was volatile, so the rotary evaporatory water bath was cooled to $0{ }^{\circ} \mathrm{C}$ during concentration. NMR data showed the crude product was pure. ${ }^{1} \mathrm{H}$ NMR $\left(400 \mathrm{MHz}, \mathrm{CDCl}_{3}\right) \delta 7.36$ (s, 2H), $6.38(\mathrm{~s}, 1 \mathrm{H}), 4.46(\mathrm{~d}, J=4.9 \mathrm{~Hz}, 2 \mathrm{H}), 2.92(\mathrm{~d}, J=4.9 \mathrm{~Hz}, 1 \mathrm{H})$. 


\section{Preparation of $\mathbf{S} 2^{5,6}$}

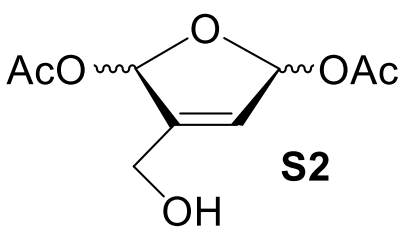

Without purification, $\mathbf{S 1}$ (474.6 mg, $4.84 \mathrm{mmol}, 1 \mathrm{eq})$ was combined with $\mathrm{Pb}(\mathrm{OAc})_{4}(3.22 \mathrm{~g}, 7.22 \mathrm{mmol}, 1.5 \mathrm{eq})$. Glacial acetic acid (12.5 mL) was added to the flask, which was then flushed with Argon. The reaction was

stirred at $25^{\circ} \mathrm{C}$ for $21 \mathrm{~h}$. When the reaction was complete by TLC (3:7 EtOAc/DCM, $\mathrm{R}_{\mathrm{f}}=0.4$, stained with PAA), AcOH was removed via vacuum. Ether $(50 \mathrm{~mL})$ was added to the resulting residue and the precipitate was triturated with ether and removed. The filtrate was concentrated under vacuum and purified by column chromatography (7:3 Hexanes/EtOAc) to give $518 \mathrm{mg}$ $(58 \%)$ of a 2:1 mixture of diastereomers (S2). ${ }^{1} \mathrm{H}$ NMR $\left(400 \mathrm{MHz}, \mathrm{CDCl}_{3}\right) \delta 6.90(\mathrm{dd}, J=1.0,4.7$ $\mathrm{Hz}, 1 \mathrm{H}), 6.69(\mathrm{dd}, J=1.0,4.7 \mathrm{~Hz}, 1 \mathrm{H}), 6.15-6.05(\mathrm{~m}, 1 \mathrm{H}), 4.30(\mathrm{q}, J=1.0 \mathrm{~Hz}, 2 \mathrm{H}), 2.19-2.07$ $(\mathrm{m}, 6 \mathrm{H})$.

\section{Preparation of S3}

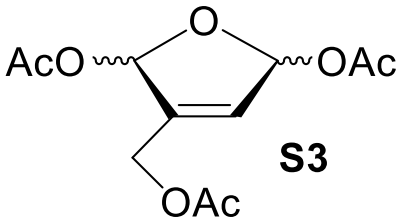

with Argon and dissolved in DCM (1.25 mL). The mixture was cooled

to $0{ }^{\circ} \mathrm{C}$. Acetic anhydride $(0.33 \mathrm{~mL}, 3.5 \mathrm{mmol}, 5 \mathrm{eq})$ was added slowly to the flask via syringe. Pyridine $(0.68 \mathrm{~mL}, 8.56 \mathrm{mmol}, 12.5 \mathrm{eq})$ was added dropwise to the solution via syringe. After $2 \mathrm{~h}$, the reaction was confirmed complete by TLC (6:4 EtOAc/DCM, $\mathrm{R}_{\mathrm{f}}=0.6$, stained with PAA) and was quenched with sat. $\mathrm{NaHCO}_{3}$ until the $\mathrm{pH}$ was neutral. The mixture was diluted with EtOAc $(5 \mathrm{~mL})$ and washed with water $(2 \times 5 \mathrm{~mL})$. The aqueous layer was extracted with EtOAc $(2 \times 10$ $\mathrm{mL})$, the combined organic layers were washed with brine $(1 \times 30 \mathrm{~mL})$, dried over $\mathrm{Na}_{2} \mathrm{SO}_{4}$, and concentrated under vacuum. The crude residue was purified by column chromatography $(5: 1$ DCM/EtOAc) to yield $167 \mathrm{mg}(85 \%)$ of $\mathbf{S 3} .{ }^{1} \mathrm{H}$ NMR (400 MHz, $\left.\mathrm{CDCl}_{3}\right) \delta 6.83(\mathrm{~s}, 1 \mathrm{H}), 6.70-$ 
$6.56(\mathrm{~m}, 1 \mathrm{H}), 6.22-5.89(\mathrm{~m}, 1 \mathrm{H}), 4.83-4.57(\mathrm{~m}, 2 \mathrm{H}), 2.11-1.96(\mathrm{~m}, 9 \mathrm{H})$.

${ }^{13} \mathrm{C} \mathrm{NMR}\left(\mathrm{CDCl}_{3}\right)$ 166.4, 152.3, 138.1, 111.6, 85.9, 85.8, 62.3, 38.1, 12.4, 9.2.

ESI-TOF m/z calculated for $\mathrm{C}_{11} \mathrm{H}_{14} \mathrm{O}_{7}(\mathrm{M}+\mathrm{H})$ - 258.0740, 258.0703 observed.

\section{Preparation of S4}

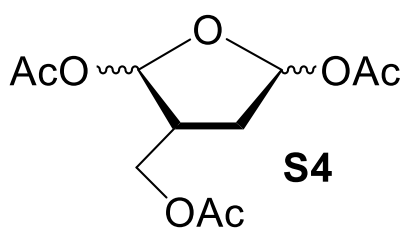

Compound S3 (150 mg, 0.69 mmol, 1 eq) was dissolved in EtOAc (17 $\mathrm{mL})$. Rhodium on alumina catalyst $(75.5 \mathrm{mg})$ was added to the pressure bottle equipped with a regulator. The vial was pressurized with $\mathrm{H}_{2}$ to 70 psi, purged three times, and stirred at $25^{\circ} \mathrm{C}$ for $2-4 \mathrm{~h}$. After venting the pressure bottle, TLC (1:1 Hex/EtOAc, $\mathrm{R}_{\mathrm{f}}=0.4$, stained with PAA) showed the starting material was no longer present. When complete, the reaction mixture was passed through celite to remove the $\mathrm{Rh}$ catalyst. The filtrate was concentrated under vacuum to give $127.5 \mathrm{mg}(85 \%)$ of pale, yellow compound S4. No purification was needed. ${ }^{1} \mathrm{H}$ NMR $\left(400 \mathrm{MHz}, \mathrm{CDCl}_{3}\right) \delta 6.25-6.15(\mathrm{~m}, 2 \mathrm{H}), 4.06(\mathrm{~m}, 1 \mathrm{H}), 4.03-$ $3.91(\mathrm{~m}, 1 \mathrm{H}), 2.71-2.56(\mathrm{~m}, 1 \mathrm{H}), 2.38(\mathrm{~m}, 1 \mathrm{H}), 2.04-1.88(\mathrm{~m}, 9 \mathrm{H}), 1.83-1.67(\mathrm{~m}, 1 \mathrm{H})$.

${ }^{13} \mathrm{C} \mathrm{NMR}\left(\mathrm{CDCl}_{3}\right)$ 170.7, 169.9, 169.5, 98.5, 96.4, 62.1, 41.6, 32.7, 21.5, 20.9, 20.7.

ESI-TOF m/z calculated for $\mathrm{C}_{11} \mathrm{H}_{16} \mathrm{O}_{7}(\mathrm{M}+\mathrm{H})$ - 260.0896, 260.0900 observed.

\section{Preparation of S5}

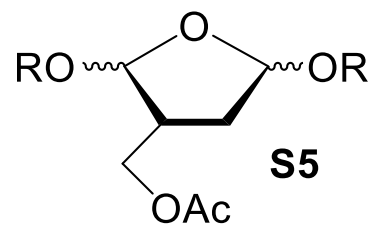

$\mathrm{R}=\zeta_{\xi}$

$\mathrm{BF}_{3} \bullet$ etherate was distilled from $\mathrm{CaH}_{2}$ under vacuum and kept under Argon. Compound S4 (750 mg, $2.88 \mathrm{mmol}, 1 \mathrm{eq}, 160 \mathrm{mM})$ was dissolved in DCM $(18 \mathrm{~mL})$ and cooled to $0{ }^{\circ} \mathrm{C} .4-$ Pentenol $(1.86 \mathrm{~mL}$, $1.49 \mathrm{~g}, 17.3 \mathrm{mmol}, 6 \mathrm{eq})$ was added to the reaction. $\mathrm{BF}_{3} \bullet$ etherate $(8.14 \mathrm{~mL}, 1.67 \mathrm{M})$ was slowly added to the solution over a period of $15-20 \mathrm{~min}$ (until diluted to $28 \mathrm{~mL}, 600 \mathrm{mM})$. After $30 \mathrm{~min}$, the reaction was incomplete when analyzed by TLC (7:3 $\mathrm{Hex} / \mathrm{Et}_{2} \mathrm{O}$, stained with PAA) but additional products began to appear, so the reaction was 
quenched with sat. $\mathrm{NaHCO}_{3}(5 \mathrm{~mL})$, diluted with $\mathrm{DCM}(20 \mathrm{~mL})$, and washed with sat. $\mathrm{NaHCO}_{3}$ (1 x $15 \mathrm{~mL})$. The aqueous layer was extracted with DCM $(4 \times 20 \mathrm{~mL})$. The organic layer was washed with water $(1 \times 30 \mathrm{~mL})$, brine $(1 \times 30 \mathrm{~mL})$, and dried over $\mathrm{Na}_{2} \mathrm{SO}_{4}$. The residue was concentrated under vacuum and purified by column chromatography (8:2 hex/EtOAc) to give $228.6 \mathrm{mg}(25.4 \%)$ of $\mathbf{S 5 a}$ and $519 \mathrm{mg}(57.7 \%)$ of $\mathbf{S 5 b}$ (totaling 83\%), which were each a mixture of diastereomers. S5a ${ }^{1} \mathrm{H}$ NMR $\left(400 \mathrm{MHz}, \mathrm{CDCl}_{3}\right) \delta 5.82-5.65(\mathrm{~m}, 2 \mathrm{H}), 5.21-4.84(\mathrm{~m}, 6 \mathrm{H})$, $4.24-3.99(\mathrm{~m}, 2 \mathrm{H}), 3.75-3.57(\mathrm{~m}, 2 \mathrm{H}), 3.45-3.22(\mathrm{~m}, 2 \mathrm{H}), 2.61(\mathrm{~m}, 1 \mathrm{H}), 2.42-2.17(\mathrm{~m}, 1 \mathrm{H})$, $2.08-2.01(\mathrm{~m}, 4 \mathrm{H}), 1.99(\mathrm{~d}, J=9.5 \mathrm{~Hz}, 3 \mathrm{H}), 1.93-1.74(\mathrm{~m}, 1 \mathrm{H}), 1.67-1.50(\mathrm{~m}, 4 \mathrm{H}) . \mathbf{S 5 b}{ }^{1} \mathrm{H}$ NMR (400 MHz, $\left.\mathrm{CDCl}_{3}\right) \delta 5.91-5.68(\mathrm{~m}, 2 \mathrm{H}), 5.10-4.83(\mathrm{~m}, 6 \mathrm{H}), 4.15-3.88(\mathrm{~m}, 2 \mathrm{H}), 3.73$ (m, 2H), $3.55-3.32(\mathrm{~m}, 2 \mathrm{H}), 2.65(\mathrm{ddd}, J=5.5,7.4,13.5 \mathrm{~Hz}, 1 \mathrm{H}), 2.39(\mathrm{~s}, 1 \mathrm{H}), 2.32-2.18(\mathrm{~m}$, 1H), $2.16-2.08(\mathrm{~m}, 4 \mathrm{H}), 2.05(\mathrm{~s}, 3 \mathrm{H}), 1.81$ (ddd, $J=5.5,7.4,13.5 \mathrm{~Hz}, 1 \mathrm{H}), 1.73-1.59(\mathrm{~m}, 4 \mathrm{H})$. S5a and S5b ${ }^{13} \mathrm{C}$ NMR $\left(\mathrm{CDCl}_{3}\right)$ 170.9, 170.8, 138.20, 138.18, 138.15, 114.8, 106.9, 106.2, 104.7, 104.2, 103.5, 103.2, 67.6, 67.5, 67.4, 67.3, 67.2, 67.0, 64.8, 64.5, 63.3, 43.8, 43.2, 40.7, 34.7, 34.2, $33.4,30.4,30.3,29.9,28.9,28.8,20.9,20.8$.

ESI-TOF m/z calculated for $\mathrm{C}_{17} \mathrm{H}_{28} \mathrm{O}_{5}(\mathrm{M}+\mathrm{H})-312.1937,312.1942$ observed.

\section{Preparation of $\mathbf{S 6}^{6}$}

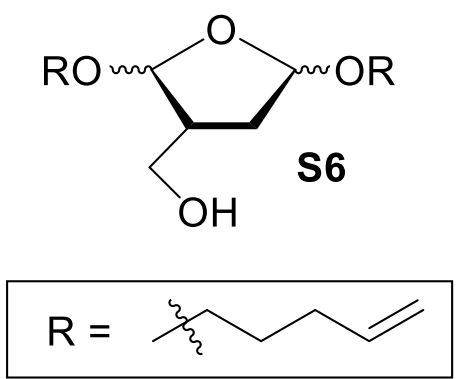

The diastereomerically enriched mixture (S5a or S5b) $(82 \mathrm{mg}, 0.26$ mmol, 1 eq, $150 \mathrm{mM})$ was dissolved in $\mathrm{MeOH}(1.7 \mathrm{~mL})$. Sodium methoxide stock solution $(700 \mathrm{mM})$ was prepared by dissolving $\mathrm{Na}$ metal (122 mg, $5.3 \mathrm{mmol})$ in $\mathrm{MeOH}(7.5 \mathrm{~mL})$. An aliquot of $\mathrm{NaOMe}$

(700 mM, $0.3 \mathrm{~mL}$ ) was added to the reaction slowly (effectively diluting NaOMe to $100 \mathrm{mM}$ ). After $2 \mathrm{~h}$, TLC (6:4 Hex/EtOAc, $\mathrm{R}_{\mathrm{f}}=0.2$, stained with PAA) confirmed the reaction was complete by the disappearance of $\mathbf{S 5}$. The reaction was quenched with a few drops of AcOH until neutral 
pH. The reaction was diluted with DCM $(20 \mathrm{~mL})$ and washed with $\mathrm{H}_{2} \mathrm{O}(2 \times 15 \mathrm{~mL})$. The aqueous layer was extracted with DCM (4 x $20 \mathrm{~mL})$ and the combined organic layers were washed with brine $(1 \times 30 \mathrm{~mL})$ and dried over $\mathrm{Na}_{2} \mathrm{SO}_{4}$. The reaction was concentrated under vacuum to give $49.3 \mathrm{mg}(70 \%)$ of $\mathbf{S 6}$. No purification was needed. ${ }^{1} \mathrm{H}$ NMR (400 MHz, $\left.\mathrm{CDCl}_{3}\right) \delta 5.91-5.65(\mathrm{~m}$, 2H), $5.23-4.88(\mathrm{~m}, 6 \mathrm{H}), 3.93-3.71(\mathrm{~m}, 2 \mathrm{H}), 3.72-3.61(\mathrm{~m}, 2 \mathrm{H}), 3.49-3.31(\mathrm{~m}, 2 \mathrm{H}), 2.63-$ $2.46(\mathrm{~m}, 1 \mathrm{H}), 2.38-2.23(\mathrm{ddd}, J=5.0,9.5,13.3 \mathrm{~Hz}, 1 \mathrm{H}), 2.26-2.13(\mathrm{~m}, 1 \mathrm{H}), 2.13-2.03(\mathrm{~m}, 4 \mathrm{H})$, $1.82(\mathrm{ddd}, J=1.5,7.8,13.3 \mathrm{~Hz}, 1 \mathrm{H}), 1.65$ (dddt, $J=1.5,5.0,7.8,9.5 \mathrm{~Hz}, 4 \mathrm{H})$.

\section{Preparation of 4}

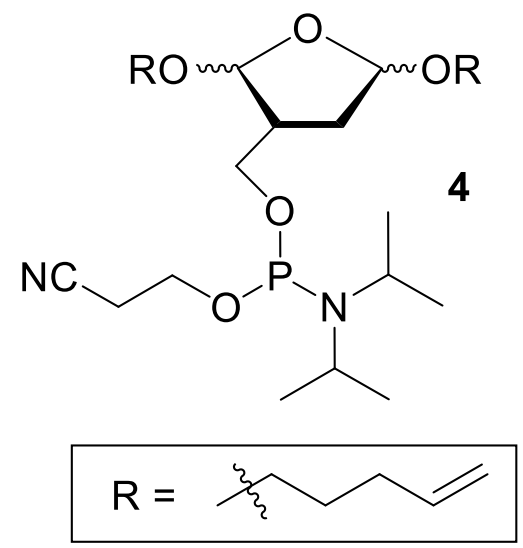

Compound S6 (58.2 mg, $0.22 \mathrm{mmol})$ was azeotropically dried with pyridine $(2 \times 0.5 \mathrm{~mL})$. The reagent was cooled to $0{ }^{\circ} \mathrm{C}$. DIPEA $(0.18 \mathrm{~mL}, 133 \mathrm{mg}, 0.88 \mathrm{mmol}, 4 \mathrm{eq})$ was added to the cold starting material and the reactants were dissolved in DCM $(2.1 \quad \mathrm{~mL}, \quad 100 \quad \mathrm{mM}) . \quad$ 2-Cyanoethyl-N, $\quad \mathrm{N}-$ diisopropylchlorophosphoramidite $(0.06 \mathrm{~mL}, 60.4 \mathrm{mg}, 0.26$

mmol. 1.2 eq) was added and the cold mixture stirred with periodic monitoring by TLC (7:1 Hex/EtOAc, $\mathrm{R}_{\mathrm{f}}=0.3$, stained with PAA). After $2 \mathrm{~h}$, TLC showed complete conversion to the phosphoramidite. The reaction was diluted with freshly distilled EtOAc $(10 \mathrm{~mL})$. The organic layer was washed with saturated bicarbonate solution $(2 \times 15 \mathrm{~mL})$ and the aqueous layers were extracted with distilled EtOAc $(2 \times 20 \mathrm{~mL})$. The combined organic layers were washed with brine ( 1 × 25 $\mathrm{mL}$ ) and dried over $\mathrm{Na}_{2} \mathrm{SO}_{4}$. The organic layer was concentrated under vacuum and purified by column chromatography (7:1 distilled hexanes/distilled EtOAc) yielding $55.9 \mathrm{mg}(54 \%)$ of $4 .{ }^{1} \mathrm{H}$ NMR (400 MHz, $\left.\mathrm{CDCl}_{3}\right) \delta 5.80$ (dddt, $\left.J=4.1,8.2,13.5,16.0 \mathrm{~Hz}, 2 \mathrm{H}\right), 5.18-4.93(\mathrm{~m}, 6 \mathrm{H}), 3.86$ $-3.72(\mathrm{~m}, 2 \mathrm{H}), 3.64(\mathrm{dtd}, J=2.1,6.0,8.2 \mathrm{~Hz}, 2 \mathrm{H}), 3.59-3.51(\mathrm{~m}, 2 \mathrm{H}), 3.34$ (dddd, $J=2.1,4.1$, 
9.4, 16.0 Hz, 2H), $2.71-2.52(\mathrm{~m}, 2 \mathrm{H}), 2.30(\mathrm{ddd}, J=6.0,9.4,13.5 \mathrm{~Hz}, 2 \mathrm{H}), 2.11-2.02(\mathrm{~m}, 4 \mathrm{H})$, $1.93-1.76(\mathrm{~m}, 1 \mathrm{H}), 1.65-1.55(\mathrm{~m}, 6 \mathrm{H}), 1.17(\mathrm{~m}, 12 \mathrm{H})$.

${ }^{13} \mathrm{C} \mathrm{NMR}\left(400 \mathrm{MHz}, \mathrm{CDCl}_{3}\right): \delta 170.92,170.91,138.28,138.25,138.23,114.75,114.73,114.69$, $114.68,114.64,106.9,105.7,105.2,104.5,103.8,102.6,67.6,67.3,66.6,64.5,63.4,44.8,43.8$, $43.2,42.8,34.7,30.0,30.3,28.8,20.9,20.8$.

${ }^{31} \mathrm{P}$ NMR $\left(400 \mathrm{MHz}, \mathrm{CDCl}_{3}\right) \delta 147.87$.

ESI-TOF m/z calculated for $\mathrm{C}_{24} \mathrm{H}_{43} \mathrm{~N}_{2} \mathrm{O}_{5} \mathrm{P}(\mathrm{M}+\mathrm{H})-471.2910,471.2887$ observed.

\section{Preparation of $3^{7,8}$}

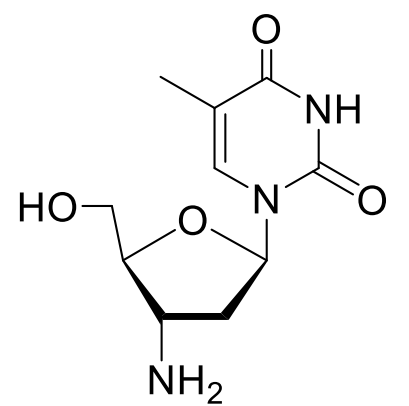

precursor to 3

AZT $(2.19,8.2 \mathrm{mmol})$ was dissolved in $50 \% \mathrm{MeOH}, 30 \% \mathrm{tBuOH}, 20 \%$ $\mathrm{H}_{2} \mathrm{O}(82 \mathrm{~mL}, 100 \mathrm{mM})$. Activated palladium on carbon $(1.3 \mathrm{~g}, 60 \mathrm{wt} \%)$ was added and flushed with a hydrogen balloon three times. The reaction was continuously sparged with $\mathrm{H}_{2}(1 \mathrm{~atm})$. After $3 \mathrm{~h}$, TLC $(3 \% \mathrm{MeOH}$ in DCM, UV active and stained with PAA) confirmed the starting material $\left(\mathrm{R}_{\mathrm{f}}=0.8\right)$ converted to the product $\left(\mathrm{R}_{\mathrm{f}}=0.02\right)$. The crude mixture was filtered through Celite and concentrated to yield $1.7 \mathrm{~g}(86 \%)$ of the 3 '-amine precursor to $3 .{ }^{1} \mathrm{H}$ NMR $\left(400 \mathrm{MHz}, \mathrm{CD}_{3} \mathrm{OD}\right) \delta$ $7.87(\mathrm{~s}, 1 \mathrm{H}), 6.18(\mathrm{dd}, J=2,6.8 \mathrm{~Hz}, 1 \mathrm{H}), 3.86(\mathrm{dd}, J=2,10 \mathrm{~Hz}, 1 \mathrm{H}), 3.77(\mathrm{dd}, J=3.2,10 \mathrm{~Hz}$, 1H), 3.70 (quint, $J=3.2 \mathrm{~Hz}, 1 \mathrm{H}), 3.54(\mathrm{q}, J=6.8 \mathrm{~Hz}, 1 \mathrm{H}), 2.26(\mathrm{~m}, 1 \mathrm{H}), 2.20(\mathrm{~m}, 1 \mathrm{H}), 1.88(\mathrm{~s}$, $3 H)$. 


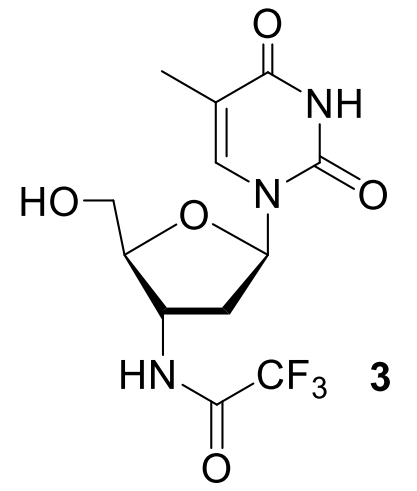

The crude mixture $(1.72 \mathrm{~g}, 7.12 \mathrm{mmol})$ was dissolved in THF $(25 \mathrm{~mL}$, $280 \mathrm{mM})$. Triethylamine (14 mL, $106.8 \mathrm{mmol}, 15 \mathrm{eq})$ and ethyl trifluoroacetate $(8.4 \mathrm{~mL}, 71.3 \mathrm{mmol}, 10 \mathrm{eq})$ were added to the flask to make a final concentration of $100 \mathrm{mM}$. The reaction was stirred for $4 \mathrm{~h}$ at $25{ }^{\circ} \mathrm{C}$. TLC $\left(3 \% \mathrm{MeOH}\right.$ in DCM, R $\mathrm{R}_{\mathrm{f}}=0.5, \mathrm{UV}$ active and stained by PAA) confirmed conversion to product. The reaction was concentrated and purified by column chromatography (1\% MeOH in DCM to yield $2.29 \mathrm{~g}(93 \%)$ of $3 .{ }^{1} \mathrm{H}$ NMR $\left(400 \mathrm{MHz}, \mathrm{CD}_{3} \mathrm{OD}\right) \delta 7.85(\mathrm{~s}, 1 \mathrm{H}), 6.27(\mathrm{t}, J=6.4 \mathrm{~Hz}, 1 \mathrm{H}), 4.60(\mathrm{q}, J=6.4 \mathrm{~Hz}, 1 \mathrm{H}), 3.97$ (quint, $J=2.8 \mathrm{~Hz}, 1 \mathrm{H}), 3.85(\mathrm{dd}, J=2.8,12 \mathrm{~Hz}, 1 \mathrm{H}), 3.73(\mathrm{dd}, J=2.8,12 \mathrm{~Hz}, 1 \mathrm{H}), 2.40(\mathrm{~m}, 2 \mathrm{H}), 1.89$ $(\mathrm{s}, 3 \mathrm{H})$.

${ }^{13} \mathrm{C}$ NMR (400 MHz, $\left.\mathrm{CD}_{3} \mathrm{OD}\right) \delta 166.2,159.4,158.9,158.6,152.2,138.0,118.6,115.8,111.5$, $85.9,85.6,62.3,50.7,37.9,12.3,9.09$.

ESI-TOF $\mathrm{m} / \mathrm{z}$ calculated for $\mathrm{C}_{12} \mathrm{H}_{14} \mathrm{~F}_{3} \mathrm{~N}_{3} \mathrm{O}_{5}(\mathrm{M}+\mathrm{H})-338.0886,338.3413$ observed.

\section{Preparation of 5}

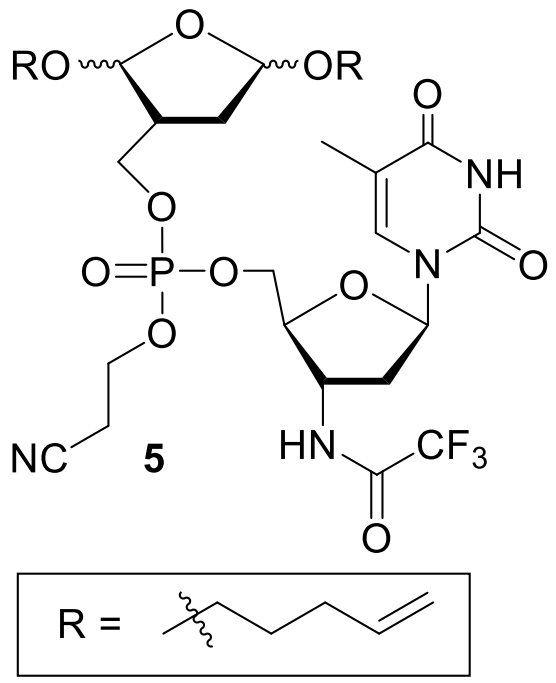

Phosphoramidite 4 (101 mg, $0.38 \mathrm{mmol}, 1.2 \mathrm{eq}$ ) and 3 (172 $\mathrm{mg}, 0.32 \mathrm{mmol}, 1 \mathrm{eq})$ were azeotropically dried together with toluene $(2 \times 1 \mathrm{~mL})$. S-Ethyl tetrazole/MeCN $(250 \mathrm{mM}, 1.5 \mathrm{~mL}$, $0.38 \mathrm{mmol}, 1.2 \mathrm{eq})$ was added to the flask. After $4 \mathrm{~h}$, TLC (1:1 EtOAc/Hex, $\mathrm{R}_{\mathrm{f}}=0.6, \mathrm{UV}$ active and stained with PAA) indicated that the majority of $\mathbf{5 5}$ was consumed. $\mathrm{tBuOOH}$ (500 $\mathrm{mM}, 200 \mu \mathrm{L}, 1 \mathrm{mmol}, 3 \mathrm{eq}$ ) was added and the reaction was stirred for 15-20 min. The reaction was concentrated under 
vacuum and column chromatography (2:1 EtOAc/Hex) yielded $131 \mathrm{mg}(56 \%)$ of 5. ${ }^{1} \mathrm{H}$ NMR (400 $\left.\mathrm{MHz}, \mathrm{CDCl}_{3}\right) \delta 10.36(\mathrm{~d}, J=10.1 \mathrm{~Hz}, 1 \mathrm{H}), 8.86(\mathrm{~d}, J=5 \mathrm{~Hz}, 1 \mathrm{H}), 7.46(\mathrm{~d}, J=2 \mathrm{~Hz}, 1 \mathrm{H}), 6.38$ (q, $J=5 \mathrm{~Hz}, 1 \mathrm{H}), 5.74$ (dsextet, $J=2,4 \mathrm{~Hz}, 2 \mathrm{H}), 5.10-4.90(\mathrm{~m}, 6 \mathrm{H}), 4.51(\mathrm{~s}, 1 \mathrm{H}), 4.34(\mathrm{~s}, 2 \mathrm{H})$, 4.25 (q, $J=6 \mathrm{~Hz}, 2 \mathrm{H}), 4.16(\mathrm{~s}, 2 \mathrm{H}), 4.06(\mathrm{~m}, 1 \mathrm{H}), 3.63$ (sextet, $J=2 \mathrm{~Hz}, 2 \mathrm{H}), 3.33(\mathrm{~m}, 2 \mathrm{H}), 2.75$ (q, $J=6 \mathrm{~Hz}, 3 \mathrm{H}), 2.44$ (q, $J=8 \mathrm{~Hz}, 2 \mathrm{H}), 2.28(\mathrm{~m}, 1 \mathrm{H}), 2.15(\mathrm{~m}, 1 \mathrm{H}), 2.01(\mathrm{~d}, J=4 \mathrm{~Hz}, 4 \mathrm{H}), 1.96$ (s, 3H), 1.58 (q, $J=4 \mathrm{~Hz}, 4 \mathrm{H})$.

${ }^{13} \mathrm{C}$ NMR (400 MHz, $\left.\mathrm{CD}_{3} \mathrm{OD}\right) \delta 166.23,159.79,152.15,141.21,139.40,137.73,129.01,115.25$, $113.27,112.05,106.87,105.52,104.85,85.22,84.82,68.26,67.38,64.33,61.54,50.55,48.65$, $45.97,37.24,33.76,31.45,30.10,27.94,20.10,15.31,12.63$.

${ }^{31} \mathrm{P}$ NMR $\left(400 \mathrm{MHz}, \mathrm{CDCl}_{3}\right) \delta-2.14$.

ESI-TOF m/z calculated for $\mathrm{C}_{30} \mathrm{H}_{42} \mathrm{~F}_{3} \mathrm{~N}_{4} \mathrm{O}_{11} \mathrm{P}(\mathrm{M}+\mathrm{H})-723.2540 .2717,723.2303$ observed.

\section{Preparation of 6}

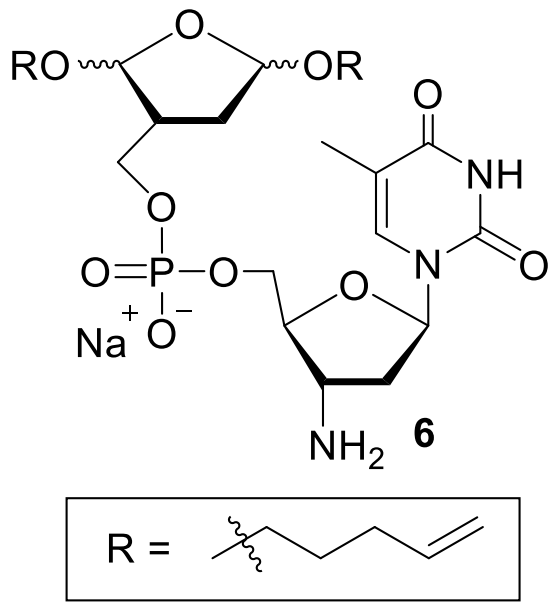

Compound 5 (115 $\mathrm{mg}, 0.15 \mathrm{mmol})$ was dissolved in concentrated aqueous ammonia $(1.5 \mathrm{~mL})$. The reaction was stirred at $0{ }^{\circ} \mathrm{C}$ for $4 \mathrm{~h}$. After $4 \mathrm{~h}$, TLC $(20 \% \mathrm{MeOH}$ in DCM, $\mathrm{R}_{\mathrm{f}}=0.2$, $\mathrm{UV}$ active and stained with $\mathrm{KMnO}_{4}$ ) confirmed the disappearance of starting material. The reaction was concentrated to yield $85 \mathrm{mg}(100 \%)$ of $6 .{ }^{1} \mathrm{H}$ NMR $(400 \mathrm{MHz}$, $\left.\mathrm{CD}_{3} \mathrm{OD}\right) \delta 6.34(\mathrm{t}, J=5.8 \mathrm{~Hz}, 1 \mathrm{H}), 5.78(\mathrm{~m}, 2 \mathrm{H}), 5.10-4.98(\mathrm{~m}$, $6 \mathrm{H}), 4.13(\mathrm{~s}, 3 \mathrm{H}), 3.88(\mathrm{~m}, 2 \mathrm{H}), 3.66(\mathrm{~m}, 2 \mathrm{H}), 3.40(\mathrm{q}, J=5.8 \mathrm{~Hz}, 2 \mathrm{H}), 2.81(\mathrm{~s}, 2 \mathrm{H}), 2.68(\mathrm{t}, J=7$ $\mathrm{Hz}, 1 \mathrm{H}), 2.49(\mathrm{~m}, 1 \mathrm{H}), 2.44(\mathrm{~m}, 2 \mathrm{H}), 2.30(\mathrm{~m}, 1 \mathrm{H}), 2.06(\mathrm{t}, J=7 \mathrm{~Hz}, 4 \mathrm{H}), 1.93(\mathrm{~s}, 3 \mathrm{H}), 1.60$ (quint, $J=7 \mathrm{~Hz}, 4 \mathrm{H})$. 
${ }^{13} \mathrm{C}$ NMR (400 MHz, CD 3 OD): $\delta$ 164.92, 150.84, 138.03, 137.99, 136.57, 116.47, 113.84, 110.75,

105.95, 104.39, 103.54, 67.30, 66.66, 50.97, 35.82, 35.58, 30.04, 30.02, 28.72, 15.82, 14.19, 11.28.

${ }^{31} \mathrm{P}$ NMR (400 MHz, $\left.\mathrm{CD}_{3} \mathrm{OD}\right) \delta 0.07$.

ESI-TOF m/z calculated for $\mathrm{C}_{25} \mathrm{H}_{39} \mathrm{~N}_{3} \mathrm{O}_{10} \mathrm{P}(\mathrm{M}-\mathrm{H})-572.2379,572.2399$ observed.

\section{General Procedure for the preparation of first-generation library}

Amine scaffold 6 (100 nmol) was azeotropically dried with carboxylic acid (140 nmol, 1.4 eq) in pyridine ( 1 x $15 \mu \mathrm{L})$ using a Speed Vac concentrator in a 384-well microtiter plate (VWR). To each well, activating solution (5 $\mu \mathrm{L} ; 28 \mathrm{mM} \mathrm{HBTU}$ and $28 \mathrm{mM}$ HOBt in DMF), DIPEA (2 $\mu \mathrm{L})$, and DMF $(3 \mu \mathrm{L})$ were added. The final concentrations during reaction were: $[6]=10 \mathrm{mM}$, $[$ acid $]=14 \mathrm{mM},[\mathrm{HBTU}]=14 \mathrm{mM},[\mathrm{HOBt}]=14 \mathrm{mM}, 20 \%$ DIPEA in DMF. The well plate was shaken at $25{ }^{\circ} \mathrm{C}$ overnight. Some wells were analyzed by ESI-MS to confirm coupling efficiency. The solutions were concentrated to dryness using a Speed Vac concentrator and the well plate was covered and stored at $-80{ }^{\circ} \mathrm{C}$.

Immediately before an assay, the amide was thawed, dissolved in DMF (4 $\mu \mathrm{L}, 25 \mathrm{mM})$. An aliquot ( $2 \mu \mathrm{L}, 50 \mathrm{nmol})$ was mixed with NBS $\left(8 \mu \mathrm{L}, 15 \mathrm{mM}, 2.4\right.$ eq, $40 \% \mathrm{H}_{2} \mathrm{O}$ in $\left.\mathrm{MeCN}\right)$ at 0 ${ }^{\circ} \mathrm{C}$ for $9 \mathrm{~min}$. The concentrations during reaction were: $[\mathrm{SM}]=5 \mathrm{mM},[\mathrm{NBS}]=12 \mathrm{mM}, 20 \% \mathrm{DMF}$, $30 \% \mathrm{H}_{2} \mathrm{O}$ in $\mathrm{MeCN}$. After 9 min, $\mathrm{Na}_{2} \mathrm{~S}_{2} \mathrm{O}_{3}(5 \mu \mathrm{L}, 200 \mathrm{mM})$ was added and reaction quenched on ice for $10 \mathrm{~min}$. Samples were concentrated with a Speed Vac concentrator. Some samples were analyzed ESI-MS to confirm product formation. 


\section{Preparation of 7}

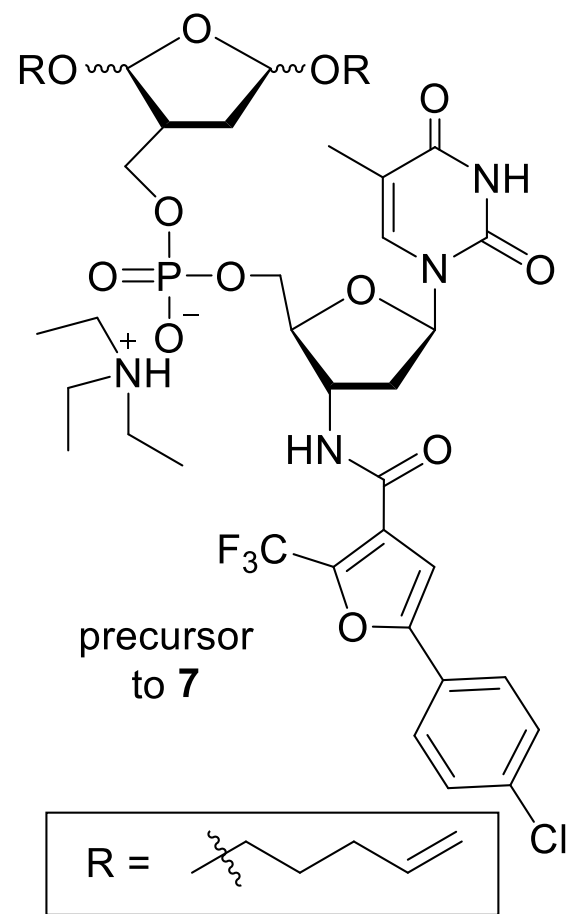

Scaffold 6 (17 mg, $0.03 \mathrm{mmol}$ ) and 5-(4-chlorophenyl)-3(trifluoromethyl) furan-2-carboxylic acid (11 mg, 0.04 mmol, 1.4 eq) were azeotropically dried together with pyridine (2 x $1 \mathrm{~mL})$. HBTU (14.0 mg, $0.037 \mathrm{mmol}, 1.4 \mathrm{eq})$ and HOBt (5 mg, $0.037 \mathrm{mmol}, 1.4 \mathrm{eq})$ were added to the starting materials. The contents were dissolved in DMF $(1.04 \mathrm{~mL})$ and DIPEA $(260 \mu \mathrm{L})$. The reaction was stirred at $25{ }^{\circ} \mathrm{C}$ overnight. TLC $\left(20 \% \mathrm{MeOH}\right.$ in $\mathrm{DCM}, \mathrm{R}_{\mathrm{f}}=0.3, \mathrm{UV}$ active and stained with PAA) suggested $\mathbf{5 7}$ was consumed. The reaction was concentrated and purified by column

chromatography (5\% MeOH in DCM) to yield $21.2 \mathrm{mg}(96 \%)$ of the precursor to $7 .{ }^{1} \mathrm{H}$ NMR (400 $\left.\mathrm{MHz}, \mathrm{CD}_{3} \mathrm{OD}\right) \delta 7.76(\mathrm{~d}, J=6.8 \mathrm{~Hz}, 1 \mathrm{H}), 7.70(\mathrm{~d}, J=7.6 \mathrm{~Hz}, 2 \mathrm{H}), 7.59(\mathrm{~d}, J=6.8 \mathrm{~Hz}, 2 \mathrm{H}), 7.50$ $(\mathrm{d}, J=7.6 \mathrm{~Hz}, 1 \mathrm{H}), 7.35$ (quint, $J=6.8 \mathrm{~Hz}, 4 \mathrm{H}), 6.37(\mathrm{t}, J=3.6 \mathrm{~Hz}, 1 \mathrm{H}), 5.78(\mathrm{~m}, 2 \mathrm{H}), 5.00(\mathrm{~m}$, $6 \mathrm{H}), 4.68(\mathrm{~m}, 1 \mathrm{H}), 4.15(\mathrm{~d}, J=1.6 \mathrm{~Hz}, 1 \mathrm{H}), 4.10(\mathrm{~m}, 2 \mathrm{H}), 3.90(\mathrm{~m}, 2 \mathrm{H}), 3.66(\mathrm{dd}, J=1.6,5.2 \mathrm{~Hz}$, 2H), $3.21(\mathrm{q}, J=8 \mathrm{~Hz}, 6 \mathrm{H}), 2.49(\mathrm{~m}, 1 \mathrm{H}), 2.40(\mathrm{~d}, J=1.6 \mathrm{~Hz}, 2 \mathrm{H}), 2.30(\mathrm{~m}, 1 \mathrm{H}), 2.07(\mathrm{~d}, J=6.4$ $\mathrm{Hz}, 4 \mathrm{H}), 1.97$ (s, 3H), $1.90(\mathrm{~m}, 1 \mathrm{H}), 1.60$ (quint, $J=6.4 \mathrm{~Hz}, 4 \mathrm{H}), 1.32$ (t, $J=8 \mathrm{~Hz}, 9 \mathrm{H})$.

${ }^{13} \mathrm{C}$ NMR $\left(400 \mathrm{MHz}, \mathrm{CDCl}_{3}\right) \delta 169.9 ., 169.7,163.8,150.2,136.2,134.9,128.6,123.9,116.6$, $111.43,111.40,98.45,98.42,96.1,87.3,87.2,86.2,86.1,80.9,80.8,67.3,66.3,66.2,62.5,62.45$, $62.43,42.9,42.8,42.7,36.1,32.3,32.2,21.1,19.72,19.67,12.4$.

${ }^{31} \mathrm{P}$ NMR $\left(400 \mathrm{MHz}, \mathrm{CD}_{3} \mathrm{OD}\right) \delta-2.4,-3.0$.

ESI-TOF m/z calculated for $\mathrm{C}_{37} \mathrm{H}_{44} \mathrm{ClF}_{3} \mathrm{~N}_{3} \mathrm{O}_{12} \mathrm{P}(\mathrm{M}-\mathrm{H})$ - 844.2303, 844.2221 observed. 
$\varepsilon_{273}\left(50 \% \mathrm{MeCN}\right.$ in $\left.\mathrm{H}_{2} \mathrm{O}\right)=2.0 \times 10^{4} \mathrm{M}^{-1} \mathrm{~cm}^{-1}$

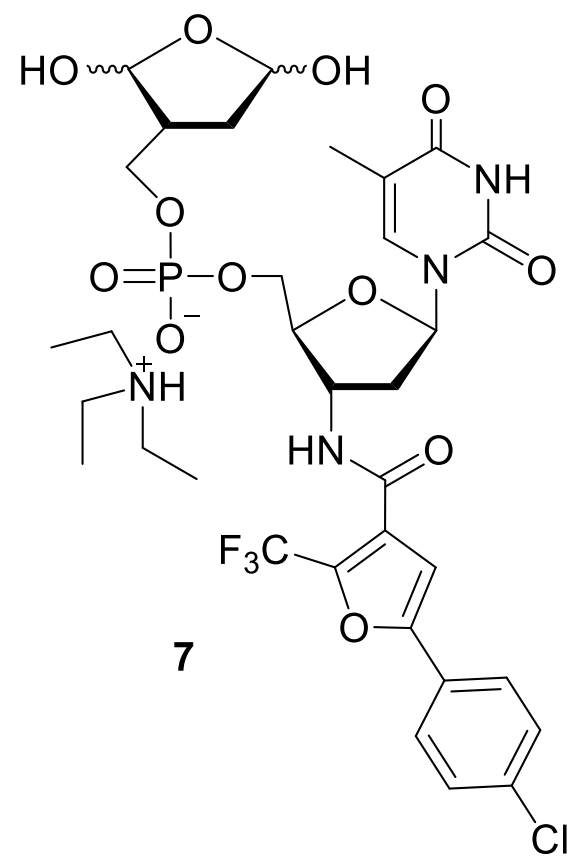

The pentenoyl protected inhibitor was stored as a $25 \mathrm{mM}$ stock solution in DMF at $-20{ }^{\circ} \mathrm{C}$. An aliquot of the starting material (2 $\mu \mathrm{L}, 50 \mathrm{nmol})$ was placed in a microtiter well plate and cooled to $4{ }^{\circ} \mathrm{C}$. Cold $\mathrm{H}_{2} \mathrm{O}(3 \mu \mathrm{L})$ was added to the well. NBS in $\mathrm{MeCN}(25 \mathrm{mM}, 5 \mu \mathrm{L})$ was added and the well plate was shaken at $4{ }^{\circ} \mathrm{C}$ for $9 \mathrm{~min}$. After $9 \mathrm{~min}$, the reaction was quenched by an equal volume of $\mathrm{Na}_{2} \mathrm{~S}_{2} \mathrm{O}_{3}\left(200 \mathrm{mM}\right.$ in $\mathrm{H}_{2} \mathrm{O}$, $10 \mu \mathrm{L}$ ) and the plate was shaken for additional 5-10 min. The reaction was concentrated by speed vacuum, redissolved in

1:1 $\mathrm{MeCN} / \mathrm{H}_{2} \mathrm{O}$ and used directly.

Reaction Conditions: $[\mathrm{SM}]=5 \mathrm{mM},[\mathrm{NBS}]=12.5 \mathrm{mM}, 30 \% \mathrm{H}_{2} \mathrm{O}, 20 \% \mathrm{DMF}, 50 \% \mathrm{MeCN}$

Quenching Conditions: $[\mathrm{SM}]=2.5 \mathrm{mM},[\mathrm{NBS}]=6.25 \mathrm{mM},\left[\mathrm{Na}_{2} \mathrm{~S}_{2} \mathrm{O}_{3}\right]=100 \mathrm{mM}, 65 \% \mathrm{H}_{2} \mathrm{O}$, $10 \% \mathrm{DMF}, 25 \% \mathrm{MeCN}$.

ESI-MS m/z calculated for $\mathrm{C}_{27} \mathrm{H}_{27} \mathrm{ClF}_{3} \mathrm{~N}_{3} \mathrm{O}_{12} \mathrm{P}(\mathrm{M}-\mathrm{H})-708.09,708.20$ observed.

\section{Preparation of $\mathbf{8}^{9}$}

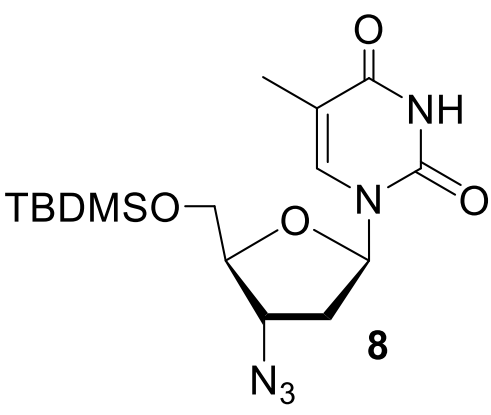

AZT (587 mg, $2.19 \mathrm{mmol}, 1 \mathrm{eq}$ ) was azeotropically dried twice with pyridine $(2 \times 1 \mathrm{~mL})$. Imidazole $(604 \mathrm{mg}, 8.76 \mathrm{mmol}, 4 \mathrm{eq})$ and TBDMSCl (672 mg, $4.38 \mathrm{mmol}, 2 \mathrm{eq})$ were added and dissolved in DMF (4.5 mL, $500 \mathrm{mM})$. The reaction was heated to $50^{\circ} \mathrm{C}$ overnight. When confirmed complete by TLC $(5 \% \mathrm{MeOH}$ in DCM, $\mathrm{R}_{\mathrm{f}}=0.5$, UV active and stained with PAA), the reaction was cooled and diluted with 
EtOAc $(10 \mathrm{~mL})$. The organic layer was washed with sat. $\mathrm{NH} 4 \mathrm{Cl}(3 \times 15 \mathrm{~mL})$ and brine $(2 \times 15$ $\mathrm{mL})$. The combined aqueous layers were extracted using EtOAc $(2 \times 50 \mathrm{~mL})$. The combined organic layers were dried over $\mathrm{Na}_{2} \mathrm{SO}_{4}$ and concentrated under vacuum. The residue was purified by column chromatography (2:1 Hex/EtOAc) yielding $825 \mathrm{mg}(95 \%)$ of $8 .{ }^{1} \mathrm{H}$ NMR (400 MHz, $\left.\mathrm{CDCl}_{3}\right) \delta 8.72(\mathrm{~s}, 1 \mathrm{H}), 7.43(\mathrm{~s}, 1 \mathrm{H}), 6.22(\mathrm{t}, J=6.8 \mathrm{~Hz}, 1 \mathrm{H}), 4.24(\mathrm{q}, J=3.2 \mathrm{~Hz}, 1 \mathrm{H}), 3.96(\mathrm{~d}, J=$ $3.2 \mathrm{~Hz}, 1 \mathrm{H}), 3.94(\mathrm{dd}, J=2.8,14 \mathrm{~Hz}, 1 \mathrm{H}), 3.79(\mathrm{dd}, J=2.8,14 \mathrm{~Hz}, 1 \mathrm{H}), 2.44(\mathrm{~m}, 1 \mathrm{H}), 2.22(\mathrm{~m}$, 1H), 1.91 (s, 3H), 0.93 (s, 9H), 0.13 (s, 6H).

${ }^{13} \mathrm{C}$ NMR $\left(400 \mathrm{MHz}, \mathrm{CDCl}_{3}\right) \delta 134.9,111.0,84.5,84.4,62.9,60.5,37.9,25.9,25.7,25.6,18.3$, $12.5,-5.4,-5.5$.

\section{Preparation of 9}

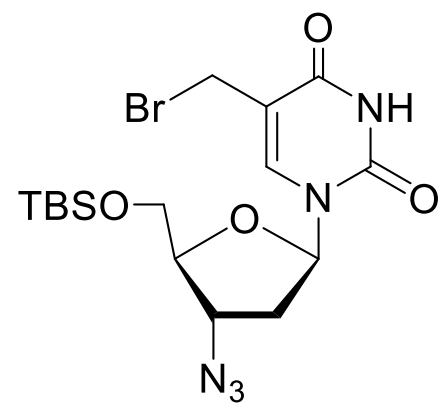

Compound 8 (982.8 mg, $2.58 \mathrm{mmol}, 1 \mathrm{eq}$ ) was mixed with NBS (366 $\mathrm{mg}, 2.06 \mathrm{mmol}, 0.8 \mathrm{eq})$ and dissolved in distilled benzene $(13 \mathrm{~mL}, 200$ $\mathrm{mM})$. The mixture was sparged with Ar for $20 \mathrm{~min}$. The reaction was activated by sun lamp. The reaction was stirred for $1 \mathrm{~h}$ while the mixture turned red. When TLC (1:1 Hex/EtOAc, UV active and stained with iodine) showed a mixture of starting material and one new spot, a second aliquot of 0.8 eq NBS was added to the reaction. After a total of $2 \mathrm{~h}$ and $2 \times 0.8$ eq NBS added, the SM was consumed to yield one major spot. The mixture was immediately filtered through a glass frit and diluted with DCM $(10 \mathrm{~mL})$ and $\mathrm{H}_{2} \mathrm{O}(20 \mathrm{~mL})$. The aqueous layer was extracted with DCM $(2 \times 20$ $\mathrm{mL})$ and the combined organic layers were washed with sat. bicarbonate solution $(1 \times 40 \mathrm{~mL})$, brine ( 1 x $40 \mathrm{~mL})$, dried over $\mathrm{Na}_{2} \mathrm{SO}_{4}$, and concentrated under vacuum to give $853.6 \mathrm{mg}(72 \%)$ a yellow crude residue. ${ }^{1} \mathrm{H}$ NMR $\left(400 \mathrm{MHz}, \mathrm{CDCl}_{3}\right) \delta 9.67(\mathrm{~s}, 1 \mathrm{H}), 7.84(\mathrm{~s}, 1 \mathrm{H}), 6.17(\mathrm{t}, J=6.4 \mathrm{~Hz}$, 
1H), $4.24(\mathrm{~m}, 2 \mathrm{H}), 4.20(\mathrm{~m}, 1 \mathrm{H}), 3.98(\mathrm{~m}, 1 \mathrm{H}), 3.96(\mathrm{dd}, J=2.8,11.6 \mathrm{~Hz}, 1 \mathrm{H}), 3.80(\mathrm{dd}, J=2.8$, $11.6 \mathrm{~Hz}, 1 \mathrm{H}), 2.50(\mathrm{~m}, 1 \mathrm{H}), 2.25(\mathrm{~m}, 1 \mathrm{H}), 0.94(\mathrm{~s}, 9 \mathrm{H}), 0.14(\mathrm{~s}, 6 \mathrm{H})$.

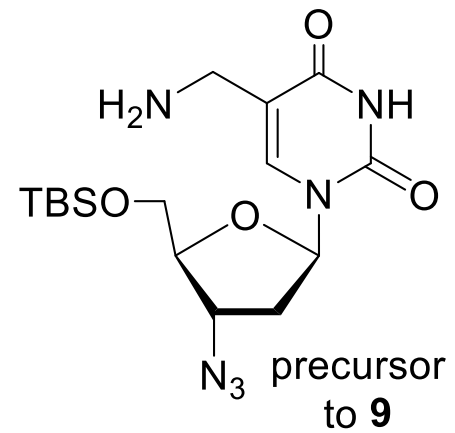

The crude bromide (853.2 mg, $1.85 \mathrm{mmol}$ ) was dissolved in $\mathrm{EtOH}$ $(13 \mathrm{~mL})$. Concentrated aqueous ammonia $(23 \mathrm{~mL}, 15.7 \mathrm{M}, 47.1$ mmol, 25 eq) was added to the flask. The reaction was stirred at 25 ${ }^{\circ} \mathrm{C}$ for $1.5 \mathrm{~h}$. After $1.5 \mathrm{~h}$, TLC (10\% MeOH in DCM) indicated the formation of product $\left(R_{f}=0.3\right)$. The reaction was concentrated and purified by column chromatography (DCM -> 3\% MeOH in DCM) to yield $339 \mathrm{mg}(43 \%)$ of the amine. ${ }^{1} \mathrm{H}$ NMR $\left(400 \mathrm{MHz}, \mathrm{CDCl}_{3}\right) \delta 7.78(\mathrm{~s}, 1 \mathrm{H}), 6.06(\mathrm{t}, J=6.4 \mathrm{~Hz}, 1 \mathrm{H}), 4.22(\mathrm{~m}, 1 \mathrm{H}), 3.88(\mathrm{q}$, $J=4.4 \mathrm{~Hz}, 1 \mathrm{H}), 3.82(\mathrm{~d}, J=4.4 \mathrm{~Hz}, 1 \mathrm{H}), 3.78(\mathrm{~d}, J=4.4 \mathrm{~Hz}, 1 \mathrm{H}), 3.73(\mathrm{~s}, 2 \mathrm{H}), 2.35(\mathrm{t}, J=6.4$ $\mathrm{Hz}, 2 \mathrm{H}), 0.85$ (s, 9H), 0.05 (s, 6H).

${ }^{13} \mathrm{C}$ NMR $\left(400 \mathrm{MHz}, \mathrm{CDCl}_{3}\right) \delta 164.3,150.3,140.2,109.2,85.1,84.6,62.9,60.6,50.1,37.3$, $25.8,22.4,18.3,-5.4,-5.5$.

ESI-TOF m/z calculated for $\mathrm{C}_{16} \mathrm{H}_{28} \mathrm{~N}_{6} \mathrm{O}_{4} \mathrm{Si}(\mathrm{M}+\mathrm{H})-397.1941$ calculated, 397.2012 observed.<smiles>COCC1OC2CC1C(C#N)C2n1cc(CNC(=O)C(F)(F)F)c(=O)[nH]c1=O</smiles>
The second intermediate $(313.5 \mathrm{mg}, 0.791 \mathrm{mmol})$ was dissolved in THF $(5.2 \mathrm{~mL}, 280 \mathrm{mM})$. Triethylamine $(1.6 \mathrm{~mL}, 11.8 \mathrm{mmol}$, 15 eq) and ethyl trifluoroacetate $(0.95 \mathrm{~mL}, 7.91 \mathrm{mmol}, 10 \mathrm{eq})$ were added to the flask to make the final concentration $100 \mathrm{mM}$.

9 The reaction was stirred for $4 \mathrm{~h}$ at $25^{\circ} \mathrm{C}$. TLC $(3 \% \mathrm{MeOH}$ in DCM, $\mathrm{R}_{\mathrm{f}}=0.5$, UV active and stained by PAA) confirmed conversion to product. The reaction was concentrated and carried further to the next step without further purification, yielding $500 \mathrm{mg}$ of 66 (91\%). ${ }^{1} \mathrm{H}$ NMR (400 MHz, $\left.\mathrm{CDCl}_{3}\right) \delta 10.17(\mathrm{~s}, 1 \mathrm{H}), 7.91(\mathrm{~s}, 1 \mathrm{H}), 7.80(\mathrm{~s}, 1 \mathrm{H}), 6.13(\mathrm{t}, J=$ 
$6.4 \mathrm{~Hz}, 1 \mathrm{H}), 4.23(\mathrm{q}, J=4 \mathrm{~Hz}, 1 \mathrm{H}), 4.20(\mathrm{~s}, 2 \mathrm{H}), 4.00(\mathrm{q}, J=4 \mathrm{~Hz}, 1 \mathrm{H}), 3.91(\mathrm{dd}, J=3.6,11.6$ Hz, 1H), 3.84 (dd, $J=3.6,11.6 \mathrm{~Hz}, 1 \mathrm{H}), 2.49$ (m, 1H), $2.24(\mathrm{~m}, 1 \mathrm{H}), 0.91(\mathrm{~s}, 9 \mathrm{H}), 0.13$ (s, 6H).

${ }^{13} \mathrm{C} \mathrm{NMR}\left(400 \mathrm{MHz}, \mathrm{CDCl}_{3}\right) \delta 162.9,161.3,160.9,149.9,138.7,117.8,114.9,109.2,84.8,84.6$, $60.8,59.9,53.2,49.2,45.5,37.4,35.7,7.9$.

ESI-TOF $\mathrm{m} / \mathrm{z}$ calculated for $\mathrm{C}_{18} \mathrm{H}_{27} \mathrm{~F}_{3} \mathrm{~N}_{6} \mathrm{O}_{5} \mathrm{Pi}(\mathrm{M}+\mathrm{H})-493.1764,493.1716$ observed.

\section{Preparation of 10}

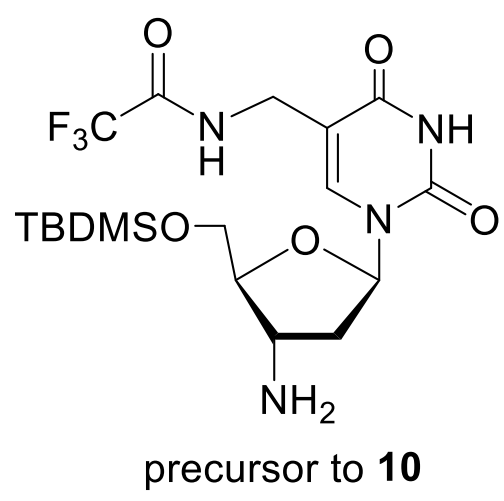

Compound 9 (22.5 mg, $0.05 \mathrm{mmol})$ was dissolved in $50 \% \mathrm{MeOH}$, $20 \% \mathrm{H}_{2} \mathrm{O}, 30 \% \mathrm{tBuOH}(1 \mathrm{~mL})$. Activated $\mathrm{Pd} / \mathrm{C}(14.1 \mathrm{mg}, 60 \mathrm{wt} \%)$ was added to the solution. The reaction was continuously sparged with $\mathrm{H}_{2}(1 \mathrm{~atm})$. After $1 \mathrm{~h}$, TLC (5\% MeOH in DCM, UV active and stained with PAA, $R_{f}=0.35$ ) suggested the reaction was complete. The mixture was passed through a Celite column and concentrated to $17 \mathrm{mg}(82 \%)$ of crude amine, which was carried forward without further purification. ${ }^{1} \mathrm{H}$ NMR $\left(400 \mathrm{MHz}, \mathrm{CD}_{3} \mathrm{OD}\right) \delta 7.83(\mathrm{~s}, 1 \mathrm{H}), 6.18(\mathrm{t}, J=6.4 \mathrm{~Hz}, 1 \mathrm{H}), 4.12(\mathrm{~s}, 2 \mathrm{H})$, $3.93(\mathrm{dd}, J=4,11.2 \mathrm{~Hz}, 1 \mathrm{H}), 3.88(\mathrm{dd}, J=4,11.2 \mathrm{~Hz}, 1 \mathrm{H}), 3.77$ (dt, $J=1.2,4 \mathrm{~Hz}, 1 \mathrm{H}), 3.50(\mathrm{q}$, $J=6.4 \mathrm{~Hz}, 1 \mathrm{H}), 2.25(\mathrm{~m}, 2 \mathrm{H}), 0.93(\mathrm{~s}, 9 \mathrm{H}), 0.12(\mathrm{~d}, J=1.2 \mathrm{~Hz}, 6 \mathrm{H})$. 


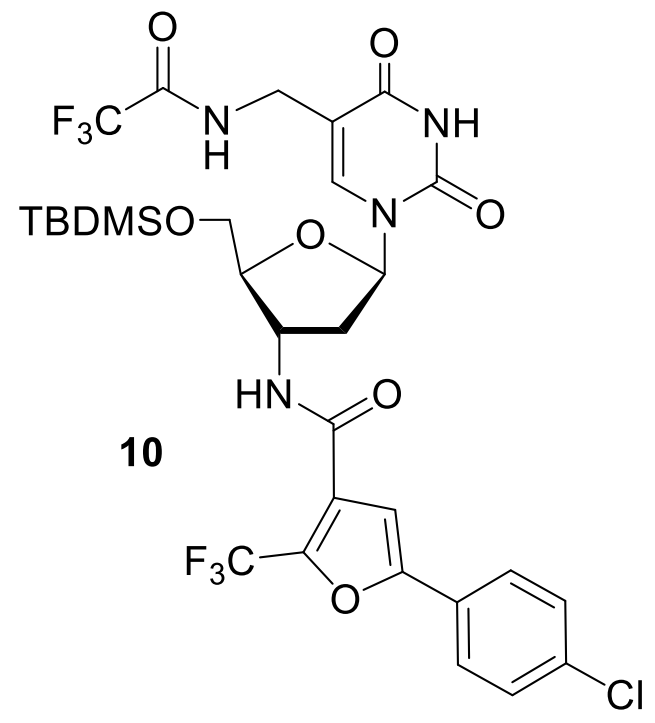

Crude amine (17 $\mathrm{mg}, \quad 0.033 \mathrm{mmol})$ and 5-(4chlorophenyl)-3-(trifluoromethyl) furan-2-carboxylic acid (14.2 mg, $0.05 \mathrm{mmol}, 1.4 \mathrm{eq})$ were azeotropically dried together with pyridine $(2 \times 1 \mathrm{~mL})$. HBTU $(17.8 \mathrm{mg}$, $0.05 \mathrm{mmol}, 1.4 \mathrm{eq})$ and $\mathrm{HOBt}(6.3 \mathrm{mg}, 0.05 \mathrm{mmol}, 1.4 \mathrm{eq})$ were added to the starting materials. The contents were dissolved in DMF $(528 \mu \mathrm{L})$ and DIPEA $(132 \mu \mathrm{L})$. The reaction was stirred at $25^{\circ} \mathrm{C}$ overnight. TLC $(10 \% \mathrm{MeOH}$ in DCM, $\mathrm{R}_{\mathrm{f}}=0.4$, UV active and stained with PAA) suggested the starting material was gone. The reaction was concentrated and purified by column chromatography $(1: 1 \mathrm{Hex} / \mathrm{EtOAc}->5 \% \mathrm{MeOH}$, 1:1 Hex/EtOAc) to yield $18.1 \mathrm{mg}(75 \%)$ of $\mathbf{1 0} .{ }^{1} \mathrm{H}$ NMR (400 MHz, $\left.\mathrm{CDCl}_{3}\right) \delta 8.23(\mathrm{~s}, 1 \mathrm{H}), 8.10$ $(\mathrm{d}, J=6.4 \mathrm{~Hz}, 1 \mathrm{H}), 7.86(\mathrm{~s}, 1 \mathrm{H}), 7.75(\mathrm{~d}, J=8.2 \mathrm{~Hz}, 2 \mathrm{H}), 7.63(\mathrm{~d}, J=8.2 \mathrm{~Hz}, 2 \mathrm{H}), 6.09(\mathrm{t}, J=6.4$ $\mathrm{Hz}, 1 \mathrm{H}), 4.59(\mathrm{t}, J=4 \mathrm{~Hz}, 1 \mathrm{H}), 4.12(\mathrm{t}, J=4 \mathrm{~Hz}, 2 \mathrm{H}), 3.88(\mathrm{~m}, 2 \mathrm{H}), 2.43(\mathrm{~m}, 1 \mathrm{H}), 2.25(\mathrm{~m}, 1 \mathrm{H})$, $0.82(\mathrm{~s}, 9 \mathrm{H}), 0.04(\mathrm{~s}, 6 \mathrm{H})$.

${ }^{13} \mathrm{C}$ NMR (400 MHz, $\left.\mathrm{CDCl}_{3}\right) \delta 162.7,160.8,150.1,134.9,129.0,126.5,125.8,125.6,120.1$, 117.3, 110.7, 108.9, 105.9, 85.6, 54.7, 38.4, 36.5, 31.4, 25.7, 18.2, 16.9, -5.6. -5.7.

ESI-TOF m/z calculated for $\mathrm{C}_{30} \mathrm{H}_{33} \mathrm{ClF}_{6} \mathrm{~N}_{4} \mathrm{O}_{7} \mathrm{Si}(\mathrm{M}+\mathrm{H})-739.1711,739.1784$ observed. 


\section{Preparation of S7}

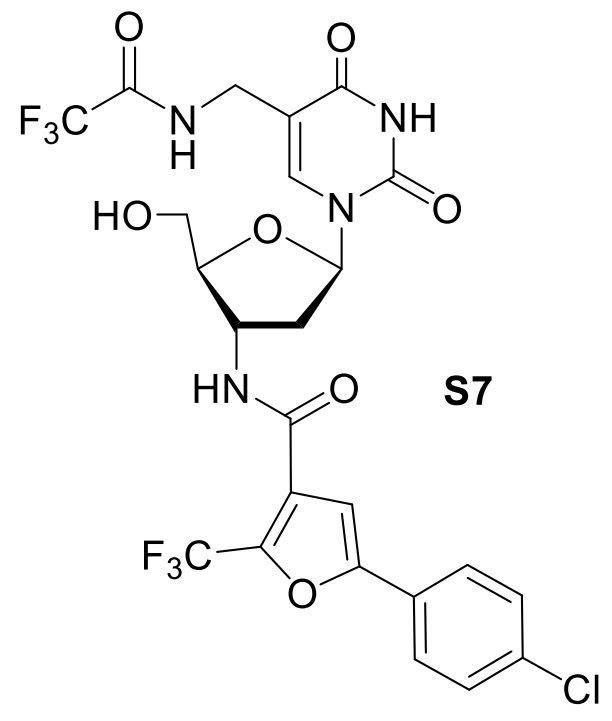

Compound 10 (135 mg, $0.19 \mathrm{mmol}$ ) was dissolved in THF (3.6 mL). TEA•3HF (74 mg, $0.46 \mathrm{mmol}, 0.08 \mathrm{~mL}, 2.5 \mathrm{eq})$ was added to the flask. The reaction was stirred at $25{ }^{\circ} \mathrm{C}$ overnight. TLC ( $5 \% \mathrm{MeOH}$ in DCM, $\mathrm{R}_{\mathrm{f}}=0.5$, $\mathrm{UV}$ active and stained with PAA) confirmed conversion to product. The reaction was concentrated and purified by column chromatography (DCM $->2 \% \mathrm{MeOH}$ ) to yield $100 \mathrm{mg}$ (86\%) of $\mathbf{S} 7 .{ }^{1} \mathrm{H}$ NMR $\left(400 \mathrm{MHz}, \mathrm{CDCl}_{3}\right) \delta 8.28(\mathrm{t}, J=6.9$, 1H), $7.79(\mathrm{~m}, 3 \mathrm{H}), 7.74(\mathrm{dd}, J=1.6,6.9 \mathrm{~Hz}, 1 \mathrm{H}), 7.57$ (dd, $J=1.6,8 \mathrm{~Hz}, 1 \mathrm{H}), 7.23$ (d, $J=8 \mathrm{~Hz}$, 1H), $7.19(\mathrm{~m}, 2 \mathrm{H}), 6.06(\mathrm{q}, J=4.4 \mathrm{~Hz}, 1 \mathrm{H}), 4.54(\mathrm{t}, J=7.6 \mathrm{~Hz}, 1 \mathrm{H}), 4.32(\mathrm{~d}, J=7.6 \mathrm{~Hz}, 1 \mathrm{H}), 4.21$ (dd, $J=5.6,14.8 \mathrm{~Hz}, 1 \mathrm{H}), 4.15$ (dd, $J=5.6,14.8 \mathrm{~Hz}, 1 \mathrm{H}), 3.84$ (d, $J=10.8 \mathrm{~Hz}, 1 \mathrm{H}), 3.74$ (d, $J=$ $10.8 \mathrm{~Hz}, 1 \mathrm{H}), 2.30(\mathrm{~m}, 2 \mathrm{H})$.

${ }^{13} \mathrm{C}$ NMR $\left(400 \mathrm{MHz}, \mathrm{CDCl}_{3}\right) \delta 163.2,160.8,157.2,153.0,149.9,134.1,128.6,127.4,126.1$, $124.4,123.9,120.2,117.9,110.9,108.6,107.4,83.9,50.1,46.1,8.31,8.29,8.26,8.24$.

ESI-TOF $\mathrm{m} / \mathrm{z}$ calculated for $\mathrm{C}_{24} \mathrm{H}_{19} \mathrm{ClF}_{3} \mathrm{~N}_{4} \mathrm{O}_{7}(\mathrm{M}+\mathrm{H})-625.0846,625.0844$ observed. 


\section{Preparation of 12}

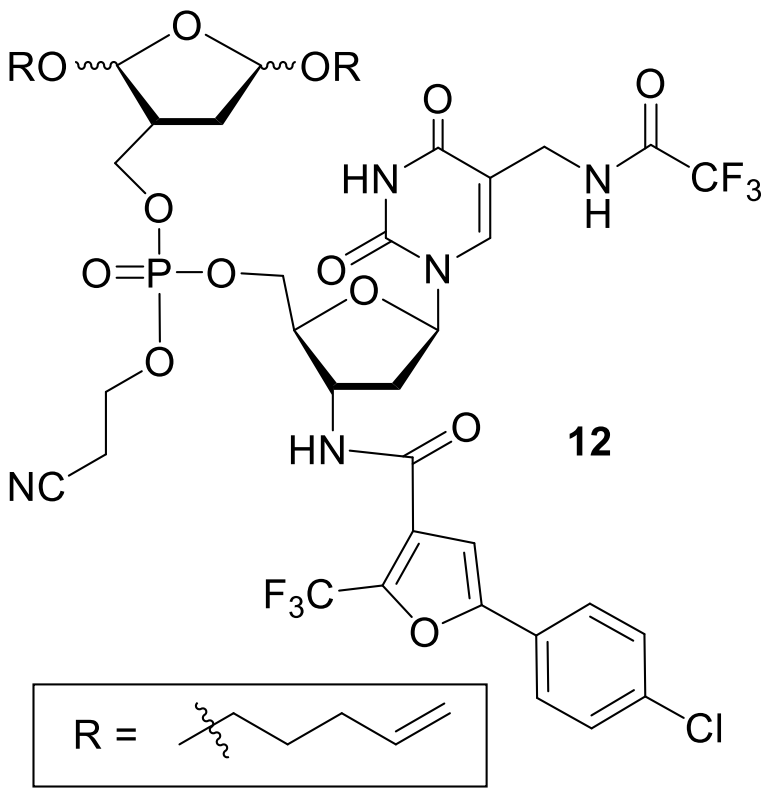

Compounds $\mathbf{S 7}$ (61 mg, $0.08 \mathrm{mmol}, 1.2 \mathrm{eq})$ and 4 (32 $\mathrm{mg}, 0.07 \mathrm{mmol}, 1 \mathrm{eq}$ ) were azeotropically dried with toluene $(2 \times 10.5 \mathrm{~mL})$. S-Ethyl tetrazole/MeCN (250 mM, $1 \mathrm{~mL}, 0.24 \mathrm{mmol}, 1.2$ eq) was added to the reaction flask. After $3 \mathrm{~h}$, TLC (2:1 EtOAc/Hex, $\mathrm{R}_{\mathrm{f}}=0.5$, UV active and stained with PAA) indicated that the majority of S7 was consumed. tBuOOH (500 mM, $18 \mathrm{mg}, 40$ $\mu \mathrm{L}, 0.20 \mathrm{mmol}, 3 \mathrm{eq}$ ) was added for $15-20 \mathrm{~min}$.

The reaction was concentrated and column chromatography (2:1 EtOAc/Hex) yielded $61 \mathrm{mg}$ (90 \%) of 12. ${ }^{1} \mathrm{H}$ NMR $\left(400 \mathrm{MHz}, \mathrm{CDCl}_{3}\right) \delta 7.87(\mathrm{~d}, J=5.9,1 \mathrm{H}), 7.56(\mathrm{~d}, J=8.4 \mathrm{~Hz}, 2 \mathrm{H}), 7.35(\mathrm{~d}, J$ $=8.4 \mathrm{~Hz}, 2 \mathrm{H}), 7.07(\mathrm{~d}, J=3.6 \mathrm{~Hz}, 1 \mathrm{H}), 6.22(\mathrm{t}, J=5.9,1 \mathrm{H}), 5.78(\mathrm{~m}, 2 \mathrm{H}), 4.99(\mathrm{~m}, 6 \mathrm{H}), 4.75(\mathrm{~m}$, 1H), $4.40(\mathrm{~m}, 3 \mathrm{H}), 4.30(\mathrm{~m}, 4 \mathrm{H}), 4.28(\mathrm{~m}, 2 \mathrm{H}), 3.88(\mathrm{~m}, 2 \mathrm{H}), 3.61(\mathrm{~m}, 2 \mathrm{H}), 3.38(\mathrm{~m}, 2 \mathrm{H}), 2.78$ (quint, $J=3.6 \mathrm{~Hz}, 2 \mathrm{H}), 2.63(\mathrm{~m}, 1 \mathrm{H}), 2.52(\mathrm{~m}, 2 \mathrm{H}), 2.45(\mathrm{~m}, 1 \mathrm{H}), 2.08(\mathrm{~m}, 4 \mathrm{H}), 1.88(\mathrm{~m}, 1 \mathrm{H})$, $1.62(\mathrm{~m}, 4 \mathrm{H})$.

${ }^{13} \mathrm{C}$ NMR $\left(400 \mathrm{MHz}, \mathrm{CDCl}_{3}\right) \delta 137.9,135.1,129.0,126.5,125.6,114.6,114.5,66.6,65.8,30.1$, $30.0,28.6,269,26.1,14.6$.

${ }^{31} \mathrm{P}$ NMR $\left(400 \mathrm{MHz}, \mathrm{CDCl}_{3}\right) \delta 7.8,-0.9,-1.0,-2.57,-2.62,-2.63,-2.65,-2.67,-2.69,-2.71,-3.06$, -3.1 .

${ }^{19} \mathrm{~F}$ NMR $\left(300 \mathrm{MHz}, \mathrm{CDCl}_{3}\right) \delta-64.02,-64.03,-64.1,-78.12,-78.13-78.2$.

ESI-TOF $\mathrm{m} / \mathrm{z}$ calculated for $\mathrm{C}_{42} \mathrm{H}_{47} \mathrm{ClF}_{6} \mathrm{~N}_{5} \mathrm{O}_{13} \mathrm{P}(\mathrm{M}+\mathrm{H})-1010.2501,1010.2183$ observed. 


\section{Preparation of 13}

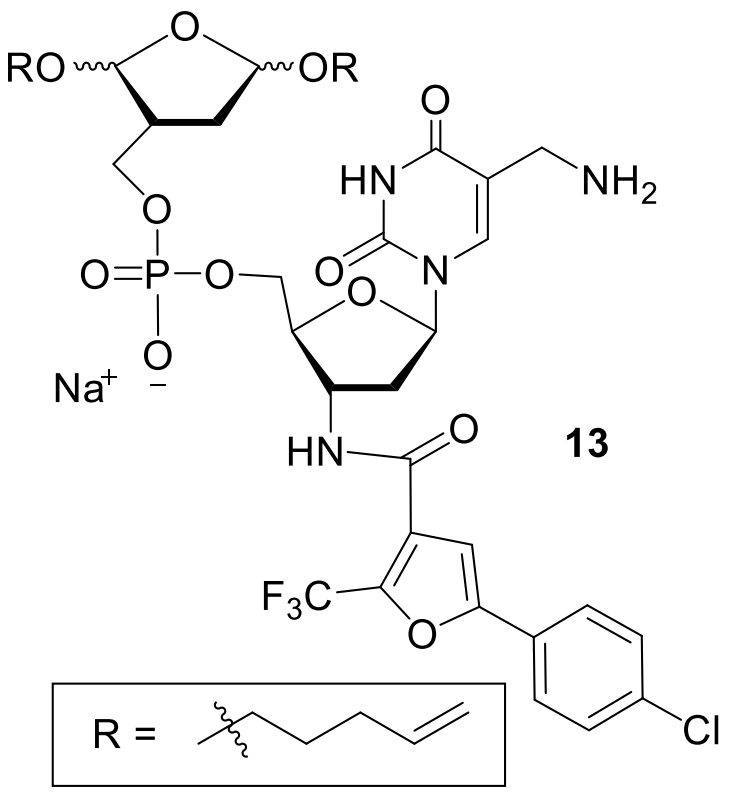

Compound 12 ( $8 \mathrm{mg}, 0.008 \mathrm{mmol})$ was dissolved in concentrated aqueous ammonia $(160 \mu \mathrm{L})$. The reaction was capped and stirred at $25^{\circ} \mathrm{C}$. After $5 \mathrm{~h}$, TLC $\left(15 \% \mathrm{MeOH}\right.$ in DCM, $\mathrm{R}_{\mathrm{f}}=0.1, \mathrm{UV}$ active and stained with PAA) confirmed the disappearance of starting material and formation of a new spot. The reaction was concentrated and purified by column chromatography $(5 \% \mathrm{MeOH}$ in $\mathrm{DCM} \rightarrow 20 \%$ $\mathrm{MeOH}$ in DCM) to yield $9.3 \mathrm{mg}(73 \%)$ of 13 . The

product was passed through a Dowex $(\mathrm{Na}+)$ column. ${ }^{1} \mathrm{H}$ NMR $\left(400 \mathrm{MHz}, \mathrm{CD}_{3} \mathrm{OD}\right) \delta 8.37(\mathrm{~s}, 1 \mathrm{H})$, $7.76(\mathrm{~d}, J=11.6 \mathrm{~Hz}, 2 \mathrm{H}), 7.68(\mathrm{q}, J=5.2 \mathrm{~Hz}, 1 \mathrm{H}), 7.50(\mathrm{~d}, J=11.6 \mathrm{~Hz}, 2 \mathrm{H}), 7.24(\mathrm{~m}, 3 \mathrm{H}), 6.28$ $(\mathrm{t}, J=5.2 \mathrm{~Hz}, 1 \mathrm{H}), 5.80(\mathrm{~m}, 2 \mathrm{H}), 4.95(\mathrm{~m}, 6 \mathrm{H}), 4.78(\mathrm{q}, J=8.6 \mathrm{~Hz}, 1 \mathrm{H}), 4.26(\mathrm{~m}, 2 \mathrm{H}), 4.08(\mathrm{~m}$, 2H), $3.83(\mathrm{~m}, 4 \mathrm{H}), 3.63(\mathrm{~m}, 2 \mathrm{H}), 2.53(\mathrm{q}, J=8.6 \mathrm{~Hz}, 2 \mathrm{H}), 2.47(\mathrm{~m}, 2 \mathrm{H}), 2.09(\mathrm{~m}, 4 \mathrm{H}), 1.60(\mathrm{~m}$, $4 \mathrm{H})$.

${ }^{13} \mathrm{C}$ NMR (400 MHz, CD $\left.{ }_{3} \mathrm{OD}\right) \delta 166.3,164.8,139.4,137.9,136.3,130.3,128.4,128.3,127.0$, 115.0, 114.98, 111.3, 108.1, 106.0, 68.5, 68.2, 62.2, 55.7, 43.7, 36.8, 35.1, 31.5, 31.4, 31.39, 31.35, $30.03,30.00,19.2,18.6,17.2,13.0,12.5$.

${ }^{31} \mathrm{P}$ NMR $\left(400 \mathrm{MHz}, \mathrm{CD}_{3} \mathrm{CN}\right) \delta-2.3$.

ESI-TOF m/z calculated for $\mathrm{C}_{37} \mathrm{H}_{45} \mathrm{ClF}_{3} \mathrm{~N}_{4} \mathrm{O}_{12} \mathrm{P}(\mathrm{M}-\mathrm{H})$ - 859.2412, 859.2277 observed.

\section{General Procedure for the preparation of second-generation library}

Amine scaffold 13 (100 nmol) was azeotropically dried with carboxylic acid (120 nmol, 1.2 eq) in pyridine $(1 \times 15 \mu \mathrm{L})$ using a Speed Vac concentrator in a 384-well microtiter plate 
(VWR). To each well, activating solution ( $5 \mu \mathrm{L} ; 24 \mathrm{mM} \mathrm{HBTU}$ and $24 \mathrm{mM} \mathrm{HOBt}$ in DMF), DIPEA $(2 \mu \mathrm{L})$, and DMF ( $3 \mu \mathrm{L})$ were added. The final concentrations during reaction were: [13] $=10 \mathrm{mM},[\mathrm{acid}]=12 \mathrm{mM},[\mathrm{HBTU}]=12 \mathrm{mM},[\mathrm{HOBt}]=12 \mathrm{mM}, 20 \%$ DIPEA in DMF. The well plate was shaken at $25{ }^{\circ} \mathrm{C}$ overnight. Some wells were analyzed by ESI-MS to confirm coupling efficiency. The solutions were concentrated to dryness using a Speed Vac concentrator and the well plate was covered and stored at $-80{ }^{\circ} \mathrm{C}$.

Immediately before an assay, the amide was thawed, dissolved in DMF (4 $\mu \mathrm{L}, 25 \mathrm{mM})$. An aliquot ( $2 \mu \mathrm{L}, 50 \mathrm{nmol})$ was mixed with NBS $\left(8 \mu \mathrm{L}, 15 \mathrm{mM}, 2.4\right.$ eq, $40 \% \mathrm{H}_{2} \mathrm{O}$ in $\left.\mathrm{MeCN}\right)$ at 0 ${ }^{\circ} \mathrm{C}$ for $9 \mathrm{~min}$. The concentrations during reaction were: $[\mathrm{SM}]=5 \mathrm{mM},[\mathrm{NBS}]=12 \mathrm{mM}, 20 \% \mathrm{DMF}$, $30 \% \mathrm{H}_{2} \mathrm{O}$ in $\mathrm{MeCN}$. After 9 min, $\mathrm{Na}_{2} \mathrm{~S}_{2} \mathrm{O}_{3}(5 \mu \mathrm{L}, 200 \mathrm{mM})$ was added and reaction quenched on ice for 10 min. Samples were concentrated to dryness with a Speed Vac concentrator. Some samples were analyzed ESI-MS to confirm product formation.<smiles>O=C(O)c1c(O)cc2cc(Br)ccc2c1Br</smiles>

Preparation of S8<smiles>O=C1CCC(=O)N1Cl</smiles><smiles>O=C(O)c1c(O)cc2cc(Br)ccc2c1Br</smiles>

S8

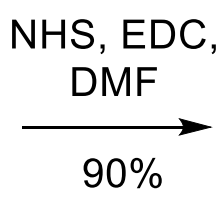

Commercially available 1,6-dibromo-3-hydroxy-2-naphthoic acid (102 mg, $0.3 \mathrm{mmol}$ ) was azeotropically dried in pyridine (2 x $1 \mathrm{~mL})$. NHS (54 mg, $0.45 \mathrm{mmol}, 1.5 \mathrm{eq})$, and EDC (86 $\mathrm{mg}, 0.45 \mathrm{mmol}, 1.5 \mathrm{eq})$ were added to the flask and the

reagents were dissolved in DMF and stirred overnight at $25{ }^{\circ} \mathrm{C}$. After $16 \mathrm{~h}$, TLC $(2 \% \mathrm{MeOH}$ in $\mathrm{DCM}, \mathrm{R}_{\mathrm{f}}=0.8$, UV active) suggested the SM was completely converted so the reaction was 
concentrated. The product was purified by column chromatography (DCM -> $1 \% \mathrm{MeOH}$ in DCM) to yield $119 \mathrm{mg}(90 \%)$ of NHS ester (S8). ${ }^{1} \mathrm{H}$ NMR $\left(400 \mathrm{MHz}, \mathrm{CDCl}_{3}\right) \delta 9.79(\mathrm{~s}, 1 \mathrm{H}), 8.60(\mathrm{~s}$, $1 \mathrm{H}), 8.09(\mathrm{~d}, J=8.8 \mathrm{~Hz}, 1 \mathrm{H}), 8.01(\mathrm{~s}, 1 \mathrm{H}), 7.75(\mathrm{~d}, J=8.8 \mathrm{~Hz}, 1 \mathrm{H}), 2.97(\mathrm{~s}, 4 \mathrm{H})$.

${ }^{13} \mathrm{C}$ NMR $\left(400 \mathrm{MHz}, \mathrm{CDCl}_{3}\right) \delta 169.6,162.5,153.4,134.6,133.6,131.2,130.6,128.2,127.7$,

$118.3,115.0,107.2,53.4,53.1,36.4,31.4,29.6$.

ESI-TOF $\mathrm{m} / \mathrm{z}$ calculated for $\mathrm{C}_{15} \mathrm{H}_{9} \mathrm{NO}_{5}(\mathrm{M}+\mathrm{H})-441.8847,441.8807$ observed.

\section{Preparation of 14}

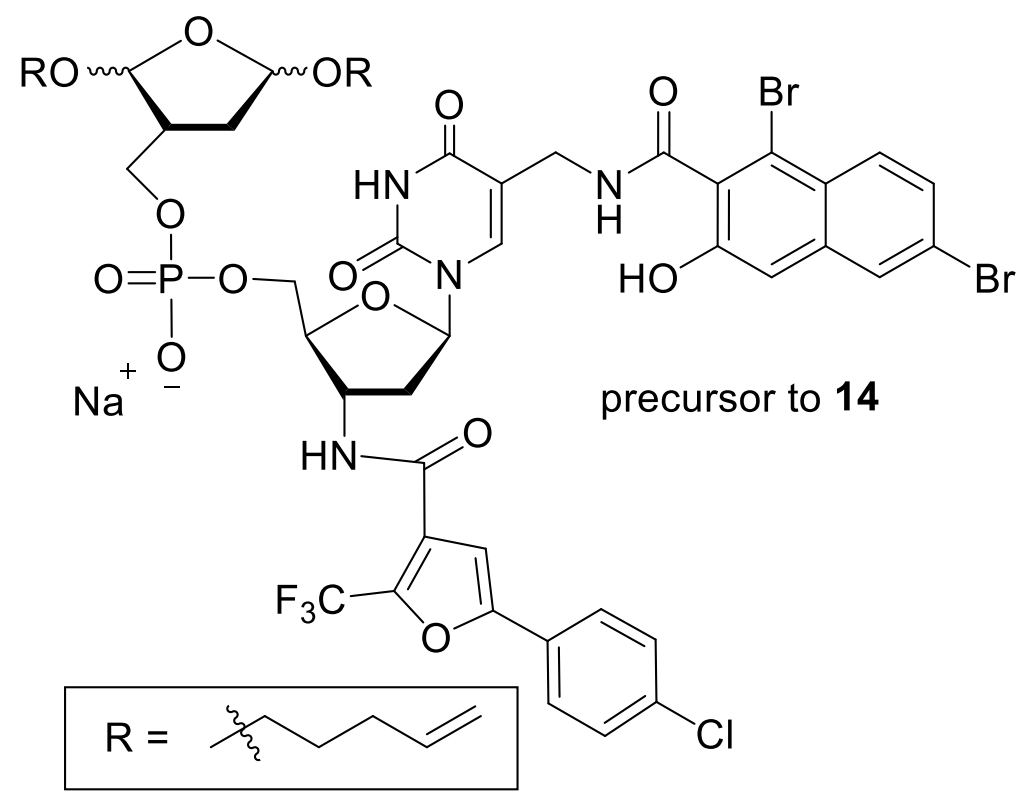

Scaffold 13 (14 mg, $0.016 \mathrm{mmol})$ and 15 (11 mg, $0.024 \mathrm{mmol}, 1.5$ eq) were azeotropically dried together with pyridine $(2 \times 1 \mathrm{~mL})$. The contents were dissolved in DMF $(350 \mu \mathrm{L})$ and DIPEA $(5 \mu \mathrm{L})$. The reaction was stirred at $25{ }^{\circ} \mathrm{C}$ overnight. TLC $(20 \% \mathrm{MeOH}$ in DCM) indicated formation of product $\left(\mathrm{R}_{\mathrm{f}}=0.3\right.$, UV active and stained with PAA). The reaction was concentrated and purified by column chromatography (2:1 Hex/EtOAc $->$ 1:1 Hex/EtOAc $->$ 1:1 Hex/EtOAc, 5\% MeOH) to yield $12.2 \mathrm{mg}(45 \%)$ of the precursor to 14 . The product was passed through a Dowex $(\mathrm{Na}+)$ column. ${ }^{1} \mathrm{H}$ NMR (400 MHz, $\left.\mathrm{CD}_{3} \mathrm{OD}\right) \delta 8.38$ (s, 2H), 8.02 (s, 3H), 7.98 (d, $\left.J=7.2 \mathrm{~Hz}, 2 \mathrm{H}\right), 7.74$ $(\mathrm{d}, J=8.8 \mathrm{~Hz}, 1 \mathrm{H}), 7.61(\mathrm{~d}, J=7.2,2 \mathrm{H}), 7.48(\mathrm{~d}, J=8.8 \mathrm{~Hz}, 1 \mathrm{H}), 7.24(\mathrm{~m}, 1 \mathrm{H}), 6.30(\mathrm{~s}, 1 \mathrm{H}), 5.82$ (m, 2H), $4.99(\mathrm{~m}, 6 \mathrm{H}), 4.73(\mathrm{~s}, 1 \mathrm{H}), 4.44(\mathrm{~s}, 1 \mathrm{H}), 4.22(\mathrm{~s}, 1 \mathrm{H}), 4.1(\mathrm{~m}, 1 \mathrm{H}), 3.73(\mathrm{~m}, 3 \mathrm{H}), 3.66(\mathrm{~m}$, 
2H), $3.41(\mathrm{~m}, 2 \mathrm{H}), 2.53(\mathrm{~m}, 1 \mathrm{H}), 2.48(\mathrm{~m}, 2 \mathrm{H}), 2.12(\mathrm{q}, J=7.2 \mathrm{~Hz}, 4 \mathrm{H}), 2.05(\mathrm{~m}, 2 \mathrm{H}), 1.63(\mathrm{q}, J$ $=7.2 \mathrm{~Hz}, 4 \mathrm{H})$.

${ }^{13} \mathrm{C}$ NMR (600 MHz, $\left.\mathrm{CD}_{3} \mathrm{OD}\right) \delta 173.8,172.4,169.0,163.8,161.7,155.7,154.3,143.8,139.6$, 138.1, 135.0, 133.9, 132.2, 131.2, 130.7, 129.8, 128.5, 127.1, 126.7, 125.7, 122.4, 116.3, 113.7, 106.5, 106.1, 105.6, 104.5, 85.6, 83.6, 45.4, 35.3, 31.7, 30.1, 29.4, 28.7, 24.8, 22.3, 13.0.

${ }^{31} \mathrm{P}$ NMR (400 MHz, $\left.\mathrm{CD}_{3} \mathrm{OD}\right) \delta 4.8,1.7,-0.1,-0.2$.

ESI-TOF $\mathrm{m} / \mathrm{z}$ calculated for $\mathrm{C}_{48} \mathrm{H}_{49} \mathrm{ClF}_{3} \mathrm{~N}_{4} \mathrm{O}_{14} \mathrm{P}(\mathrm{M}-\mathrm{H})-1185.0990,1185.0579$ observed. $\varepsilon_{275}\left(50 \% \mathrm{MeCN}\right.$ in $\left.\mathrm{H}_{2} \mathrm{O}\right)=1.96 \times 10^{4} \mathrm{M}^{-1} \mathrm{~cm}^{-1}, \varepsilon_{370}=3.81 \times 10^{3} \mathrm{M}^{-1} \mathrm{~cm}^{-1}$

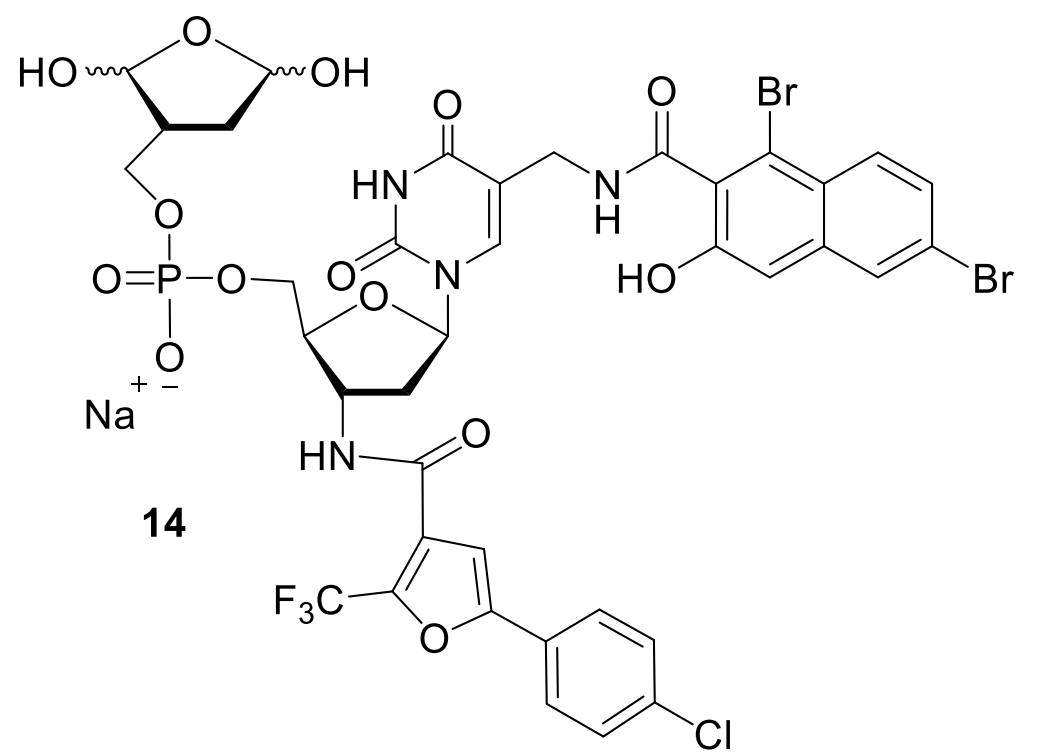

The starting material was stored as a $25 \mathrm{mM}$ stock solution in DMF at $-20{ }^{\circ} \mathrm{C}$. An aliquot of the starting material $(2 \mu \mathrm{L}, 50 \mathrm{nmol})$ was placed in a microtiter well plate and cooled to $4{ }^{\circ} \mathrm{C}$. Cold $\mathrm{H}_{2} \mathrm{O}(3$ $\mu \mathrm{L})$ and NBS in $\mathrm{MeCN}(25 \mathrm{mM}, 5$ $\mu \mathrm{L}$ ) was added and the well plate

was shaken at $4{ }^{\circ} \mathrm{C}$ for $9 \mathrm{~min}$. After $9 \mathrm{~min}$, the reaction was quenched by an equal volume of $\mathrm{Na}_{2} \mathrm{~S}_{2} \mathrm{O}_{3}\left(200 \mathrm{mM}\right.$ in $\mathrm{H}_{2} \mathrm{O}$ ) and well plate was shaken for additional 5-10 min. The reaction was concentrated by speed vacuum, redissolved in $1: 1 \mathrm{MeCN} / \mathrm{H}_{2} \mathrm{O}$ and used directly.

Reaction Conditions: $[\mathrm{SM}]=5 \mathrm{mM},[\mathrm{NBS}]=12.5 \mathrm{mM}, 30 \% \mathrm{H}_{2} \mathrm{O}, 20 \% \mathrm{DMF}, 50 \% \mathrm{MeCN}$

Quenching Conditions: $[\mathrm{SM}]=2.5 \mathrm{mM},[\mathrm{NBS}]=6.25 \mathrm{mM},\left[\mathrm{Na}_{2} \mathrm{~S}_{2} \mathrm{O}_{3}\right]=100 \mathrm{mM}, 65 \% \mathrm{H}_{2} \mathrm{O}$, 
$10 \% \mathrm{DMF}, 25 \% \mathrm{MeCN}$.

${ }^{1} \mathrm{H}$ NMR $\left(800 \mathrm{MHz}, \mathrm{CD}_{3} \mathrm{CN}\right) \delta 9.31(\mathrm{~s}, 1 \mathrm{H}), 8.46(\mathrm{~s}, 1 \mathrm{H}), 8.00(\mathrm{~m}, 1 \mathrm{H}), 7.91(\mathrm{~d}, \mathrm{~J}=8 \mathrm{~Hz}, 1 \mathrm{H})$, $7.75(\mathrm{~d}, \mathrm{~J}=8 \mathrm{~Hz}, 2 \mathrm{H}), 7.71(\mathrm{~s}, 1 \mathrm{H}), 7.68(\mathrm{~m}, 1 \mathrm{H}), 7.64(\mathrm{~m}, 1 \mathrm{H}), 7.53(\mathrm{~d}, \mathrm{~J}=8 \mathrm{~Hz}, 2 \mathrm{H}), 7.50(\mathrm{~m}$, 1H), $7.37(\mathrm{~s}, 1 \mathrm{H}), 7.32(\mathrm{~m}, 2 \mathrm{H}), 7.11(\mathrm{~s}, \mathrm{H}), 6.32(\mathrm{t}, \mathrm{J}=8 \mathrm{~Hz}, 1 \mathrm{H}), 4.93(\mathrm{~d}, \mathrm{~J}=8 \mathrm{~Hz}, 1 \mathrm{H}), 4.78(\mathrm{~m}$, 1H), $4.67(\mathrm{~m}, 1 \mathrm{H}), 4.48(\mathrm{~s}, 1 \mathrm{H}), 4.37(\mathrm{~s}, 1 \mathrm{H}), 4.22(\mathrm{~m}, 1 \mathrm{H}), 4.17(\mathrm{~m}, 1 \mathrm{H}), 4.05(\mathrm{~m}, 1 \mathrm{H}), 3.91(\mathrm{~s}$ 1H), $3.91(\mathrm{~s}, 1 \mathrm{H}), 3.80(\mathrm{~s}, 1 \mathrm{H}), 3.69(\mathrm{~m}, 3 \mathrm{H}), 3.59(\mathrm{~m}, 2 \mathrm{H}), 3.43(\mathrm{~s}, 1 \mathrm{H}), 2.95(\mathrm{~s}, 2 \mathrm{H}), 2.47(\mathrm{~m}$, $3 \mathrm{H}), 2.28(\mathrm{~m}, 3 \mathrm{H})$.

ESI-TOF m/z calculated for $\mathrm{C}_{48} \mathrm{H}_{49} \mathrm{ClF}_{3} \mathrm{~N}_{4} \mathrm{O}_{14} \mathrm{P}(\mathrm{M}+\mathrm{H})-1049.9738,1049.9699$ observed.

\section{Scheme S2. Synthesis of pro-14}

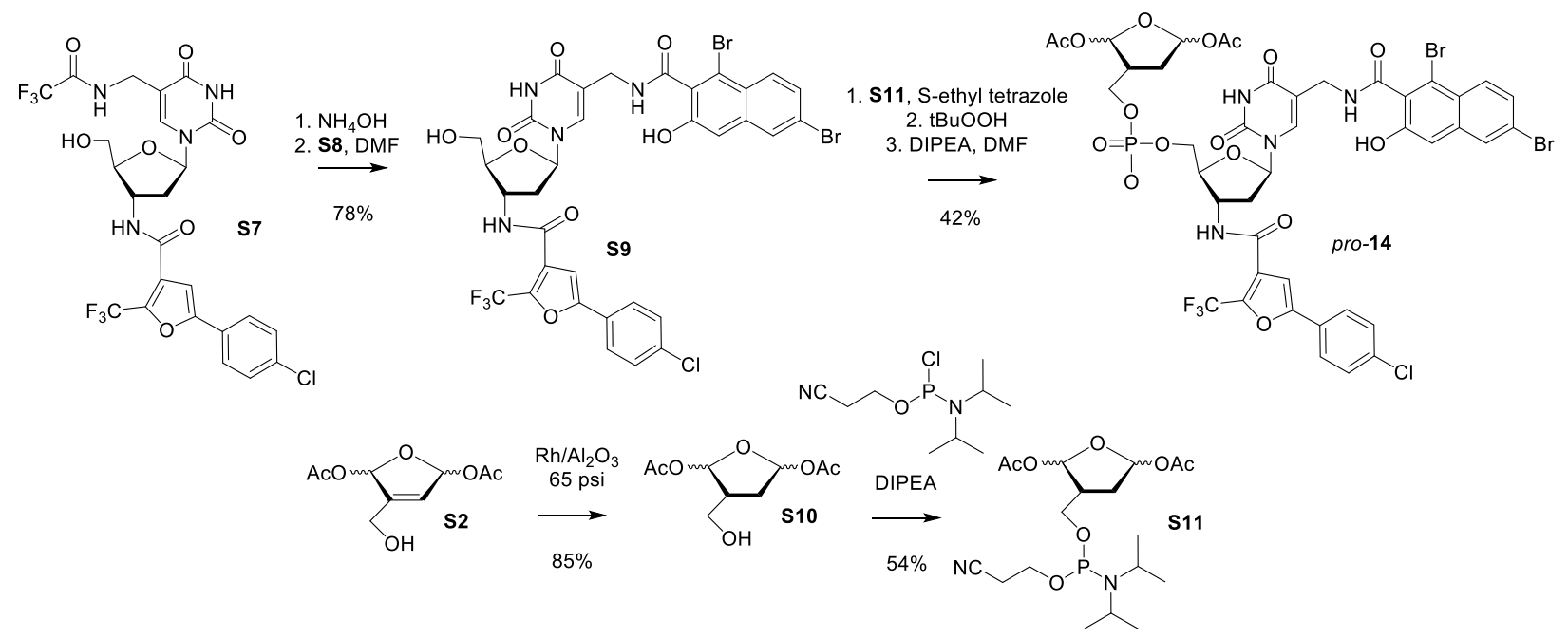




\section{Preparation of S9}

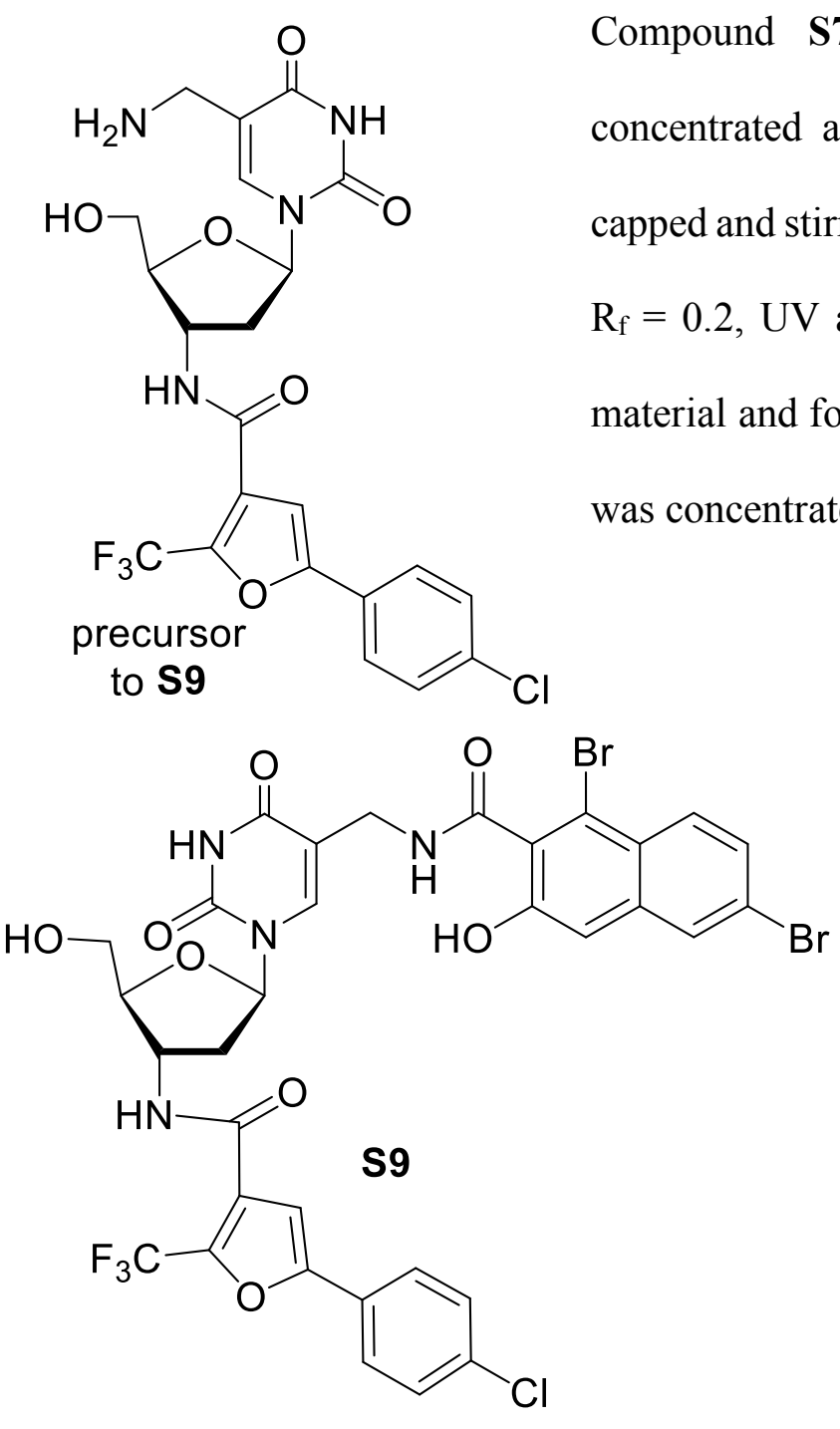

The crude amide (45 mg, $0.08 \mathrm{mmol}$ ) and NHS ester S8 (36 mg, 0.09 mmol. $1.1 \mathrm{eq)} \mathrm{were}$ azeotropically dried together in pyridine $(2 \mathrm{x}$ $0.5 \mathrm{~mL}$ ). The contents were dissolved in DMF (1.6 mL). The reaction was stirred at $25^{\circ} \mathrm{C}$ overnight. TLC (1:1 EtOAc/Hex, 2\% MeOH, $\mathrm{UV}$ active, $\mathrm{R}_{\mathrm{f}}=0.2$ ) indicated the starting materials were converted to product. The

reaction was concentrated and purified by column chromatography $(2: 1$ Hex/EtOAc $->1: 1$ Hex/EtOAc -> 1:1 Hex/EtOAc -> 2\% MeOH -> 1:1 Hex/EtOAc, 5\% MeOH) to yield $53 \mathrm{mg}(78 \%)$ of S9. ${ }^{1} \mathrm{H}$ NMR (400 MHz, CD $\left.{ }_{3} \mathrm{OD}\right) \delta 8.56(\mathrm{~s}, 3 \mathrm{H}), 8.34(\mathrm{~s}, 1 \mathrm{H}), 8.26(\mathrm{~s}, 1 \mathrm{H}), 8.04(\mathrm{~m}, 3 \mathrm{H}), 7.94$ $(\mathrm{d}, J=8 \mathrm{~Hz}, 1 \mathrm{H}), 7.86(\mathrm{~d}, J=8 \mathrm{~Hz}, 1 \mathrm{H}), 7.21(\mathrm{~s}, 1 \mathrm{H}), 6.30(\mathrm{t}, J=6.8 \mathrm{~Hz}, 1 \mathrm{H}), 4.69(\mathrm{~m}, 1 \mathrm{H}), 4.34$ $(\mathrm{d}, J=3.2 \mathrm{~Hz}, 2 \mathrm{H}), 4.03(\mathrm{~d}, J=2.8 \mathrm{~Hz}, 1 \mathrm{H}), 3.87(\mathrm{dd}, J=3.2,13.9 \mathrm{~Hz}, 1 \mathrm{H}), 3.77(\mathrm{dd}, J=2.8$, $13.9 \mathrm{~Hz}, 1 \mathrm{H}), 2.45(\mathrm{~m}, 2 \mathrm{H})$. 
${ }^{13} \mathrm{C}$ NMR (600 MHz, $\left.\mathrm{CD}_{3} \mathrm{OD}\right) \delta 199.3,193.6,193.1,163.4,161.7,159.9,157.7,150.4,142.3$, $141.9,140.0,139.2,138.9,135.1,129.0,128.9,126.7,125.9,125.2,121.1,119.6,118.0,117.7$, $116.9,110.3,109.3,107.3,105.9,85.7,81.5,64.6,57.4,50.3,41.4,37.5,36.4,36.0,29.3,25.1$, 7.8 .

ESI-TOF m/z calculated for $\mathrm{C}_{33} \mathrm{H}_{24} \mathrm{Br}_{2} \mathrm{ClF}_{3} \mathrm{~N}_{4} \mathrm{O}_{8}(\mathrm{M}+\mathrm{H})-854.9602,854.9636$ observed.

\section{Preparation of $\mathrm{S10}^{10}$}

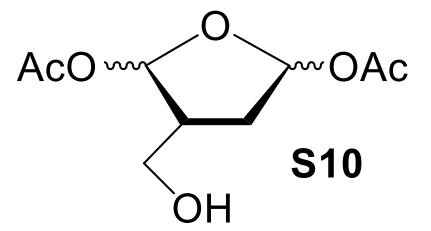

Compound S2 (163 mg, $0.886 \mathrm{mmol}, 1 \mathrm{eq})$ was dissolved in EtOAc (16 $\mathrm{mL}, 50 \mathrm{mM})$. Rhodium on alumina catalyst $(85.2 \mathrm{mg}$ ) was added to the pressure bottle equipped with a regulator. The vial was pressurized with $\mathrm{H} 2$ to $70 \mathrm{psi}$, purged three times, and stirred at $25^{\circ} \mathrm{C}$ for $2-4 \mathrm{~h}$. After venting the pressure bottle, TLC (4:6 Hex/EtOAc, $\mathrm{R}_{\mathrm{f}}=0.3$, stained with PAA) showed the starting material was no longer present. When complete, the reaction mixture was passed through celite to remove the Rh catalyst. The filtrate was concentrated under vacuum to a pale, yellow residue, which was purified by column chromatography $(1: 1 \mathrm{DCM} / \mathrm{EtOAc})$ resulting in $67 \mathrm{mg}(41 \%)$ of a mixture of diastereomers (S10). ${ }^{1} \mathrm{H}$ NMR (400 MHz, $\left.\mathrm{CDCl}_{3}\right) \delta 6.44(\mathrm{~s}, 1 \mathrm{H}), 6.34(\mathrm{~d}, J=1.0 \mathrm{~Hz}, 1 \mathrm{H}), 3.86-$ $3.75(\mathrm{~m}, 1 \mathrm{H}), 3.69(\mathrm{dt}, J=5.5,10.9 \mathrm{~Hz}, 1 \mathrm{H}), 2.56-2.43(\mathrm{~m}, 2 \mathrm{H}), 2.05(\mathrm{~s}, 3 \mathrm{H}), 2.04(\mathrm{~s}, 3 \mathrm{H}), 1.90$ (t, $J=5.5 \mathrm{~Hz}, 1 \mathrm{H}), 1.82(\mathrm{dd}, J=1.0,5.5 \mathrm{~Hz}, 1 \mathrm{H})$.

\section{Preparation of S11 ${ }^{10}$}

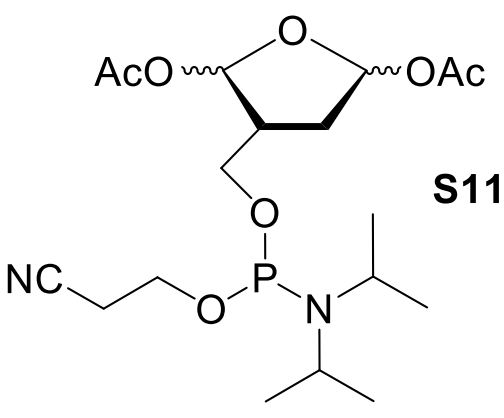

Compound S10 (67 mg, $0.28 \mathrm{mmol})$ was azeotropically dried with pyridine $(2 \times 0.5 \mathrm{~mL})$. The flask was cooled to $0{ }^{\circ} \mathrm{C}$. DIPEA ( $0.2 \mathrm{~mL}, 144 \mathrm{mg}, 1.12 \mathrm{mmol}, 4 \mathrm{eq}$ ) was added to the cold starting material and the reactants were dissolved in DCM $(1.2 \mathrm{~mL}, 200$ mM). 2-Cyanoethyl-N, N-diisopropylchlorophosphoramidite (75 
$\mu \mathrm{L}, 80 \mathrm{mg}, 0.34 \mathrm{mmol} .1 .2 \mathrm{eq}$ ) was added and the cold mixture stirred with periodic monitoring by TLC (7:1 Hex/EtOAc, $R_{\mathrm{f}}=0.2$, stained with PAA). After $2 \mathrm{~h}$, TLC showed complete conversion to the phosphoramidite. The reaction was diluted with EtOAc $(10 \mathrm{~mL})$. The organic layer was washed with saturated bicarbonate solution $(2 \times 15 \mathrm{~mL})$ and the aqueous layers were extracted with EtOAc $(2 \times 20 \mathrm{~mL})$. The combined organic layers were washed with brine $(1 \times 25 \mathrm{~mL})$ and dried over $\mathrm{Na}_{2} \mathrm{SO}_{4}$. The organic layer was concentrated under vacuum and purified by column chromatography (3:1 hexanes/ EtOAc) yielding $85 \mathrm{mg}(75 \%)$ of $\mathbf{S 1 1} .{ }^{1} \mathrm{H}$ NMR (400 MHz, $\mathrm{CDCl}_{3}$ ) $\delta 6.31(\mathrm{~m}, 1 \mathrm{H}), 4.28(\mathrm{~m}, 1 \mathrm{H}), 3.78(\mathrm{~m}, 3 \mathrm{H}), 3.55(\mathrm{~m}, 3 \mathrm{H}), 2.79(\mathrm{~m}, 1 \mathrm{H}), 2.60(\mathrm{~m}, 2 \mathrm{H}), 2.44(\mathrm{~m}$, 1H), $2.04(\mathrm{~m}, 6 \mathrm{H}), 1.81(\mathrm{~m}, 1 \mathrm{H}), 1.14(\mathrm{~m}, 12 \mathrm{H})$.

${ }^{31} \mathrm{P}$ NMR (400 MHz, $\left.\mathrm{CDCl}_{3}\right) \delta 149.7,149.5,148.3,148.1,13.2$.

\section{Preparation of pro-14}

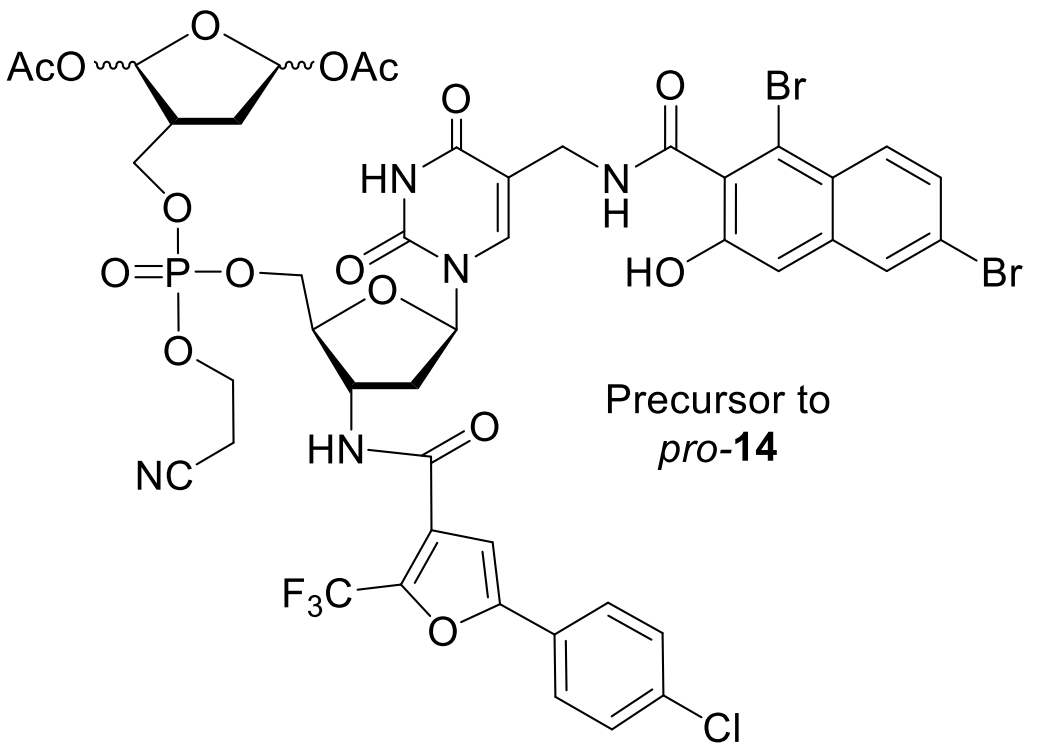

Compounds S9 $(30 \mathrm{mg}, 0.035$ mmol) and S11 (35 mg, 0.042 mmol, 1.2 eq) were azeotropically dried together in pyridine $(2 \times 1$ $\mathrm{mL}$ ). S-ethyl tetrazole/MeCN (250 mM, $0.25 \mathrm{~mL}, 0.053 \mathrm{mmol}$, 1.5 eq) was added to the reaction flask. After 4 h, TLC (1:1 EtOAc/Hex) suggested the majority of $\mathbf{S 9}$ was consumed. $\mathrm{tBuOOH}(0.5 \mathrm{M}, 10 \mathrm{mg}, 25 \mu \mathrm{L}, 0.11$ mmol, 3 eq) was added for 20 min. The reaction was concentrated and purified by column chromatography $(1: 1 \mathrm{Hex} /$ EtOAc $->1: 1 \mathrm{Hex} / \mathrm{EtOAc}, 5 \% \mathrm{MeOH})$ to yield $25 \mathrm{mg}(60 \%)$ of the phosphate triester precursor to pro-14. ${ }^{1} \mathrm{H}$ NMR $\left(400 \mathrm{MHz}, \mathrm{CDCl}_{3}\right) \delta 8.16(\mathrm{~m}, 1 \mathrm{H}), 7.87(\mathrm{~s}, 1 \mathrm{H})$, 
$7.78(\mathrm{~d}, J=8.8 \mathrm{~Hz}, 1 \mathrm{H}), 7.50(\mathrm{~s}, 1 \mathrm{H}), 7.29(\mathrm{~d}, J=8.8 \mathrm{~Hz}, 1 \mathrm{H}), 6.95(\mathrm{~s}, 1 \mathrm{H}), 6.75(\mathrm{~m}, 1 \mathrm{H}), 6.36$ (quint, $J=3.2 \mathrm{~Hz}, 1 \mathrm{H}), 6.20(\mathrm{~s}, 1 \mathrm{H}), 6.15(\mathrm{~m}, 1 \mathrm{H}), 4.74(\mathrm{q}, J=5.6 \mathrm{~Hz}, 1 \mathrm{H}), 4.31(\mathrm{~m}, 4 \mathrm{H}), 4.23$ $(\mathrm{m}, 6 \mathrm{H}), 3.82(\mathrm{~d}, J=5.6 \mathrm{~Hz}, 1 \mathrm{H}), 3.51(\mathrm{~m}, 1 \mathrm{H}), 2.77(\mathrm{~m}, 4 \mathrm{H}), 2.53(\mathrm{~m}, 1 \mathrm{H}), 2.08(\mathrm{~s}, 3 \mathrm{H}), 2.03(\mathrm{~s}$, $3 \mathrm{H}), 2.00(\mathrm{~m}, 1 \mathrm{H}), 1.87(\mathrm{~m}, 1 \mathrm{H})$.

${ }^{13} \mathrm{C}$ NMR (400 MHz, $\left.\mathrm{CDCl}_{3}\right) \delta 169.8,100.8,98.2,60.2,50.5,32.2,25.2,20.9,20.83,20.77,19.8$, 19.7, 14.6, 14.0.

${ }^{31} \mathrm{P}$ NMR $\left(400 \mathrm{MHz}, \mathrm{CDCl}_{3}\right) \delta 17.3,14.3,9.2,9.1,8.1,7.9,7.8,7.75,7.70,7.6,7.5,-0.5,-0.9,-$ $1.4,-1.9,-2.0,-2.5,-2.6,-2.7,-2.8$.

ESI-TOF $\mathrm{m} / \mathrm{z}$ calculated for $\mathrm{C}_{45} \mathrm{H}_{40} \mathrm{Br}_{2} \mathrm{ClF}_{3} \mathrm{~N}_{5} \mathrm{O}_{16} \mathrm{P}(\mathrm{M}+\mathrm{H})-1188.0215,1188.0200$ observed.

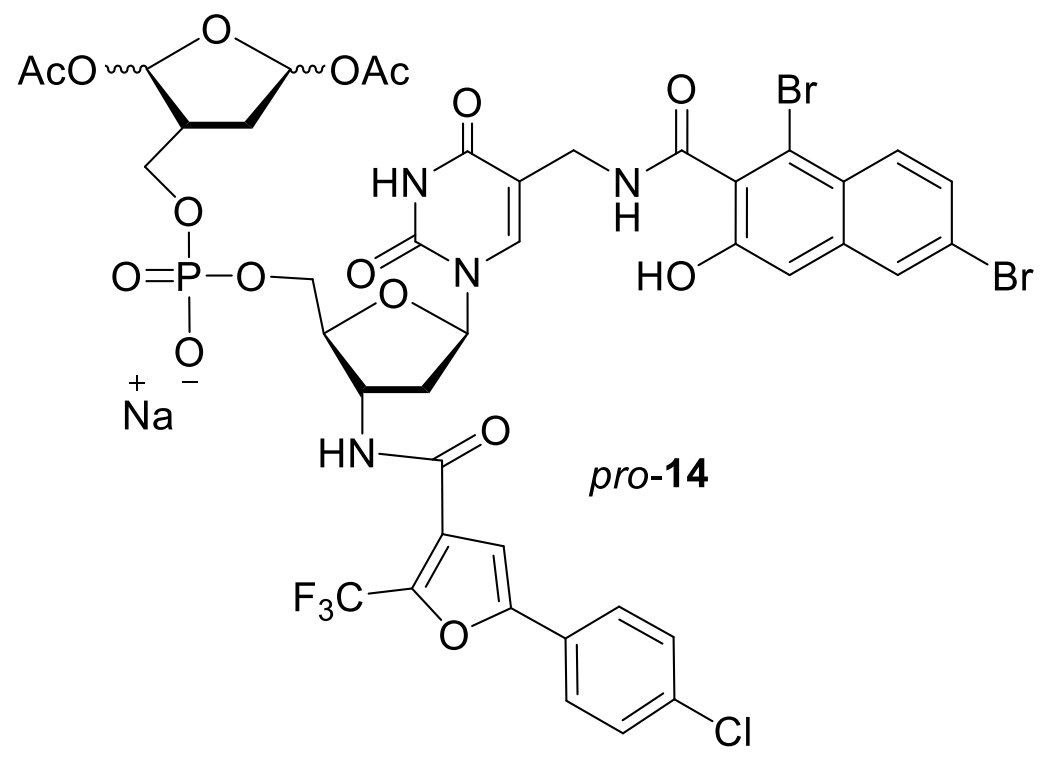

The intermediate phosphate triester $(25 \mathrm{mg}, 0.023 \mathrm{mmol})$ was dissolved in DMF $(0.5 \mathrm{~mL})$ and DIPEA $(0.5 \mathrm{~mL})$. The reaction was stirred at $25{ }^{\circ} \mathrm{C}$ overnight. The following morning, TLC ( $5 \%$ $\mathrm{MeOH}$ in DCM, $\mathrm{R}_{\mathrm{f}}=0.2, \mathrm{UV}$ active) indicated product

formation. The reaction was concentrated and purified by column chromatography $(2 \% \mathrm{MeOH}$ in $\mathrm{DCM}->5 \% \mathrm{MeOH}$ in $\mathrm{DCM}$ ) and then passed through a $\mathrm{TEA}^{+}$Dowex and then $\mathrm{Na}^{+}$Dowex column to yield $12.4 \mathrm{mg}(50 \%)$ of pro-14. A portion $(\sim 30 \%)$ of the product exists at the triethylammonium salt, even after the $\mathrm{Na}^{+}$ion exchange column. ${ }^{1} \mathrm{H} \mathrm{NMR}\left(800 \mathrm{MHz}, \mathrm{CD}_{3} \mathrm{OD}\right) \delta$ 
$8.53(\mathrm{~s}, 1 \mathrm{H}), 8.12(\mathrm{~s}, 1 \mathrm{H}), 8.02(\mathrm{~s}, 1 \mathrm{H}), 7.92(\mathrm{~d}, J=8.8 \mathrm{~Hz}, 1 \mathrm{H}), 7.78(\mathrm{~d}, J=8.5 \mathrm{~Hz}, 2 \mathrm{H}), 7.56(\mathrm{~d}$, $J=8.8 \mathrm{~Hz}, 1 \mathrm{H}), 7.53(\mathrm{~d}, J=8.5 \mathrm{~Hz}, 2 \mathrm{H}), 7.24(\mathrm{~s}, 1 \mathrm{H}), 6.30$ (quint, $J=5.4 \mathrm{~Hz}, 1 \mathrm{H}), 6.25(\mathrm{~m}, 1 \mathrm{H})$, $4.73(\mathrm{t}, J=6 \mathrm{~Hz}, 1 \mathrm{H}), 4.61(\mathrm{q}, J=6 \mathrm{~Hz}, 1 \mathrm{H}), 4.49(\mathrm{~d}, J=14 \mathrm{~Hz}, 1 \mathrm{H}), 4.42(\mathrm{dd}, J=3.6,14 \mathrm{~Hz}$, 1H), $4.24(\mathrm{~m}, 3 \mathrm{H}), 4.14(\mathrm{~m}, 1 \mathrm{H}), 4.05(\mathrm{t}, J=7 \mathrm{~Hz}, 1 \mathrm{H}), 3.06(\mathrm{q}, J=8 \mathrm{~Hz}, 1 \mathrm{H}), 2.62(\mathrm{~m}, 2 \mathrm{H}), 2.48$ (q, $J=6 \mathrm{~Hz}, 2 \mathrm{H}), 2.05(\mathrm{~m}, 3 \mathrm{H}), 1.99(\mathrm{~s}, 3 \mathrm{H}), 1.92(\mathrm{~s}, 1 \mathrm{H}), 1.84(\mathrm{~m}, 1 \mathrm{H}), 1.32(\mathrm{t}, J=8 \mathrm{~Hz}, 3 \mathrm{H})$.

${ }^{13} \mathrm{C} \mathrm{NMR}\left(800 \mathrm{MHz}, \mathrm{CDCl}_{3}\right) \delta 175.7,170.4,170.1,168.6,163.8,161.7,157.5,154.3,150.7$, 139.5, 138.6, 135.0, 133.9, 131.3, 130.8, 129.0, 128.4, 127.1, 126.5, 125.7, 125.3, 119.6, 118.3, 115.0, 111.1, 106.2, 101.1, 100.0, 98.6, 96.7, 85.7, 83.3, 65.0, 63.4, 59.7, 50.2, 43.2, 37.1, 35.4, $32.0,26.7,24.7,22.6,19.7,19.6,19.5,14.2$.

${ }^{31} \mathrm{P}$ NMR (400 MHz, $\left.\mathrm{CD}_{3} \mathrm{OD}\right) \delta 6.4,4.4,4.3,4.0,3.9,1.6,1.5,1.2,-0.26,-0.29,-0.4,-0.5$.

ESI-TOF m/z calculated for $\mathrm{C}_{42} \mathrm{H}_{37} \mathrm{Br}_{2} \mathrm{ClF}_{3} \mathrm{~N}_{4} \mathrm{O}_{16} \mathrm{P}(\mathrm{M}-\mathrm{H})-1132.9950,1133.0007$ observed.

\section{Radiolabeling and Preparation of Oligonucleotide Complexes}

Oligonucleotides were $5^{\prime}{ }^{32} \mathrm{P}$ labeled by T4 polynucleotide kinase and $\gamma_{-}{ }^{32} \mathrm{P}-\mathrm{ATP}$. Ternary complexes were hybridized by mixing ${ }^{32} \mathrm{P}$-labeled oligonucleotides with the appropriate template and flanking strand in a 1:2.5:5 ratio in phosphate buffered saline (10 mM sodium phosphate, 100 $\mathrm{mM} \mathrm{NaCl}, \mathrm{pH} 7.3$ ), heating to $95^{\circ} \mathrm{C}$, and slowly cooling to $25^{\circ} \mathrm{C}$.

Ternary complexes containing fluorophore labeled oligonucleotides were prepared by

annealing the fluorophore-labeled strand with the appropriate quencher-labeled template and flanking strand in a 1:2:3 ratio. All oligonucleotides used to prepare ternary complexes are described in Table S1. 
Table S1. DNA substrates for assays.

\begin{tabular}{|c|c|}
\hline $\begin{array}{l}\text { Pol } \beta \text { and } \\
\text { Klenow (TC1) }\end{array}$ & $\begin{array}{l}\text { 5'- d(TCA CCC TCG TAC GAC TC } \\
\text { 3'- } d(\text { TTT TTT GGG AGC ATG CTG AG__AAA AAA AAA ACG Q) - 5' }\end{array}$ \\
\hline Pol $\theta(\mathbf{P} 2)$ & 5'- d(TTT TTT TAG GTT T) -3' \\
\hline Pol $\eta$ (D3) & $\begin{array}{l}\text { 5'- d(TCA CCC TCG TAC GAC TC) -3' } \\
\text { 3'- d(AGT GGG AGC ATG GTC AGG ACC T) -3' }\end{array}$ \\
\hline Pol $\lambda($ TC4) & $\begin{array}{l}\text { 5'- d(ACC ATG GGA CGT GCT G ACT CCA CTA GAT ACA CTT) -3' } \\
\text { 3'- d(TGG TAC CCT GCA CGA CTC TGA GGT GAT CTA TGT GGA) -5' }\end{array}$ \\
\hline $\begin{array}{l}\text { Fluorescence } \\
\text { Anisotropy (TC5) }\end{array}$ & $\begin{array}{l}\text { 5'- d(TAA TGG CTA ACG CTT pFCC GTA ATG CAG TCT) -3' } \\
\text { 3'- d(ATT ACC GAT TGC GAA_AGG CAT TAC GTC AGA FI) -5' }\end{array}$ \\
\hline
\end{tabular}

$\mathrm{X}=\mathrm{dRP}, \mathrm{F}=\mathrm{TAMRA}, \mathrm{Q}=\mathrm{BHQ}, \quad \mathrm{pF}=$
$\mathrm{Fl}=$ dichloro-diphenyl-fluorescein (SIMA-HEX)

\section{General Procedure for Library Screening}

A $1 \mathrm{mM}$ stock solution of each inhibitor is prepared using $50 \% \mathrm{MeCN}$ in $\mathrm{H}_{2} \mathrm{O}$. A solution of Pol $\beta(100 \mathrm{nM})$ was preincubated with library compounds $(25 \mu \mathrm{M})$ in $1 \mathrm{X}$ reaction buffer (total volume: $50 \mu \mathrm{L} ; 50 \mathrm{mM}$ HEPES buffer $\mathrm{pH}=7.4,5 \mathrm{mM} \mathrm{MgCl}$, $0.2 \mathrm{mM}$ EDTA, $50 \mathrm{mM} \mathrm{KCl,} 0.01$ $\%$ Tween $20,0.01 \mathrm{mg} / \mathrm{mL}$ BSA, and $4 \%$ glycerol by volume) in a 384 -well plate at $25{ }^{\circ} \mathrm{C}$ for 30 min. In control experiments, an equal volume of a control solution (containing all coupling and deprotection reagents but lacking inhibitor) was added to keep the percentage of solvents and reagents consistent. An aliquot $(3 \mu \mathrm{L})$ was diluted with a $2 \mathrm{X}$ solution $(15 \mu \mathrm{L})$ containing $\mathbf{T C 1}$ (100 nM, Table S1) and dTTP $(200 \mu \mathrm{M})$ in $1 \mathrm{X}$ reaction buffer (total volume: $30 \mu \mathrm{L})$ in a different 384-well plate. The final reaction mixture contained $10 \mathrm{nM}$ Pol $\beta, 5 \mu \mathrm{M}$ inhibitor, $50 \mathrm{nM}$ DNA, $100 \mu \mathrm{M}$ dTTP, $1 \mathrm{X}$ reaction buffer, and $0.25 \% \mathrm{MeCN}$. The solution in each well was mixed thoroughly, and the fluorescence measurements were collected immediately. 


\section{Time-dependent irreversible kinetics of Pol $\beta$}

A $1 \mathrm{mM}$ stock solution of each inhibitor is prepared using $50 \% \mathrm{MeCN}$ in $\mathrm{H}_{2} \mathrm{O}$. A solution of Pol $\beta(50 \mathrm{nM})$ was preincubated with $14(0,100,250,400,500,750 \mathrm{nM})$ in $1 \mathrm{X}$ reaction buffer (total volume: $50 \mu \mathrm{L} ; 50 \mathrm{mM}$ HEPES buffer $\mathrm{pH}=7.4,5 \mathrm{mM} \mathrm{MgCl2,} 0.2 \mathrm{mM}$ EDTA, $50 \mathrm{mM} \mathrm{KCl}$, $0.01 \%$ Tween $20,0.01 \mathrm{mg} / \mathrm{mL} \mathrm{BSA}$, and $4 \%$ glycerol by volume) in a $384-$ well plate at $25{ }^{\circ} \mathrm{C}$ for various preincubation times $(2,5,10,15,20 \mathrm{~min})$. In control experiments, an equal volume of a control solution (containing all coupling and deprotection reagents but lacking inhibitor) was added to keep the percentage of solvents and reagents consistent. The volume of inhibitor solution added was unchanged across experiments that used various inhibitor concentrations. To achieve various inhibitor concentrations, the stock solution of inhibitor (1 mM) was diluted appropriately for the desired conditions.

An aliquot $(3 \mu \mathrm{L})$ was diluted with a $2 \mathrm{X}$ solution $(15 \mu \mathrm{L})$ containing TC1 (100 nM, Table S1) and dTTP $(200 \mu \mathrm{M})$ in $1 \mathrm{X}$ reaction buffer (total volume: $30 \mu \mathrm{L}$ ) in a different 384 -well plate. The final reaction mixture contained $5 \mathrm{nM}$ Pol $\beta, 14(0,10,25,40,50,75 \mathrm{nM}), 50 \mathrm{nM}$ DNA, 100 $\mu \mathrm{M}$ dTTP, $1 \mathrm{X}$ reaction buffer, and $0.25 \% \mathrm{MeCN}$. The solution in each well was mixed thoroughly, and the fluorescence measurements were collected immediately.

The data were fit to a single exponential growth equation (1) that follows a plateau. The plateau was important because the strand displacement assay exhibited an induction period in which several nucleotides of the fluorescently labelled DNA were displaced before the fluorescently labeled oligonucleotide was released into solution. This induction time was determined by inspection and typically varied between 10 and $15 \mathrm{~min}$. The data were fit beginning at the time when a growth in fluorescence was observed. ${ }^{12,13}$ 


$$
\mathrm{Y}=\mathrm{F}_{0}+\left(\mathrm{F}_{1}-\mathrm{F}_{0}\right) \times\left(1-\mathrm{e}^{-k t}\right)
$$

$\mathrm{Y}$ is the fluorescence intensity, $\mathrm{F}_{0}$ is the fluorescence value at time $0, \mathrm{~F}_{1}$ is the fluorescence value at time $\infty, k$ is the rate constant, and $\mathrm{t}$ is time. Rate constants are extracted for each experiment and relative rates are determined using equation (2).

$$
k_{\text {rel }}=k_{\text {inhibitor }} / k_{\text {pol } \beta}
$$

Where $k_{\text {inhibitor }}$ is the rate constant for experiments containing inhibitor and $k_{\mathrm{pol}}$ is the rate constant for control experiments lacking inhibitor.

This procedure was also used to measure strand displacement activity of Klenow exo- with minor changes: (1) the concentration of $\mathbf{1 4}$ during preincubation was 0.5 or $10 \mu \mathrm{M}$, and (2) the samples were preincubated for $20 \mathrm{~min}$.

\section{Primer Extension Assay $(\operatorname{Pol} \theta)^{14}$}

A solution of 10X $14(5 \mu \mathrm{M}$ or $100 \mu \mathrm{M}, 2 \mu \mathrm{L})$ was mixed with a 40X solution of Pol $\theta$ $(200 \mathrm{nM}, 5 \mu \mathrm{L})$ in $1 \mathrm{X}$ reaction buffer $(20 \mathrm{mM}$ Tris $\bullet \mathrm{HCl} \mathrm{pH} 7.5,100 \mathrm{mM} \mathrm{NaCl}, 5 \mathrm{mM} \mathrm{MnCl} 2,0.5$ $\mathrm{mM}$ TCEP, $10 \%$ glycerol, $0.01 \% \mathrm{NP}-40,0.1 \mathrm{mg} / \mathrm{mL}$ BSA) in a 384 microtiter well plate. This 10X preincubation mixture ( $50 \mathrm{nM}$ Pol $\theta, 0.5$ or $10 \mu \mathrm{M}$ 14) was incubated at $25^{\circ} \mathrm{C}$ for $20 \mathrm{~min}$. An aliquot of the 10X preincubation mixture $(2 \mu \mathrm{L})$ containing Pol $\theta$ and $\mathbf{1 4}$ was added to a new well and mixed with $1 \mathrm{X}$ buffer $(8 \mu \mathrm{L})$ and $2 \mathrm{X}$ cocktail solution $(10 \mu \mathrm{L})$ containing DNA substrate $\mathbf{P 2}$ ( $1 \mu \mathrm{M}$, Table S1), dNTPs (0.8 mM each), and 2X SYBR Gold in $1 \mathrm{X}$ buffer (Table 1$)$. The final reaction mixture $(20 \mu \mathrm{L})$ contained $5 \mathrm{nM}$ Pol $\theta, 0.05$ or $1 \mu \mathrm{M}$ 14, $500 \mathrm{nM} \mathrm{P2}, 0.4 \mathrm{mM}$ dNTPs, $1 \mathrm{X}$ Sybr Gold in 1X reaction buffer. Fluorescence data was collected for 80-120 min on a Varian Cary Eclipse fluorescence spectrophotometer. 


\section{Primer Extension Assays $(\operatorname{Pol} \eta \text { and Pol } \lambda)^{15}$}

A $10 X$ working solution of $14(5$ or $100 \mu \mathrm{M})$ was prepared in $1: 1 \mathrm{MeCN} / \mathrm{H}_{2} \mathrm{O}$. A $10 \mathrm{X}$ preincubation mixture was prepared by mixing a $50 \mathrm{X}$ working solution of polymerase $(250 \mathrm{nM})$ with an aliquot of the inhibitor ( 5 or $100 \mu \mathrm{M}, 10 \mathrm{X})$ in $1 \mathrm{X}$ reaction buffer $(50 \mathrm{mM}$ Tris $\bullet \mathrm{HCl}, 50$ $\mathrm{mM} \mathrm{NaCl}, 5 \mathrm{mM} \mathrm{MgCl}$, $5 \mathrm{mM}$ DTT, $0.1 \mathrm{mg} / \mathrm{mL}$ BSA, 10\% glycerol, $\mathrm{pH}$ 7.5) (see Table 19 for volumes). The concentration of the preincubation mixture was $50 \mathrm{nM}$ polymerase (10X) and $0,0.5$ or $10 \mu \mathrm{M} 14(1 \mathrm{X})$.

Table S2. 10X preincubation mixture for primer extension assays.

\begin{tabular}{|c|c|c|}
\hline & Pol $\eta$ (volume added, $\mu \mathrm{L})$ & Pol $\lambda$ (volume added, $\mu \mathrm{L}$ ) \\
\hline 50X Polymerase $(250 \mathrm{nM})$ & 2 & 3 \\
\hline $\begin{array}{c}\text { 10X 14 }(5 \text { or } 100 \mu \mathrm{M})(\text { or } 1: 1 \\
\text { MeCN/ } \mathrm{H}_{2} \mathrm{O} \text { for control) }\end{array}$ & 1 & 1.5 \\
\hline 20X reaction buffer & 1 & 9 \\
\hline $\mathrm{H}_{2} \mathrm{O}$ & 6 & 15 \\
\hline Total $^{1}$ & 10 & 1.5 \\
\hline
\end{tabular}

${ }^{1}$ Preincubated at $25{ }^{\circ} \mathrm{C}$ for $20 \mathrm{~min}$.

The samples containing $50 \mathrm{nM}$ polymerase and $14(0,0.5$, or $10 \mu \mathrm{M})$ were preincubated at $25^{\circ} \mathrm{C}$ for $20 \mathrm{~min}$. After preincubation, an aliquot $(2 \mu \mathrm{L}$, pol $\eta$ or $3 \mu \mathrm{L}$, pol $\lambda)$ was diluted with 10X ternary complex (pol $\eta: 2 \mu \mathrm{L}, 500 \mathrm{nM}$ D3 or pol $\lambda: 3 \mu \mathrm{L}, 100 \mathrm{nM}$ TC4), 10X dNTPs (5 mM; $2 \mu \mathrm{L}$, pol $\eta$ or $3 \mu \mathrm{L}$, pol $\lambda$ ), and $1 \mathrm{X}$ reaction buffer $(14 \mu \mathrm{L}$, pol $\eta$ or $21 \mu \mathrm{L}$, pol $\lambda$ ) (see Table 20 for volumes). While the samples were incubated at $37^{\circ} \mathrm{C}$, aliquots (pol $\eta: 0,2,5,10,15,20 \mathrm{~min}$, $3 \mu \mathrm{L}$ or pol $\lambda: 0,5,15,20,30 \mathrm{~min}, 5 \mu \mathrm{L}$ ) were removed and quenched by the addition of $95 \%$ formamide, $20 \mathrm{mM}$ EDTA loading buffer $(10 \mu \mathrm{L})$. Aliquots were heated at $95{ }^{\circ} \mathrm{C}$ for $5 \mathrm{~min}$, spun down, and loaded onto a 20\% denaturing PAGE and run for $4 \mathrm{~h}$ at 55 watts. The gel was exposed in a radiography cassette, which was scanned using a Phosphorimager. 
Table S3. Reaction mixture for primer extension assays.

\begin{tabular}{|c|c|c|}
\hline & Pol $\eta$ (volume added, $\mu \mathrm{L})$ & Pol $\lambda$ (volume added, $\mu \mathrm{L})$ \\
\hline 10X preincubation & 2 & 3 \\
\hline 10X DNA & $2(500 \mathrm{nM} \mathrm{D3})$ & $3(100 \mathrm{nM}$ TC4) \\
\hline 10X dNTPs $(5 \mathrm{mM})$ & 2 & 3 \\
\hline 1X reaction buffer & 14 & 21 \\
\hline Total $^{1}$ & 20 & 30 \\
\hline
\end{tabular}

${ }^{1}$ Incubated at $37^{\circ} \mathrm{C}$, taking time points between $0-30 \mathrm{~min}$.

\section{General Procedure for Dialysis}

Pol $\beta(100 \mathrm{nM}$, total volume $200 \mu \mathrm{L})$ was preincubated in the absence or presence of $\mathbf{1 4}$ (e.g. $750 \mathrm{nM}$ ) in $1 \mathrm{X}$ reaction buffer (50 mM HEPES buffer $\mathrm{pH}=7.5,5 \mathrm{mM} \mathrm{MgCl}_{2}, 0.2 \mathrm{mM}$ EDTA, $50 \mathrm{mM} \mathrm{KCl}, 0.01 \%$ Tween $20,0.01 \mathrm{mg} / \mathrm{mL} \mathrm{BSA}$, and $4 \%$ glycerol) at $25^{\circ} \mathrm{C}$ for $20 \mathrm{~min}$. The strand displacement activity of each sample was immediately measured by mixing an aliquot of each sample ( $3 \mu \mathrm{L}, 100 \mathrm{nM}$ Pol $\beta, \pm 750 \mathrm{nM} 14)$ with a $2 X$ solution $(15 \mu \mathrm{L})$ containing TC1 $(100 \mathrm{nM})$ and dTTP $(200 \mu \mathrm{M})$ in $1 \mathrm{X}$ reaction buffer (total volume: $30 \mu \mathrm{L})$. The final concentrations during kinetics were $10 \mathrm{nM} \mathrm{Pol} \beta, 750 \mathrm{nM} 14,50 \mathrm{nM} \mathrm{TC1}$, and $100 \mu \mathrm{M}$ dTTP.

The remaining sample $(197 \mu \mathrm{L})$ was dialyzed in a 3.50K MW cassette in reaction buffer (1 L, buffer exchanged after $12 \mathrm{~h}$ ) containing $50 \mathrm{mM}$ HEPES buffer $(\mathrm{pH}=7.4,5 \mathrm{mM} \mathrm{MgCl}, 4$ mM DTT) for $24 \mathrm{~h}$. The volume of the solution in the cassette was marked and no considerable volume change was observed after dialysis. The remaining strand displacement activity of the enzyme was measured as previously described. An aliquot $(3 \mu \mathrm{L})$ was mixed with a $2 \mathrm{X}$ solution $(15 \mu \mathrm{L})$ containing TC1 $(100 \mathrm{nM})$ and dTTP $(200 \mu \mathrm{M})$ in $1 \mathrm{X}$ reaction buffer (total volume: 30 $\mu \mathrm{L})$.

This method was also used to analyze the effect of $\mathrm{pH}$ on the inhibitory activity of 14 with one minor change: the dialysis buffer contained $50 \mathrm{mM}$ HEPES buffer $\left(\mathrm{pH}=8.0,5 \mathrm{mM} \mathrm{MgCl}_{2}, 4\right.$ mM DTT). 


\section{UPLC MS/MS Analysis of Pol $\boldsymbol{\beta}$ modification by covalent inhibitors}

A solution of Pol $\beta(25 \mu \mathrm{L}, 20 \mu \mathrm{M}, 500$ pmol) was mixed with $14(5 \mu \mathrm{L}, 30 \mu \mathrm{M}, 100 \mathrm{X})$, $\mathrm{H}_{2} \mathrm{O}(420 \mu \mathrm{L})$ and $10 \mathrm{X}$ reaction buffer $(50 \mu \mathrm{L}, 500 \mathrm{mM}$ HEPES buffer, $\mathrm{pH}=7.4,50 \mathrm{mM} \mathrm{MgCl}$, $20 \mathrm{mM}$ DTT) and incubated at $25{ }^{\circ} \mathrm{C}$ for $30 \mathrm{~min}$. The reaction mixture was concentrated by centrifugation using an Amicon $3 \mathrm{~K}$ centrifugal filter. To prevent the loss of protein, the centrifugal was blocked with Pol $\beta$ prior to addition of the sample. Blocking was conducted by adding Pol $\beta$ $(500 \mu \mathrm{L}, 0.5 \mu \mathrm{M})$, followed by centrifugation $\left(13,000 \mathrm{~g}, 25 \mathrm{~min}, 4{ }^{\circ} \mathrm{C}\right)$ and removal of the supernatant. Following blocking of the membrane filter, the sample (500 $\mu \mathrm{L}, 1 \mu \mathrm{M}$ Pol $\beta \pm 300$ $\mathrm{nM}$ 14) was added to the Amicon centrifugal filter, and centrifugation was carried out $(13,000 \mathrm{~g}$, $25 \mathrm{~min}, 4{ }^{\circ} \mathrm{C}$ ). The sample was then washed twice with $500 \mu \mathrm{L}$ of $1 \mathrm{X}$ reaction buffer can concentrated by centrifugation in the Amicon filter to $50 \mu \mathrm{L}(10 \mu \mathrm{M}$ Pol $\beta)$. Digestion buffer (25 $\mu \mathrm{L}, 500 \mathrm{mM}$ Tris $\bullet \mathrm{HCl} \mathrm{pH} 7.4), 10 \mathrm{X}$ trypsin $(25 \mu \mathrm{L}, 400 \mu \mathrm{M})$, and $\mathrm{H}_{2} \mathrm{O}(150 \mu \mathrm{L})$ were added to yield a final mixture of $2 \mu \mathrm{M}$ Pol $\beta$ and $40 \mu \mathrm{M}$ trypsin (1:20 ratio) in 1X digestion buffer (total volume, $250 \mu \mathrm{L}, 50 \mathrm{mM}$ Tris• $\mathrm{HCl}, \mathrm{pH}$ 7.4).

The digestion sample was incubated at $37^{\circ} \mathrm{C}$ overnight. A portion $(100 \mu \mathrm{L})$ of the digestion mixture was spun down $\left(16,000 \mathrm{~g}, 10 \mathrm{~min}, 4^{\circ} \mathrm{C}\right)$. The sample $(10 \mu \mathrm{L})$ was injected onto and analyzed by UPLC-MS/MS using an ACQUITY UPLC HSS T3 Column (100 $\AA, 1.8 \mu \mathrm{m}, 2.1 \mathrm{~mm}$ x $100 \mathrm{~mm}$ ). The flow rate was $0.3 \mathrm{~mL} / \mathrm{min}$ running a gradient from 85:5:10 water: acetonitrile: $1 \%$ formic acid to 50:40:10 water: acetonitrile: $1 \%$ formic acid over $35 \mathrm{~min}$. Analysis was conducted using BioPharmaLynx with tolerance set to $30 \mathrm{ppm}$ and allowing for 4 missed cleavages. 


\section{Fluorescence Anisotropy ${ }^{16}$}

Anisotropy measurements were conducted using a solution of dichloro-diphenylfluorescein-labeled TC5 (2.5 nM, Table S1) and Pol $\beta$ (varying concentrations) in reaction buffer (50 mM HEPES, pH 7.5, $20 \mathrm{mM} \mathrm{KCl,} 1 \mathrm{mM}$ EDTA, and $1 \mathrm{mM} \beta$-mercaptoethanol). Samples also contained 10\% storage buffer (20 mM Tris $\bullet \mathrm{HCl}, \mathrm{pH}$ 7, $300 \mathrm{mM} \mathrm{NaCl}, 10 \%$ glycerol, $5 \mathrm{mM} \mathrm{BME}$ ) by volume.

In a typical experiment, a sample $(300 \mu \mathrm{L})$ was prepared by mixing Pol $\beta(30 \mu \mathrm{L}, 1 \mu \mathrm{M})$ in storage buffer with $10 \mathrm{X}$ reaction buffer $(30 \mu \mathrm{L})$, TC5 $(30 \mu \mathrm{L})$, a solution $50 \%$ MeCN in $\mathrm{H}_{2} \mathrm{O}$ containing or lacking $14(200 \mu \mathrm{M}, 3 \mu \mathrm{L})$ and $\mathrm{H}_{2} \mathrm{O}(207 \mu \mathrm{L})$. These samples, termed solutions A and $\mathbf{A}^{\prime}$ (A did not contain 14 and $\mathbf{A}^{\prime}$ contained $2 \mu \mathrm{M}$ 14), contained $250 \mathrm{pM}$ TC5, $100 \mathrm{nM}$ Pol $\beta$, $\pm 2 \mu \mathrm{M}$ 14. Samples containing various concentrations of Pol $\beta$ were prepared by serial dilution with solution B and B'. Solution B $(10 \mathrm{~mL})$ was prepared by mixing $\mathrm{H}_{2} \mathrm{O}(7.85 \mathrm{~mL})$, with $10 \mathrm{X}$ reaction buffer $(1 \mathrm{~mL}), 10 \mathrm{X}$ storage buffer $(1 \mathrm{~mL})$, TC5 $(50 \mathrm{nM}, 50 \mu \mathrm{L})$, and a solution of $50 \%$ MeCN in $\mathrm{H}_{2} \mathrm{O}$ containing or lacking $14(200 \mu \mathrm{M}, 100 \mu \mathrm{L})$. Similarly, solution B did not contain 14 and was used exclusively to dilute solution $\mathbf{A}$, whereas solution $\mathbf{B}^{\prime}$ contained $2 \mu \mathrm{M} 14$ and was used to dilute solution $\mathbf{A}^{\prime}$. By mixing equal volumes of $\mathbf{A}$ or $\mathbf{A}^{\prime}(150 \mu \mathrm{L})$ with $\mathbf{B}$ or $\mathbf{B}^{\prime}(150 \mu \mathrm{L})$ respectively, the concentration of Pol $\beta$ decreased to $50 \mathrm{nM}$, while the concentration of DNA and 14 remain unchanged. An aliquot $(150 \mu \mathrm{L})$ of this new solution was then mixed with solution $\mathbf{B}$ or B' $(150 \mu \mathrm{L})$ to prepare a new solution containing $25 \mathrm{nM}$ Pol $\beta$. Serial dilutions were repeated such that samples contained Pol $\beta$ concentrations of $100 \mathrm{nM}, 50 \mathrm{nM}, 25 \mathrm{nM}, 12.5 \mathrm{nM}, 6.25 \mathrm{nM}$, $3.13 \mathrm{nM}, 1.56 \mathrm{nM}, 0.78 \mathrm{nM}, 0.39 \mathrm{nM}$, and $0.2 \mathrm{nM}$. 
Samples were incubated at $25{ }^{\circ} \mathrm{C}$ for $1 \mathrm{~h}$ and fluorescence anisotropy (A) was measured using a portion $(125 \mu \mathrm{L})$ of each sample with a PMT voltage of $800 \mathrm{mV}, 8 \mathrm{~nm}$ slit width, $535 \mathrm{~nm}$ excitation and $556 \mathrm{~nm}$ emission. Fluorescence anisotropy was measured for TC5 in the absence of enzyme $\left(\mathrm{A}_{0}\right)$, and the change in anisotropy $\left(\mathrm{A}-\mathrm{A}_{0}\right)$ was calculated for each sample and plotted against the concentration of Pol $\beta$. Each fluorescence anisotropy measurement was collected in triplicate.

\section{Growing conditions for different cell lines}

Mouse embryonic fibroblast cells were grown in DMEM with high glucose supplemented with $9 \% \mathrm{FBS}$ at $34^{\circ} \mathrm{C}$ in a $10 \% \mathrm{CO}_{2}$ humidified incubator.

HeLa cells were grown in DMEM with high glucose supplemented with 9\% FBS and 1\% antibiotic antimycotic solution (penicillin, streptomycin, and amphotericin B). HeLa cells were grown at $37{ }^{\circ} \mathrm{C} 5 \% \mathrm{CO}_{2}$ in a humidified incubator.

\section{Clonogenic assay for cell survival}

Approximately $2 \times 10^{5} \mathrm{HeLa}$ cells were plated in each well of a 6-well culture plate (well size; $35 \mathrm{~mm} \times 18 \mathrm{~mm})$ in DMEM containing 10\% FBS (1 mL) and kept in a humidified incubator at $37{ }^{\circ} \mathrm{C}$ with $5 \% \mathrm{CO}_{2}$. After overnight incubation, cells were subjected to either the vector $(50 \%$ $\mathrm{MeCN}$ in $\mathrm{H}_{2} \mathrm{O}$ ) or treatment (100X pro-14, $10 \mu \mathrm{L}$; in $50 \% \mathrm{MeCN}$ in $\mathrm{H}_{2} \mathrm{O}$ and/or $100 \mathrm{X}$ DNA damaging agent (e.g. $20 \mathrm{mM}$ MMS, $200 \mu \mathrm{M}$ BLM; $10 \mu \mathrm{L}$; in DMEM-FBS medium). For alkylation experiments, cells were incubated with MMS ( 0 or $0.2 \mathrm{mM})$, with or without pro-14 (5, $25 \mu \mathrm{M}$ ) at $37^{\circ} \mathrm{C}$ with $5 \% \mathrm{CO}_{2}$ for 1 or $2 \mathrm{~h}$. After treatment, the medium was removed, and the cells were washed with 1 X PBS $(2 \times 1 \mathrm{~mL})$. The cells were trypsinized with $0.25 \mathrm{w} / \mathrm{v}$ TrypsinEDTA $\left(1 \mathrm{~mL}\right.$ in each well, $5 \mathrm{~min}$ incubation at $\left.37^{\circ} \mathrm{C}\right)$, washed with DMEM-FBS $(10 \mathrm{~mL})$ to quench the trypsin cleavage, and spun down (3,000 RCF x 5 min). The medium was removed, and 
the cells were resuspended with fresh DMEM-FBS $(10 \mathrm{~mL})$. The single cell suspensions were collected and counted using a TC20 Automated Cell Counter (BIO-RAD).

Stock solutions of single cell suspensions were prepared for all untreated and treated cells. For example, 100 cells $/ \mathrm{mL}$ stock solution of untreated cells were prepared; 500 cells $/ \mathrm{mL}$ stock solutions of treated cells were prepared. The concentration of stock solution for each sample was determined based on expected toxicity of the treatment (i.e. higher concentrations for more toxic conditions). The appropriate number of cells for each experiment were seeded in each well of a 6well plate (well size; $35 \mathrm{~mm}$ x $18 \mathrm{~mm}$ ) in $3 \mathrm{~mL}$ of DMEM-FBS medium. The cells were grown in a humidified incubator at $37{ }^{\circ} \mathrm{C}$ with $5 \% \mathrm{CO}_{2}$ for 14 days. No significant change in media volume was observed after two weeks due to evaporation. After 14 days, the growth medium was discarded, and the attached cells were treated with $0.2 \% \mathrm{w} / \mathrm{v}$ crystal violet solution. The excess dye was washed with water. The plates were dried and scanned with an HP Scanjet 3970 and colonies were counted using ImageJ (FIJI).

Plating efficiencies (PE) and survival fractions (SF) were calculated as follows: $\mathrm{PE}=$ number of

colonies/number of cells seeded; $\mathrm{SF}=\mathrm{PE} / \mathrm{PE}_{\text {control}}$.

\section{Cell Viability Assays for MEFs. ${ }^{17,18}$}

Mouse embryonic fibroblasts (Pol $\beta$ WT, Pol $\beta-/-$, Pol $\lambda$ WT, Pol $\lambda-/-$, Pol $\beta-/ \lambda-$ ) were seeded at a density of $\sim 0.3 \times 10^{6}$ cells/well in 6-well dishes. The following day, cells were exposed for $1 \mathrm{~h}$ to a range of MMS concentrations $(0,0.1,0.2,0.5,1.0,1.5 \mathrm{mM})$ in growth medium in the presence of absence of pro-14 $(0,5,15,25 \mu \mathrm{M})$. Control wells were treated with an equal volume of vector $\left(50 \% \mathrm{MeCN}\right.$ in $\left.\mathrm{H}_{2} \mathrm{O}\right)$. Cells were washed with $1 \mathrm{X}$ PBS and fresh medium was added. Dishes were incubated for 5 days at $34^{\circ} \mathrm{C}$ in a $10 \% \mathrm{CO}_{2}$ incubator until untreated control cells were $\sim 80 \%$ confluent. Cells (triplicate wells for each treatment concentration were counted by a 
cell lysis procedure (described previously), and the results were expressed as the surviving fraction of cells in drug-treated wells relative to control wells. 
Chart S1. Carboxylic acids used to prepare inhibitor candidates.<smiles>Cc1ccc(C(=O)O)cc1N1C(=O)c2ccccc2C1=O</smiles><smiles>CCc1ccccc1N1C(=O)c2ccc(C(=O)O)cc2C1=O</smiles><smiles>O=C(O)c1c(-c2ccc(Cl)cc2)coc1C(F)(F)F</smiles><smiles>COc1ccc2cc(C(=O)O)ccc2c1</smiles><smiles>COc1cc(C(=O)O)cc(Cl)c1O</smiles><smiles>COc1cc(C(=O)O)cc(OC)c1OC</smiles><smiles>Cc1cc(C(=O)O)c2ccc(F)cc2n1</smiles><smiles>COc1ccccc1-n1cc(C(=O)O)cn1</smiles><smiles>COC(=O)c1ccc(-c2ccccc2Cl)o1</smiles><smiles>O=C(O)c1ccc(-c2ccccc2F)cc1</smiles><smiles>O=C(O)c1cccc(-c2ccccc2F)c1</smiles><smiles>O=C(O)c1cccc(-c2cccc(F)c2)c1</smiles><smiles>Cc1csc(SCC(=O)O)n1</smiles><smiles>O=C(O)c1cccc(C(=O)c2ccccc2)c1</smiles><smiles>O=C(O)c1c(O)ccc2ccccc12</smiles><smiles>COc1cc(C(O)C(=O)O)ccc1O</smiles><smiles>O=C(O)c1cc(O)c2cccc(O)c2n1</smiles><smiles>O=C(O)c1cccc2c1C(=O)c1ccccc1-2</smiles><smiles>O=C(O)c1cccnc1Oc1ccccc1</smiles><smiles>O=C(O)c1cnc2cc(O)ccc2c1O</smiles><smiles>CCCOC(=O)C(C)c1ccc(N2Cc3ccccc3C2=O)cc1</smiles><smiles>O=C(O)C1CC(=O)N(Cc2ccc(Cl)cc2)C1</smiles><smiles>COc1ccc(C(=O)O)c(Cl)c1OC</smiles><smiles>COc1cc2c(cc1C(=O)O)CCC=C2</smiles><smiles>O=C(O)c1ccc(-c2ccc([N+](=O)[O-])cc2)o1</smiles><smiles>O=C(O)c1csc(-c2ccncc2)n1</smiles><smiles>O=C(O)c1ccc(-c2ccc(Br)cc2)o1</smiles><smiles>CCCCC(C)(C)C</smiles><smiles>Cc1ccc(-c2ccc(C(=O)O)o2)c([N+](=O)[O-])c1</smiles> 

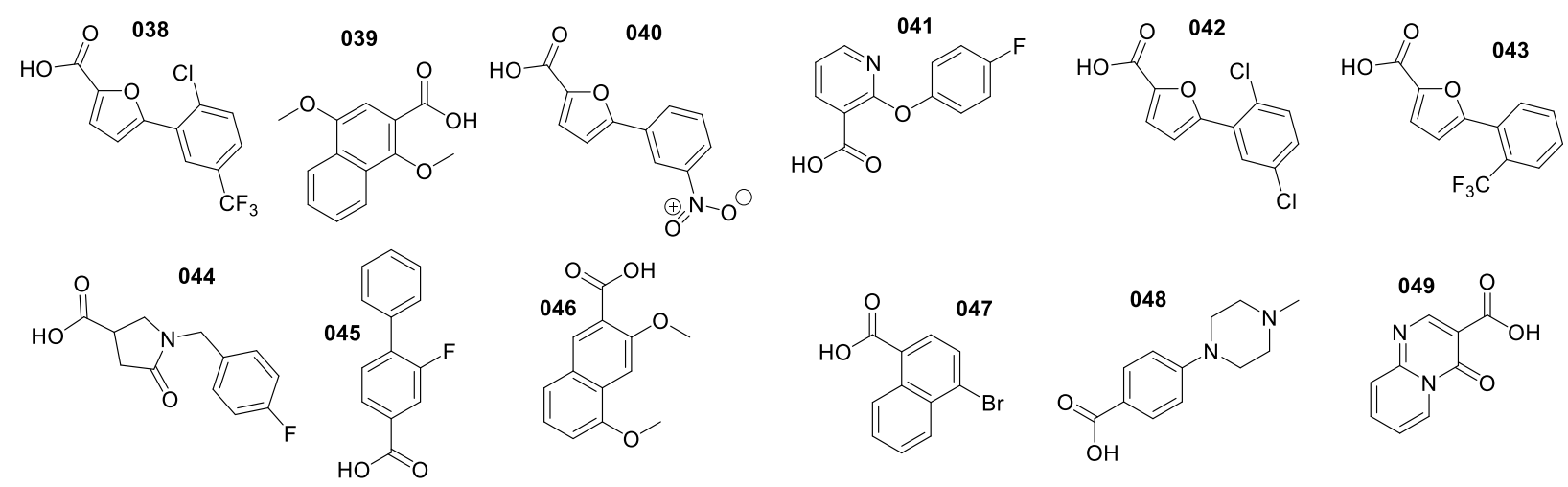<smiles>O=C(O)c1cn(C2CC2)c2nc(Cl)c(F)cc2c1=O</smiles><smiles>O=C(O)c1ccc(Cl)nc1Cl</smiles><smiles>CCCCC(C)(C)Oc1cccc(C(=O)O)c1</smiles><smiles>CC(C)(C)O[Na]</smiles><smiles>Cc1nn(-c2ccccc2)nc1C(=O)O</smiles><smiles>O=C(O)c1ccc(Oc2ccc(O)cc2)cc1</smiles><smiles>COc1cc(Cl)c(C(=O)O)cc1OC</smiles><smiles>O=C(O)c1sc(Cl)c(Cl)c1Cl</smiles><smiles>O=C(O)c1cnc2ccc(C(F)(F)F)cc2c1O</smiles><smiles>O=C(O)c1ccc2c(c1)OC(F)(F)O2</smiles><smiles>C=C(C)c1cn(CC)c2cc(Cl)c(F)cc2c1=O</smiles><smiles>CC(C)(C)O[Na]</smiles><smiles>Cc1nn(-c2ccccc2)c2sc(C(=O)O)cc12</smiles><smiles>O=C(O)c1csc(-c2cccs2)n1</smiles><smiles>CCN1C(=O)CC(Sc2ccccc2C(=O)O)C1=O</smiles><smiles>COc1ccc2cc(C(=O)O)n(C)c2c1</smiles><smiles>O=C(O)c1sc2cc(F)ccc2c1Cl</smiles><smiles>O=C(O)Cc1cc(Br)cs1</smiles><smiles>Cc1ccn2c(=O)c(C(=O)O)cnc2c1</smiles><smiles>Cc1cc(C)n(-c2ccc(C(=O)O)cc2)n1</smiles><smiles>O=C(O)c1cnc(-c2ccncc2)nc1</smiles><smiles></smiles><smiles>Clc1ccccc1</smiles><smiles>C1CCCC1</smiles><smiles>COc1ccc(-c2cccc(C(=O)O)c2)cc1</smiles><smiles>O=C(O)c1ccccc1C(=O)c1ccc(O)cc1</smiles> 
(1)

(1)<smiles>COc1ccc(C(=O)O)c([N+](=O)[O-])c1</smiles>
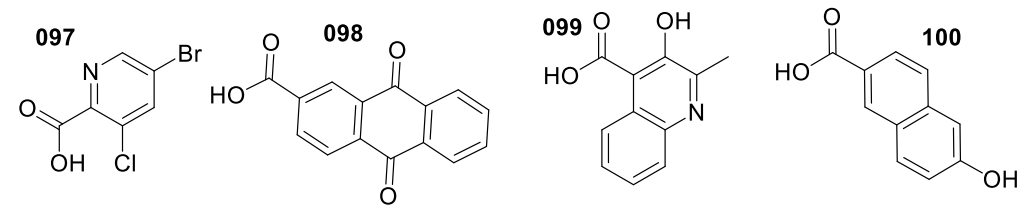

$\underbrace{101}_{\mathrm{OH}}$
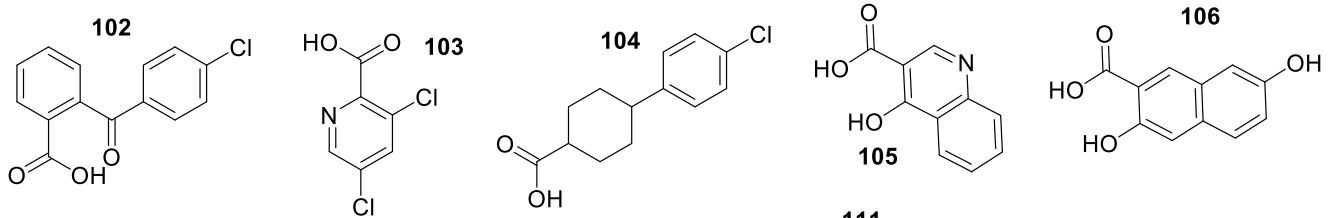

(107)<smiles>O=C(O)c1cc2ccccc2nc1O</smiles>

Cl<smiles>O=C(O)c1ncc(Cl)cc1Br</smiles><smiles>CCn1cc(C(=O)O)c(=O)c2cc3c(cc21)OCO3</smiles><smiles>O=C(O)c1ccc(-c2ccccc2)cc1</smiles><smiles>CC1(C(C(=O)O)c2ccc(Cl)cc2)CC1</smiles><smiles>[15NH]c1c(C(=O)O)cnn1-c1ccccc1</smiles><smiles>O=C(O)C1CCN(c2ccc(Br)cc2)CC1</smiles><smiles>O=C(O)c1[14cH][14c](F)c(Cl)cc1F</smiles><smiles>O=C(O)CO</smiles><smiles>Oc1ccc(Cl)cc1Cl</smiles><smiles>O=C(C=C1CCCCC1)c1ccccc1</smiles><smiles>O=C(O)c1c(O)c(Cl)cc(Cl)c1Cl</smiles><smiles>CCn1cc(C(=O)O)c(=O)c2ccc(C)nc21</smiles><smiles>Cc1cccc(Cl)c1-c1noc(C)c1C(=O)O</smiles><smiles>O=C(O)c1cc(O)c(O)c(O)c1</smiles><smiles></smiles><smiles>Cc1ccc(S(=O)(=O)n2ccc(C(=O)O)c2)cc1</smiles><smiles>CC(n1c(C(F)(F)F)nc2cc(C(=O)O)ccc21)C(C)(F)F</smiles> 

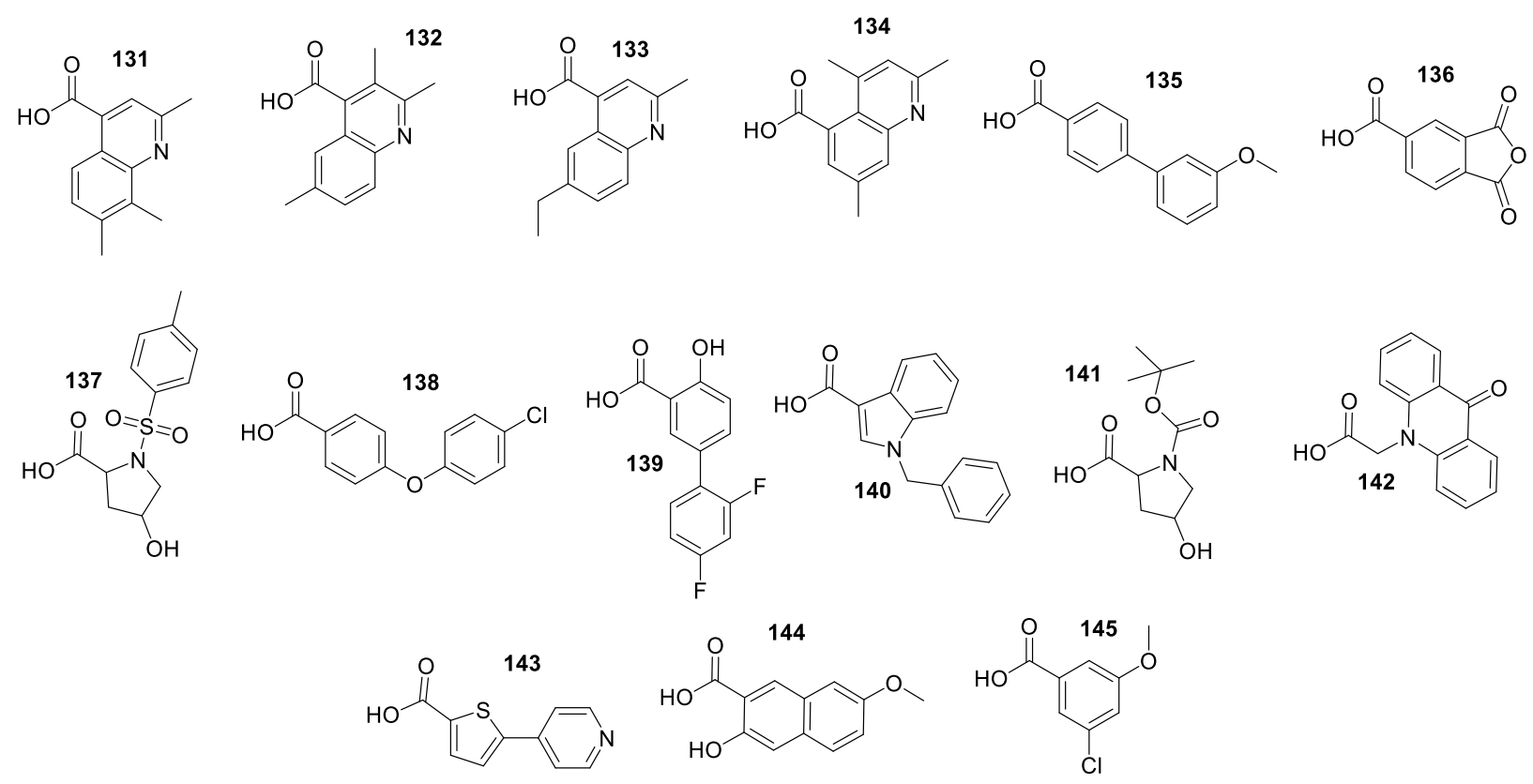
<smiles>O=C(O)c1ccc(Cc2ccccc2)cc1</smiles><smiles>CN(C)c1ccc(NNc2c(Cl)cccc2C(=O)O)cc1</smiles><smiles>Cc1nn(C)cc1-c1cc(C(=O)O)no1</smiles><smiles>[194Pb]</smiles><smiles>CCOc1ccsc1C(=O)O</smiles><smiles>O=C(O)c1cccc(-c2cccc(Br)c2)c1</smiles><smiles>Cc1cc(C(=O)O)c2ccccc2n1</smiles><smiles>O=C(O)c1cc(-c2cccs2)nc2ccccc12</smiles><smiles></smiles><smiles>CC(=O)c1c(C)oc(C(=O)O)c1C</smiles><smiles>O=C(O)c1cc(-c2ccccc2)nc(-c2ccccc2)c1</smiles><smiles>NS(=O)(=O)c1ccc(NC(=O)c2ccccc2C(=O)O)cc1</smiles><smiles>COc1ccc(C(=O)O)cc1N1CCOCC1</smiles><smiles>Cc1cc(N)c(C(=O)O)cc1Br</smiles><smiles>C/C=C\c1ccccc1NC(=O)c1ccccc1C(=O)O</smiles><smiles>O=C(O)c1cccc(CSc2cccs2)c1</smiles><smiles>O=C(O)c1ccccc1C(=O)c1cccs1</smiles><smiles>NS(=O)(=O)c1cc(C(=O)O)c(O)cc1Cl</smiles><smiles>O=C(O)c1cccc(C(=O)c2cccc(C(=O)c3cccc(C(=O)O)c3)c2)c1</smiles><smiles></smiles><smiles>O=C(O)c1sccc1-n1cccc1</smiles><smiles>CC(C)S(=O)(=O)c1csc(S(=O)(=O)O)c1N</smiles><smiles>O=C(O)c1c(Br)cnc(Cl)c1S(=O)(=O)O</smiles><smiles>NS(=O)(=O)c1cc(C(=O)O)c(NCc2ccco2)cc1Cl</smiles><smiles>O=C(O)c1cc(-n2cccc2)ccc1O</smiles><smiles>Nc1ccccc1C(=O)c1ccccc1C(=O)O</smiles><smiles>Cc1nn(C)c2sc(C(=O)O)cc12</smiles><smiles>O=C(O)c1cc(O)cc(Br)c1</smiles><smiles>COc1cc(C(=O)O)nc2ccccc12</smiles><smiles>Cc1occc1C(=O)O</smiles><smiles>O=C(O)c1ccccc1-n1cccc1C(=O)O</smiles><smiles></smiles><smiles>COc1c(N)cccc1C(=O)O</smiles><smiles>CNc1ncc(C(=O)O)c(Cl)c1-c1ccc([N+](=O)[O-])cn1</smiles> 


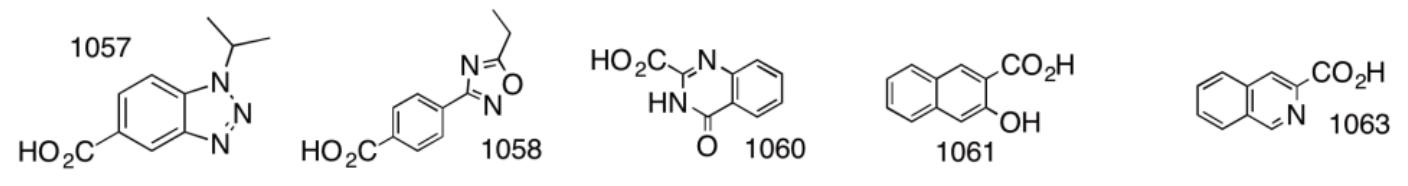<smiles>CC1CCC(C)C(C(=O)O)C1OC(=O)c1c(O)cccc1C(=O)O</smiles><smiles>COc1ccc(N)c(C(=O)O)c1N</smiles><smiles></smiles><smiles>O=C(O)c1cccc(Oc2ccccc2)c1</smiles><smiles>Cc1onc(-c2ccccc2Cl)c1C(=O)OCc1cccc(C(=O)O)c1O</smiles><smiles></smiles><smiles>CC(C)(C)N(CC(=O)O)c1ccc(C(=O)c2ccccc2C(=O)O)cc1</smiles><smiles></smiles> 


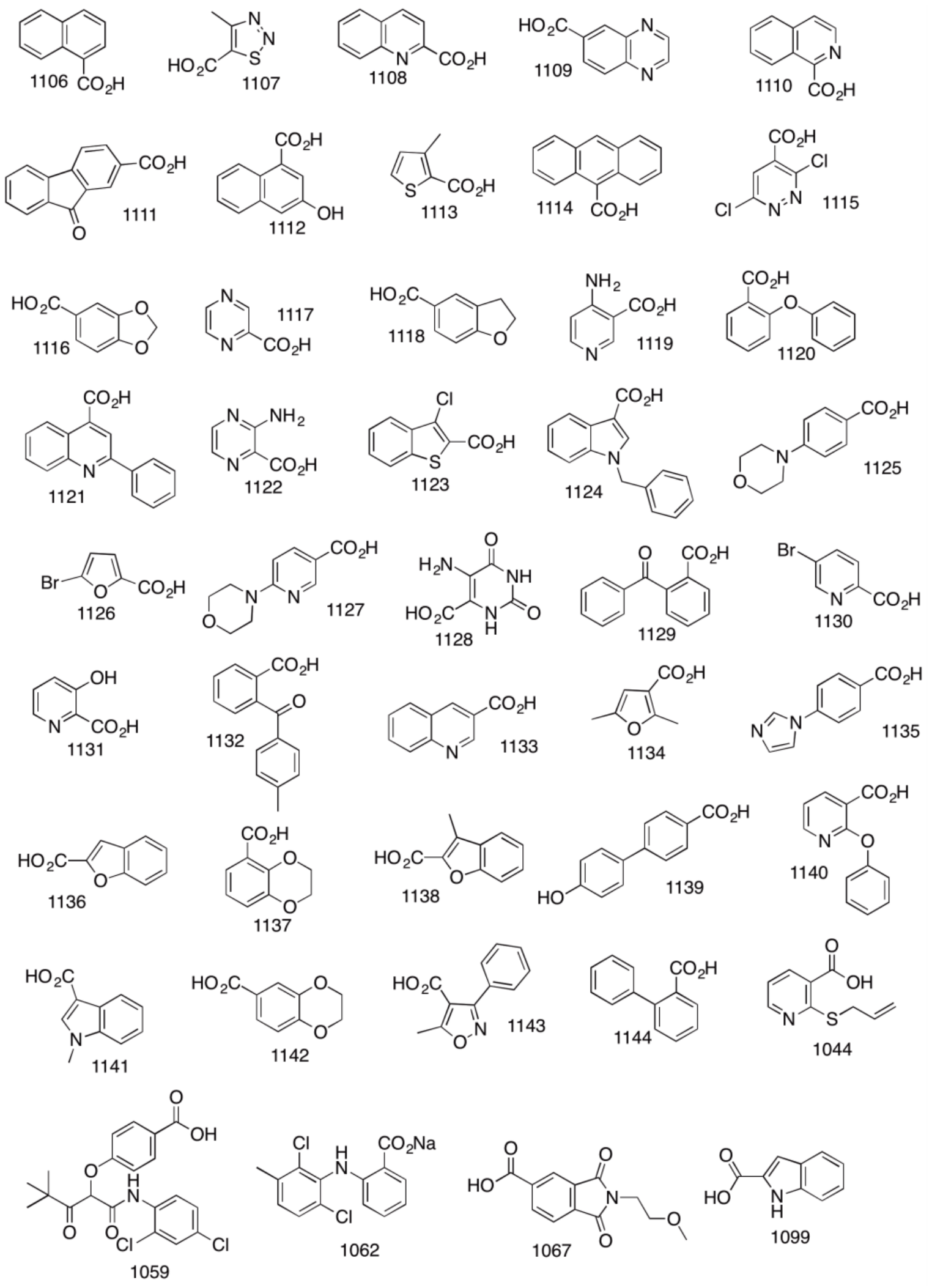




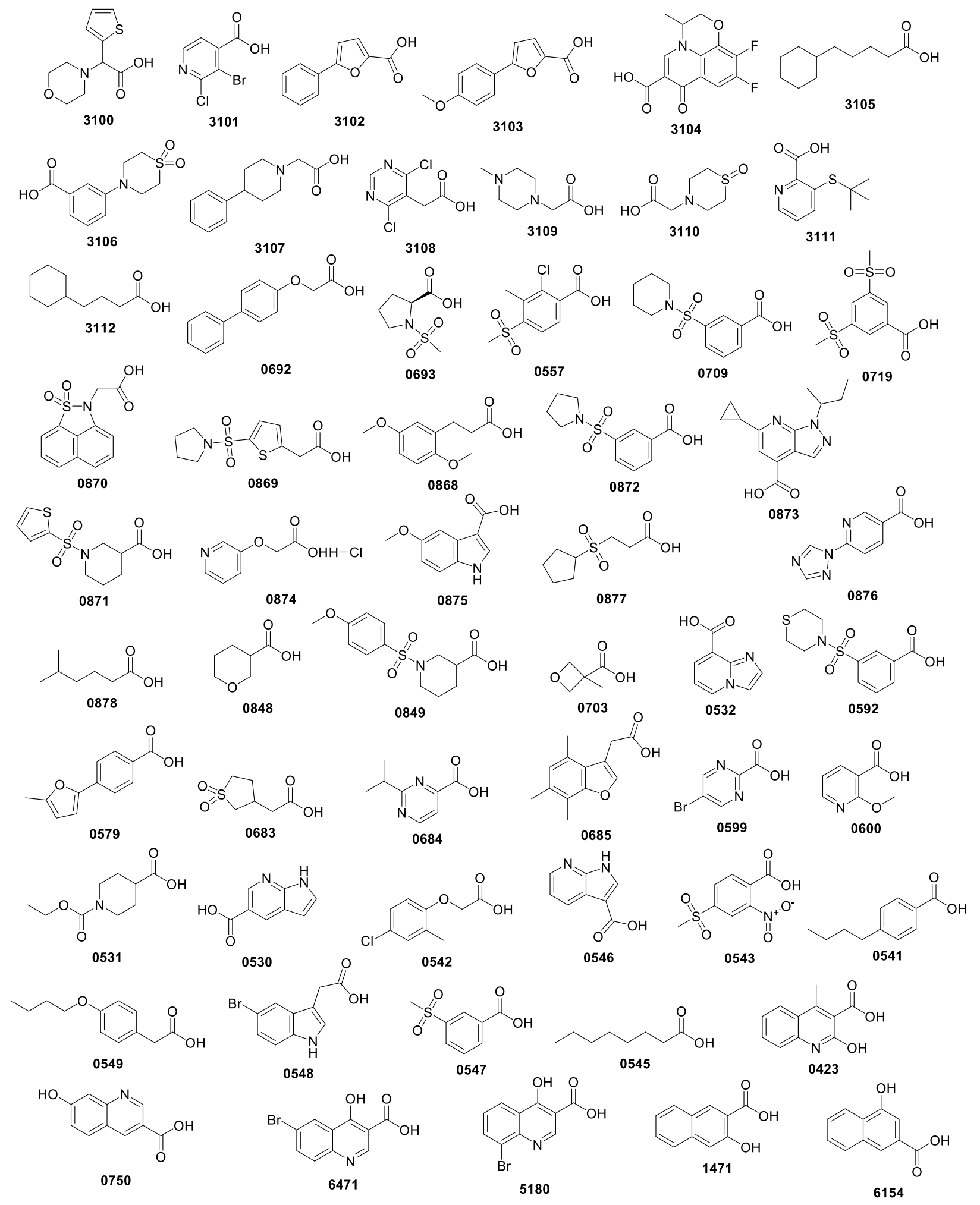


The remaining acids were only included in the second-generation library containing 375 members:<smiles>Cc1cc(Br)cc2c(O)c(C(=O)O)cnc12</smiles><smiles>O=C(O)c1ccc2[nH]c(=O)cc(O)c2c1</smiles>

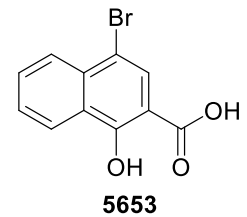<smiles>O=C(O)c1cnc2c(F)cc(Br)cc2c1O</smiles><smiles>O=C(O)c1ccc2ccc(O)cc2c1O</smiles><smiles>Cc1ccc2ncc(C(=O)O)c(O)c2c1</smiles><smiles>O=C(O)c1cc2ccncc2c(O)n1</smiles><smiles>O=C(O)c1cc2c(Cl)cccc2[nH]1</smiles>

1834<smiles>O=C(O)c1cc2cc(F)ccc2nc1O</smiles><smiles>Cc1nc2ccc(O)cc2cc1C(=O)O</smiles><smiles>CC(C)(C)O[13C](=O)c1cc2cccc(F)c2[nH]1</smiles><smiles>CC(C)(C)OC(=O)c1cc2cc(F)ccc2[nH]1</smiles><smiles>Cc1ccc2cc(C(=O)O)[nH]c2c1</smiles><smiles>O=C(O)c1c[nH]c2ccc(Br)cc12</smiles>

153<smiles>O=C(O)c1c[nH]c2c(Cl)cccc12</smiles><smiles>O=C(O)c1cc2cc(OC(F)(F)F)ccc2[nH]1</smiles><smiles>O=C(O)c1cc2ccc(Br)cc2[nH]1</smiles><smiles>O=C(O)c1[nH]c2ccccc2c1Br</smiles><smiles>O=C(O)c1cc2c(F)cc(F)cc2[nH]1</smiles><smiles>O=C(O)c1ccc2[nH]cc(Br)c2c1</smiles>

$$
7107
$$<smiles>O=C(O)c1cc2cc(O)ccc2[nH]1</smiles>
0154<smiles>O=C(O)c1coc2ccccc2c1=O</smiles>
7109<smiles>O=C(O)c1cc2cc(Cl)ccc2oc1=O</smiles>

5928<smiles>O=C(O)c1ccc(=O)n(-c2ccc(F)cc2)c1</smiles>

5597<smiles>O=C(O)c1cc2cc(Br)ccc2[nH]1</smiles><smiles></smiles><smiles>CC(C)(C)O[Mg]</smiles><smiles>O=C(O)c1c[nH]c2cccc(F)c12</smiles><smiles>O=C(O)c1cc(Br)c2cc[nH]c2c1</smiles><smiles>O=C(O)c1c[nH]c2ccc(F)cc12</smiles><smiles>[13CH3][18OH]</smiles><smiles>Cc1ccc2c(=O)cc(C(=O)O)oc2c1</smiles><smiles>C[14CH3]</smiles><smiles>Cc1cc2c(cc1C(=O)O)OCCO2</smiles><smiles>O=C(O)c1coc2ccc(F)cc2c1=O</smiles>

3775<smiles>O=C(O)c1cc(=O)c2ccc(O)cc2o1</smiles><smiles>Cc1c(C(=O)O)c(=O)oc2ccc(O)cc12</smiles><smiles>O=C(O)c1cc2ccc(C(F)(F)F)cc2[nH]1</smiles>

0149<smiles>Cc1c(CC(=O)O)c(=O)oc2cc(O)c(Cl)cc12</smiles><smiles>Cc1c(CC(=O)O)c(=O)oc2cc(O)c(O)cc12</smiles><smiles>O=C(O)Cn1c(=O)c(F)cn(C2CCCO2)c1=O</smiles><smiles>CC(C)(C)Oc1ccccc1OC(C(=O)O)C(=O)O</smiles><smiles>O=C(O)c1c[nH]c2cc(Cl)c(Cl)cc2c1=O</smiles><smiles>O=C(O)c1c[nH]c2cc(Cl)cc(Cl)c2c1=O</smiles> 
A.
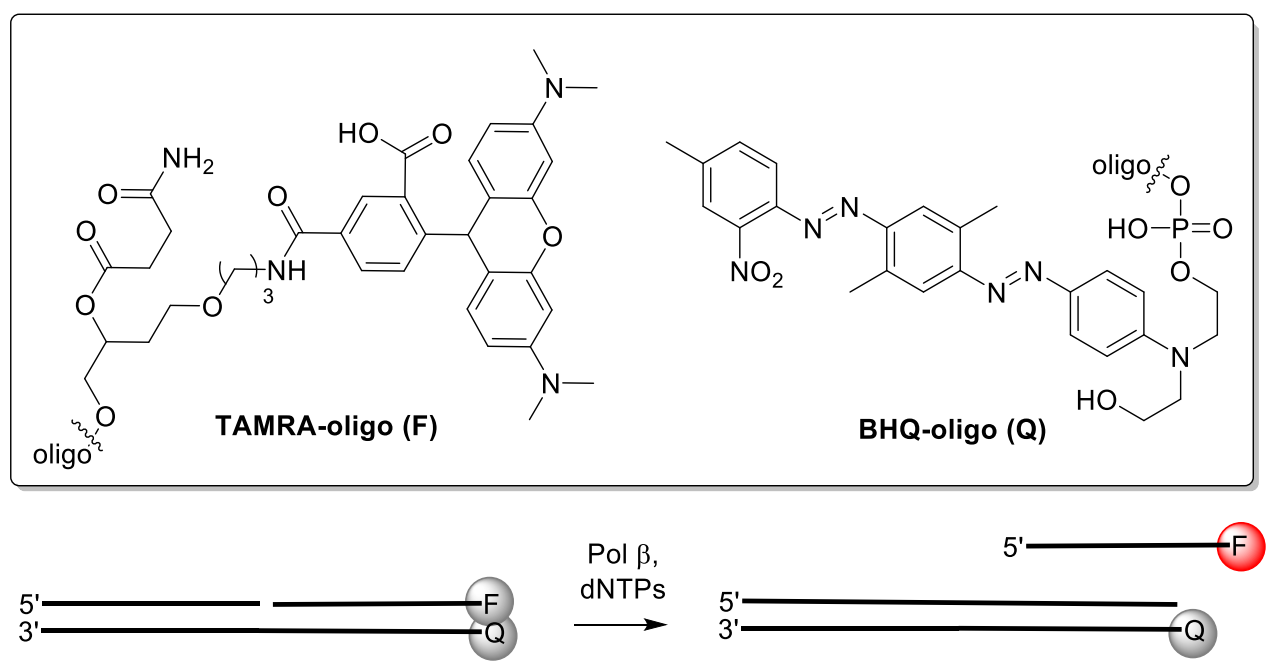

5'- d(TCA CCC TCG TAC GAC TC TTT TTT TTT TGC F) - 3'

3'- d(AGT GGG AGC ATG CTG AG_AAA AAA AAA ACG Q) - 5'

High-throughput screen

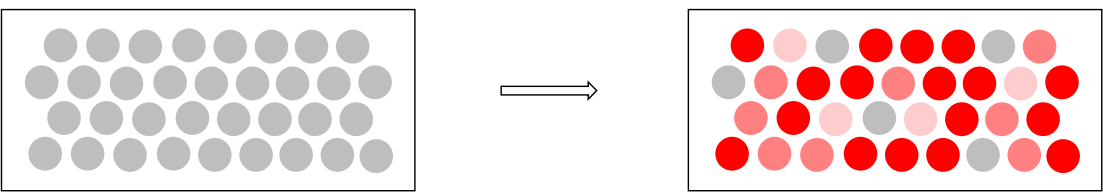

B.
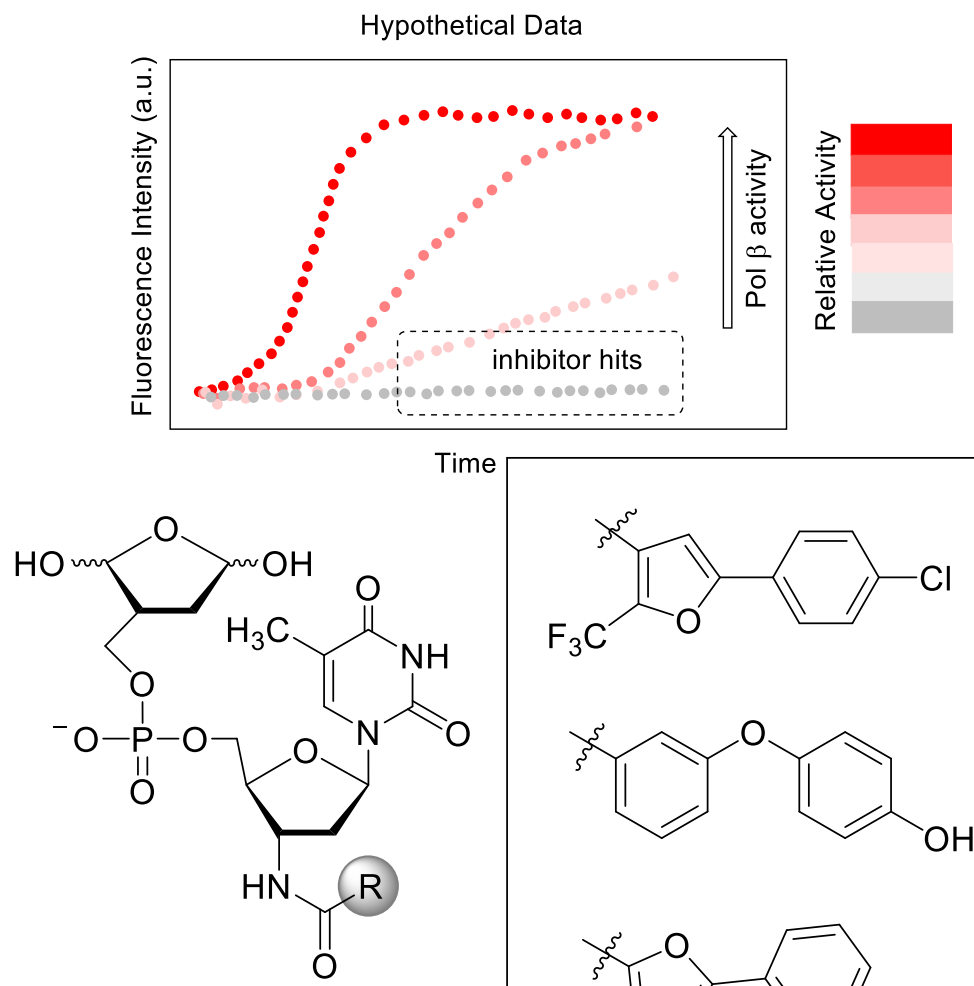<smiles>CC(C)(C)c1cc(-c2ccc(Cl)cc2)oc1C(F)(F)F</smiles><smiles>Oc1ccc(Oc2cccc(C(F)(F)F)c2)cc1</smiles><smiles>CC(C)(C)c1ccc(-c2ccccc2)o1</smiles>

Figure S1. (a) Fluorescence-based strand displacement assay. (b) First-generation hit compounds from initial screen. 


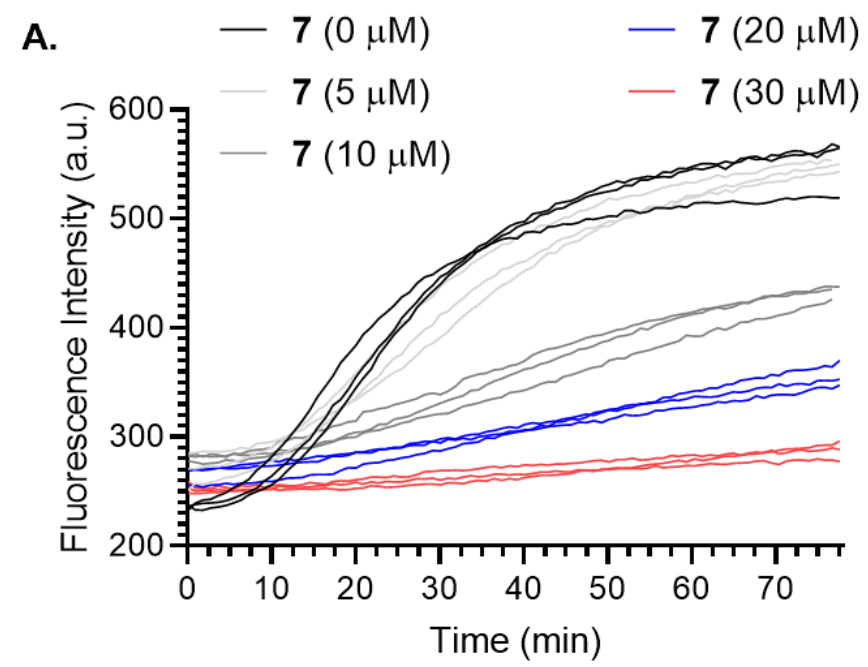

B.

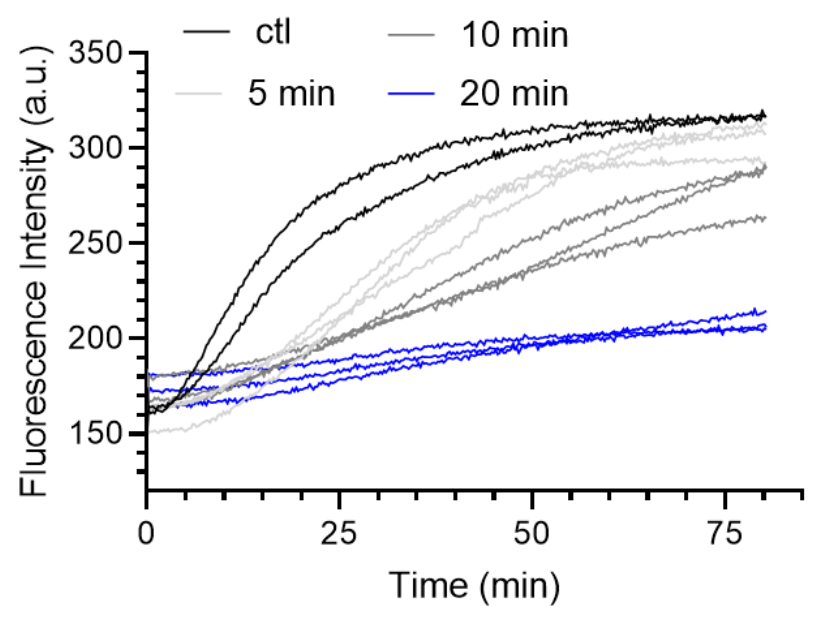

Figure S2. The inhibitory activity of first-generation inhibitor 7. (a) Pol $\beta$ strand displacement inhibition following 20 min preincubation with 7 at various concentrations (listed). (b) Effect of preincubation time on inhibitory activity of 7 at $15 \mu \mathrm{M}$. 


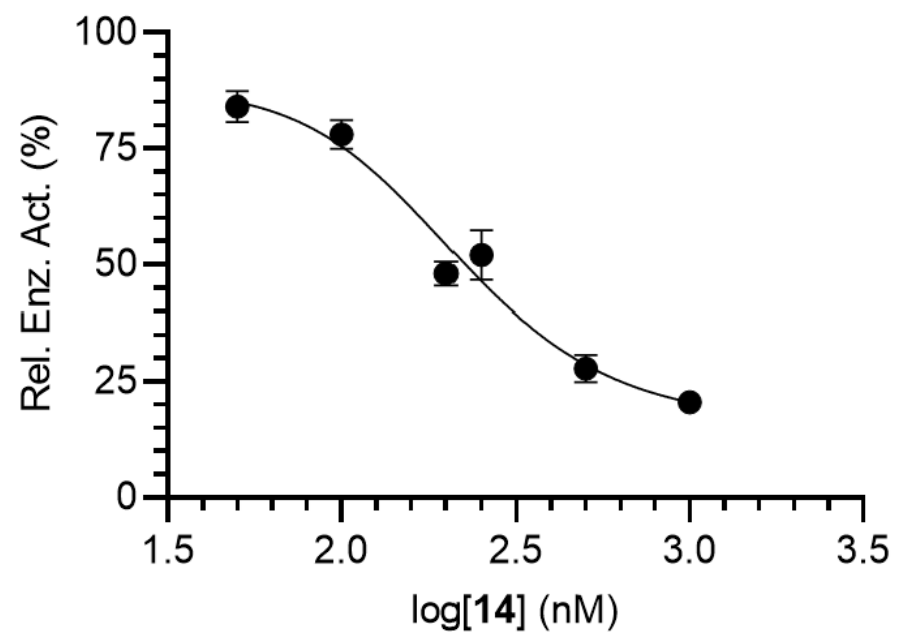

Figure S3. $\mathrm{IC}_{50}$ value of $\mathbf{1 4}$ under exact conditions used to evaluate $\mathbf{2}$. 

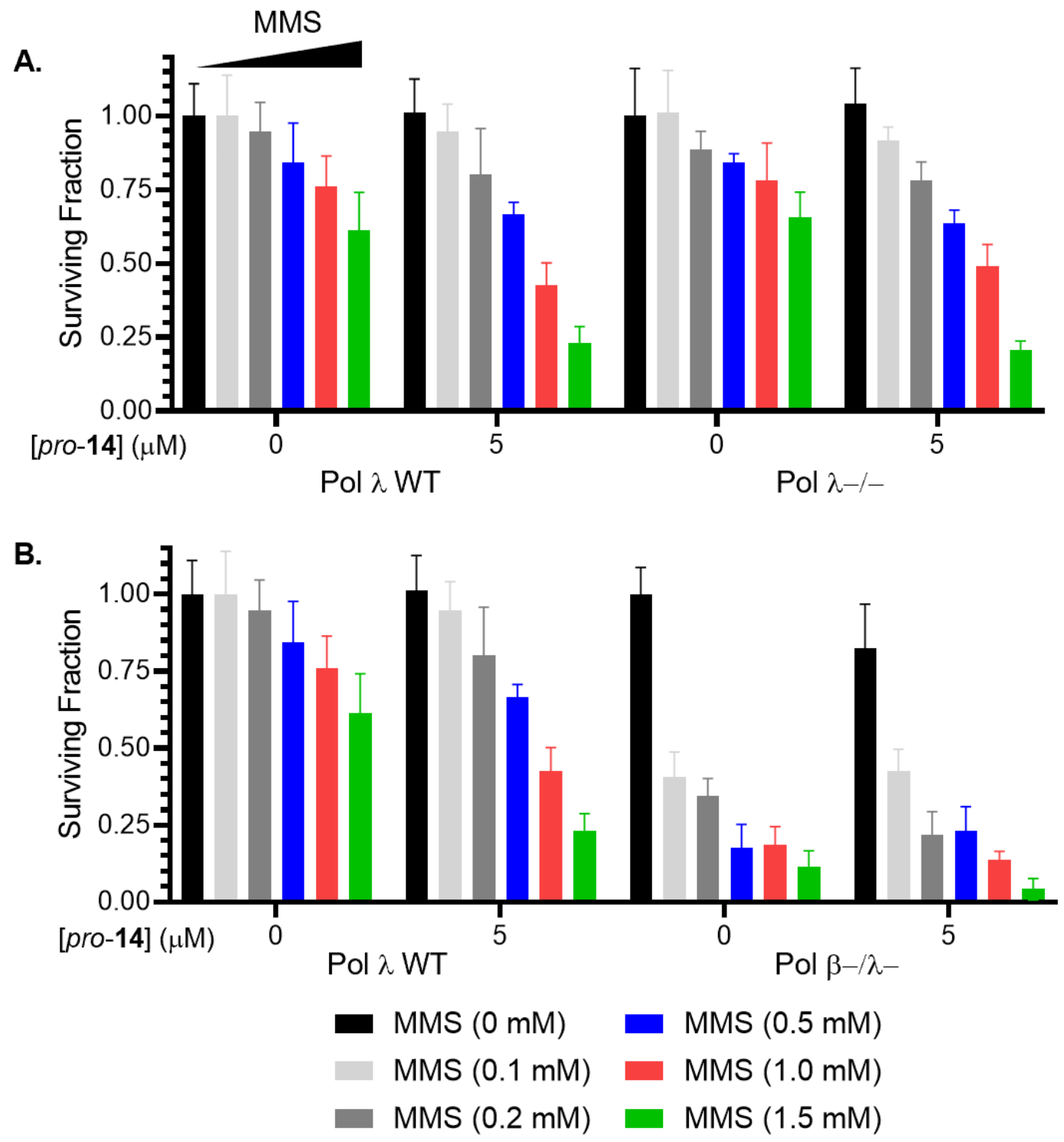

Figure S4. The effect of pro-14 on MMS cytotoxicity in MEFs containing or lacking Pol $\lambda$. (a) The effect of pro-14 on MMS cytotoxicity $(0,0.1,0.2,0.5,1.0,1.5 \mathrm{mM})$ in Pol $\lambda$ WT and Pol $\lambda$ /- MEFs. (b) The effect of pro-14 on MMS cytotoxicity $(0,0.1,0.2,0.5,1.0,1.5 \mathrm{mM})$ in Pol $\lambda$ WT and Pol $\beta-/ \lambda-$ MEFs. 


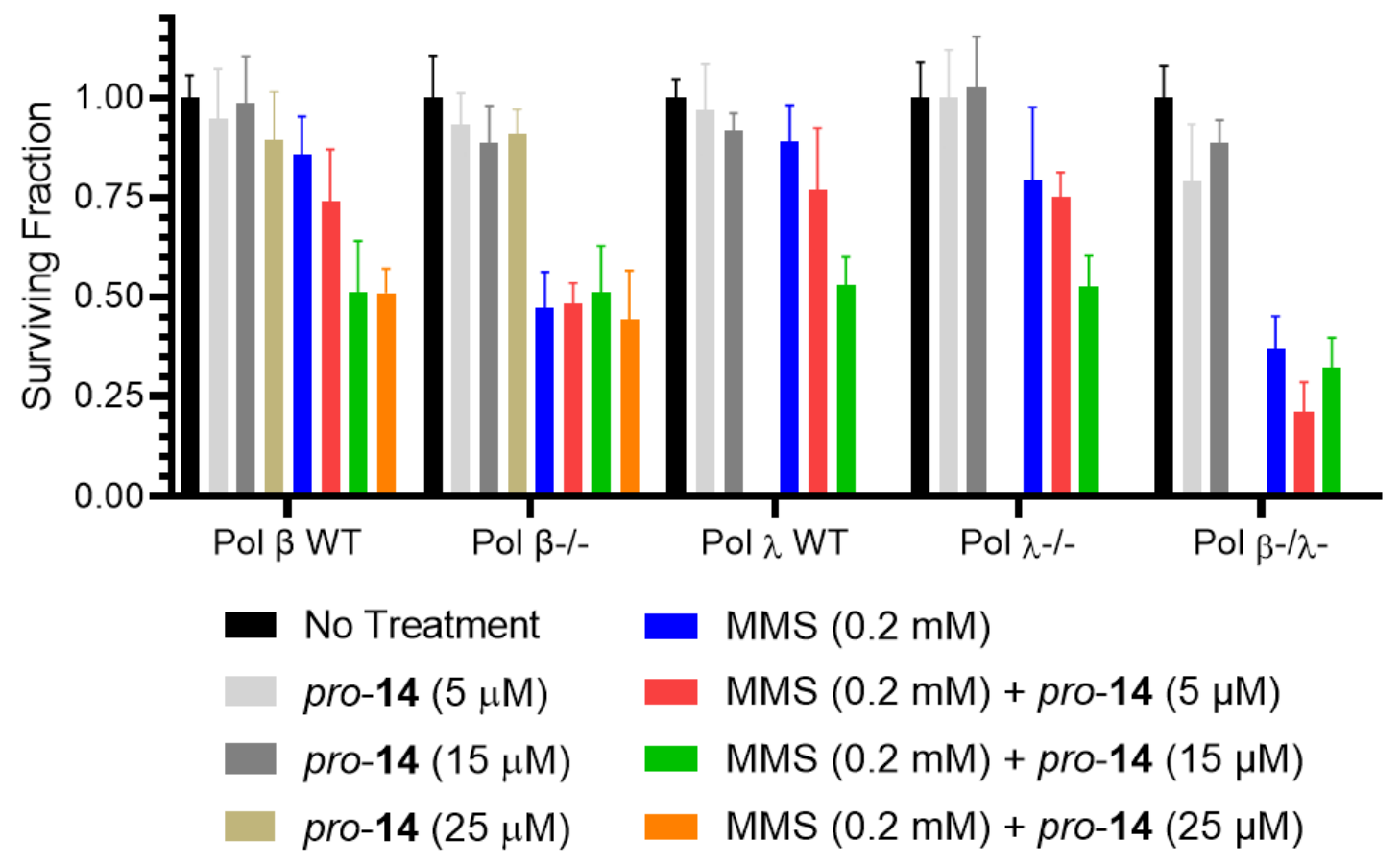

Figure S5 . The effect of greater concentrations of pro-14 $(0,5,15,25 \mu \mathrm{M})$ on MMS cytotoxicity $(0,0.1,0.2,0.5,1.0,1.5 \mathrm{mM})$ in MEFs lacking Pol $\beta$ and/or Pol $\lambda$. 

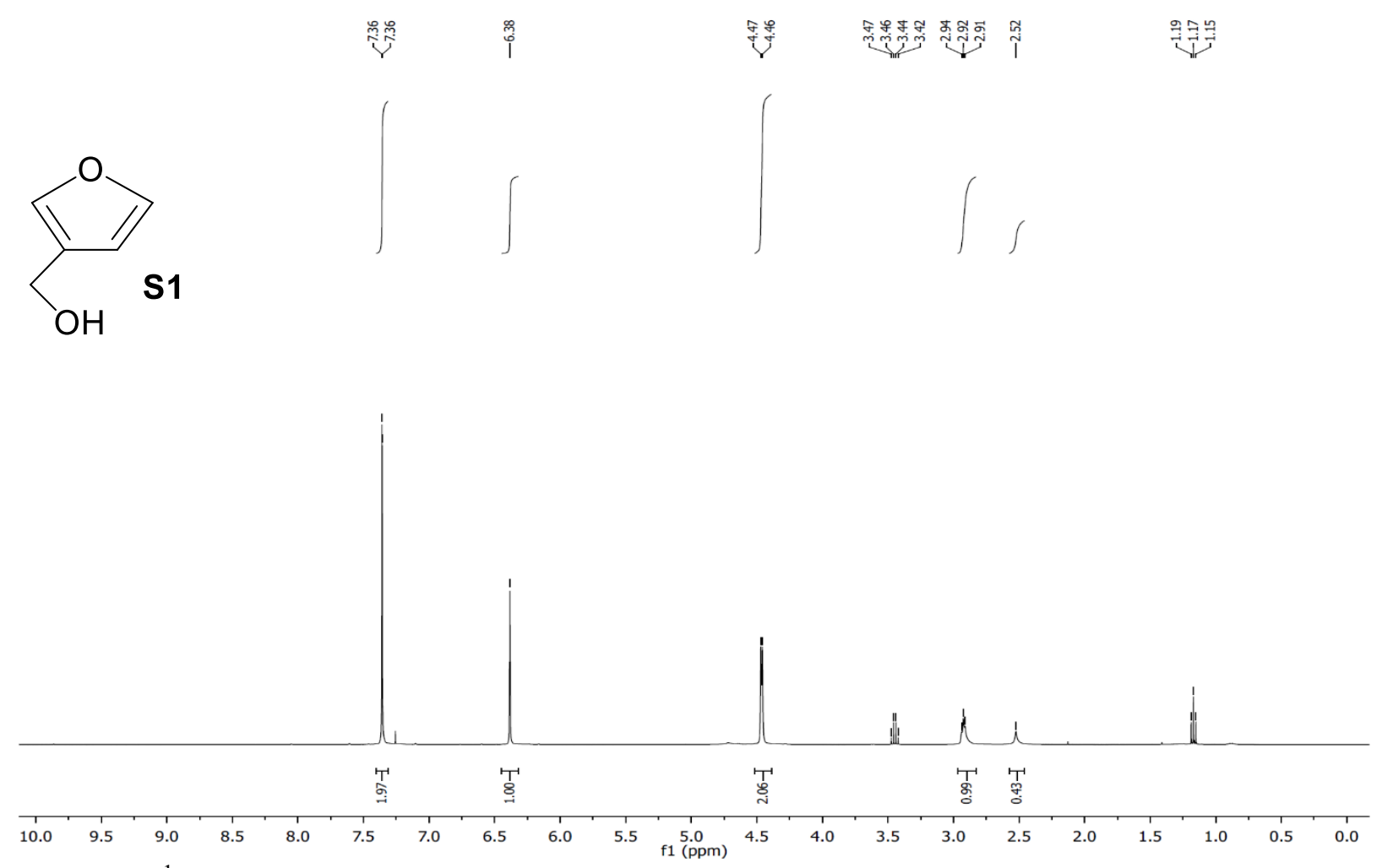

Figure S6. ${ }^{1} \mathrm{H}$ NMR spectra of S1

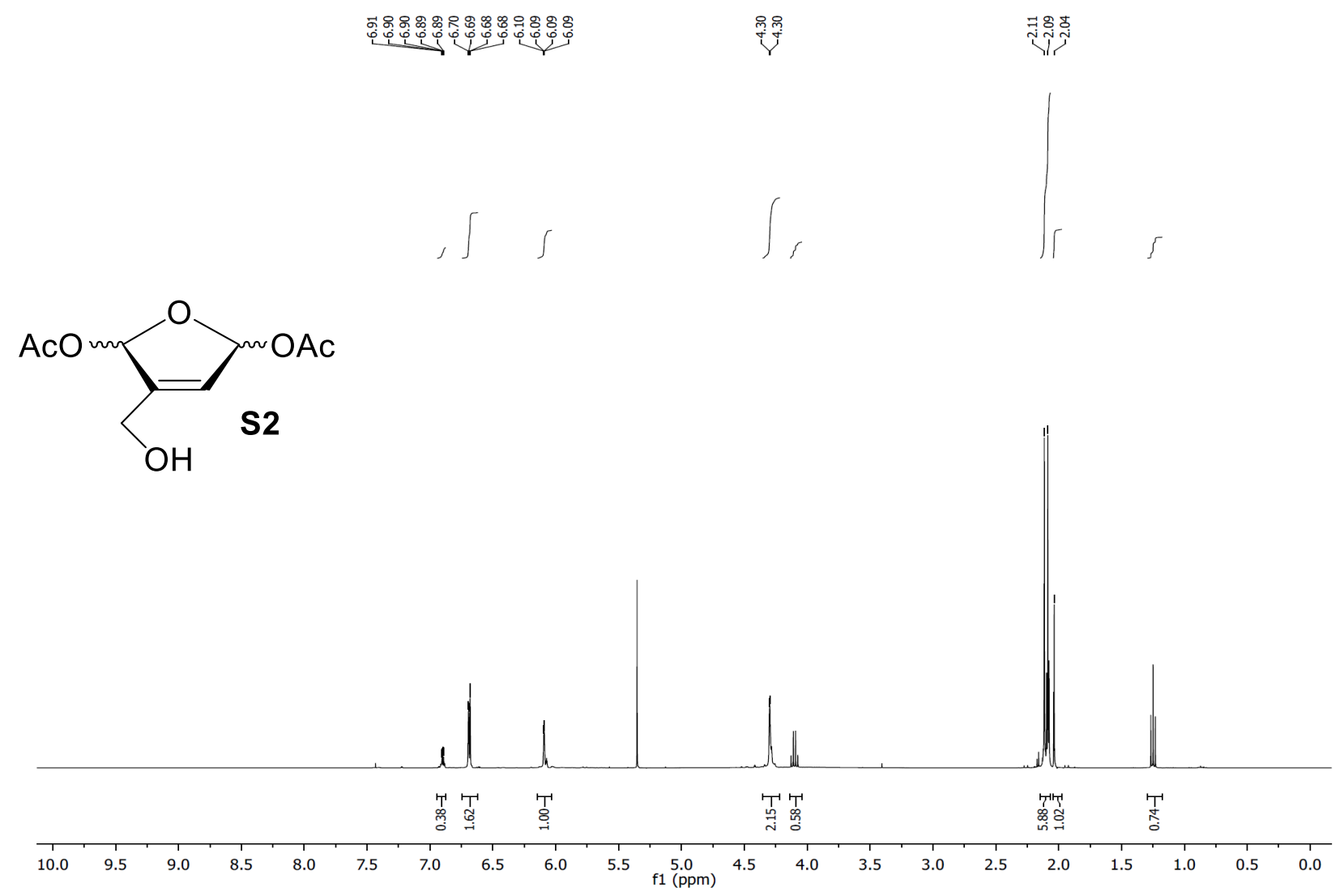

Figure S7. ${ }^{1} \mathrm{H}$ NMR spectra of S2 


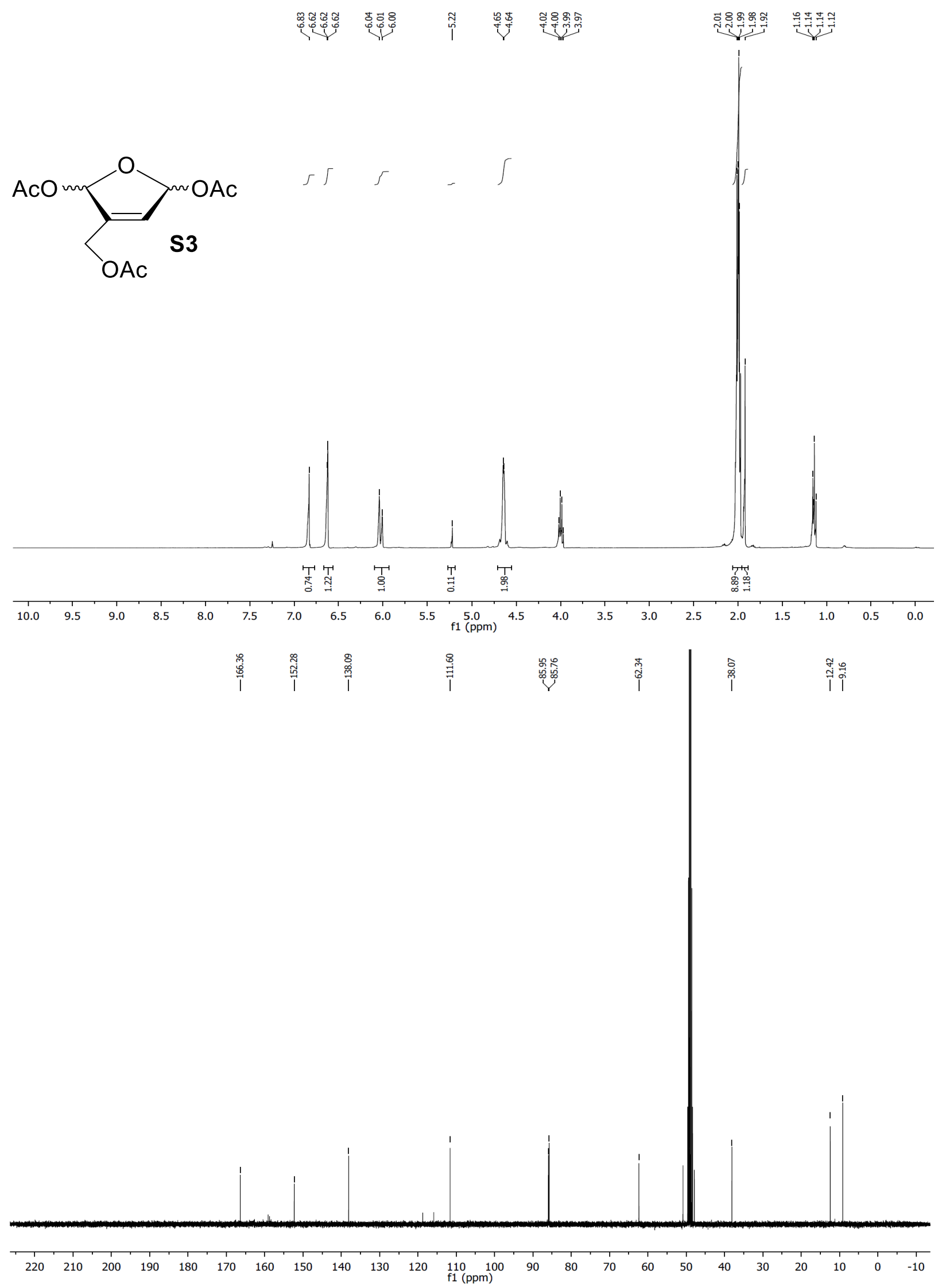

Figure S8. ${ }^{1} \mathrm{H}$ and ${ }^{13} \mathrm{C}$ NMR spectra of $\mathbf{S 3}$ 

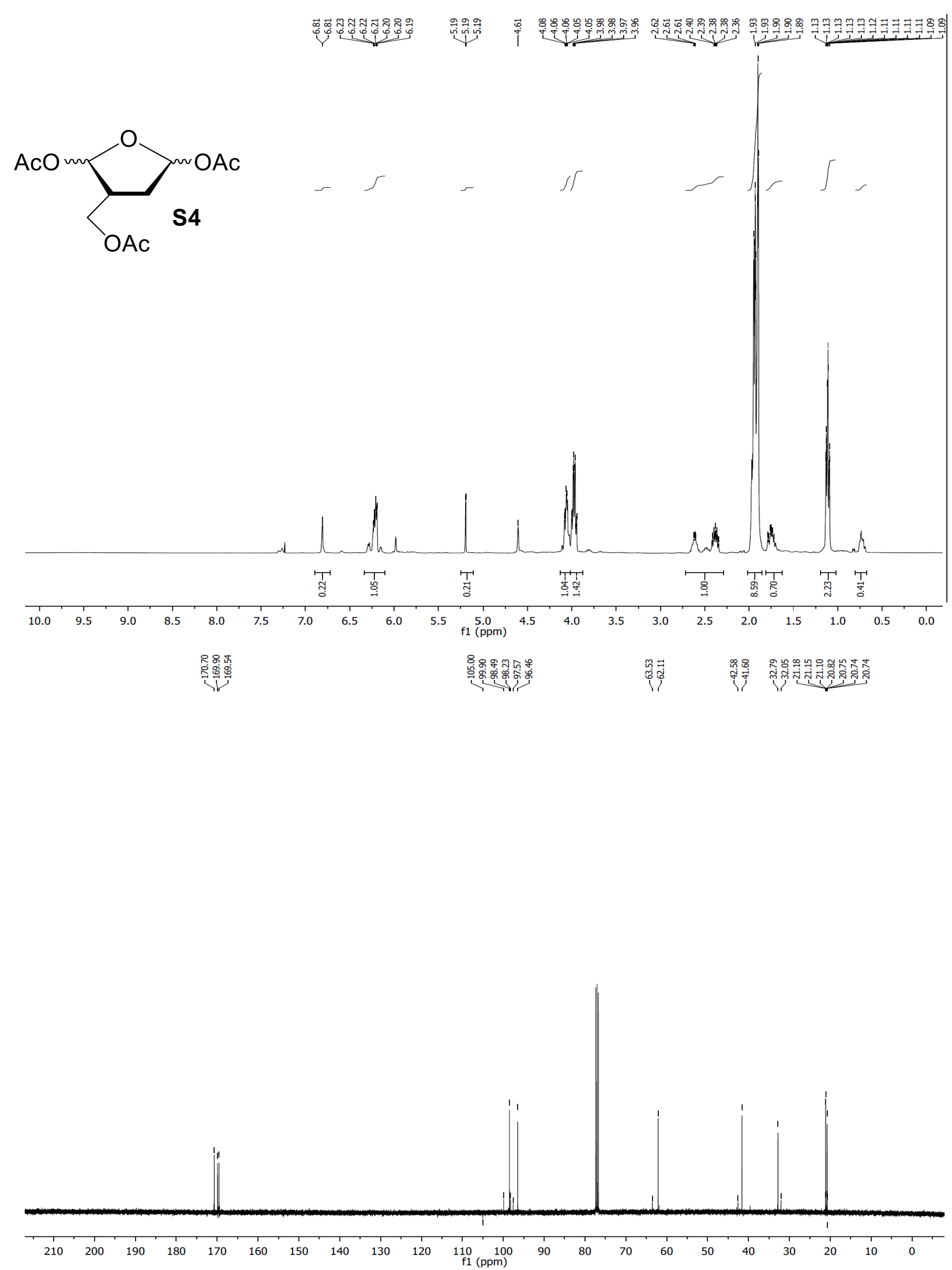

Figure S9. ${ }^{1} \mathrm{H}$ and ${ }^{13} \mathrm{C}$ NMR spectra of $\mathbf{S 4}$ 

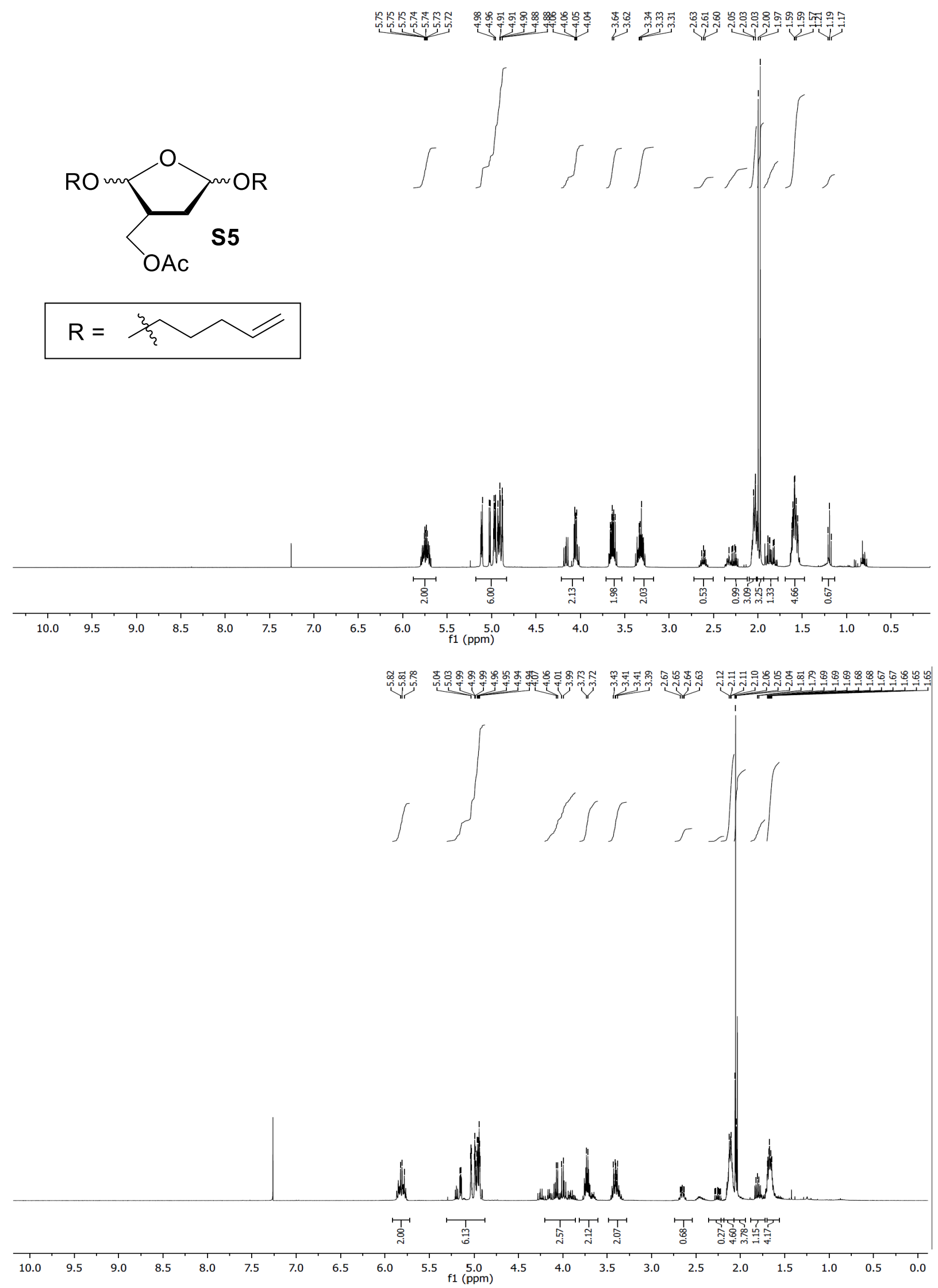

Figure S10. ${ }^{1} \mathrm{H}$ NMR spectra of S5a and S5b 


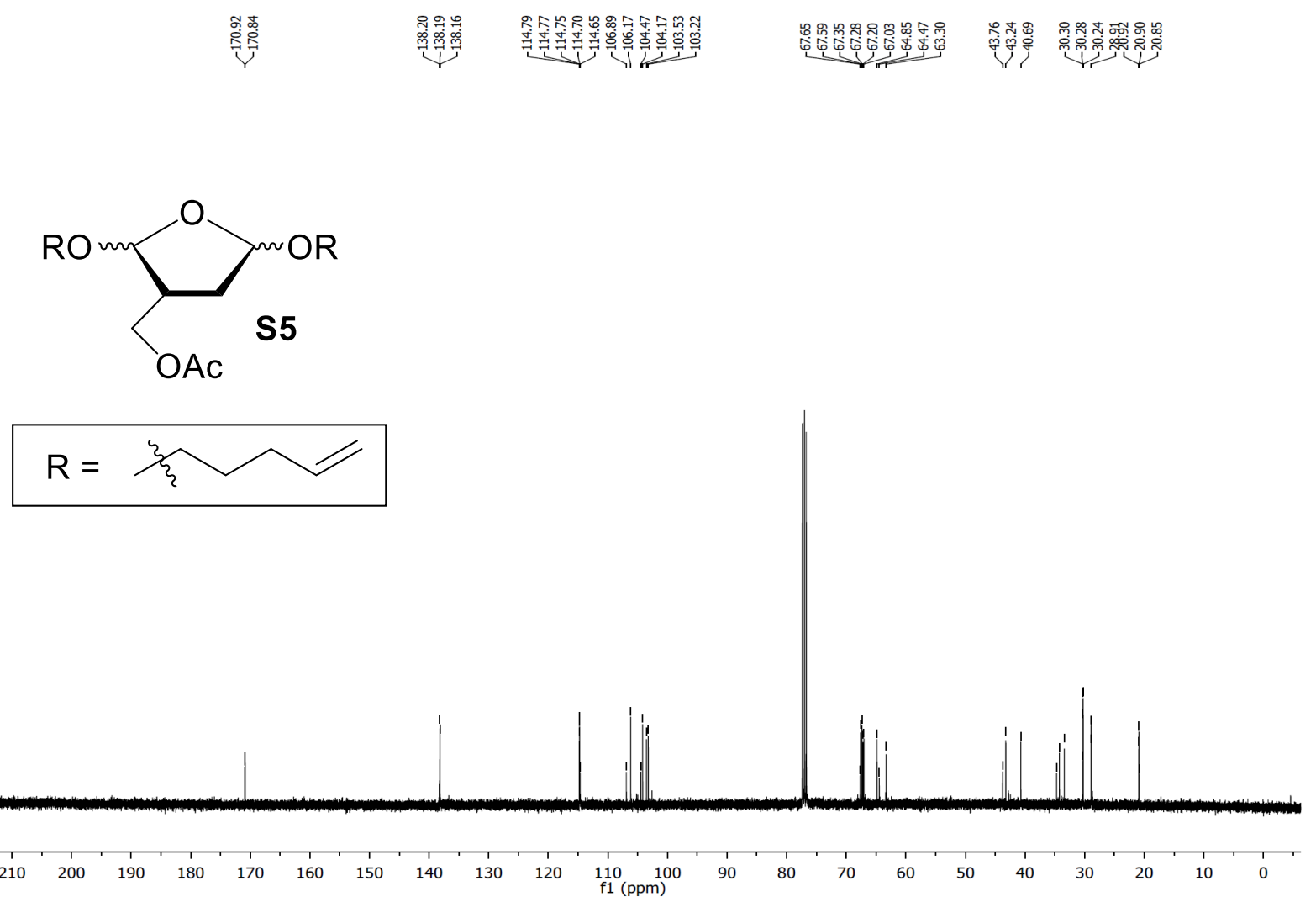

Figure S11. ${ }^{13} \mathrm{C}$ NMR spectra of S5

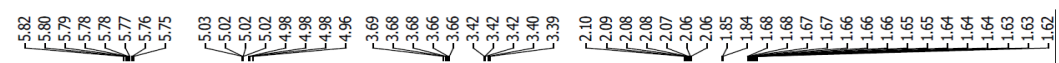
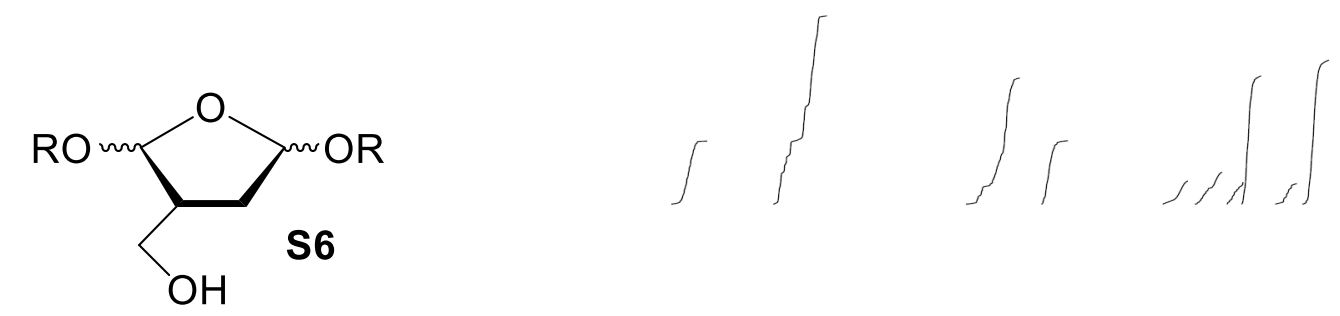

$\mathrm{R}=\xi_{\xi}$

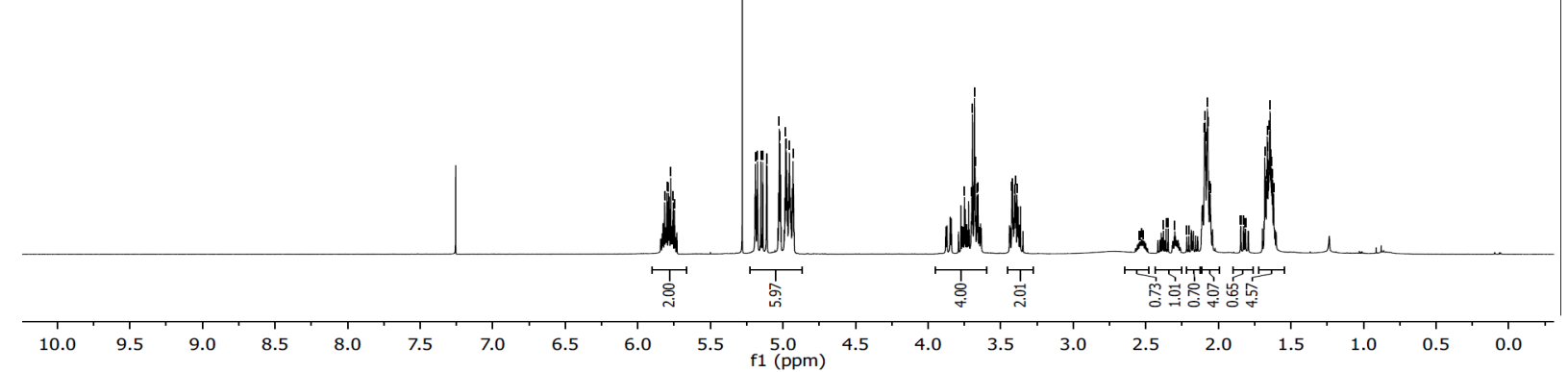

Figure S12. ${ }^{1} \mathrm{H}$ NMR spectra of $\mathbf{S 6}$ 

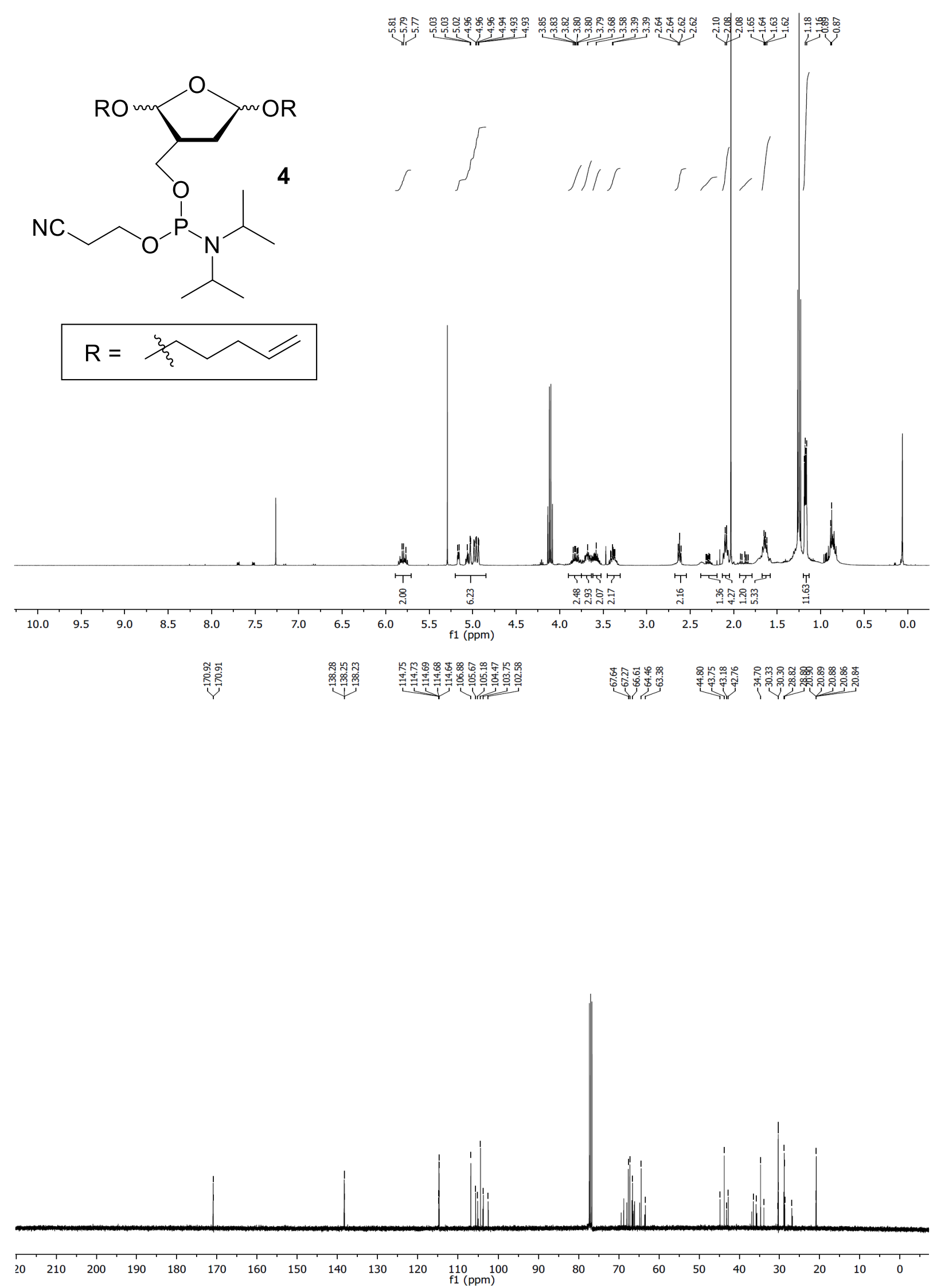

Figure S13. ${ }^{1} \mathrm{H}$ and ${ }^{13} \mathrm{C}$ NMR spectra of 4 


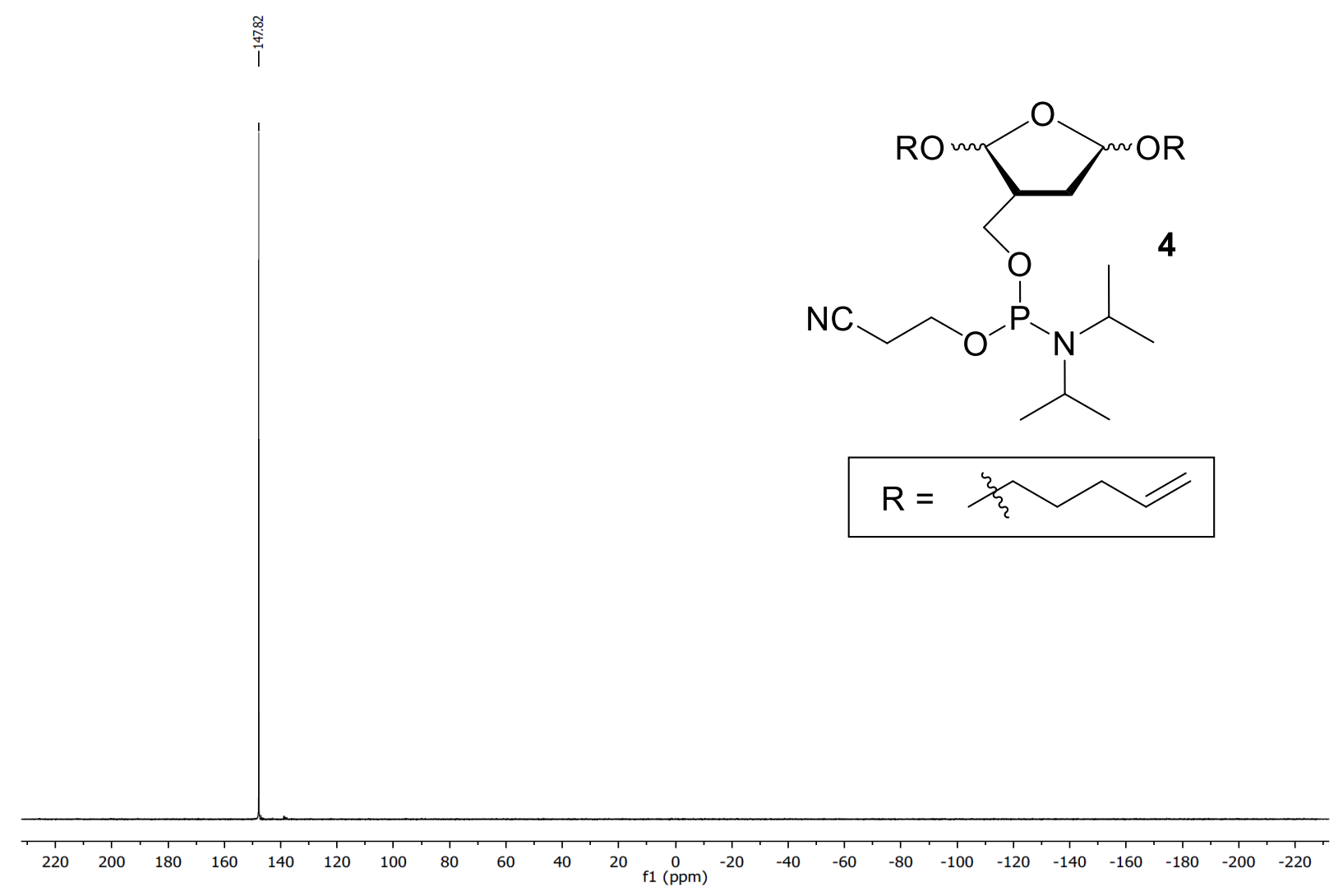

Figure S14. ${ }^{31} \mathrm{P}$ NMR spectra of 4

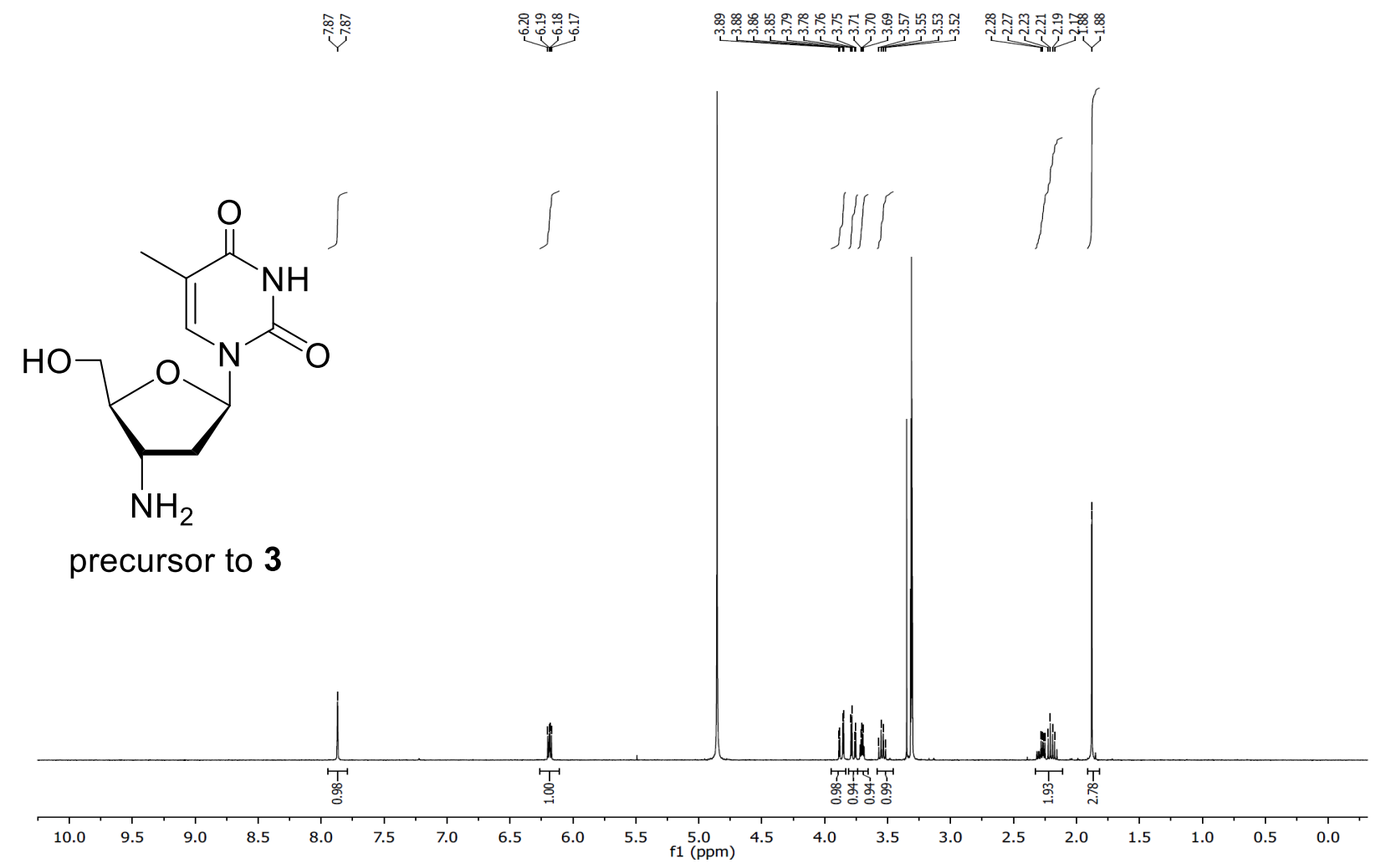

Figure S15. ${ }^{1} \mathrm{H}$ NMR spectra of precursor to 3 

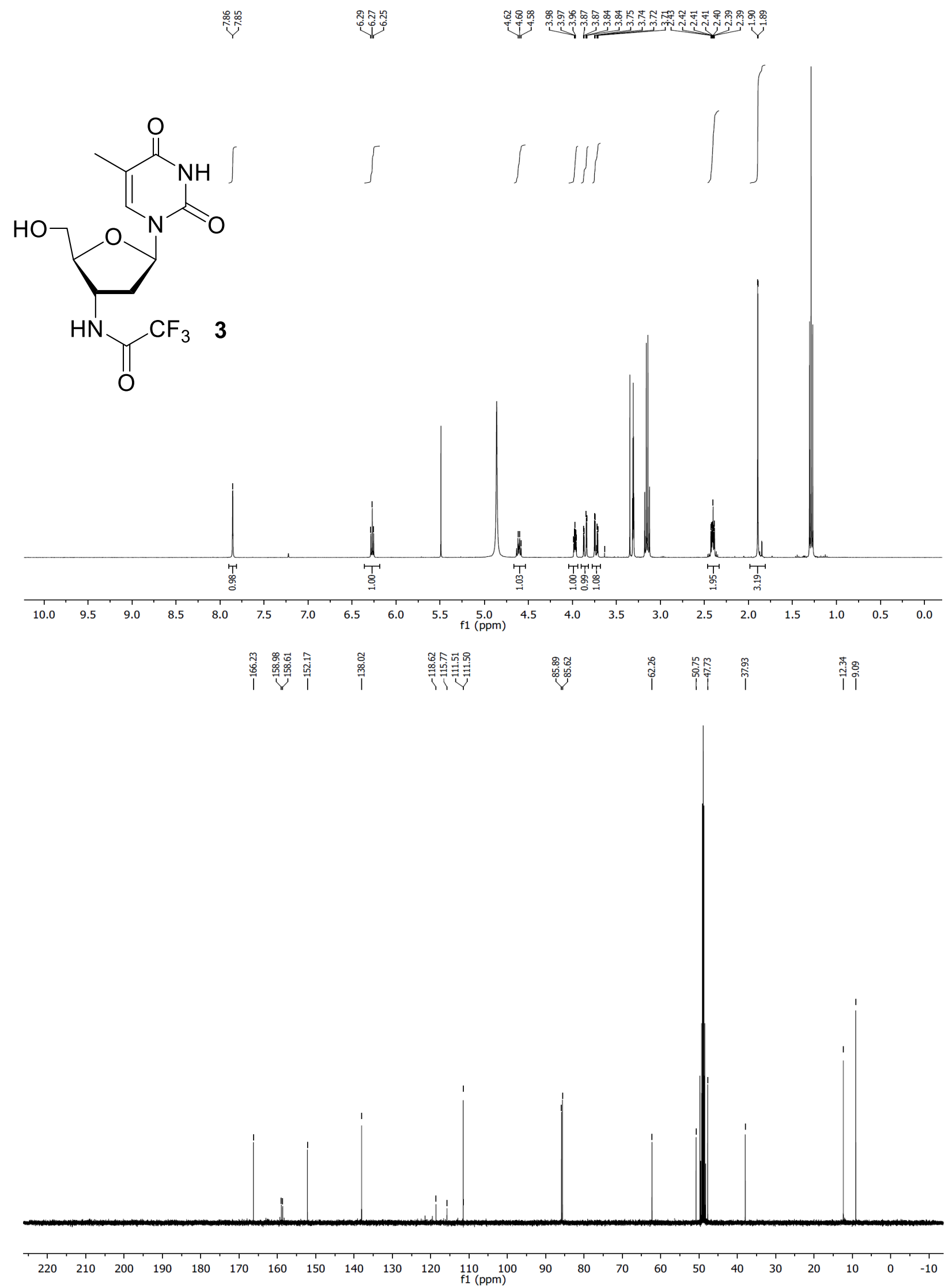

Figure S16. ${ }^{1} \mathrm{H}$ and ${ }^{13} \mathrm{C}$ NMR spectra of 3 

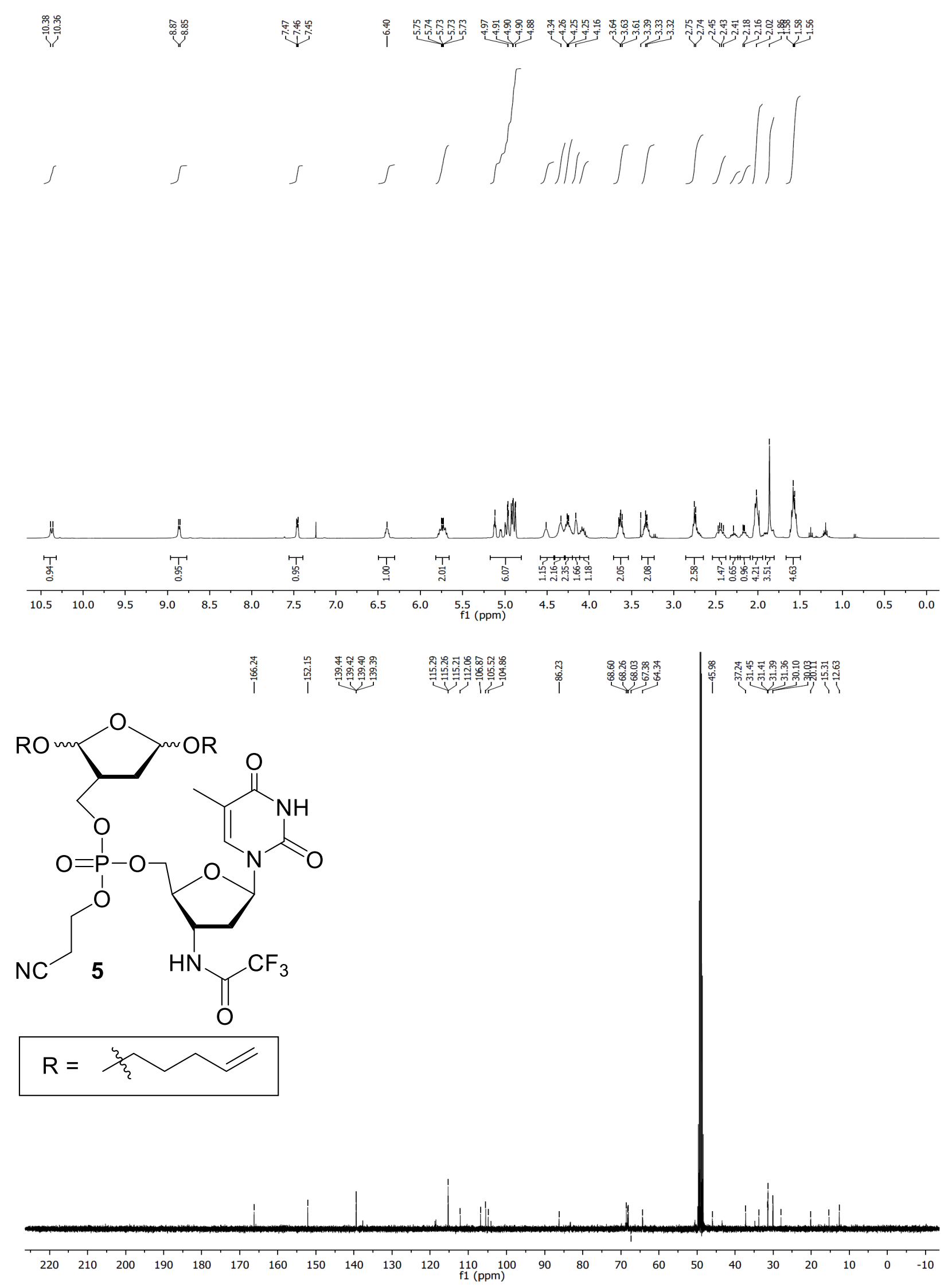

Figure S17. ${ }^{1} \mathrm{H}$ and ${ }^{13} \mathrm{C}$ NMR spectra of 5 

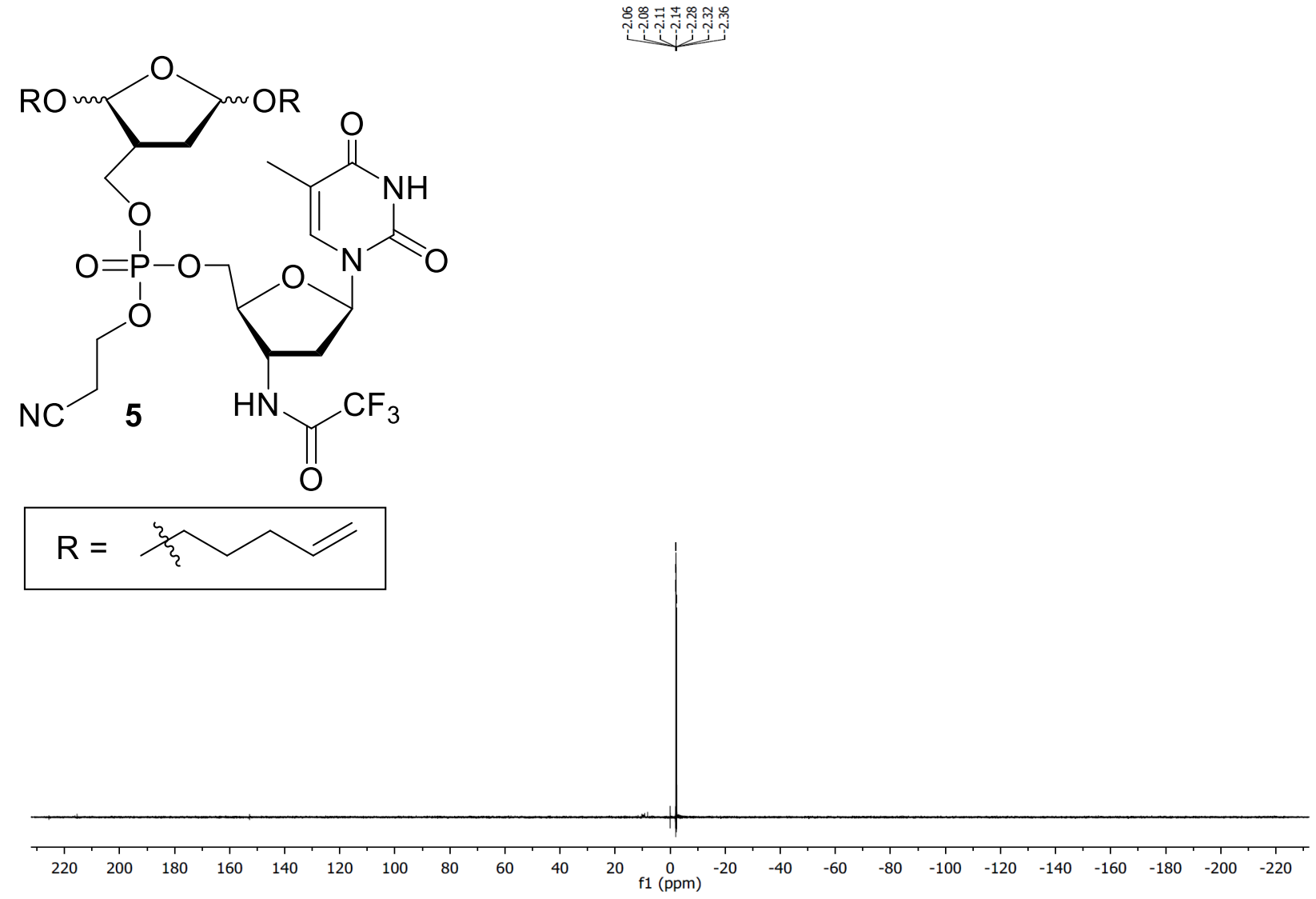

Figure S18. ${ }^{31} \mathrm{P}$ NMR spectra of 5 


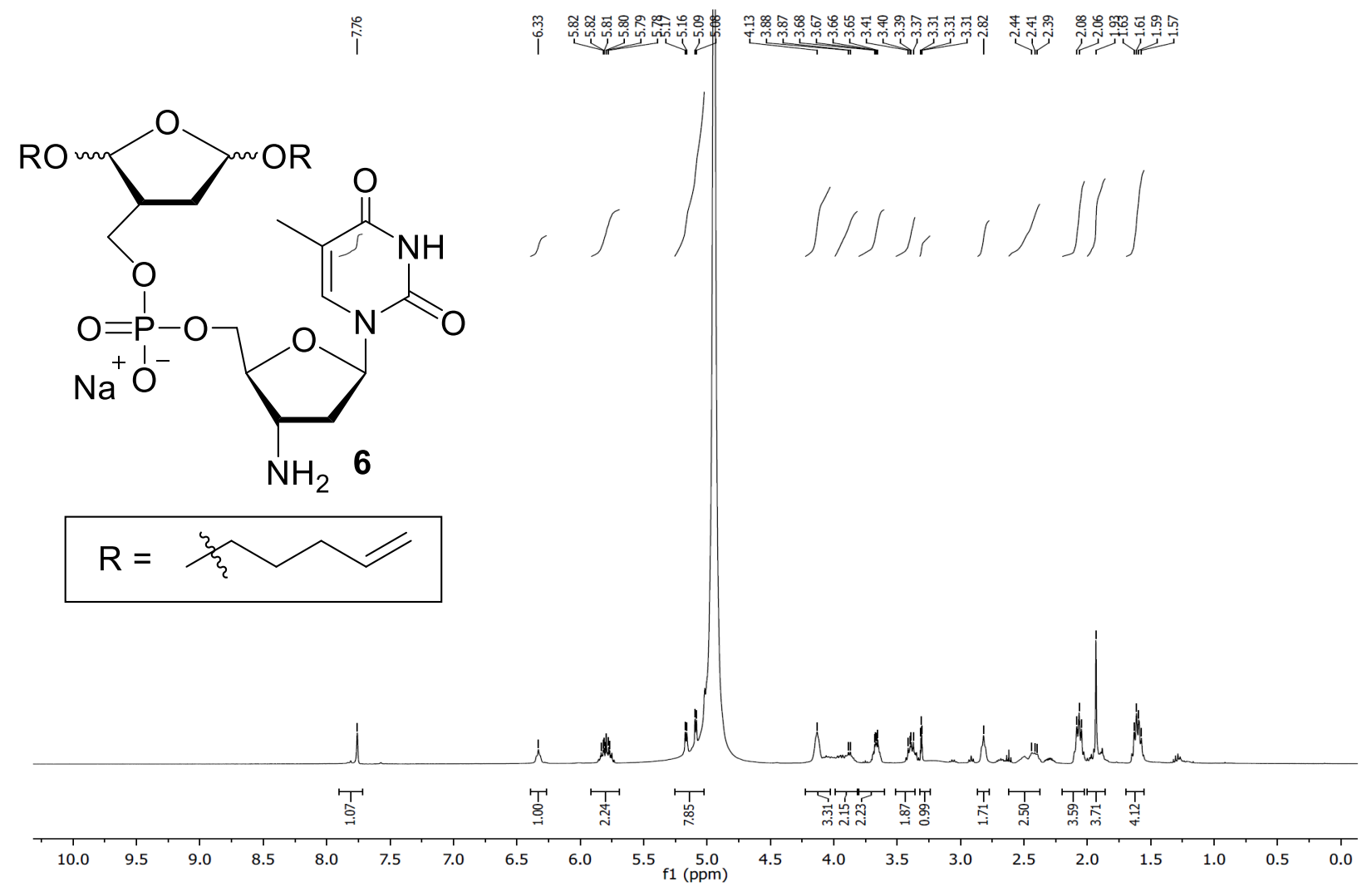

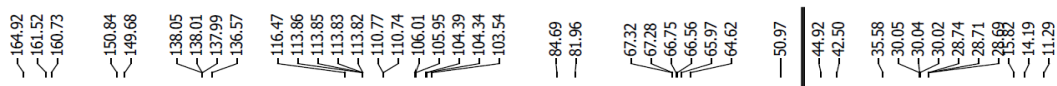

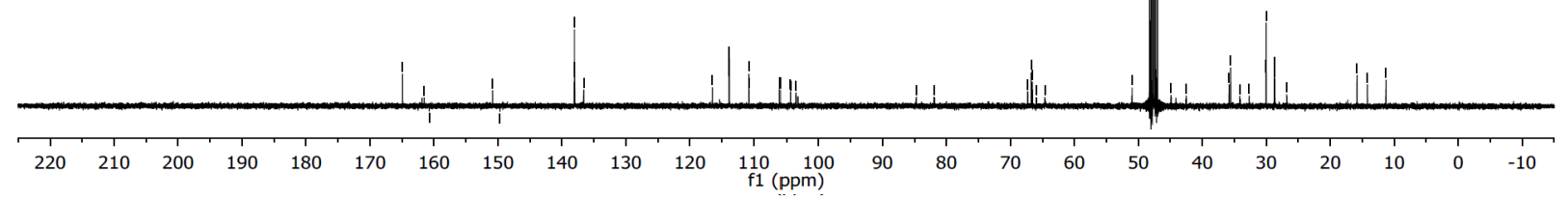

Figure S19. ${ }^{1} \mathrm{H}$ and ${ }^{13} \mathrm{C}$ NMR spectra of 6 


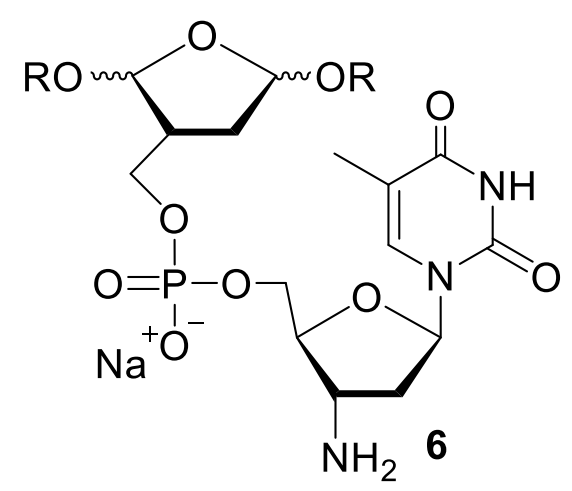

$$
\mathrm{R}=\xi_{\xi}
$$

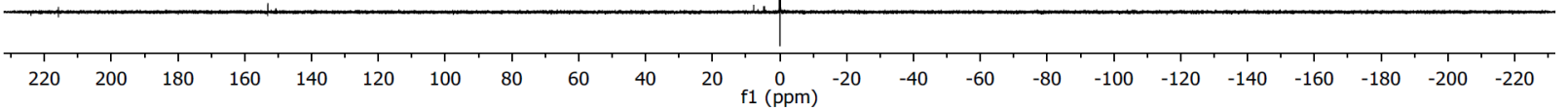

Figure S20. ${ }^{31} \mathrm{P}$ NMR spectra of 6 

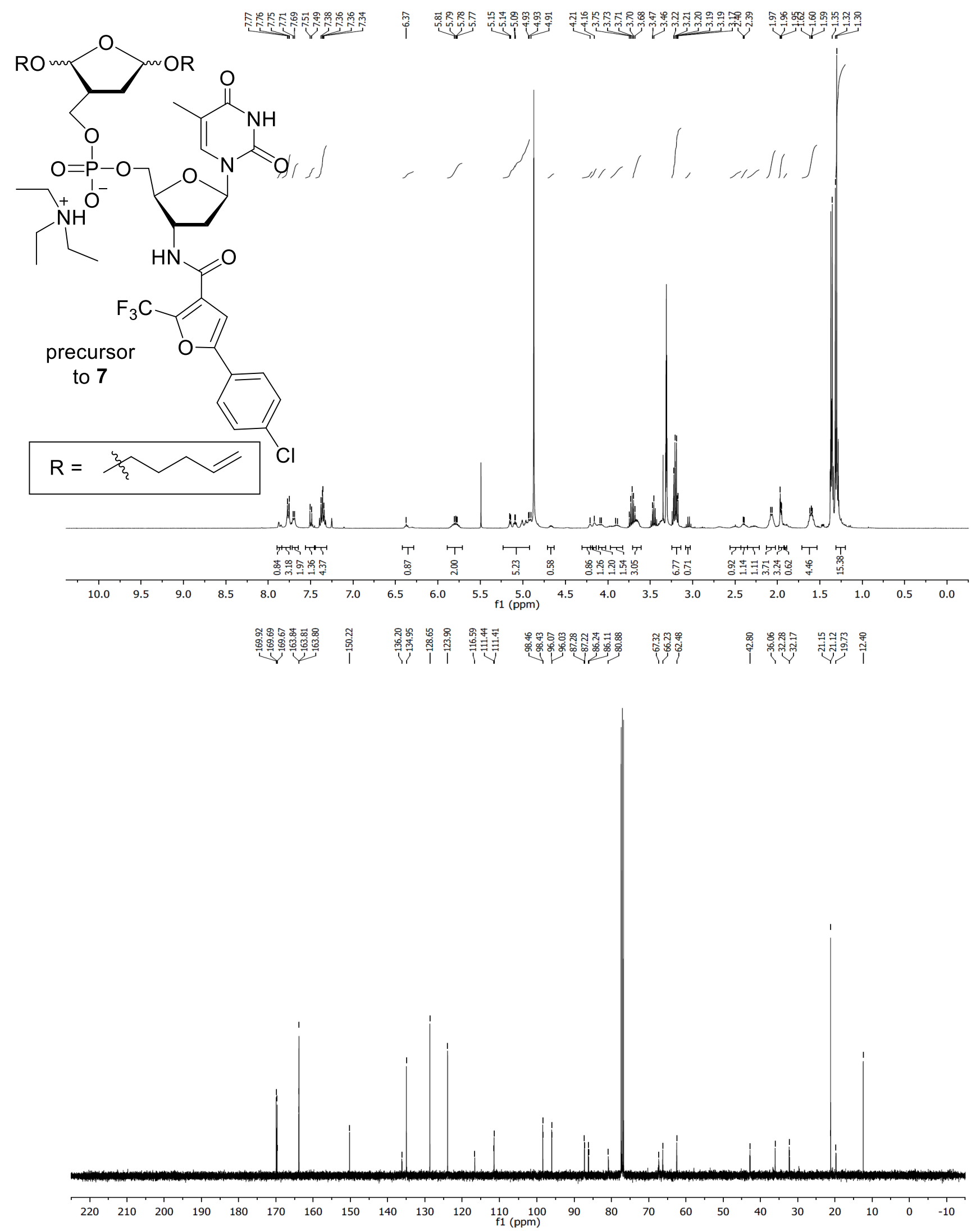

Figure S21. ${ }^{1} \mathrm{H}$ and ${ }^{13} \mathrm{C}$ NMR spectra of precursor to 7 

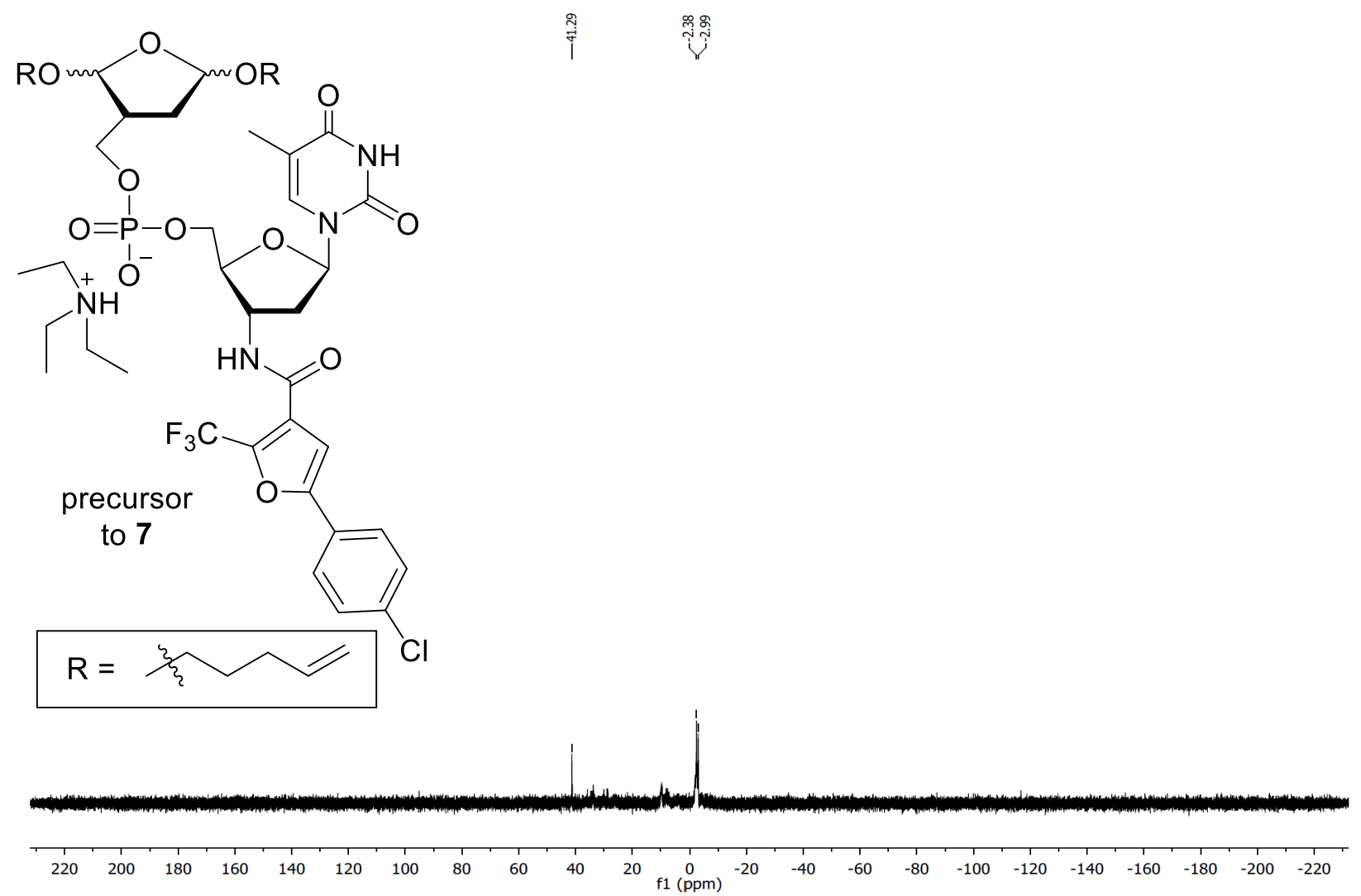

Figure S22. ${ }^{31} \mathrm{P}$ NMR spectra of precursor to 7 

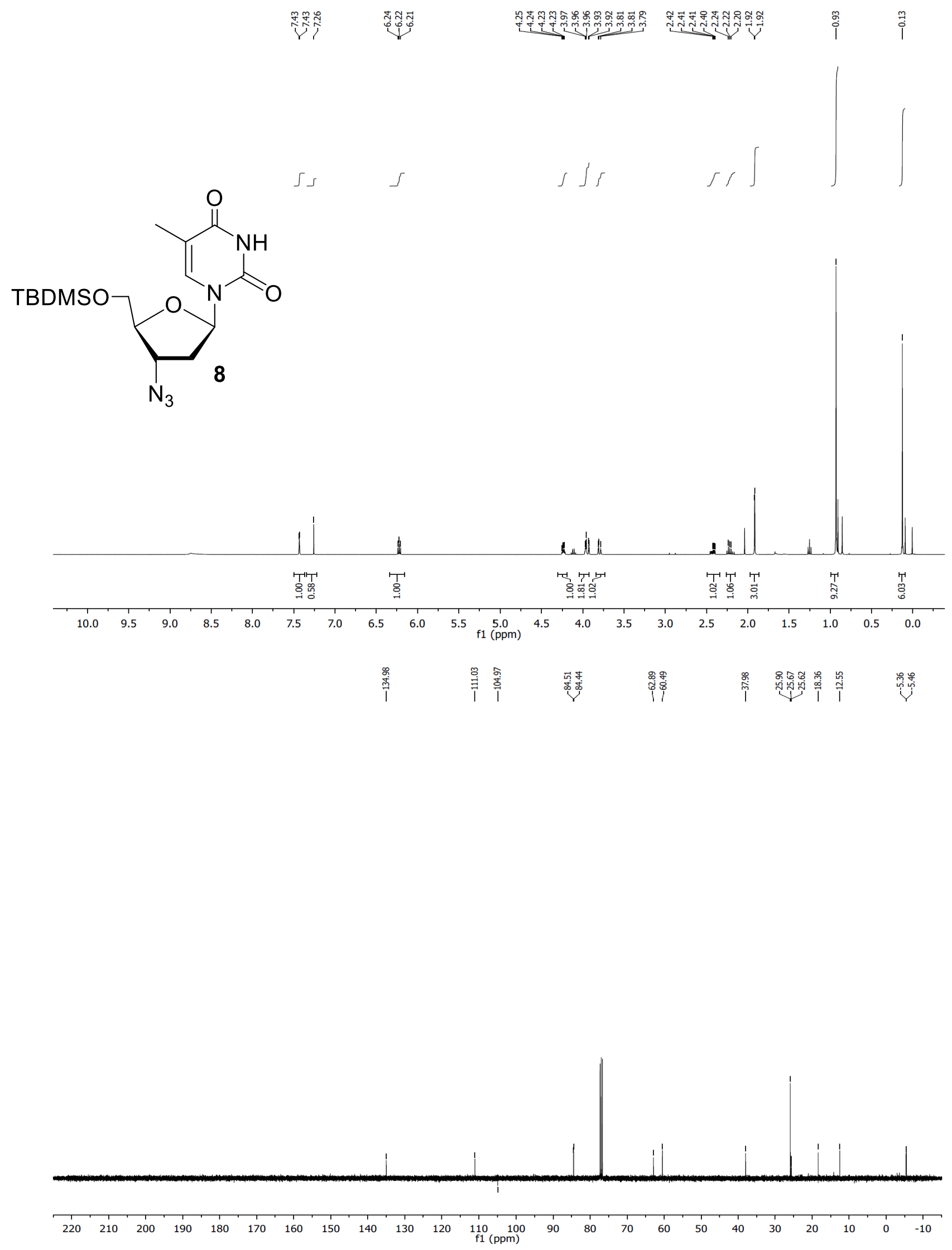

Figure S23. ${ }^{1} \mathrm{H}$ and ${ }^{13} \mathrm{C}$ NMR spectra of 8 

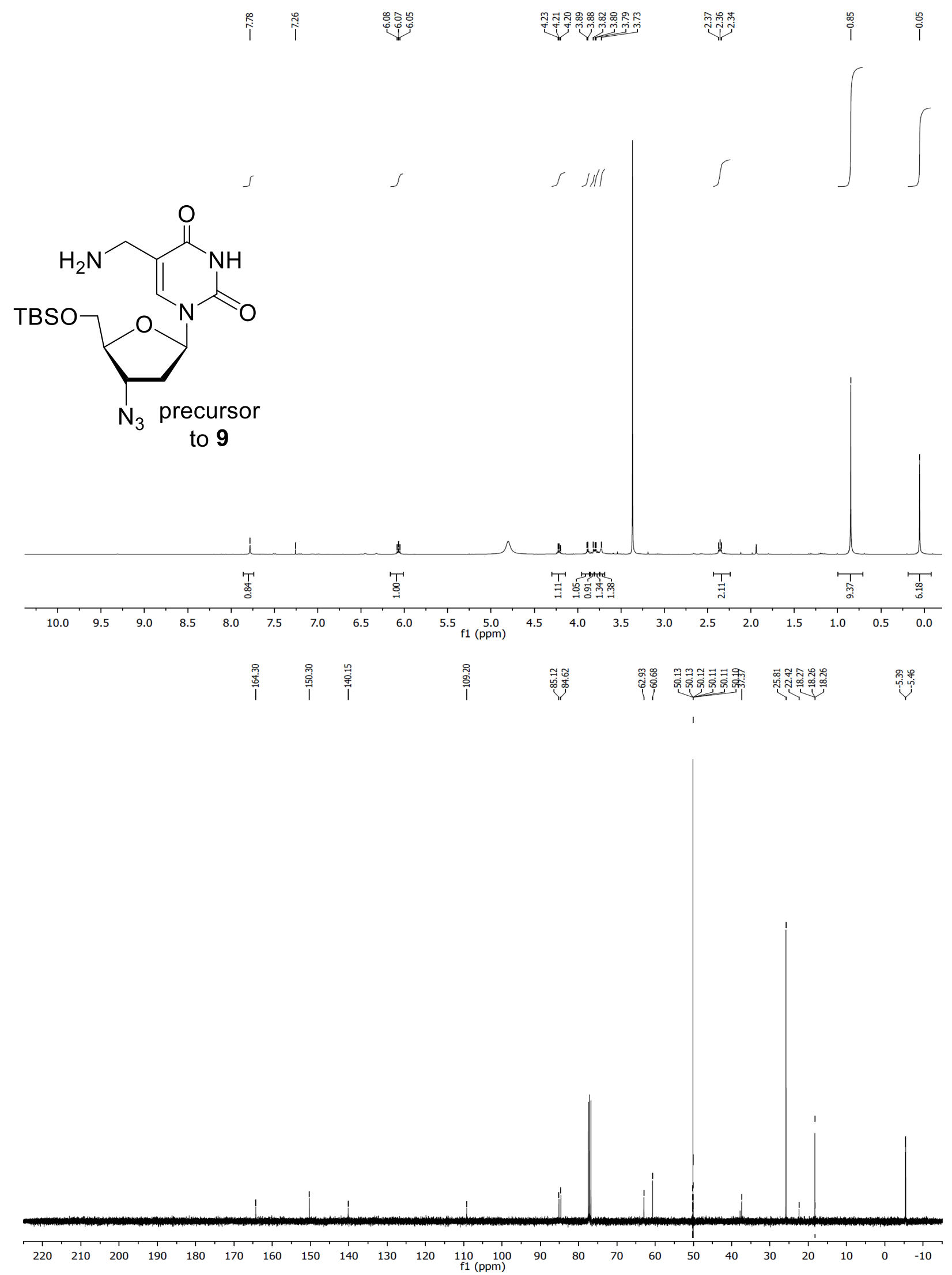

Figure S24. ${ }^{1} \mathrm{H}$ and ${ }^{13} \mathrm{C}$ NMR spectra of precursor to 9 


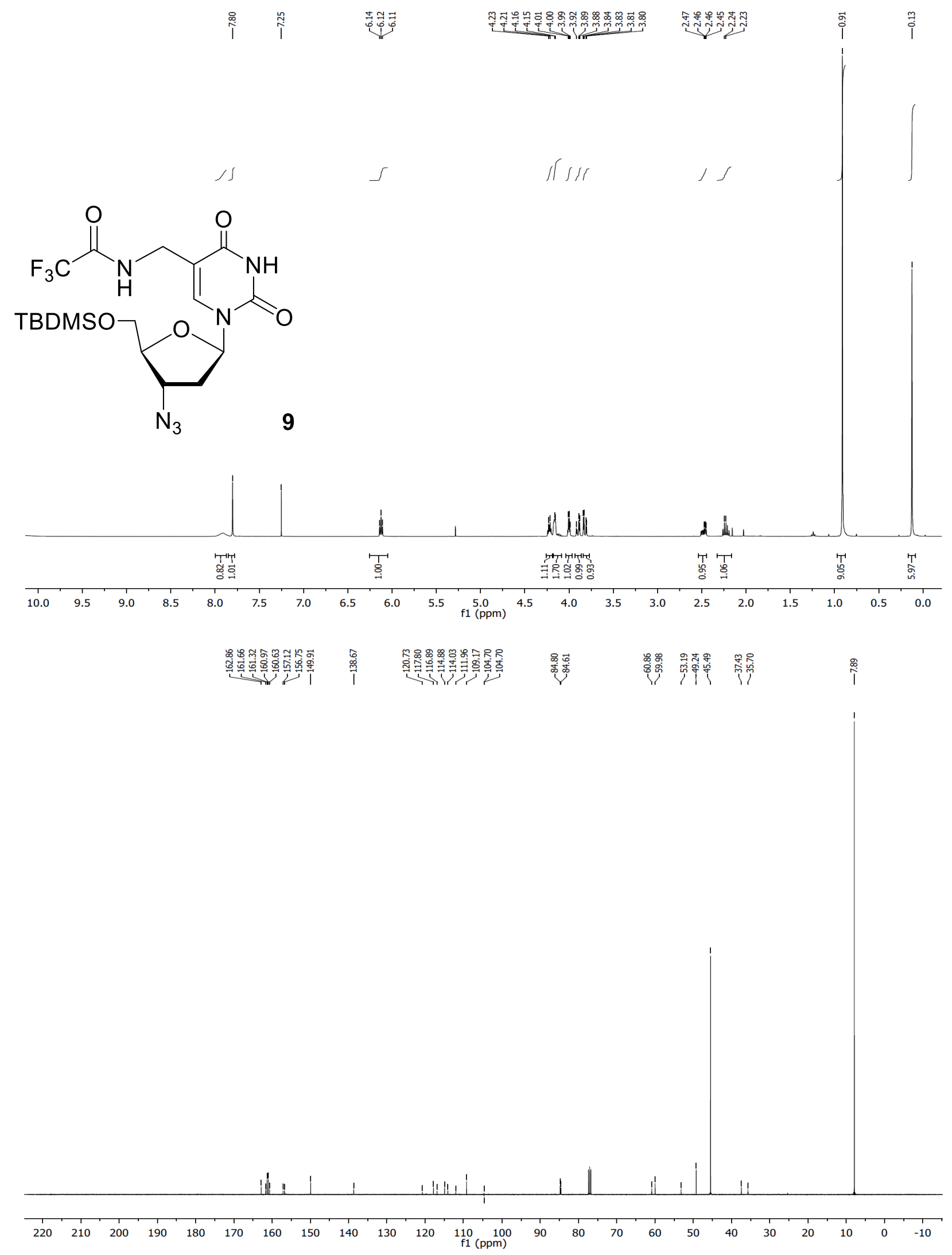

Figure S25. ${ }^{1} \mathrm{H}$ and ${ }^{13} \mathrm{C}$ NMR spectra of 9 


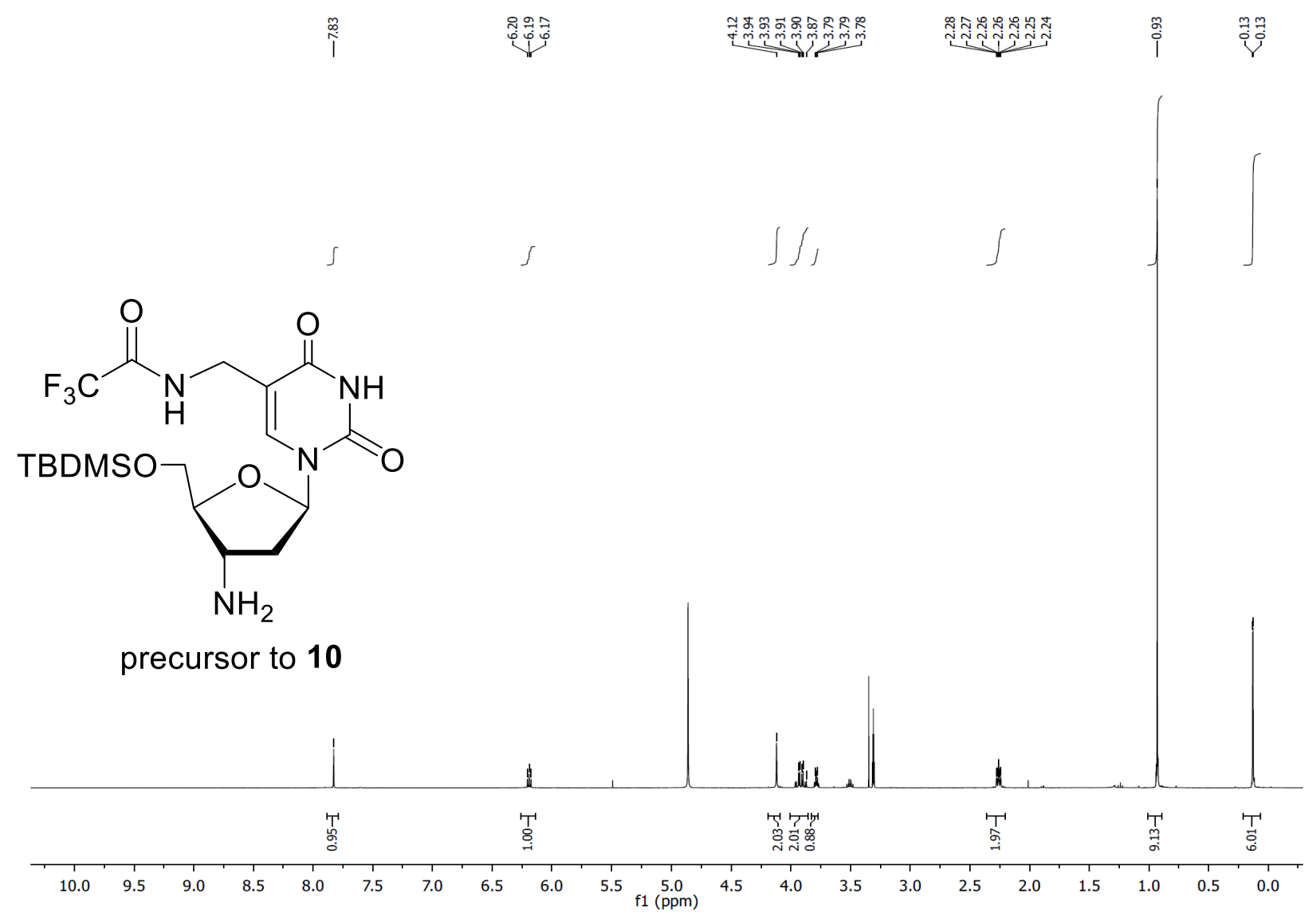

Figure S26. ${ }^{1} \mathrm{H}$ NMR spectra of precursor to $\mathbf{1 0}$ 


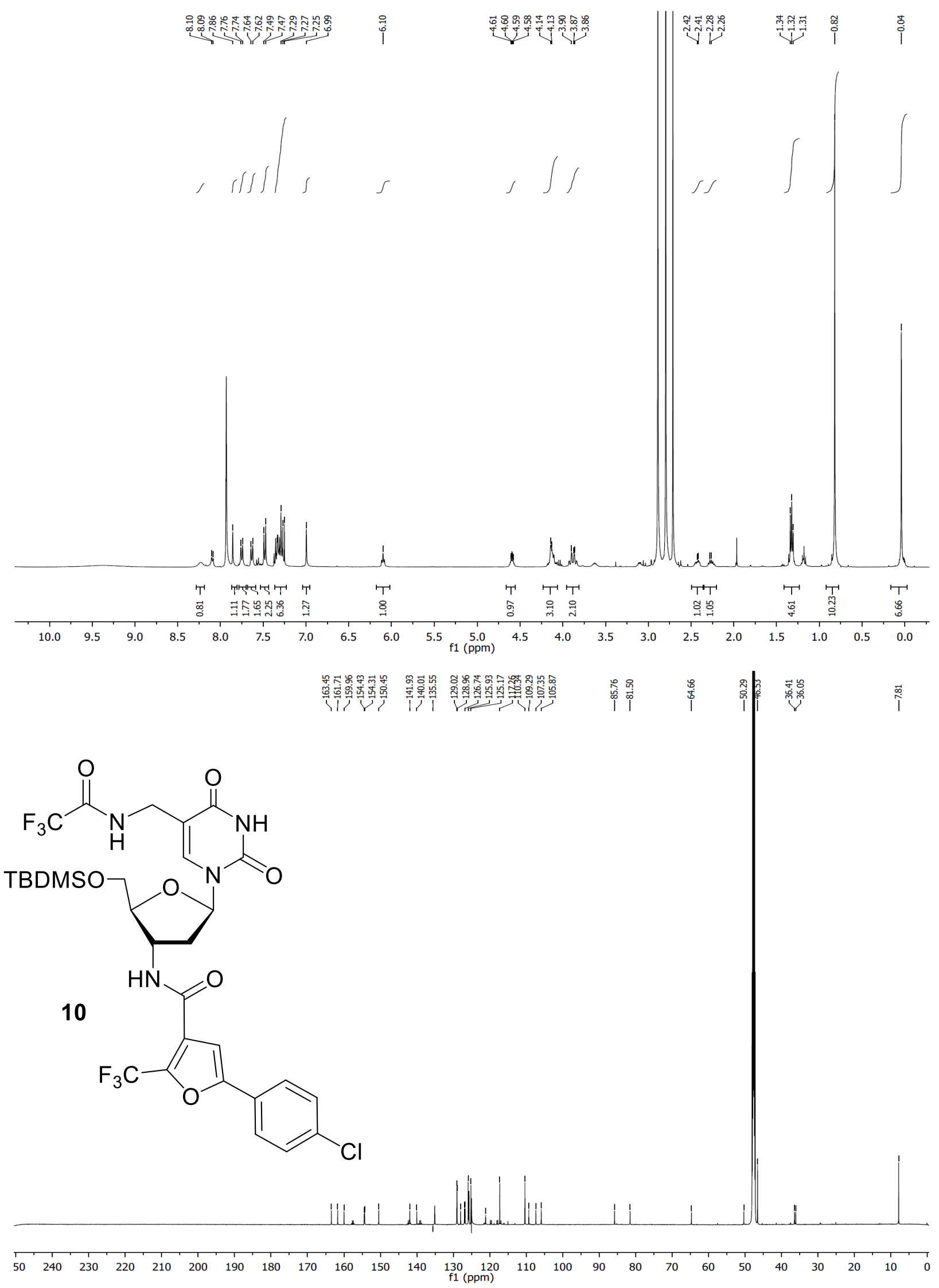

Figure S27. ${ }^{1} \mathrm{H}$ and ${ }^{13} \mathrm{C}$ NMR spectra of $\mathbf{1 0}$ 


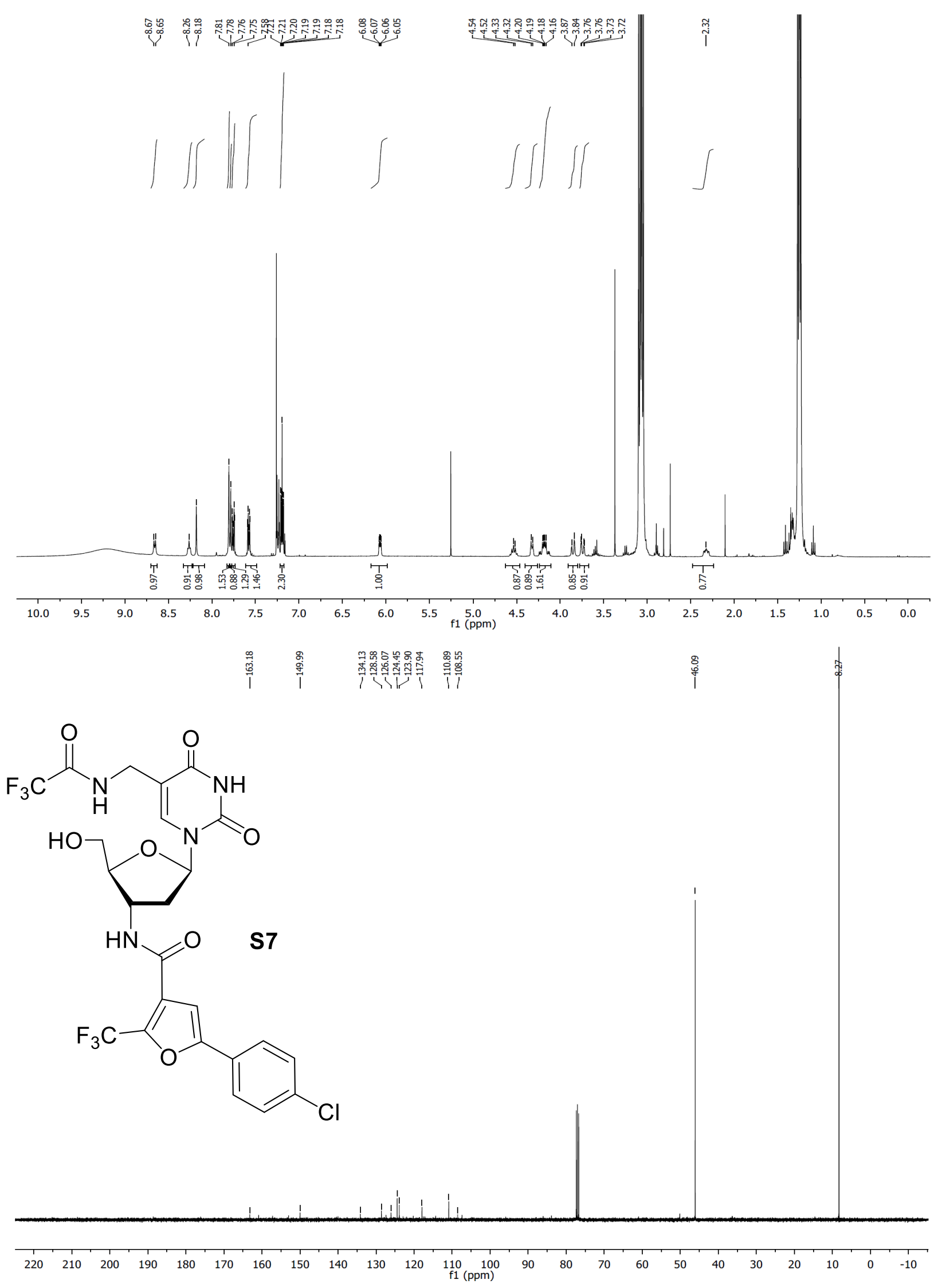

Figure S28. ${ }^{1} \mathrm{H}$ and ${ }^{13} \mathrm{C}$ NMR spectra of precursor to $\mathbf{S 7}$ 


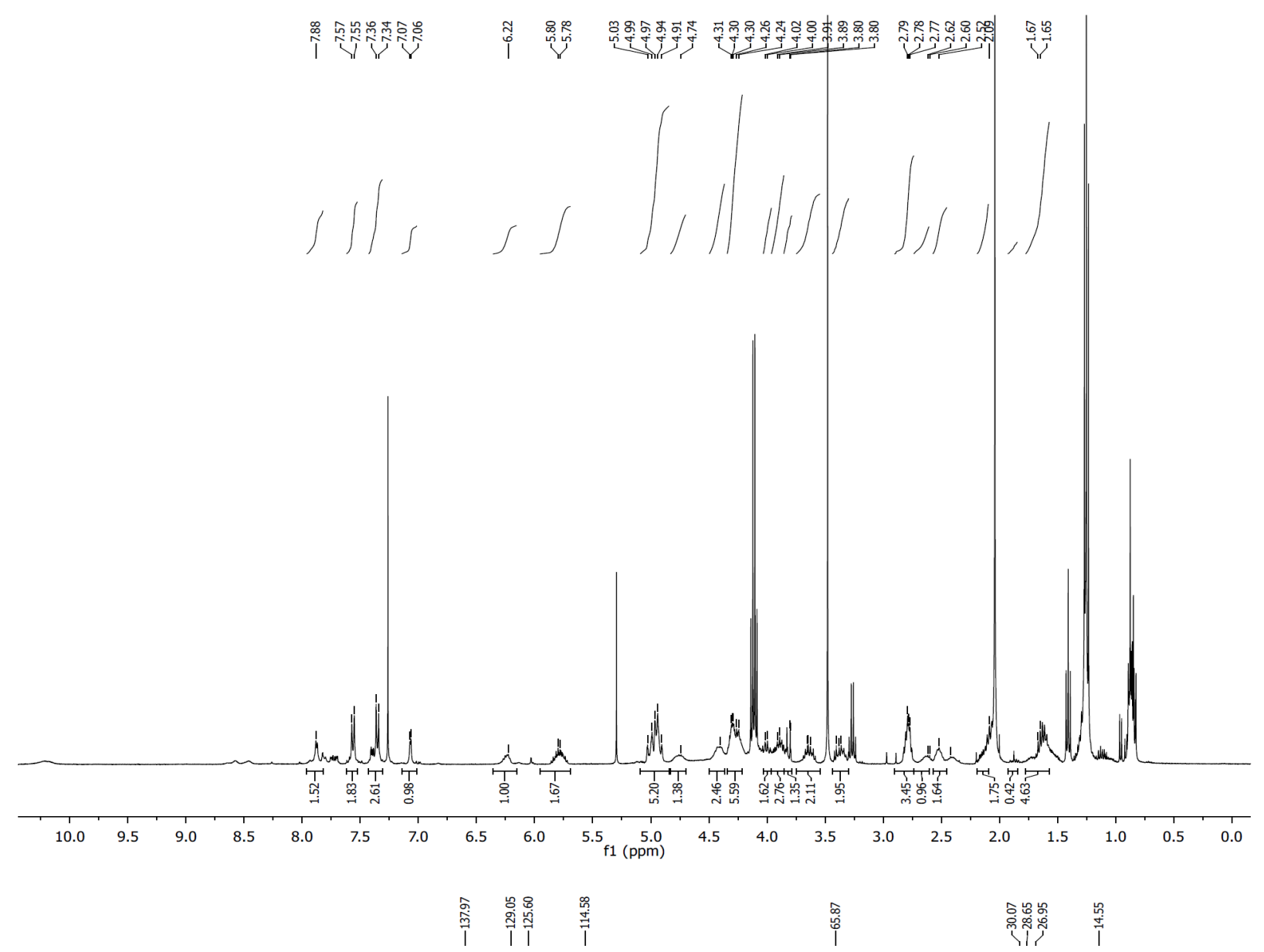

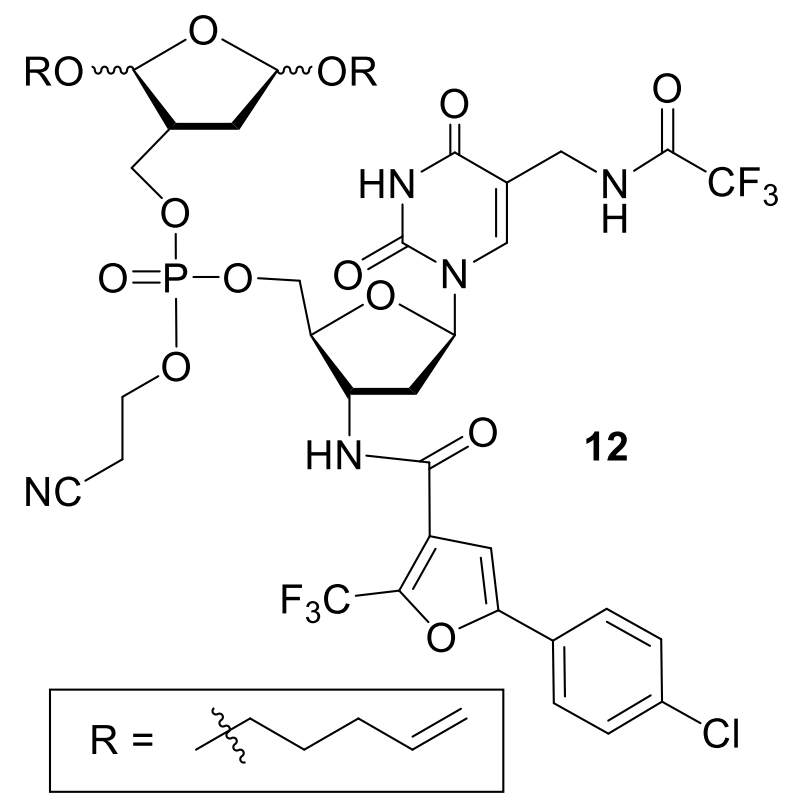

Figure S29. ${ }^{1} \mathrm{H}$ and ${ }^{13} \mathrm{C}$ NMR spectra of 12 

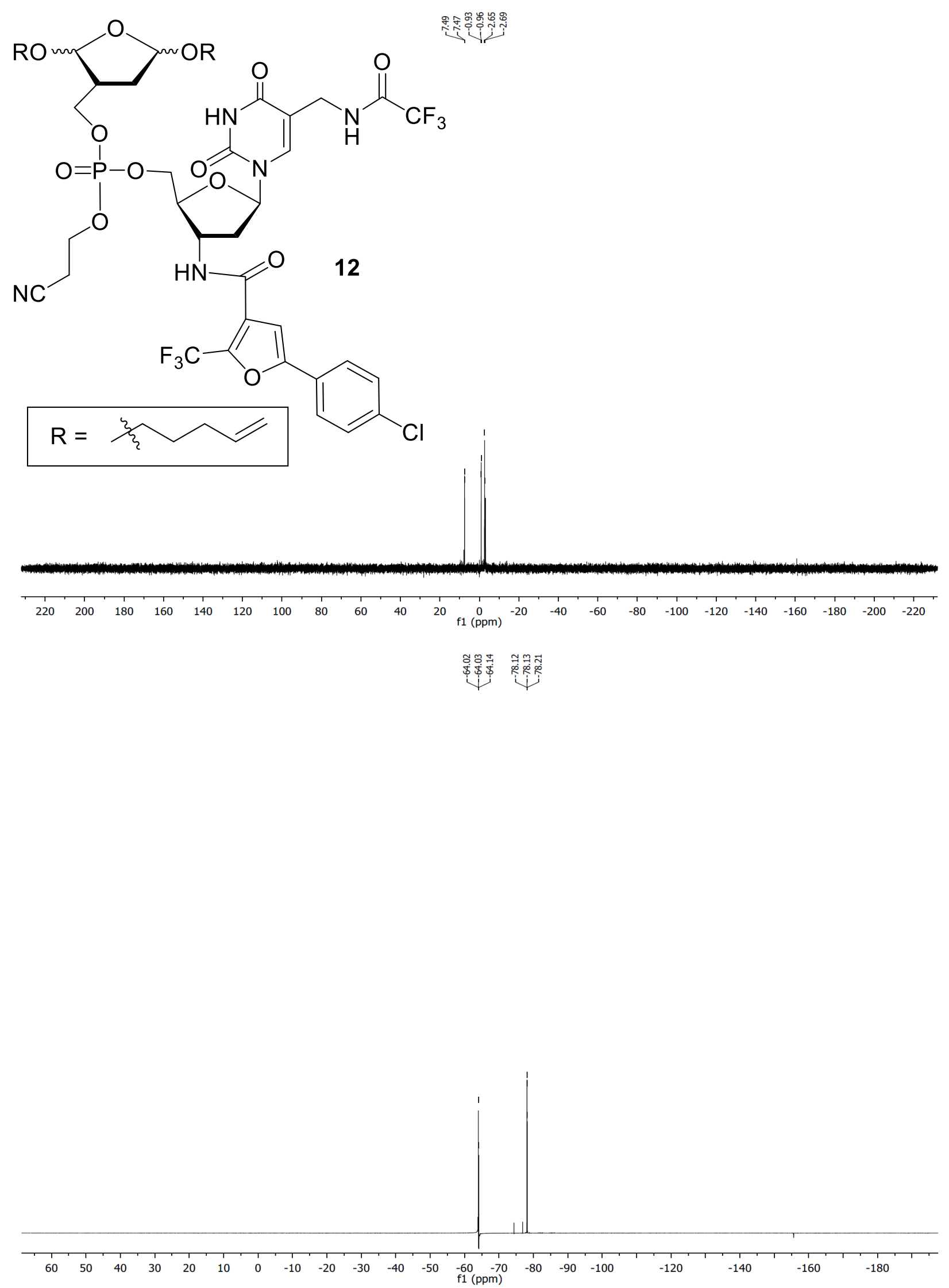

Figure S30. ${ }^{31} \mathrm{P}$ and ${ }^{19} \mathrm{~F}$ NMR spectra of 12 


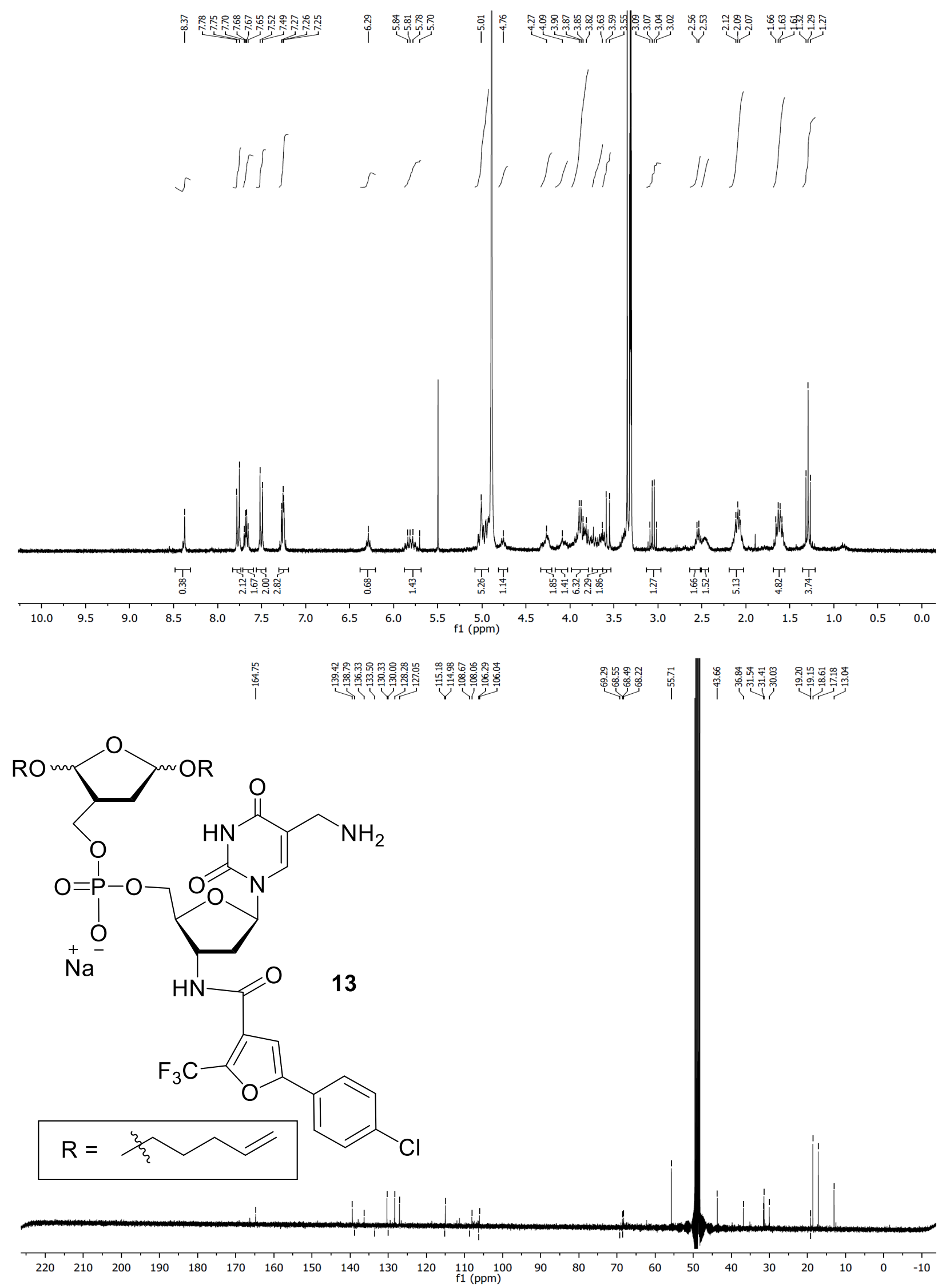

Figure S31. ${ }^{1} \mathrm{H}$ and ${ }^{13} \mathrm{C}$ NMR spectra of $\mathbf{1 3}$ 

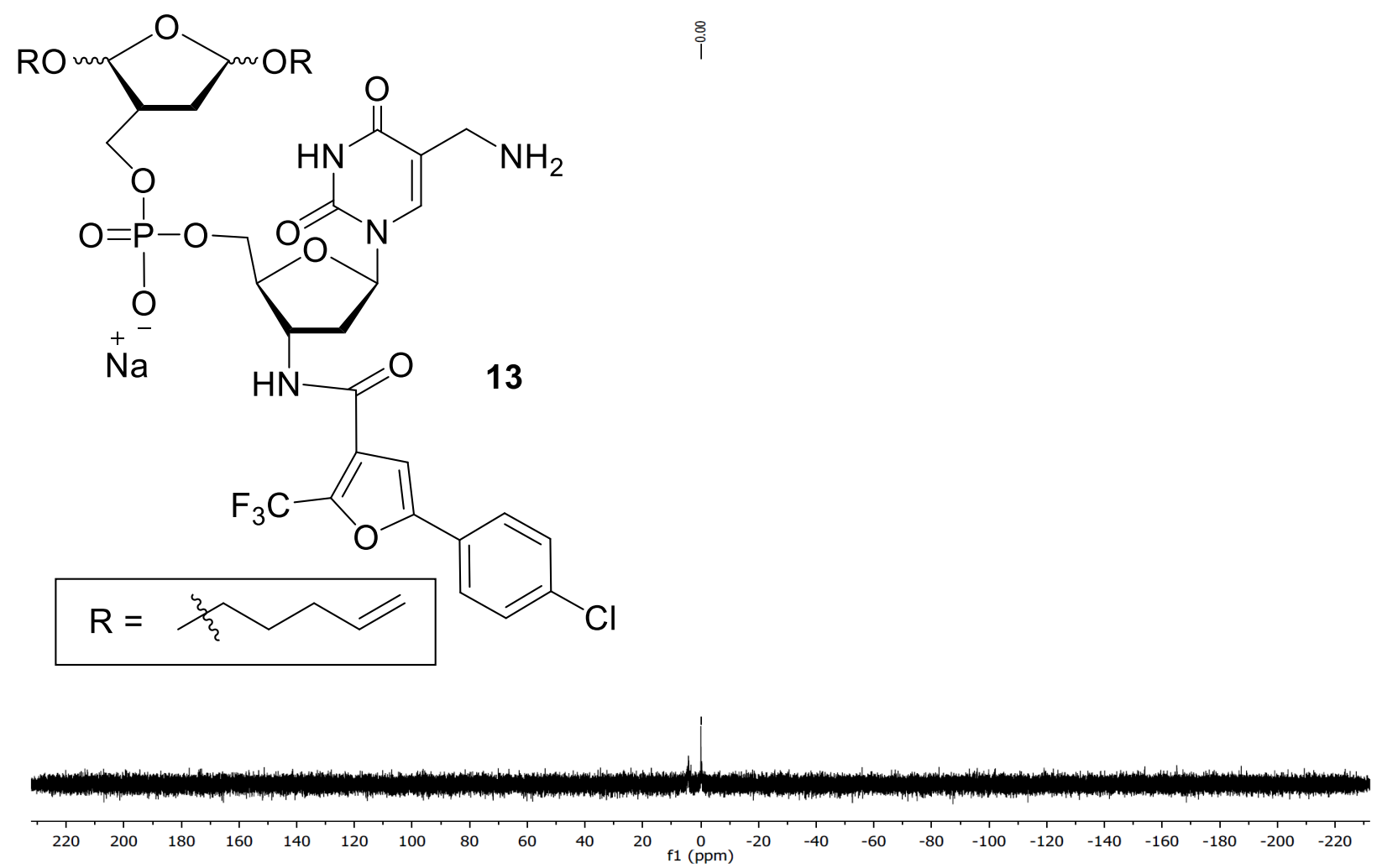

Figure S32. ${ }^{31} \mathrm{P}$ NMR spectra of $\mathbf{1 3}$

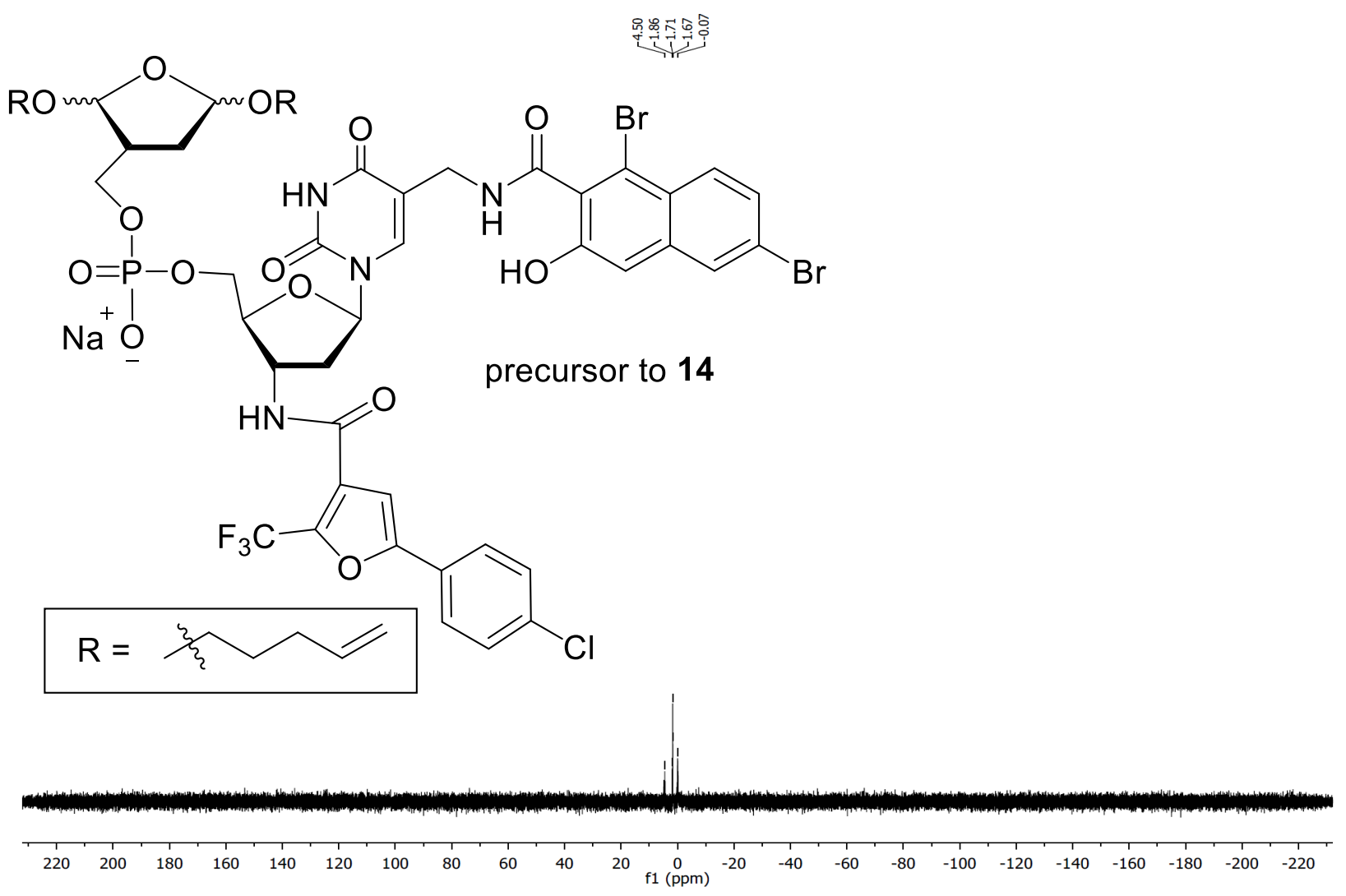

Figure S33. ${ }^{31} \mathrm{P}$ NMR spectra of precursor to 14 

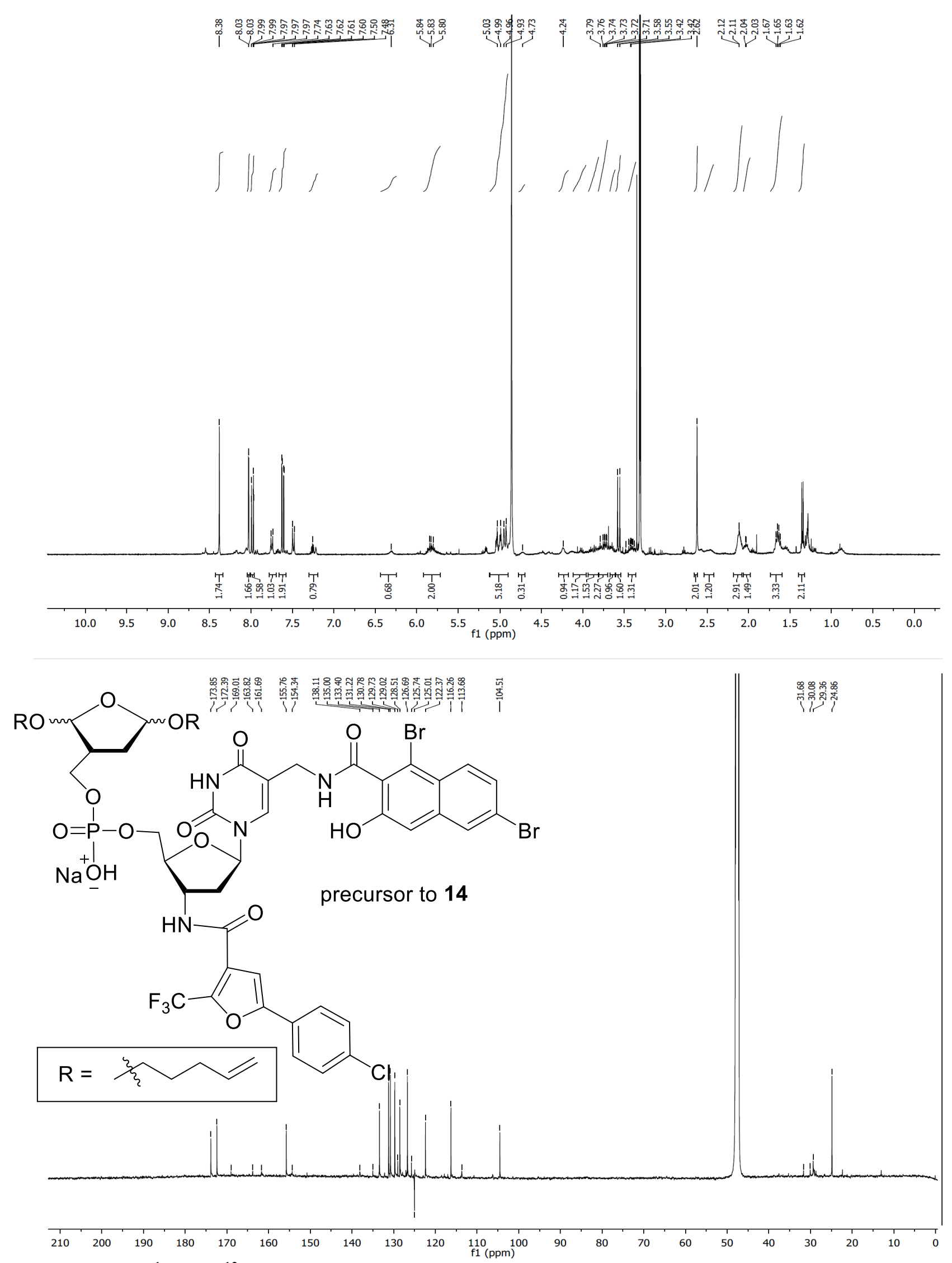

Figure S34. ${ }^{1} \mathrm{H}$ and ${ }^{13} \mathrm{C}$ NMR spectra of precursor to 14 


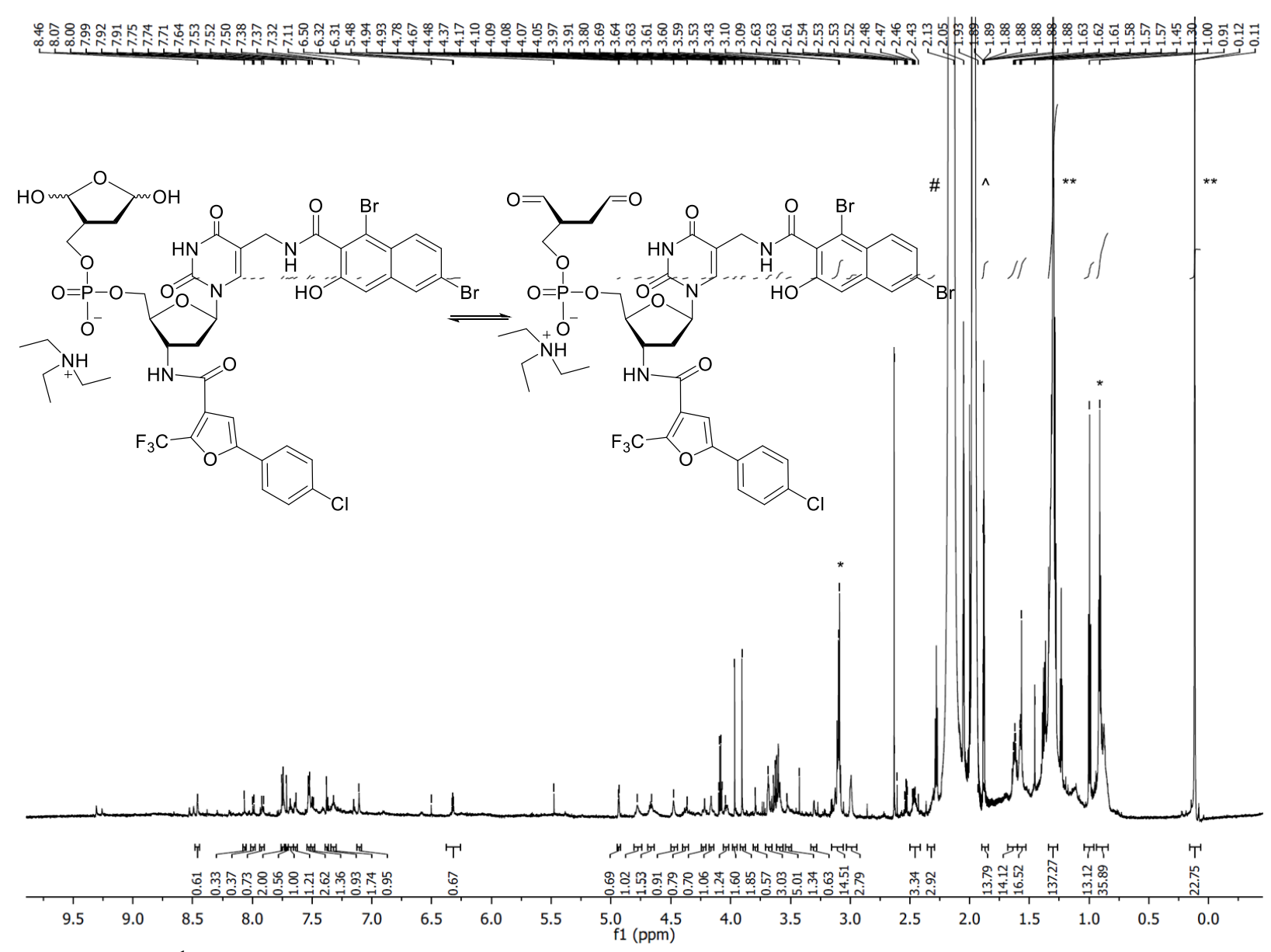

Figure S35. ${ }^{1} \mathrm{H}$ NMR spectra of 14

$\wedge \mathrm{CD}_{3} \mathrm{CN}, \# \mathrm{H}_{2} \mathrm{O}$, * triethyl ammonium salt, ** impurity from HPLC purification 

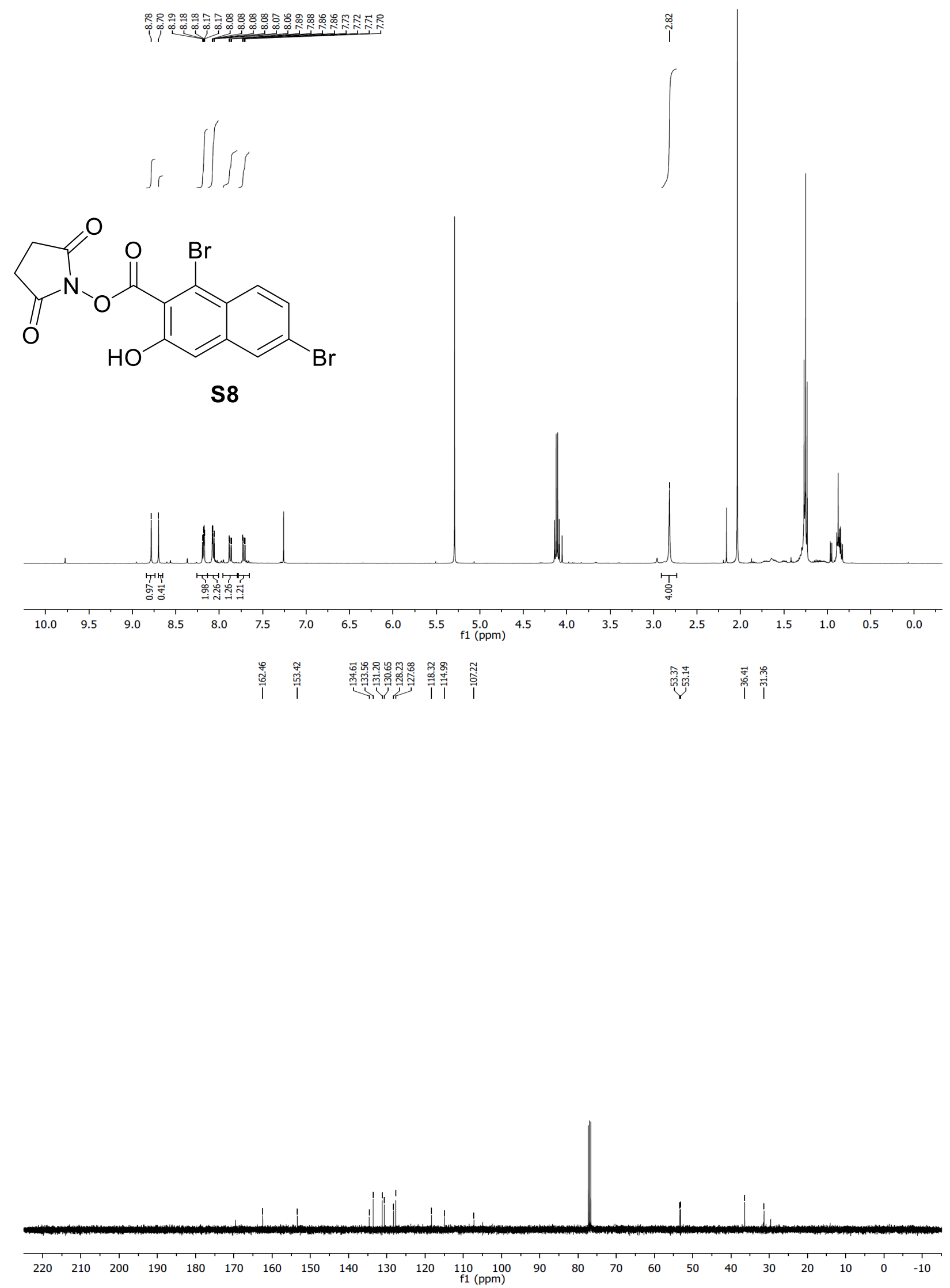

Figure S36. ${ }^{1} \mathrm{H}$ and ${ }^{13} \mathrm{C}$ NMR spectra of $\mathbf{S 8}$ 

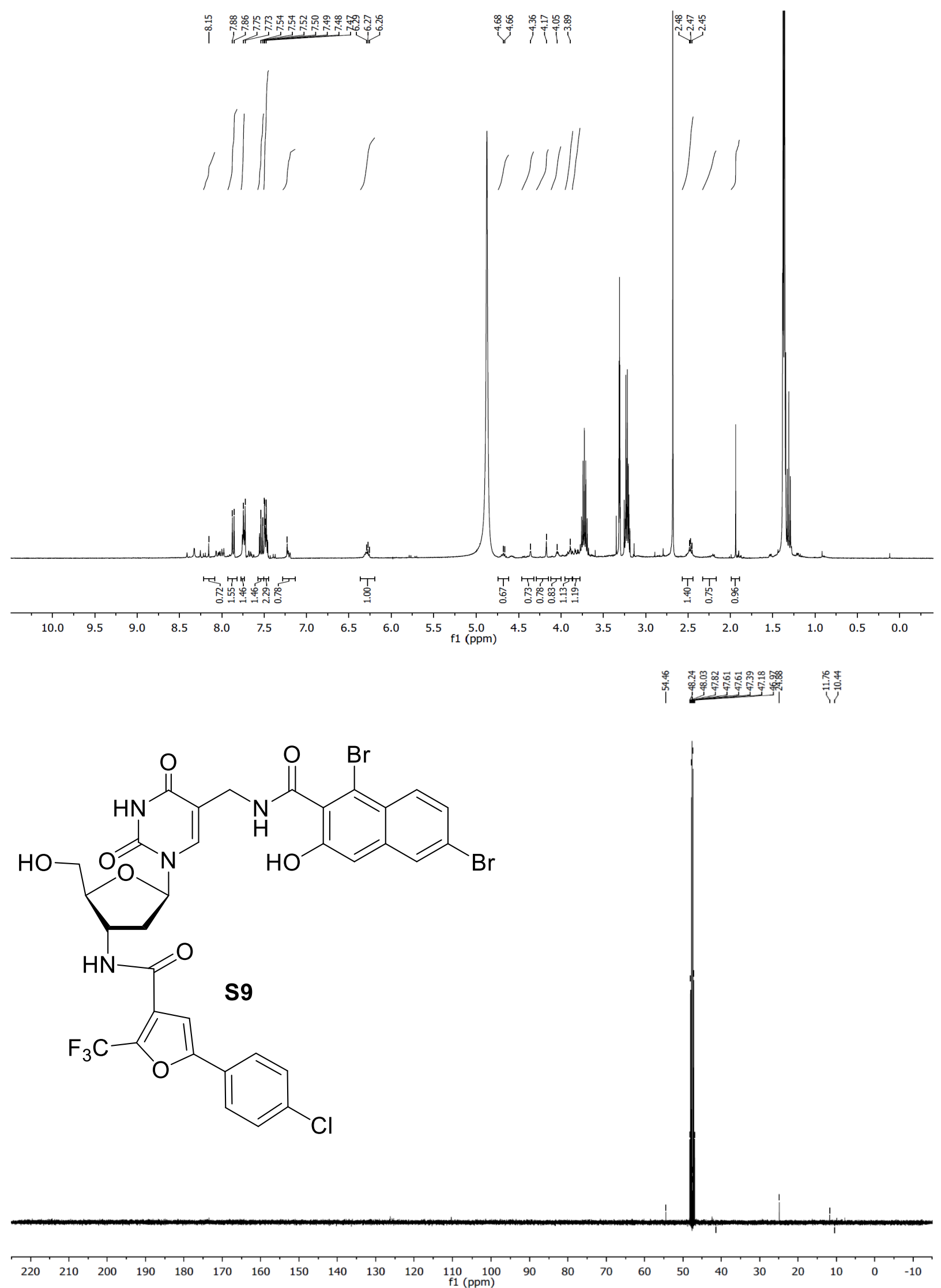

Figure S37. ${ }^{1} \mathrm{H}$ and ${ }^{13} \mathrm{C}$ NMR spectra of $\mathbf{S 9}$ 


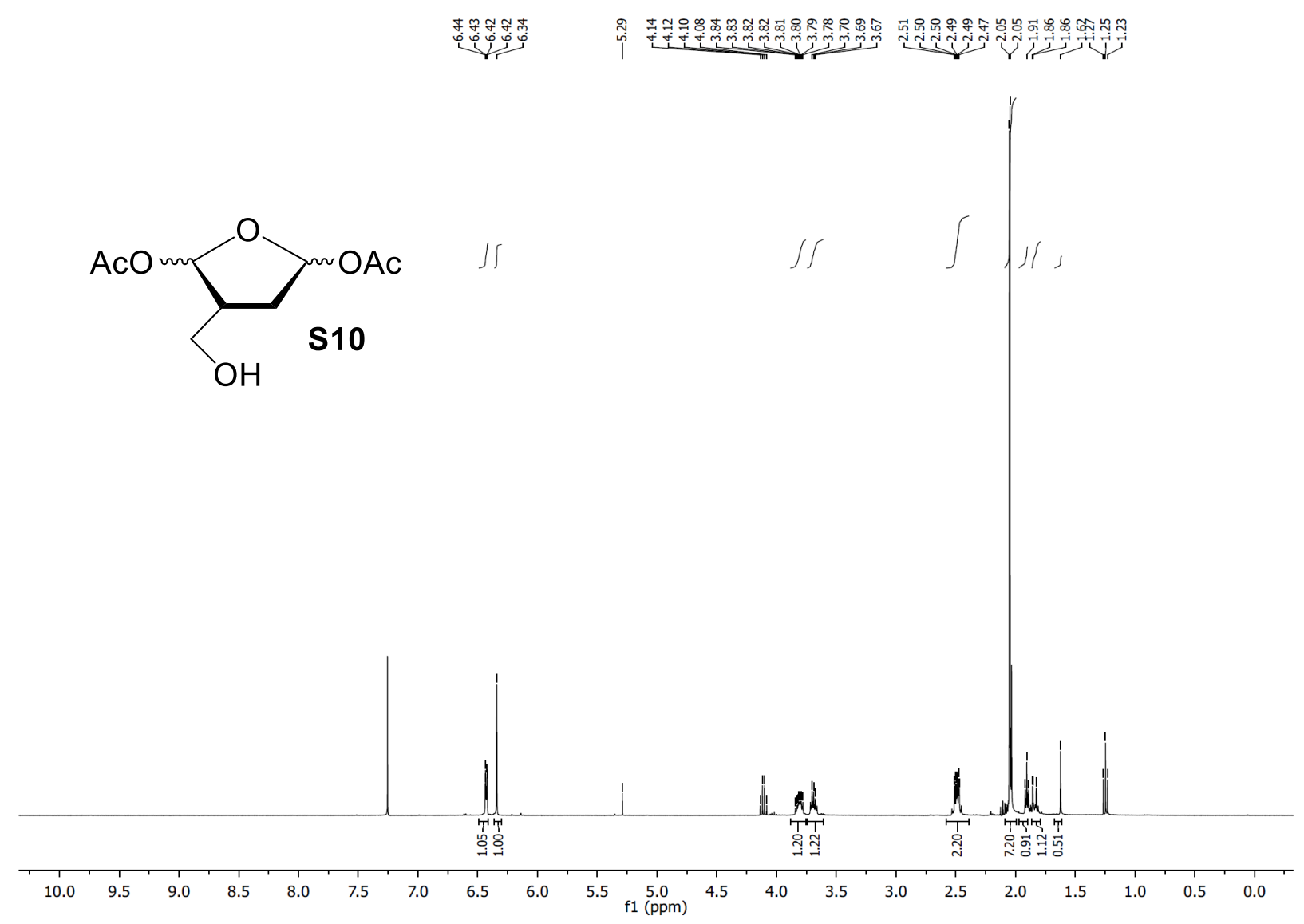

Figure S38. ${ }^{1} \mathrm{H}$ NMR spectra of $\mathbf{S 1 0}$ 

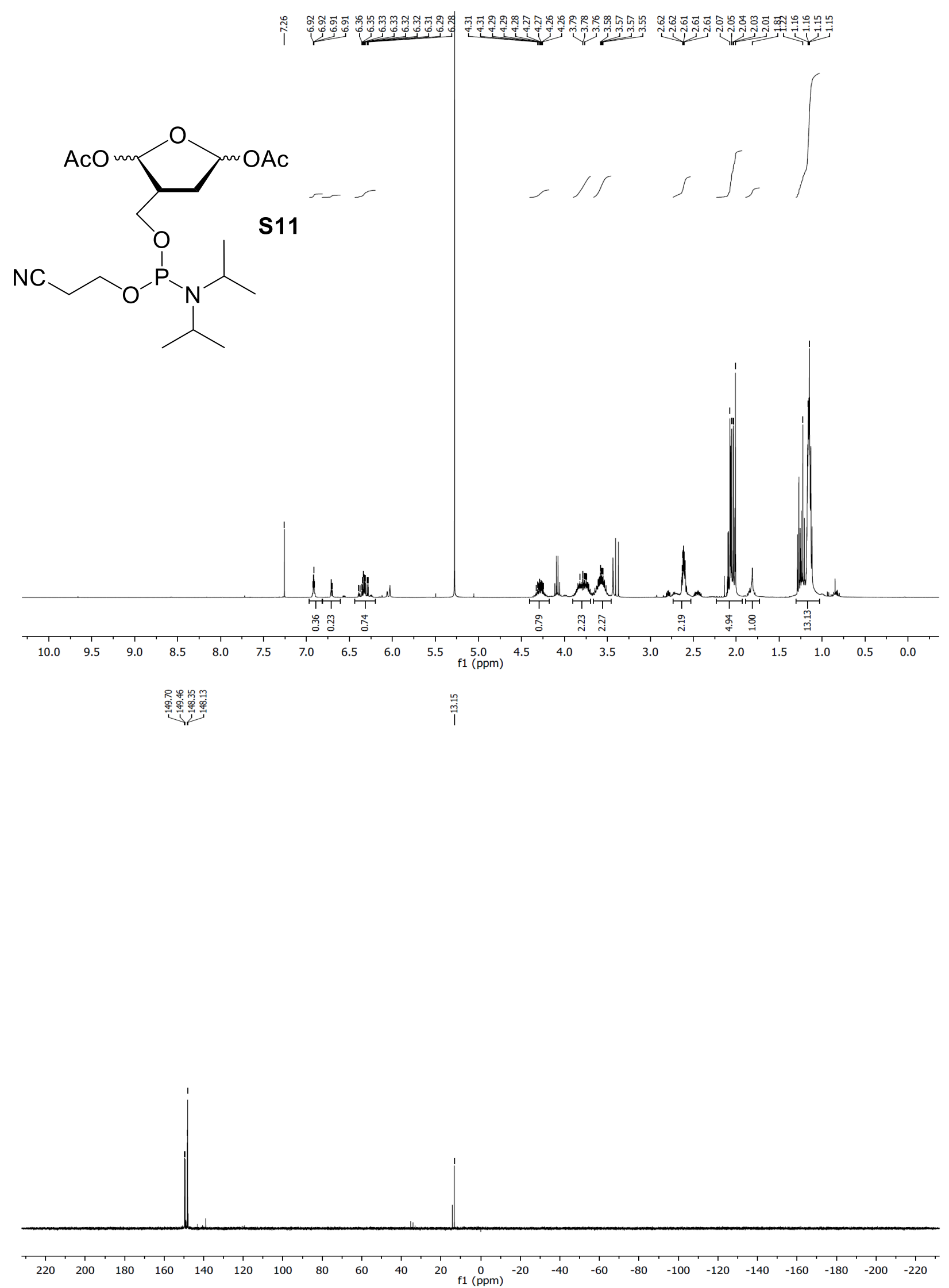

Figure S39. ${ }^{1} \mathrm{H}$ and ${ }^{31} \mathrm{P}$ NMR spectra of $\mathbf{S 1 1}$ 

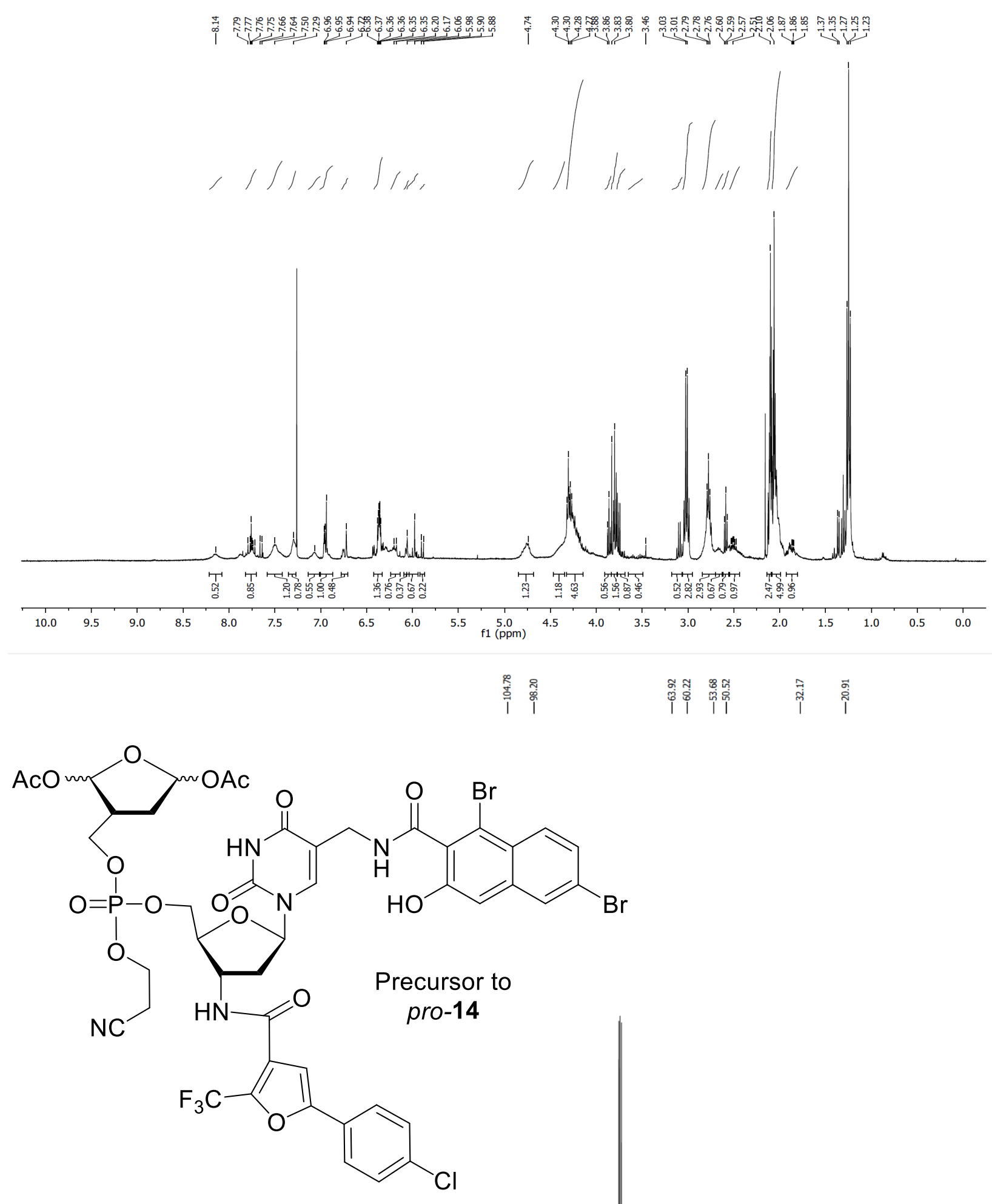

Figure S40. ${ }^{1} \mathrm{H}$ and ${ }^{13} \mathrm{C}$ NMR spectra of precursor to pro-14 


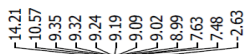

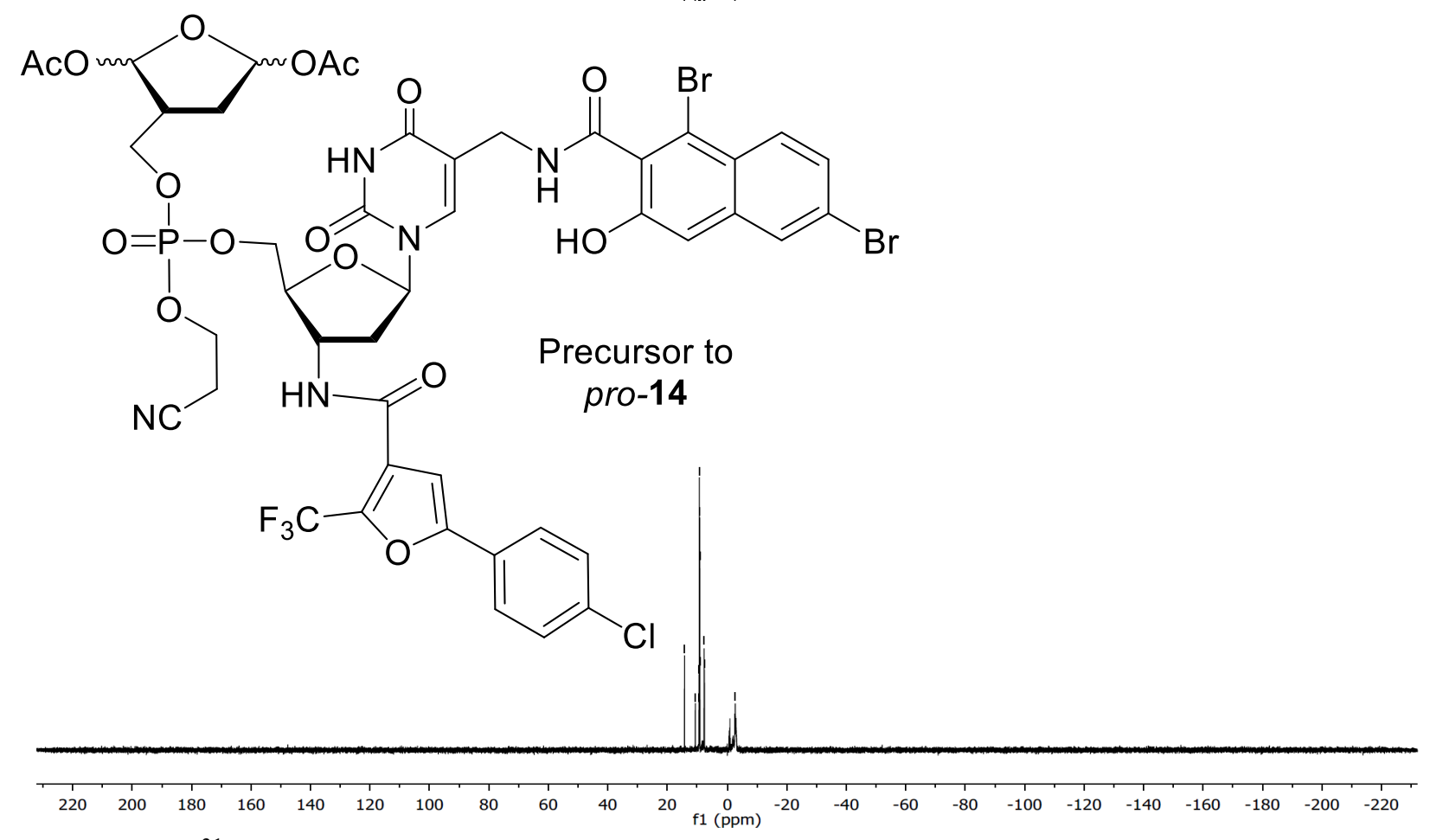

Figure S41. ${ }^{31}$ P NMR spectra of precursor to pro-14
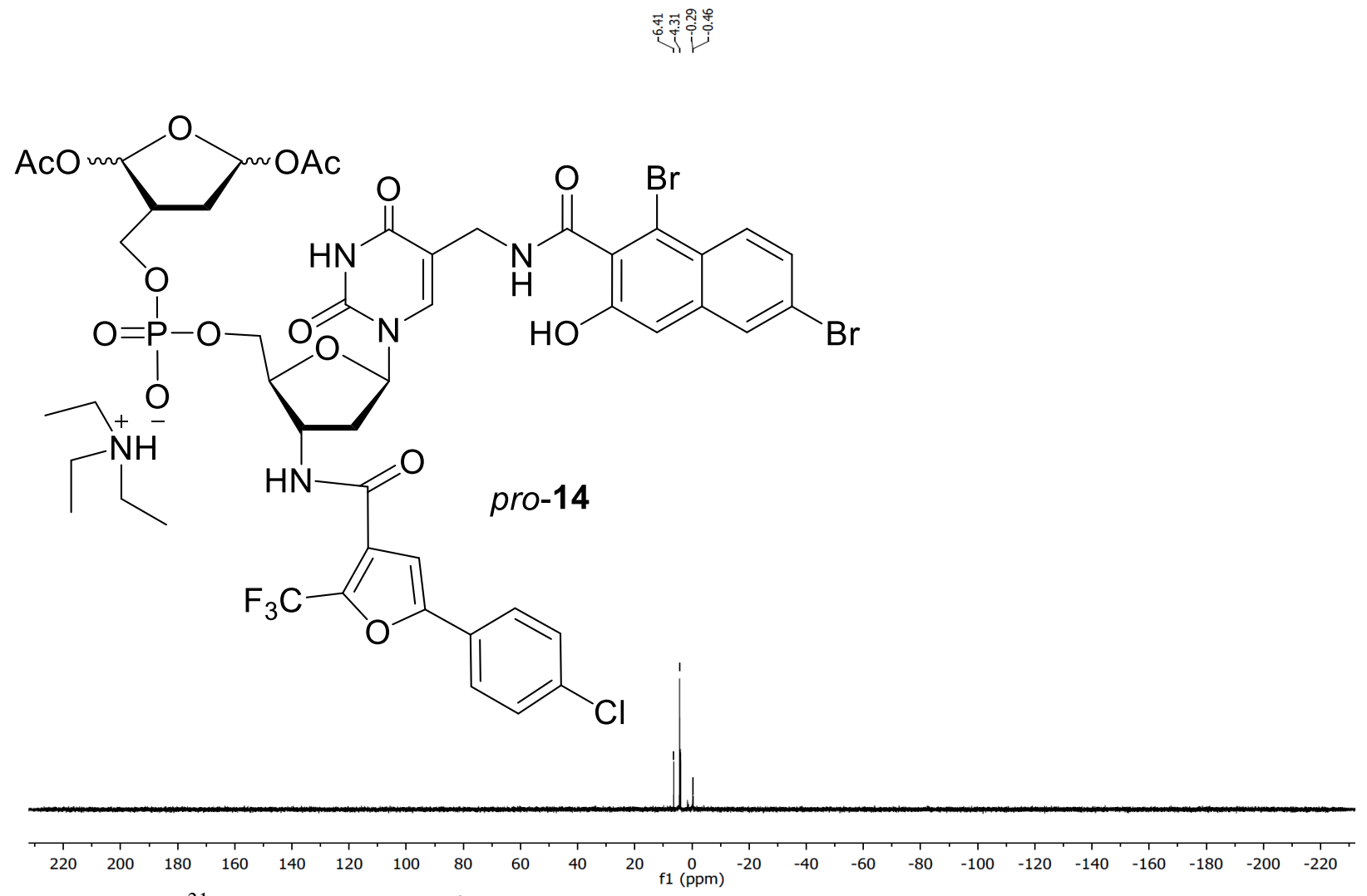

Figure S42. ${ }^{31} \mathrm{P}$ NMR spectra of pro-14 


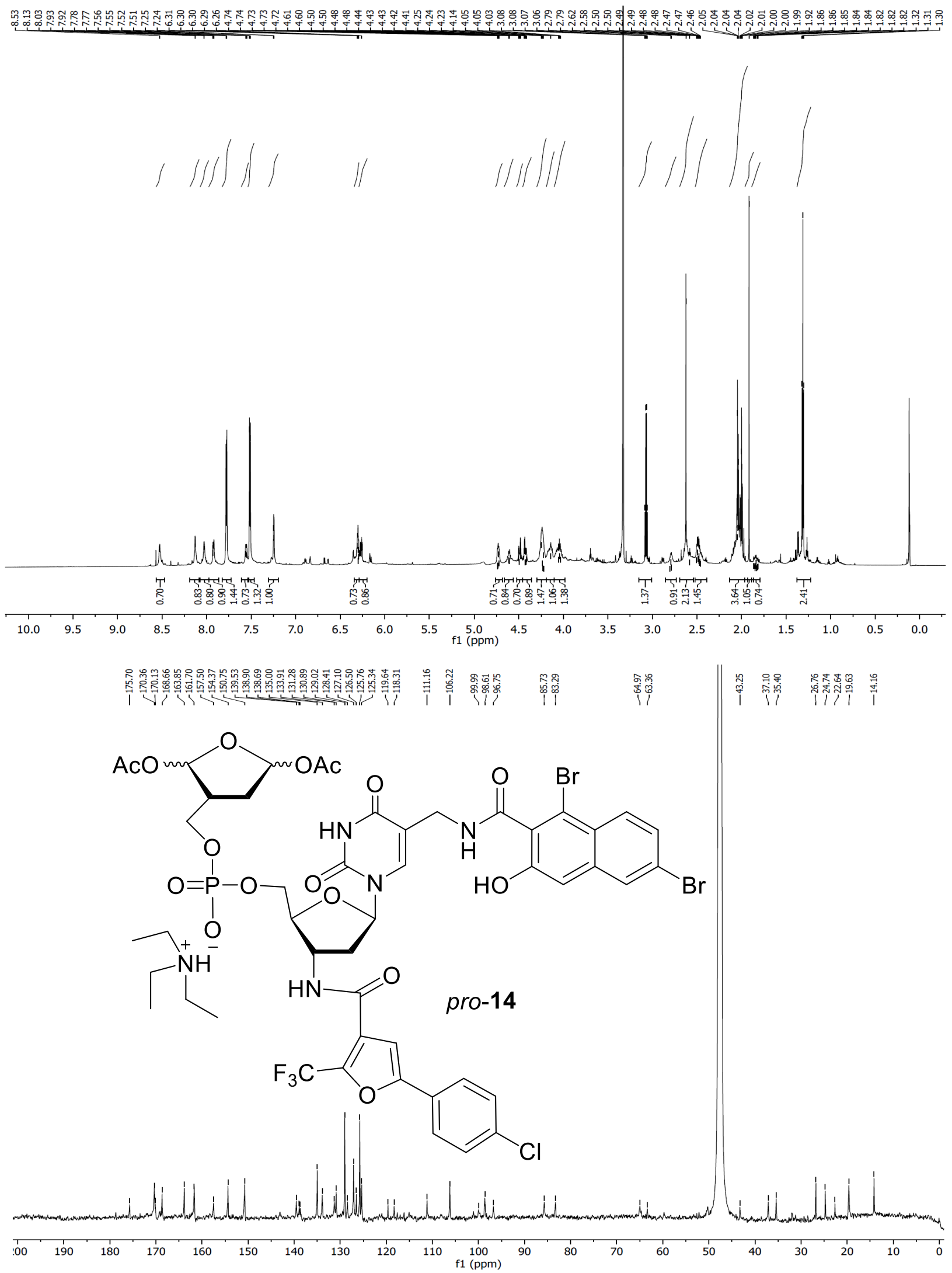

Figure S43. ${ }^{1} \mathrm{H}$ and ${ }^{13} \mathrm{C}$ NMR spectra of pro-14 

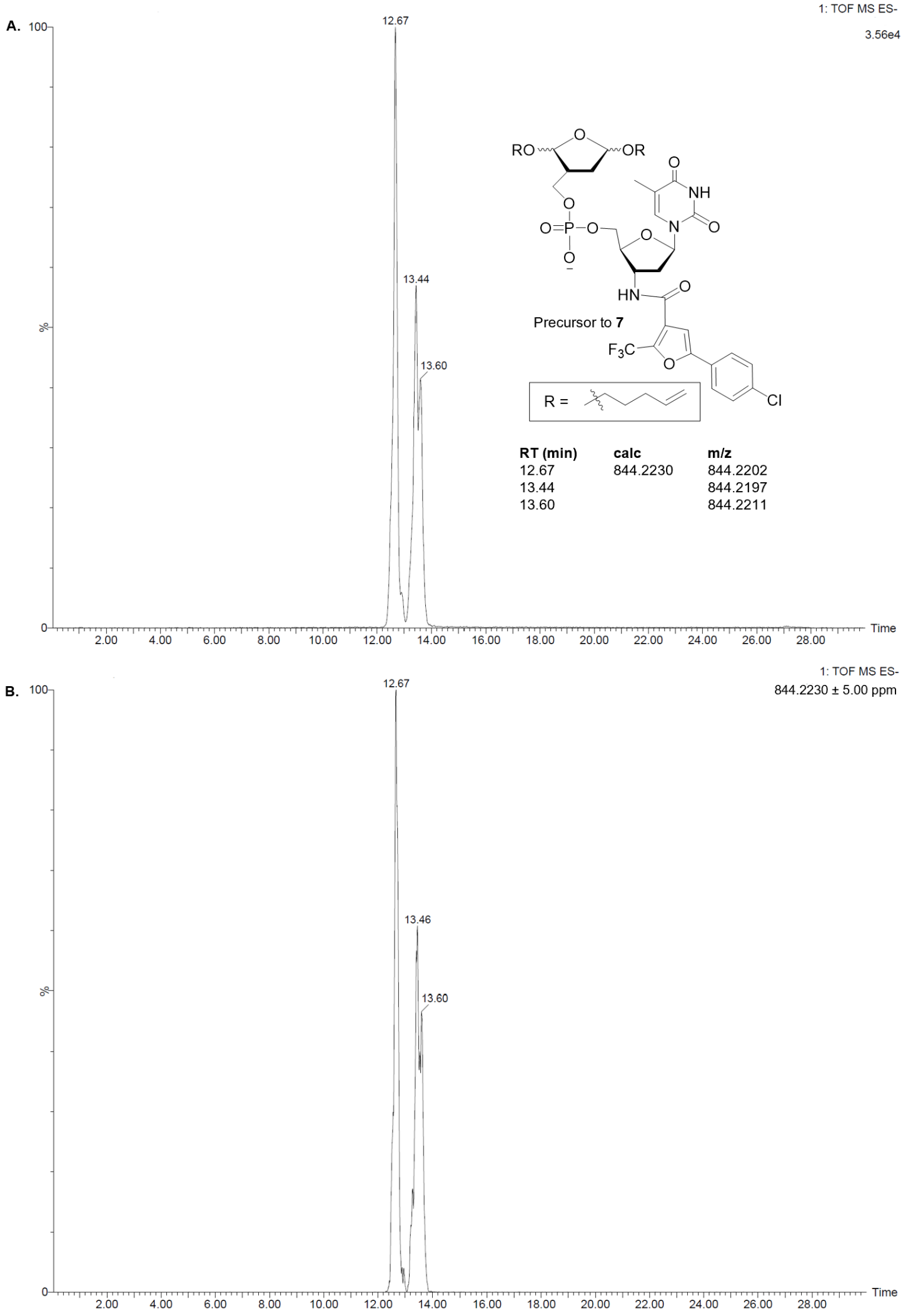

Figure S44. UPLC-MS analysis of precursor to 7. A) Total ion chromatogram. B) Extracted ion chromatogram of the molecular ion $(\mathrm{m} / \mathrm{z}=844.2230 \pm 5.00 \mathrm{ppm})$. 
A.

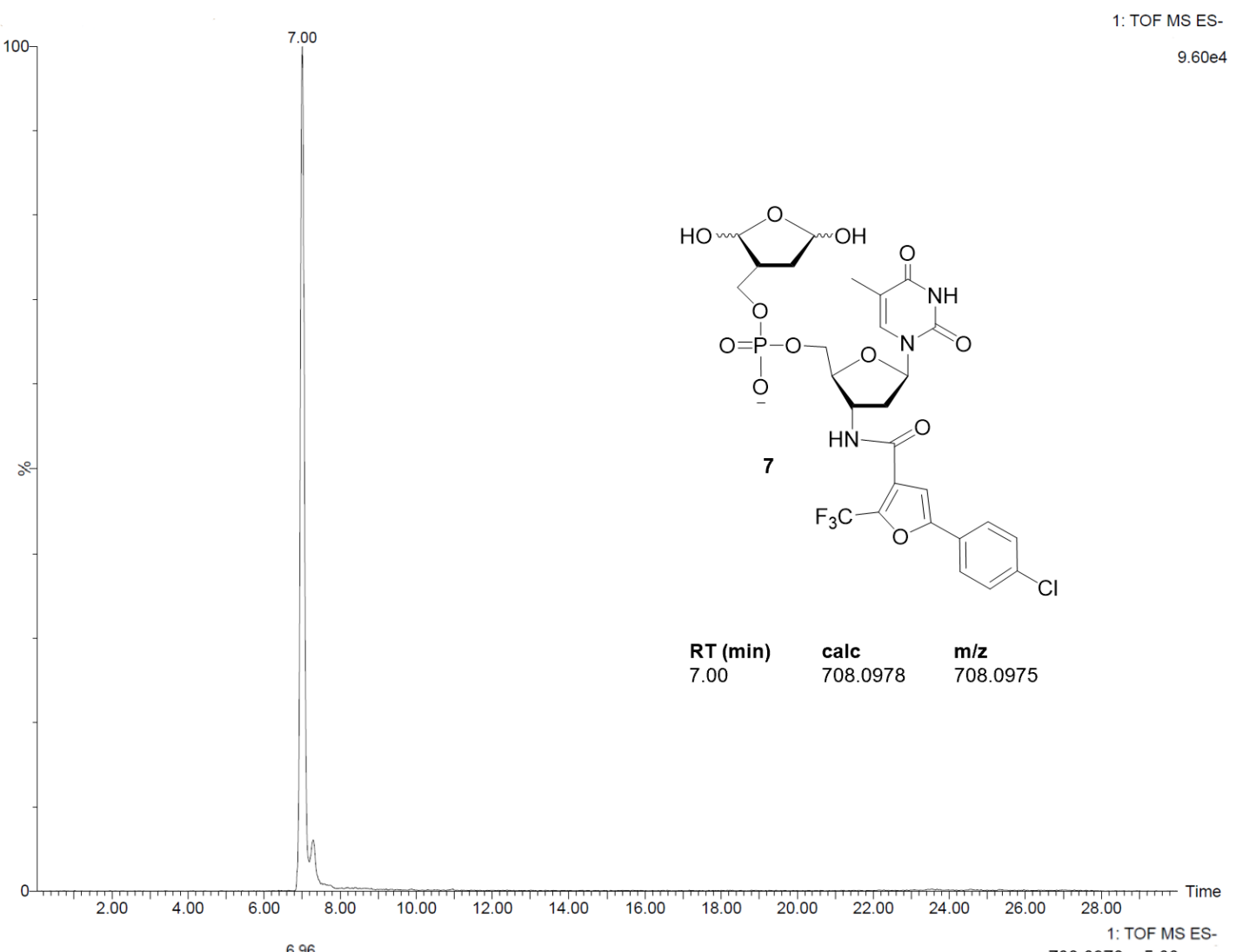

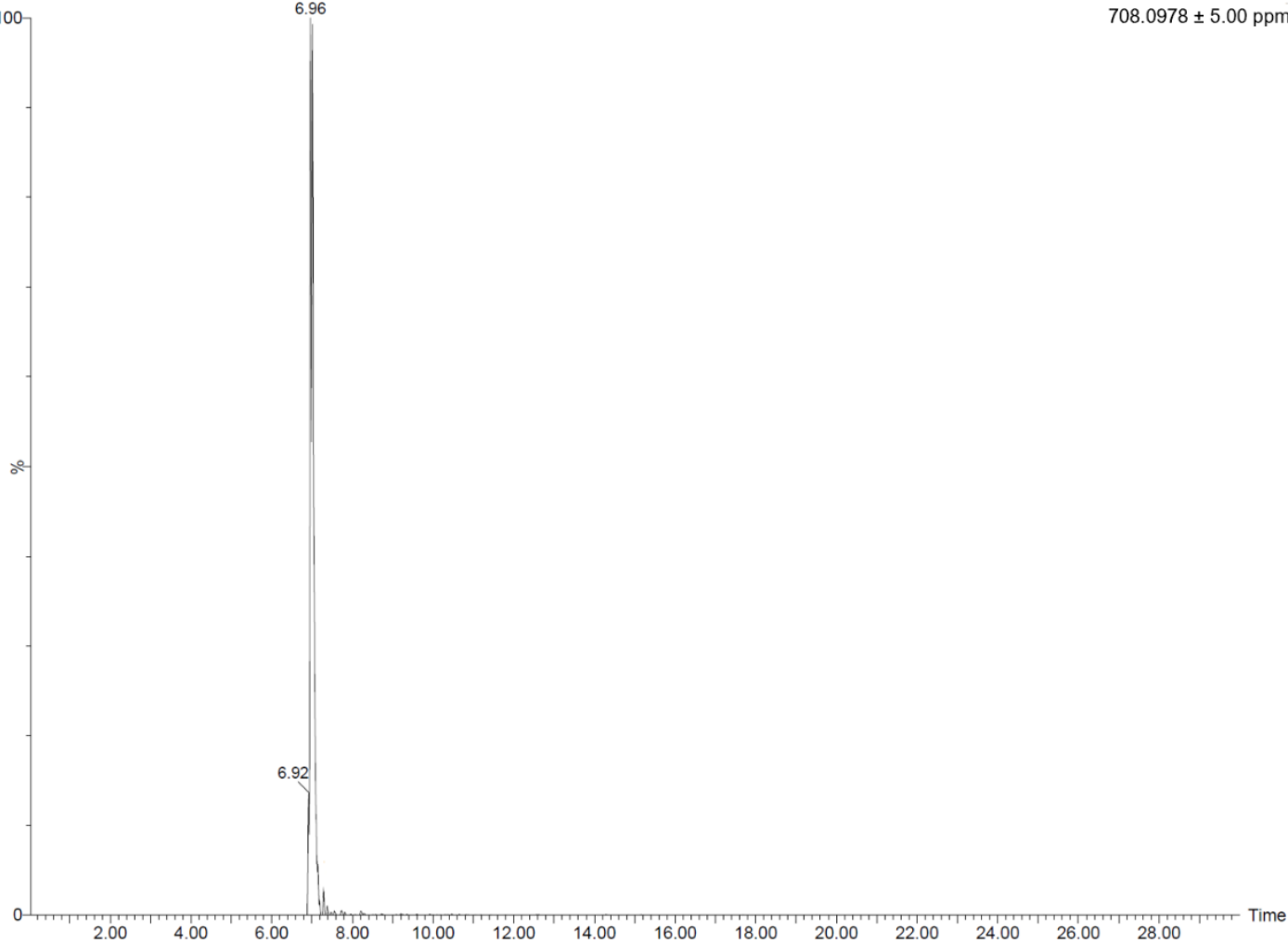

Figure S45. UPLC-MS analysis of 7. A) Total ion chromatogram. B) Extracted ion chromatogram of the molecular ion $(\mathrm{m} / \mathrm{z}=708.0978 \pm 5.00 \mathrm{ppm})$. 

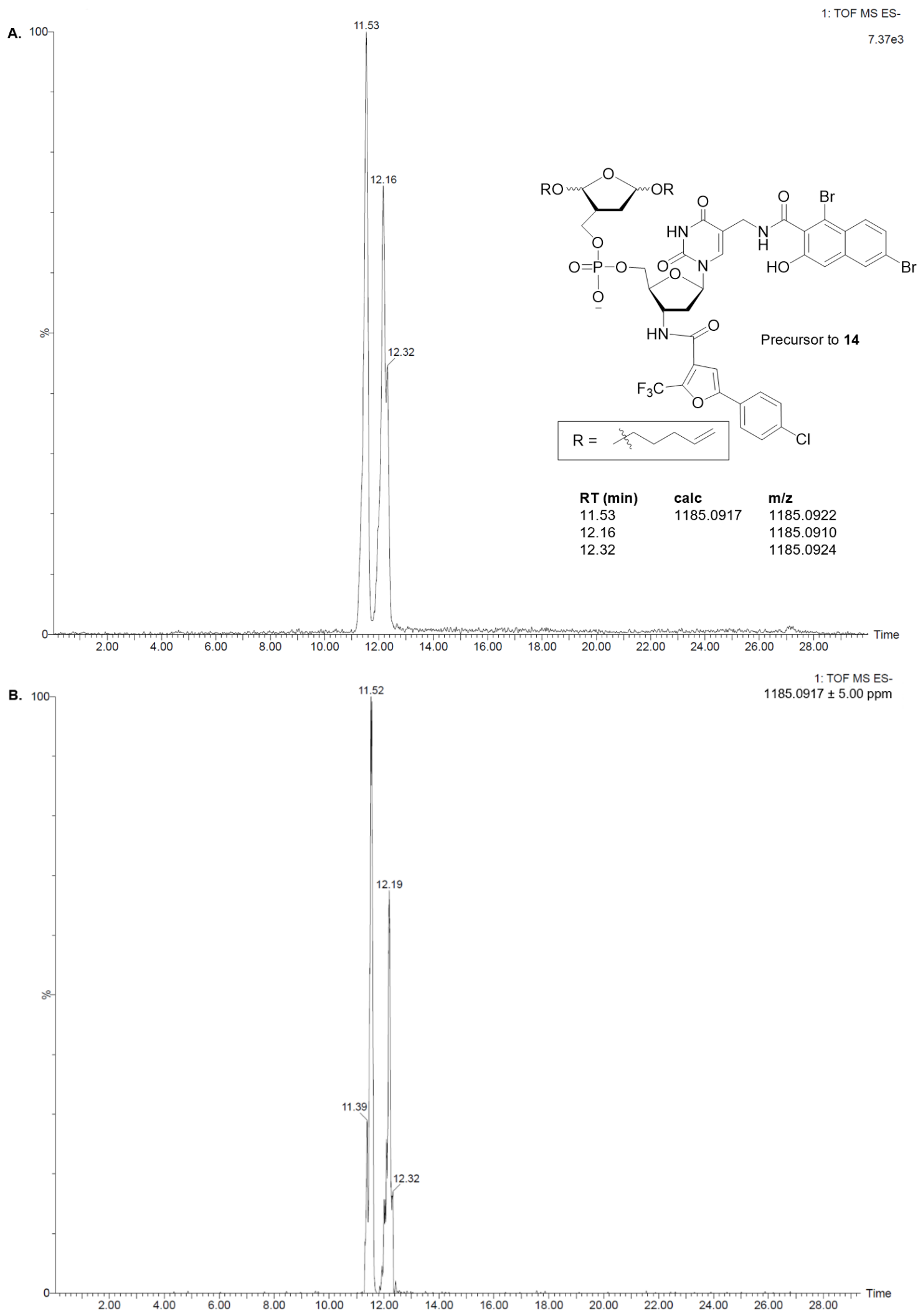

Figure S46. UPLC-MS analysis of precursor to 14. A) Total ion chromatogram. B) Extracted ion chromatogram of the molecular ion $(\mathrm{m} / z=1185.0917 \pm 5.00 \mathrm{ppm})$. 
A.

A. 100

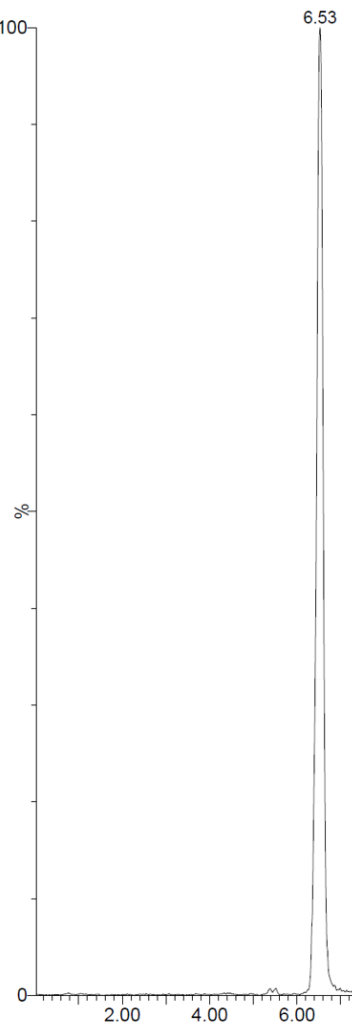

B. 100

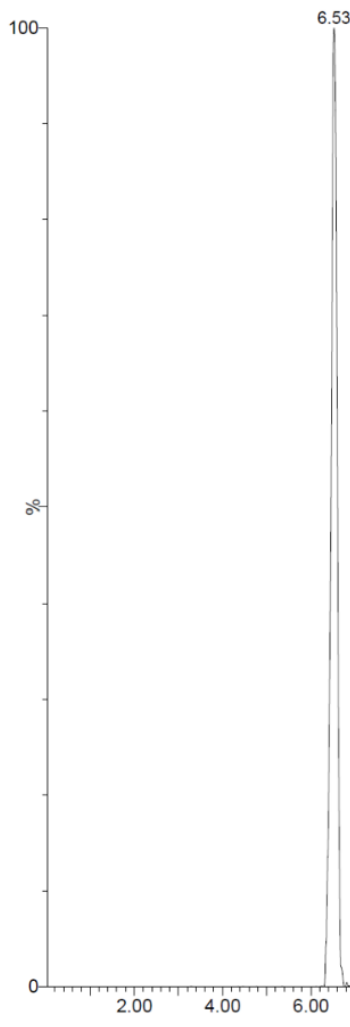

1: TOF MS ES-

$3.53 \mathrm{e} 4$

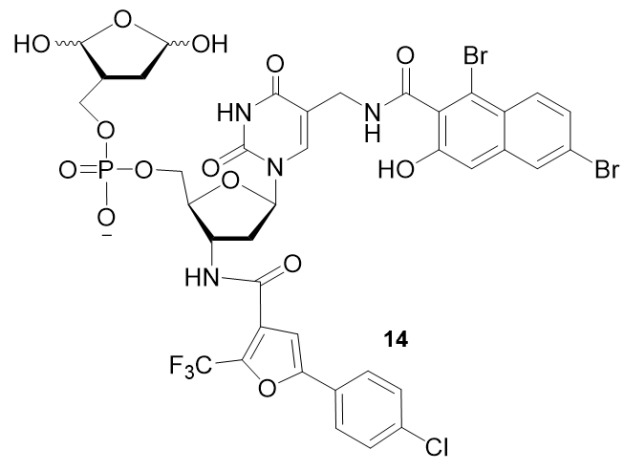

RT (min) calc $\quad \mathrm{m} / \mathbf{z}$

$\begin{array}{lll}6.53 & 1048.9665 & 1048.9670\end{array}$

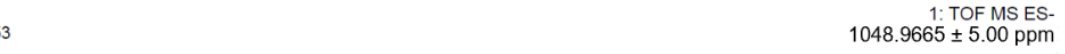

Figure S47. UPLC-MS analysis of 14. A) Total ion chromatogram. B) Extracted ion chromatogram of the molecular ion $(\mathrm{m} / \mathrm{z}=1048.9665 \pm 5.00 \mathrm{ppm})$. 

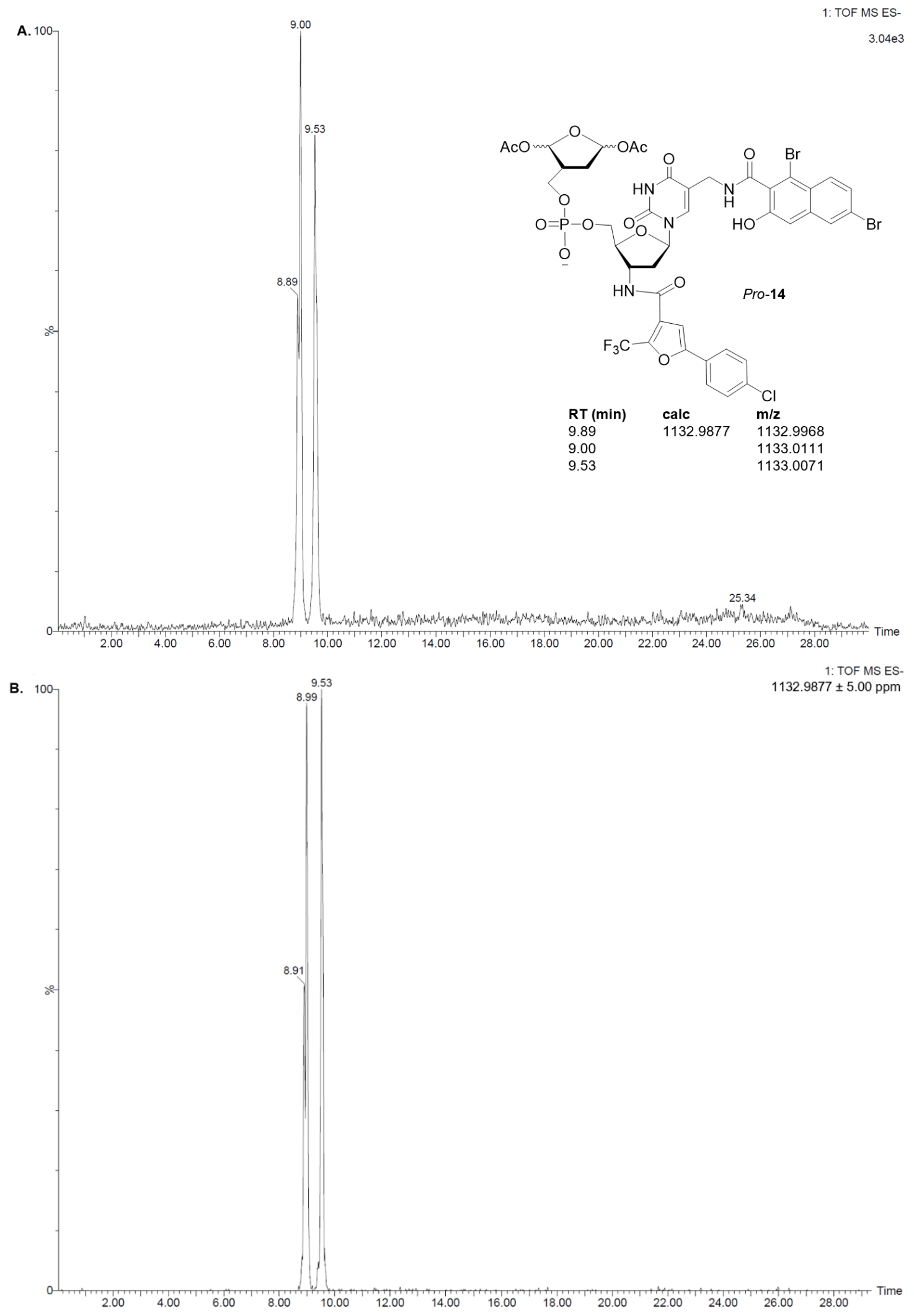

Figure S48. UPLC-MS analysis of pro-14. A) Total ion chromatogram. B) Extracted ion chromatogram of the molecular ion $(\mathrm{m} / z=1132.9877 \pm 5.00 \mathrm{ppm})$. 

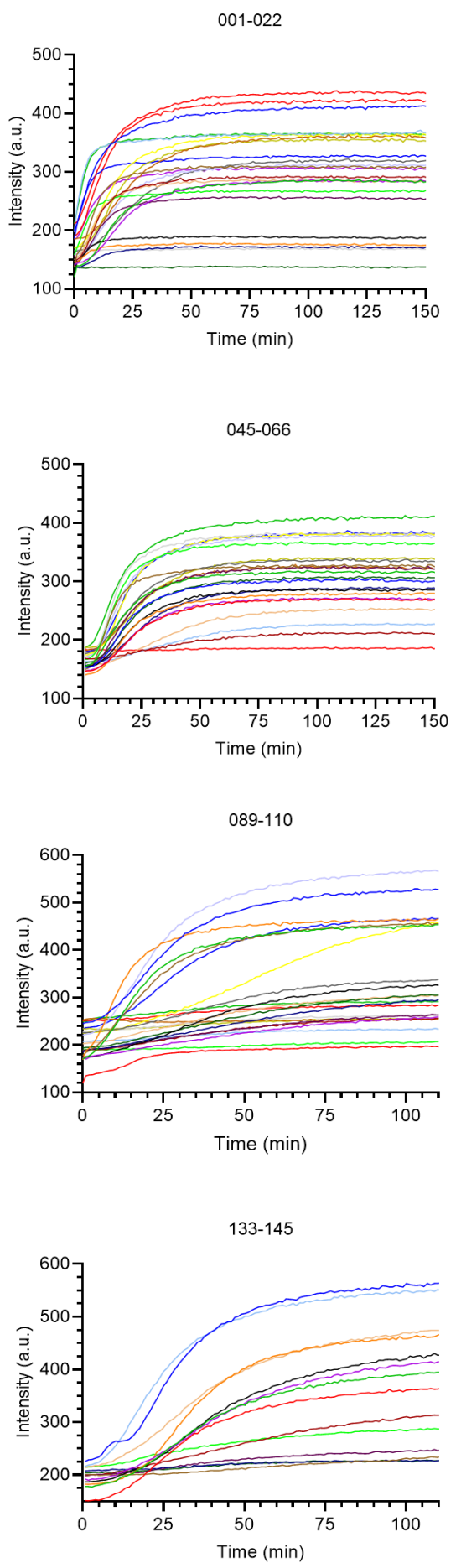

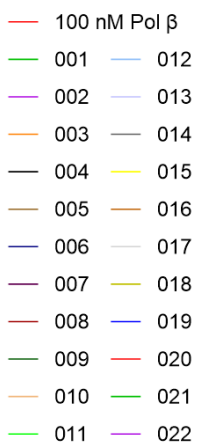

- $100 \mathrm{nM}$ Pol $\beta$

- $045-056$

$-046-057$

$-047-058$

- $048-059$

- $049-060$

$-050-061$
-051

- $051-062$

- $052-063$

$-053-064$

- $054-065$

- $055-066$

- $100 \mathrm{nM}$ Pol $\beta$

- $089-100$

$\begin{array}{r}-\quad 090-101 \\ \hline\end{array}$

$091-102$
$-\quad 109$

- $092-103$

$\begin{array}{r}093-104 \\ \hline\end{array}$

- $094-105$

- $095-106$

$-096-107$

- $097-108$

- $098-109$

$100 \mathrm{nM}$ Pol $\beta$
$-133-140$
$-134-141$
$-134-135-142$
$-136-143$
$-137-144$
$-138-145$
-139

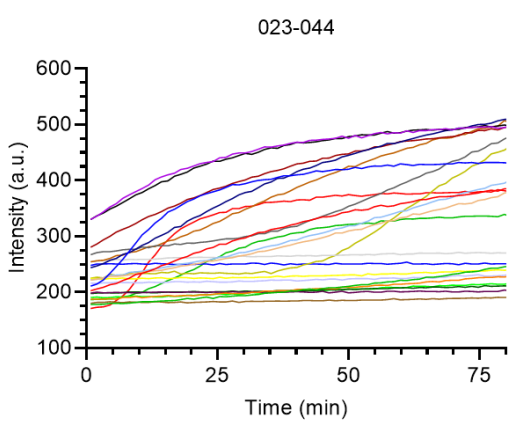

- $100 \mathrm{nM}$ Pol $\beta$

$-023-034$

$-024-035$

$-025-036$

- $026-037$

$-027-038$

$-028-039$

$-029-040$

- $030-041$

- $031-042$

- $032-043$

$-033-043$

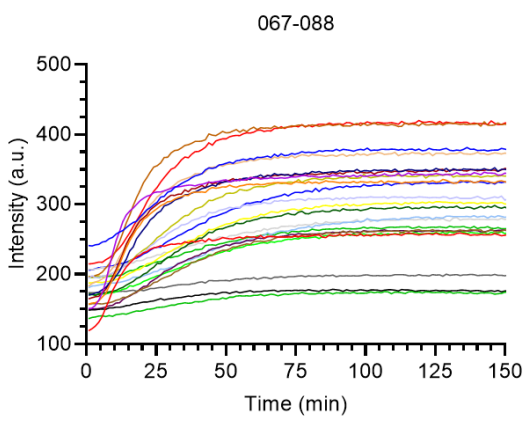

- $100 \mathrm{nM}$ Pol $\beta$

- $067-078$

- $068-079$

$-069-080$

- $070-081$

$071 \quad 082$
$-\quad 072$

$-072-083$

$-073-084$

$-074-085$

- $075-086$

$076-087$
$-077-088$
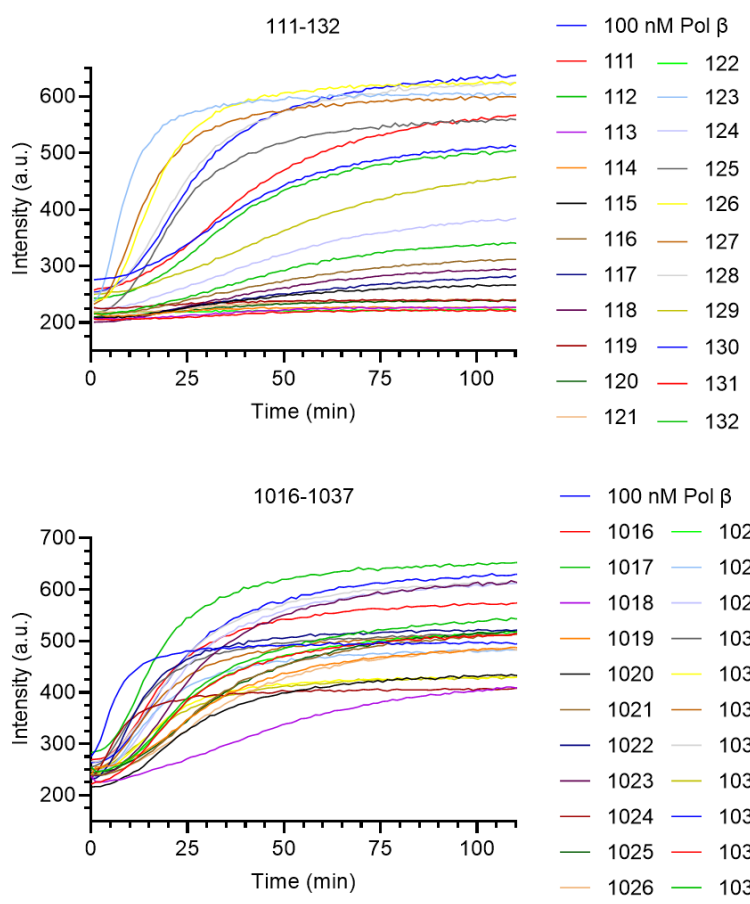

- $100 \mathrm{nM} \mathrm{Pol} \beta$

- $1016-1027$

$-1017-1028$
$-\quad 1018$

$-1018-1029$
$-\quad 1019-1030$

$-1019-1030$

- $1020-1031$

- $1021-1032$

- $1022-1033$

$-1023-1034$

- $1024-1035$

$-1025-1036$

$\begin{array}{r}1026-1037 \\ \hline\end{array}$ 


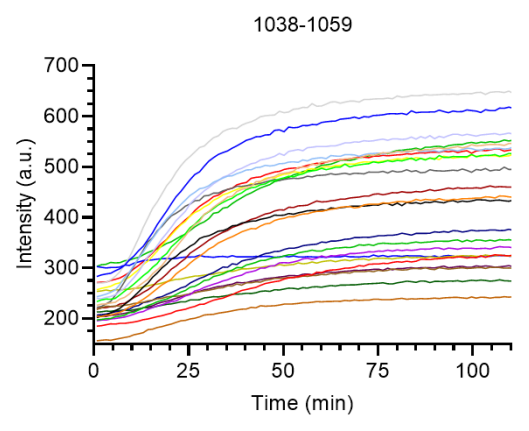

$-100 \mathrm{nM}$ Pol $\beta$
$-1038-1049$
$-1039-1050$
$-1040-1051$
$-1041-1052$
$-1042-1053$
$-1043-1054$
$-1044-1055$
$-1045-1056$
$-1046-1057$
$-1047-1058$
$-1048-1059$

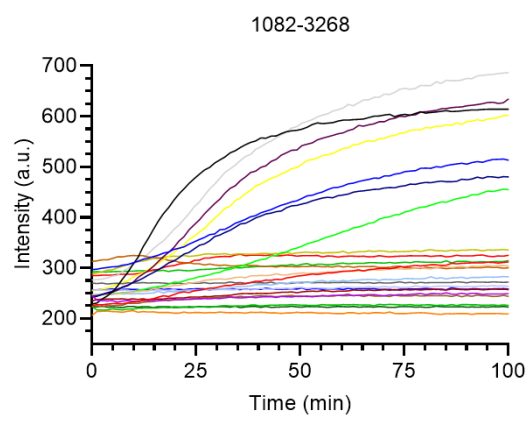

- $100 \mathrm{nM} \mathrm{Pol} \beta$

- $1082-1093$

$-1083-1094$

$-1084-1095$

$-1085-1096$

\begin{tabular}{rr}
$1086 \quad 1097$ \\
\hline
\end{tabular}

$-1087-3265$

$-1088-3267$
$-\quad 1089$

$-\quad 3271$
$-\quad 3089-3266$

- $1090-3266$

- $1091-3269$

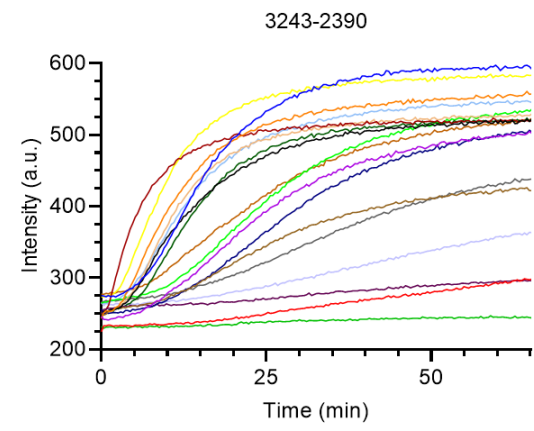

- $100 \mathrm{nM}$ Pol $\beta$

- $3243-2735$

$\begin{array}{r}3252-2736 \\ \hline\end{array}$

- $3247-2734$

- $3245-2389$

- $2738-2391$

- $2740-2388$

$\begin{array}{r}2741-2387 \\ \hline\end{array}$

- $2737-2390$

$-2739$

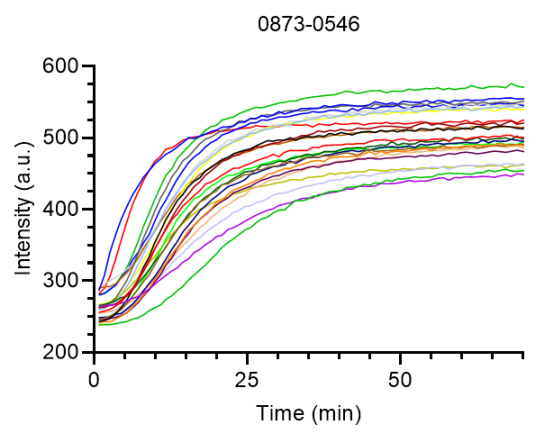

$100 \mathrm{nM}$ Pol $\beta$

- $0873-0592$

$-0871-0579$

$-0874-0683$

- $0875-0684$

$-0877-0685$

- $0876-0599$

- $0878-0600$

- $0848-0531$

- $0849-0530$

- $0703-0542$

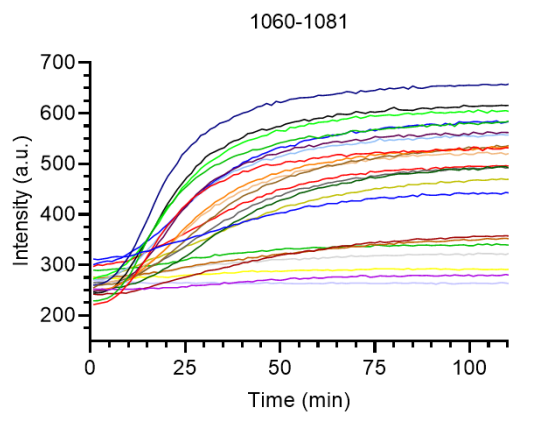

- $100 \mathrm{nM}$ Pol $\beta$

$-1060-1071$

- $1061-1072$

- $1062-1073$

- $1063-1074$

$1064-1075$
$-1065-1076$

$-1065-1076$

$-1066-1077$

- $1067-1078$

$-1068-1079$

- $1069-1080$
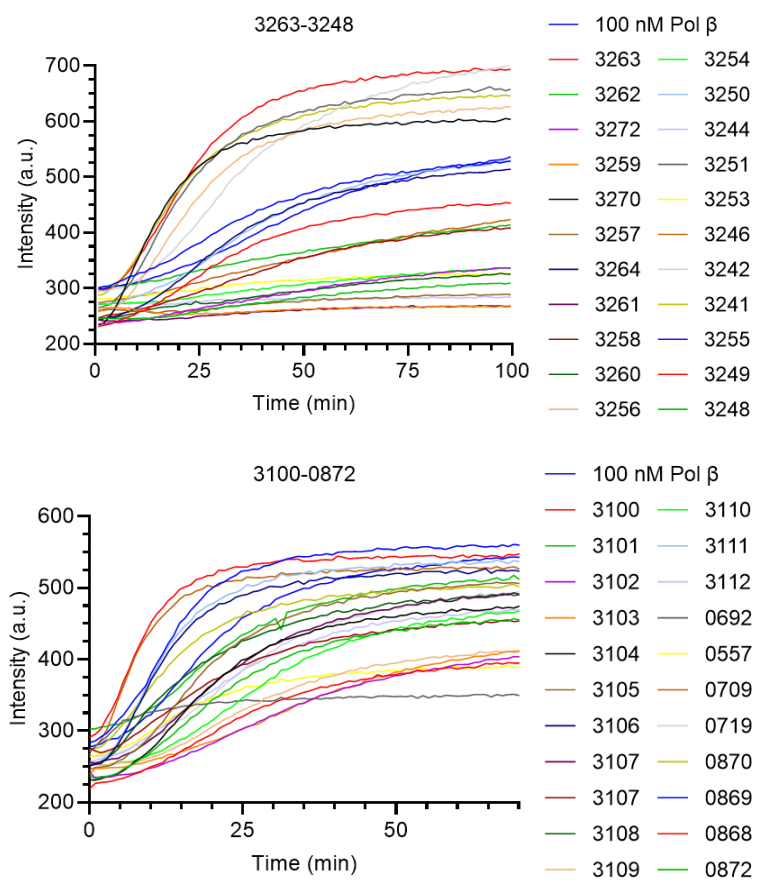

0543-0545

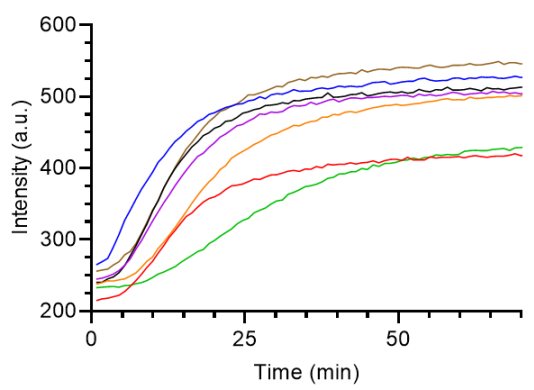

$100 \mathrm{nM}$ Pol $\beta$

- 0543

$-0541$

- 0549

- 0548

- 0547

- 0545

Figure S49. Primary fluorescence data of screened first-generation library ( $25 \mu \mathrm{M}$ inhibitor). 


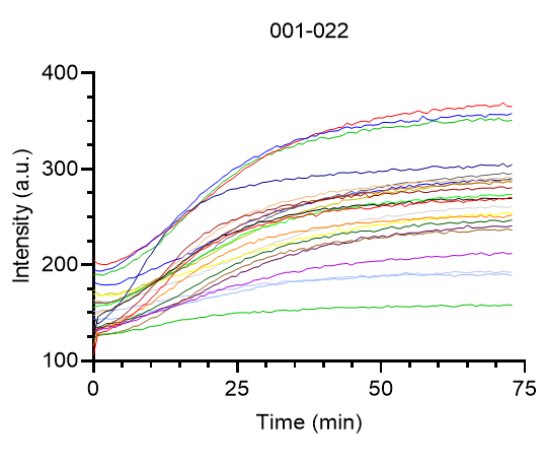

$-100 \mathrm{nM} \mathrm{Pol} \beta$
$-001-012$
$-002-013$
$-003-014$
$-004-015$
$-005-016$
$-006-017$
$-007-018$
$-008-019$
$-009-020$
$-010-021$
$011-022$

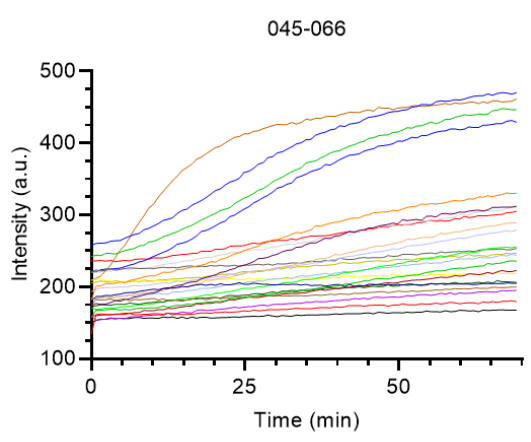

- $100 \mathrm{nM}$ Pol $\beta$

- $045-056$

$-046-057$

$-047-058$

- $048-059$

- $049-060$

- $050-061$

- $051-062$

$-052-063$

- $053-064$

$-054-065$

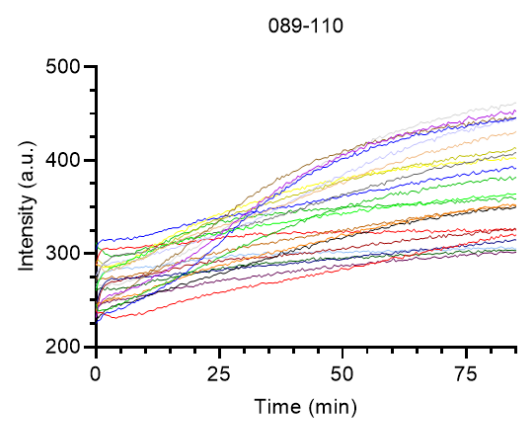

- $100 \mathrm{nM}$ Pol $\beta$

- $089-100$

- $090-101$

$091-102$
$-092-103$

$092-103$

\begin{tabular}{ll}
$-093-104$ \\
\hline
\end{tabular}

- $094-105$

$-095-106$

$-096-107$

$-097-108$

- $098-109$

133-145

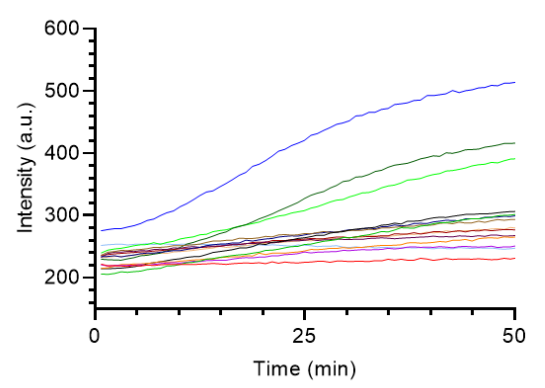

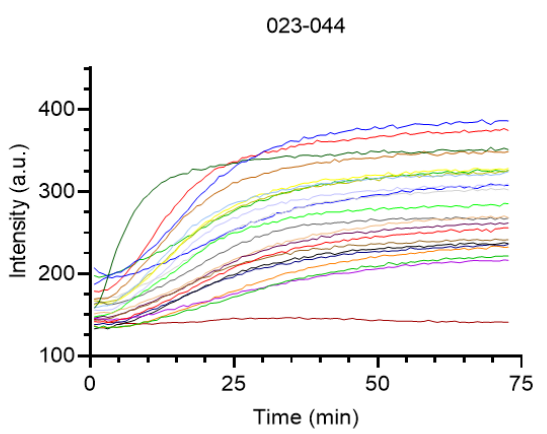

- $100 \mathrm{nM}$ Pol $\beta$

- $023-034$

- $024-035$

- $025-036$

- $026-037$

$\begin{array}{ll}-027 & 038\end{array}$

- $028-039$

- $029-040$

- $030-041$

- $031-042$

$032-043$
$033-044$
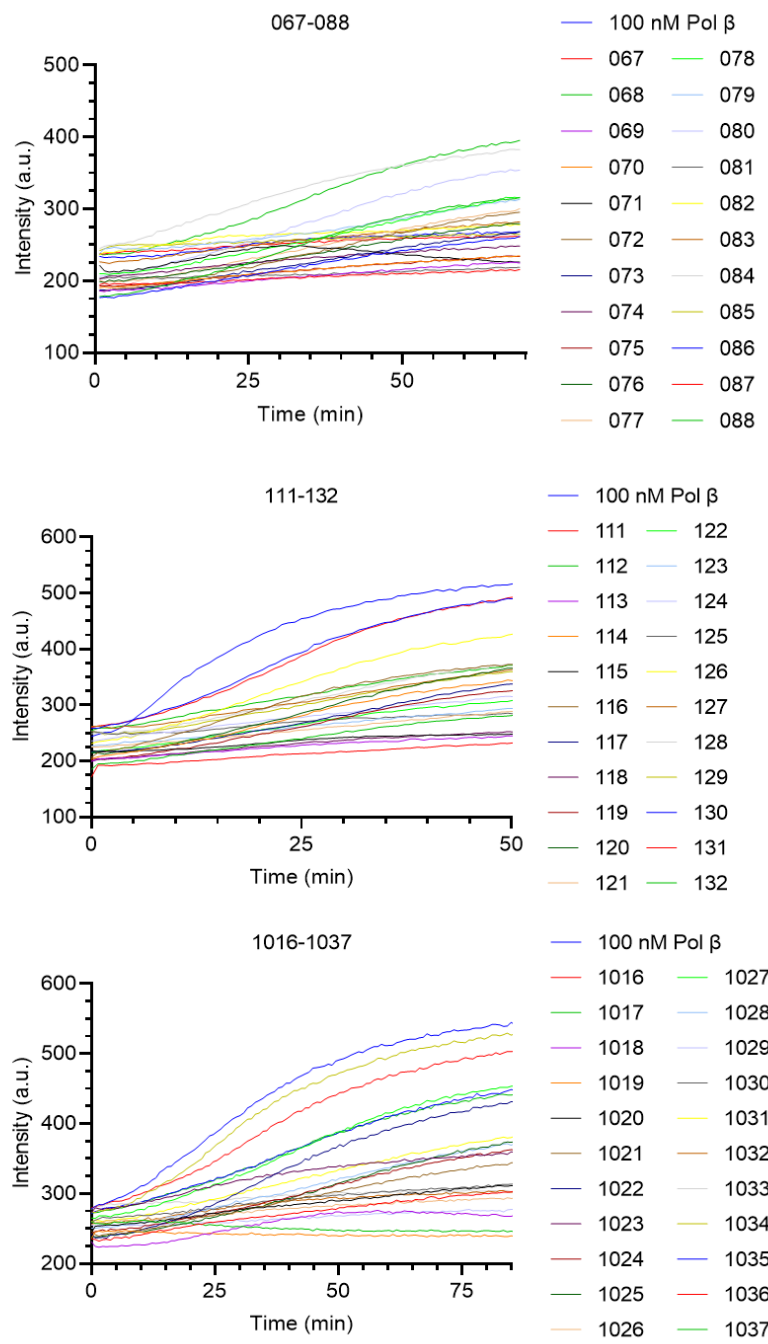

- $100 \mathrm{nM}$ Pol $\beta$

- $1016-1027$

$-1017-1028$
$-\quad 1018$

- $1018-1029$

- $1019-1030$

$1020-1031$
$-\quad 1021$

- $1021-1032$

$-1022-1033$

$-1023-1034$

- $1024-1035$

$-1025-1036$ 

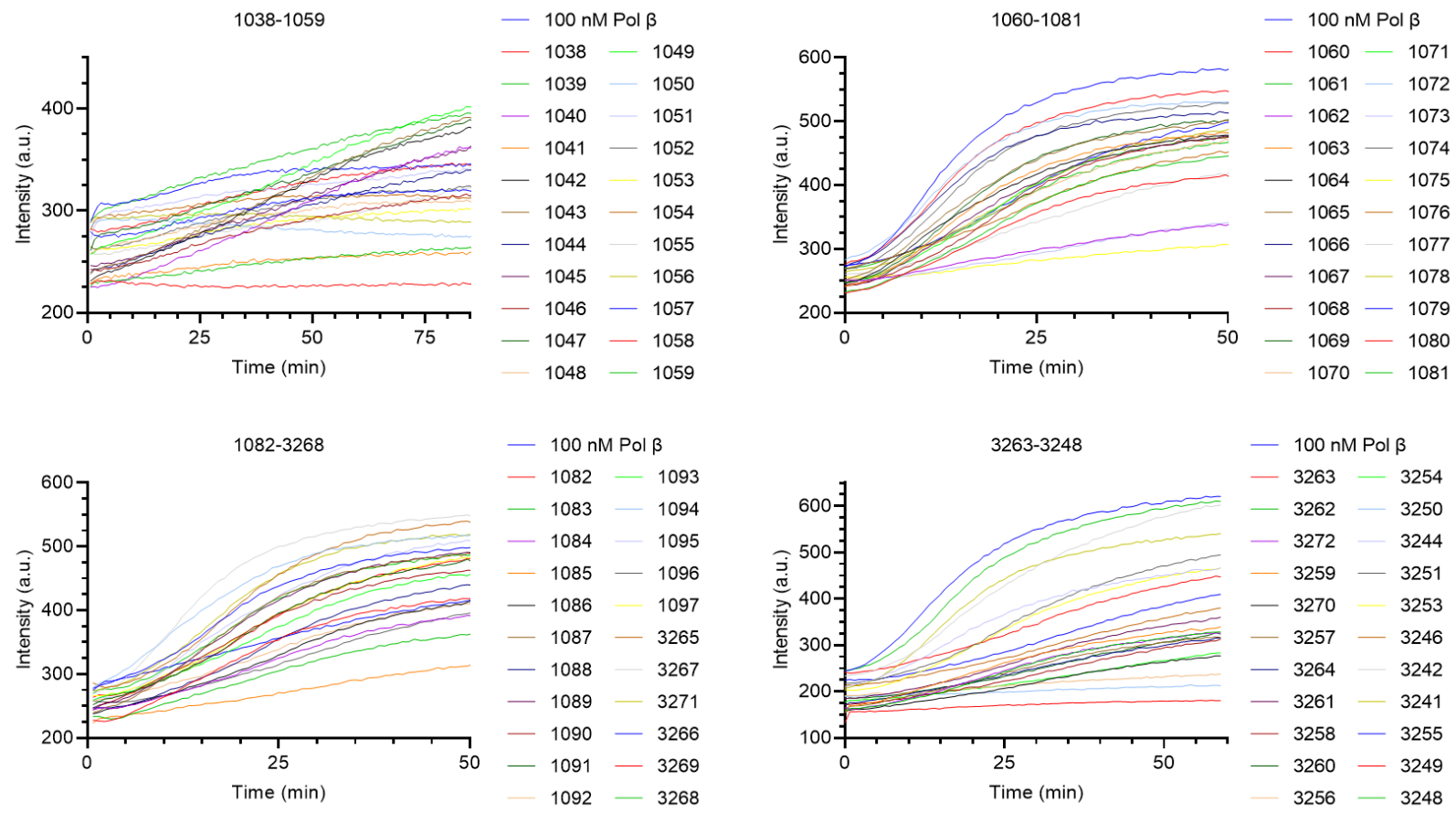

- $100 \mathrm{nM}$ Pol $\beta$
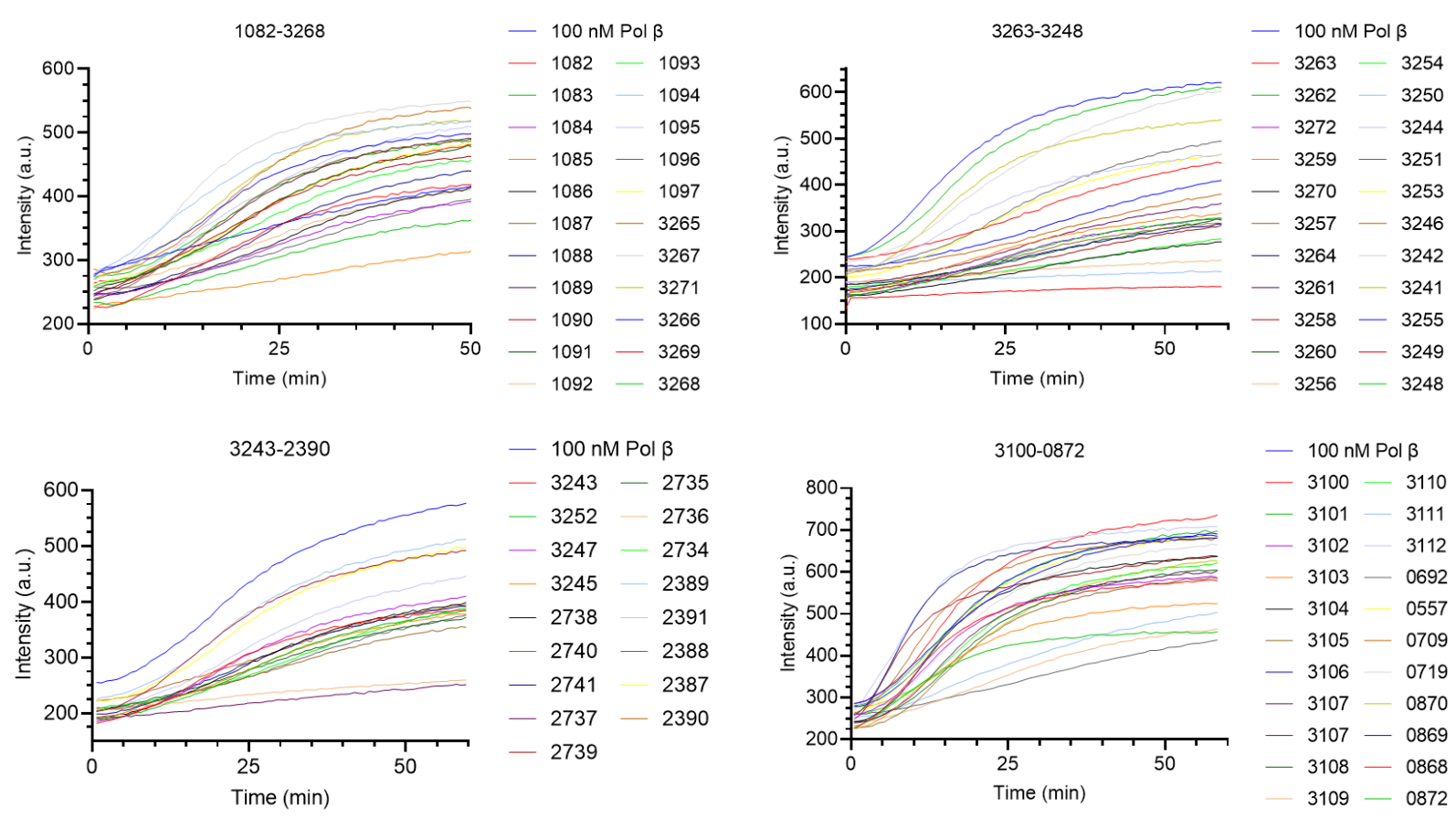

$-100 \mathrm{nM}$ Pol $\beta$
$-3243-2735$
$-3252-2736$
$-3247-2734$
$-3245-2389$
$-2738-2391$
$-2740-2388$
$-2741-2387$
$-2737-2390$
-2739

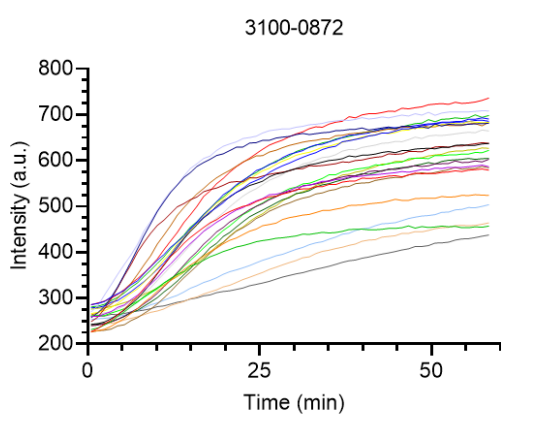

$-100 \mathrm{nM}$ Pol $\beta$
$-3100-3110$
$-3101-3111$
$-3102-3112$
$-3103-0692$
$-3104-0557$
$-3105-0709$
$-3106-0719$
$-3107-0870$
$-3107-0869$
$-3108-0868$
$3109-0872$
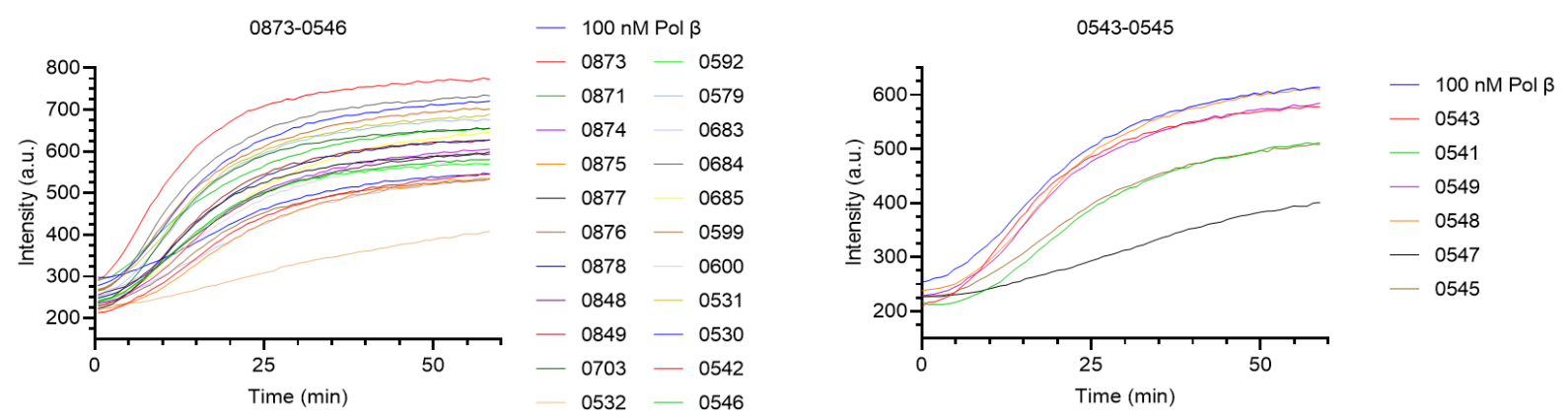

Figure S50. Primary fluorescence data of screened second-generation library (700 nM inhibitor). 

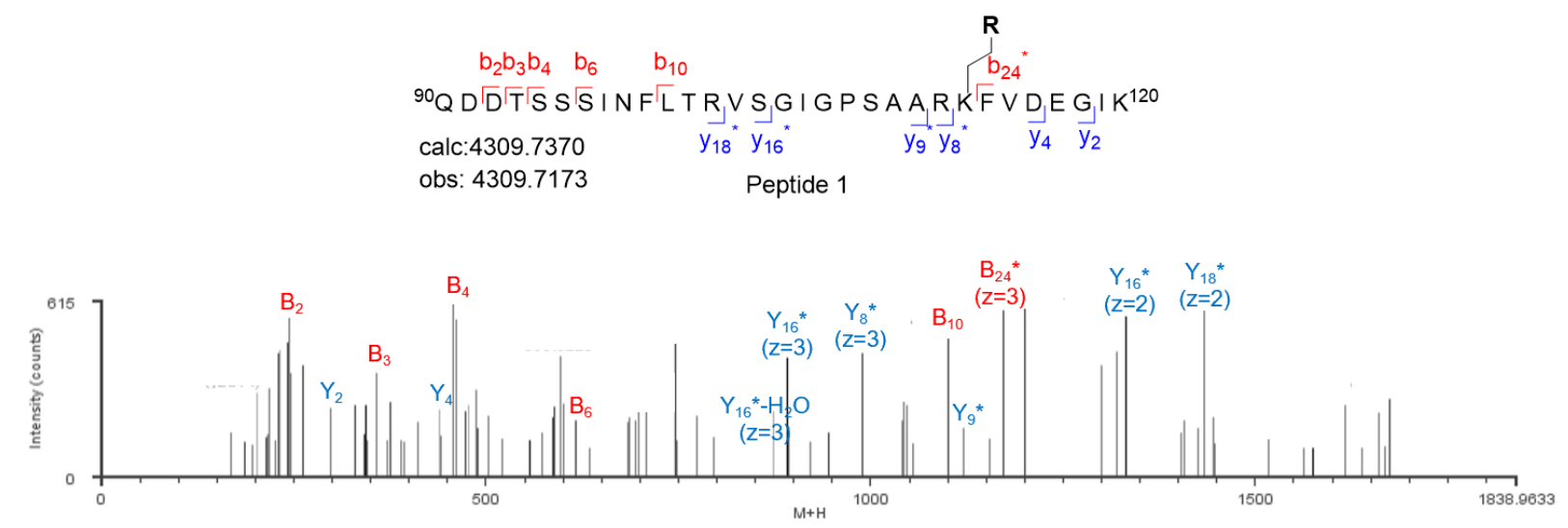

\begin{tabular}{|c|c|c|c|c|c|c|c|c|}
\hline Res & B & $\mathbf{z}$ & Calculated & Observed & $\mathbf{Y}$ & $\mathbf{z}$ & Calculated & Observed \\
\hline$Q$ & 1 & & & & 31 & & & \\
\hline $\mathrm{D}$ & 2 & 1 & 244.0928 & 244.0848 & 30 & & & \\
\hline $\mathrm{D}$ & 3 & 1 & 359.1197 & 359.1397 & 29 & & & \\
\hline $\mathrm{T}$ & 4 & 1 & 460.1675 & 460.1429 & 28 & & & \\
\hline $\mathrm{S}$ & 5 & & & & 27 & & & \\
\hline $\mathrm{S}$ & 6 & 1 & 634.2315 & 634.2309 & 26 & & & \\
\hline $\mathrm{S}$ & 7 & & & & 25 & & & \\
\hline I & 8 & & & & 24 & & & \\
\hline $\mathrm{N}$ & 9 & & & & 23 & & & \\
\hline $\mathrm{F}$ & 10 & & & & 22 & & & \\
\hline $\mathrm{L}$ & 11 & & & & 21 & & & \\
\hline $\mathrm{T}$ & 12 & & & & 20 & & & \\
\hline $\mathrm{R}$ & 13 & & & & 19 & & & \\
\hline $\mathrm{V}$ & 14 & & & & 18 & 2 & 1431.4931 & 1431.4858 \\
\hline $\mathrm{S}$ & 15 & & & & 17 & & & \\
\hline $\mathrm{G}$ & 16 & & & & 16 & 2 & 1338.4429 & 1338.4443 \\
\hline $\mathrm{I}$ & 17 & & & & 15 & & & \\
\hline $\mathrm{G}$ & 18 & & & & 14 & & & \\
\hline $\mathrm{P}$ & 19 & & & & 13 & & & \\
\hline S & 20 & & & & 12 & & & \\
\hline A & 21 & & & & 11 & & & \\
\hline A & 22 & & & & 10 & & & \\
\hline $\mathrm{R}$ & 23 & & & & 9 & 2 & 1061.7999 & 1061.8012 \\
\hline $\mathbf{K}^{*}$ & 24 & 3 & 1173.7511 & 1173.7426 & 8 & 3 & 983.7494 & 983.7632 \\
\hline $\mathrm{F}$ & 25 & & & & 7 & & & \\
\hline V & 26 & & & & 6 & & & \\
\hline $\mathrm{D}$ & 27 & & & & 5 & & & \\
\hline $\mathrm{E}$ & 28 & & & & 4 & 1 & 446.2610 & 446.2498 \\
\hline G & 29 & & & & 3 & & & \\
\hline $\mathrm{I}$ & 30 & & & & 2 & 1 & 260.1969 & 260.2005 \\
\hline $\mathrm{K}$ & 31 & & & & 1 & & & \\
\hline
\end{tabular}

Figure S51. Annotated MS/MS Spectra of modified peptide 1 


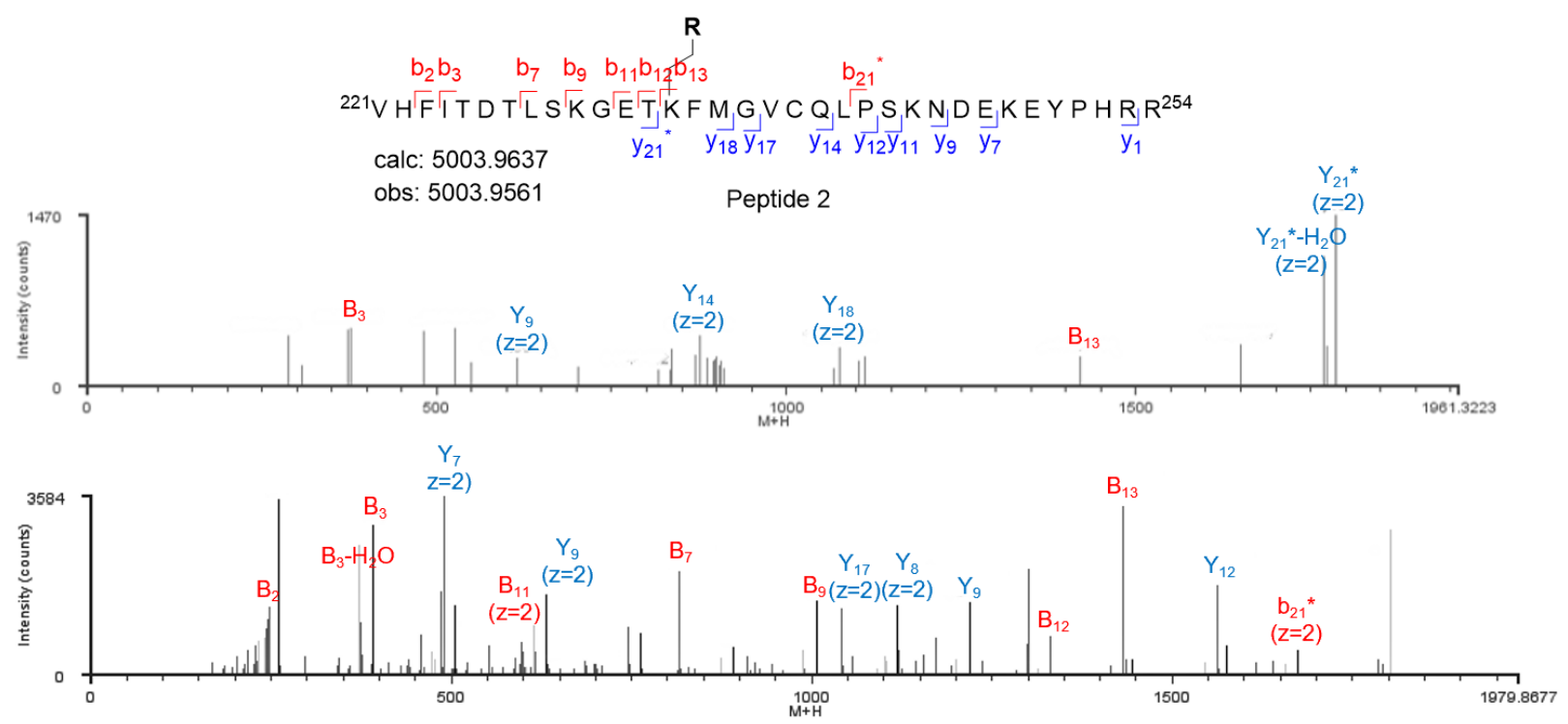

\begin{tabular}{|c|c|c|c|c|c|c|c|c|}
\hline Res & B & $\mathbf{z}$ & Calculated & Observed & $\mathbf{Y}$ & $\mathbf{z}$ & Calculated & Observed \\
\hline $\mathrm{V}$ & 1 & & & & 34 & & & \\
\hline $\mathrm{H}$ & 2 & 1 & 237.1346 & 237.1437 & 33 & & & \\
\hline $\mathrm{F}$ & 3 & 1 & 384.2030 & 384.2044 & 32 & & & \\
\hline I & 4 & & & & 31 & & & \\
\hline $\mathrm{T}$ & 5 & & & & 30 & & & \\
\hline $\mathrm{D}$ & 6 & & & & 29 & & & \\
\hline $\mathrm{T}$ & 7 & 1 & 814.4094 & 814.4096 & 28 & & & \\
\hline $\mathrm{L}$ & 8 & & & & 27 & & & \\
\hline $\mathrm{S}$ & 9 & 1 & 1014.5255 & 1014.5304 & 26 & & & \\
\hline $\mathrm{K}$ & 10 & & & & 25 & & & \\
\hline$G$ & 11 & & & & 24 & & & \\
\hline $\mathrm{E}$ & 12 & 1 & 1328.6845 & 1328.6821 & 23 & & & \\
\hline $\mathrm{T}$ & 13 & 1 & 1429.7322 & 1429.9248 & 22 & & & \\
\hline $\mathbf{K}^{*}$ & 14 & & & & 21 & 2 & 1788.1247 & 1788.1236 \\
\hline $\mathrm{F}$ & 15 & & & & 20 & & & \\
\hline $\mathrm{M}$ & 16 & & & & 19 & & & \\
\hline $\mathrm{G}$ & 17 & & & & 18 & 2 & 1078.0333 & 1078.0364 \\
\hline $\mathrm{V}$ & 18 & & & & 17 & 2 & 1049.5225 & 1049.5249 \\
\hline $\mathrm{C}$ & 19 & & & & 16 & & & \\
\hline Q & 20 & & & & 15 & & & \\
\hline $\mathrm{L}$ & 21 & 2 & 1675.7078 & 1675.6978 & 14 & 2 & 884.4544 & 884.4516 \\
\hline $\mathrm{P}$ & 22 & & & & 13 & & & \\
\hline $\mathrm{S}$ & 23 & & & & 12 & 1 & 1558.7721 & 1558.7780 \\
\hline $\mathrm{K}$ & 24 & & & & 11 & & & \\
\hline $\mathrm{N}$ & 25 & & & & 10 & & & \\
\hline $\mathrm{D}$ & 26 & & & & 9 & 2 & 614.8011 & 614.8245 \\
\hline$E$ & 27 & & & & 8 & 1 & 1114.5753 & 1114.5791 \\
\hline $\mathrm{K}$ & 28 & & & & 7 & 2 & 492.7663 & 492.7266 \\
\hline
\end{tabular}




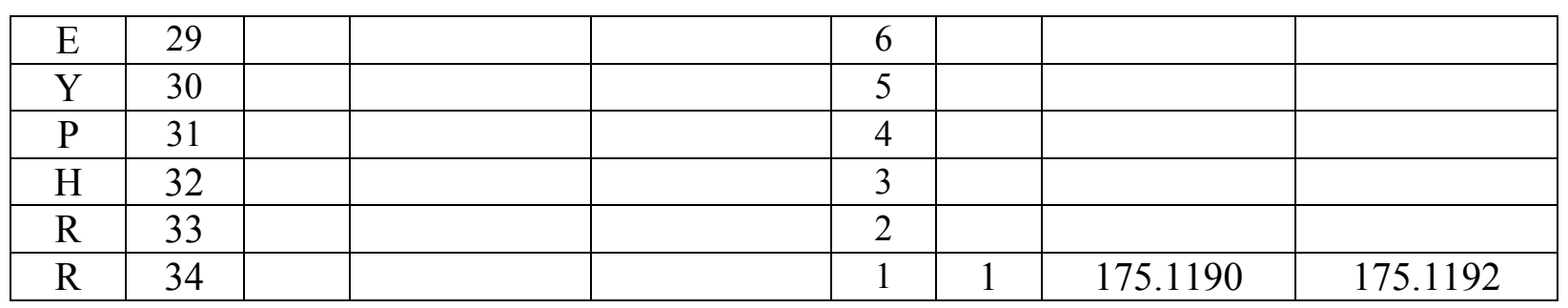

Figure S52. Annotated MS/MS Spectra of modified peptide 2 


\section{References}

(1) Prasad, R.; Kumar, A.; Widen, S.; Casas-Finet, J.; Wilson, S. Identification of Residues in the Single-Stranded DNA-Binding Site of the 8-KDa Domain of Rate DNA Polymerase b by UV Cross-Linking. J. Biol. Chem. 1993, 268, 22746-22755.

(2) Beard, W.; Wilson, S. Purification and Domain-Mapping of Mammalian DNA Polymerase b. Methods Enzymol. 1995, 262, 98-107.

(3) Garcia-Diaz, M.; Dominguez, O.; Lopez-Fernandez, L. A.; Lera, L. T. de; Saniger, M. L.; Ruiz, J. F.; Parraga, M.; Garcia-Ortiz, M. J.; Kirchhoff, T.; Mazo, J. del; Bernad, A.; Blanco, L. DNA Polymerase Lambda (Pol $\Lambda$ ), a Novel Eukaryotic DNA Polymerase with a Potential Role in Meiosis. J Mol Biol 2000, 301, 851-867.

(4) Fiala, K. A.; Abdel-Gawad, W.; Suo, Z. Pre-Steady-State Kinetic Studies of the Fidelity and Mechanism of Polymerization Catalyzed by Truncated Human DNA Polymerase $\lambda \lambda^{\dagger}$. Biochemistry 2004, 43, 6751-6762.

(5) Xu, P.; Chen, D.; Xi, J.; Yao, Z. Short Protecting Group-free Syntheses of Camptothecin and 10-Hydroxycamptothecin Using Cascade Methodologies. Chem. - Asian J. 2015, 10, 976-981.

(6) Arian, D.; Hedayati, M.; Zhou, H.; Bilis, Z.; Chen, K.; Deweese, T. L.; Greenberg, M. M. Irreversible Inhibition of DNA Polymerase Beta by Small-Molecule Mimics of a DNA Lesion. J. Am. Chem. Soc. 2014, 136, 3176-3183.

(7) Handlon, A.; Oppenheimer, N. Thiol Reduction of 3'-Azidothymidine to 3'Aminothymidine: Kinetics and Biomedical Implications. Pharm Res 1998, 5, 297-299.

(8) Vanheusden, V.; Munier-Lehmann, H.; Froeyen, M.; Dugue, L.; Heyerick, A.; Keukeleire, D. D.; Pochet, S.; Busson, R.; Herdewijn, P.; Calenbergh, S. V. 3'-C-Branched-ChainSubstituted Nucleosides and Nucleotides as Potent Inhibitors of Mycobacterium Tuberculosis Thymidine Monophosphate Kinase. J. Med. Chem. 2003, 46, 3811-3821.

(9) Vernekar, S. K. V.; Qiu, L.; Zhang, J.; Kankanala, J.; Li, H.; Geraghty, R. J.; Wang, Z. 5'Silylated 3'-1,2,3-Triazolyl Thymidine Analogues as Inhibitors of West Nile Virus and Dengue Virus. J. Med. Chem. 2015, 58, 4016-4028.

(10) Paul, R.; Banerjee, S.; Greenberg, M. M. Synergistic Effects of an Irreversible DNA Polymerase Inhibitor and DNA Damaging Agents on HeLa Cells. ACS Chem. Biol. 2017, $12,1576-1583$.

(11) Guan, L.; Greenberg, M. M. Irreversible Inhibition of DNA Polymerase Beta by an Oxidized Abasic Lesion. J. Am. Chem. Soc. 2010, 132, 5004-5005.

(12) Zhang, D. Y.; Seelig, G. Dynamic DNA Nanotechnology Using Strand-Displacement Reactions. Nat. Chem. 2011, 3, 103-113.

(13) Olson, X.; Kotani, S.; Yurke, B.; Graugnard, E.; Hughes, W. L. Kinetics of DNA Strand Displacement Systems with Locked Nucleic Acids. J. Phys. Chem. B 2017, 121, 2594-2602.

(14) He, P.; Yang, W. Template and Primer Requirements for DNA Pol $\theta$-Mediated End Joining. Proc. Natl. Acad. Sci. 2018, 115, 7747-7752.

(15) Gowda, A. S. P.; Suo, Z.; Spratt, T. E. Honokiol Inhibits DNA Polymerases $\beta$ and $\lambda$ and Increases Bleomycin Sensitivity of Human Cancer Cells. Chem. Res. Toxicol. 2017, 30, $715-725$.

(16) Laverty, D. J.; Mortimer, I. P.; Greenberg, M. M. Mechanistic Insight through Irreversible Inhibition: DNA Polymerase $\theta$ Uses a Common Active Site for Polymerase and Lyase Activities. J Am Chem Soc 2018, 140, 9034-9037. 
(17) Braithwaite, E. K.; Kedar, P. S.; Stumpo, D. J.; Bertocci, B.; Freedman, J. H.; Samson, L. D.; Wilson, S. H. DNA Polymerases $\beta$ and $\lambda$ Mediate Overlapping and Independent Roles in Base Excision Repair in Mouse Embryonic Fibroblasts. PLoS ONE 2010, 5, e12229.

(18) Hu, H. Y.; Horton, J. K.; Gryk, M. R.; Prasad, R.; Naron, J. M.; Sun, D. A.; Hecht, S. M.; Wilson, S. H.; Mullen, G. P. Identification of Small Molecule Synthetic Inhibitors of DNA Polymerase $\beta$ by NMR Chemical Shift Mapping. J. Biol. Chem. 2004, 279, 39736-39744. 